\title{
Indolent lymphoma: diagnostic, prognostic and therapeutic paradoxes
}

Citation for published version (APA):

van Besien, K. (2006). Indolent lymphoma: diagnostic, prognostic and therapeutic paradoxes. [Doctoral Thesis, Maastricht University]. Datawyse / Universitaire Pers Maastricht.

https://doi.org/10.26481/dis.20060413kb

Document status and date:

Published: 01/01/2006

DOI:

10.26481/dis.20060413kb

Document Version:

Publisher's PDF, also known as Version of record

\section{Please check the document version of this publication:}

- A submitted manuscript is the version of the article upon submission and before peer-review. There can be important differences between the submitted version and the official published version of record.

People interested in the research are advised to contact the author for the final version of the publication, or visit the DOI to the publisher's website.

- The final author version and the galley proof are versions of the publication after peer review.

- The final published version features the final layout of the paper including the volume, issue and page numbers.

Link to publication

\footnotetext{
General rights rights.

- You may freely distribute the URL identifying the publication in the public portal. please follow below link for the End User Agreement:

www.umlib.nl/taverne-license

Take down policy

If you believe that this document breaches copyright please contact us at:

repository@maastrichtuniversity.nl

providing details and we will investigate your claim.
}

Copyright and moral rights for the publications made accessible in the public portal are retained by the authors and/or other copyright owners and it is a condition of accessing publications that users recognise and abide by the legal requirements associated with these

- Users may download and print one copy of any publication from the public portal for the purpose of private study or research.

- You may not further distribute the material or use it for any profit-making activity or commercial gain

If the publication is distributed under the terms of Article $25 \mathrm{fa}$ of the Dutch Copyright Act, indicated by the "Taverne" license above, 


\section{Indolent lymphoma}

Diagnostic, prognostic and therapeutic paradoxes 
(6) Koen van Besien, Maastricht 2006

ISBN-10: 90-5278-521-X

ISBN-13: $978-90-5278-521-9$

Layout: Tiny Wouters

Production: Datawyse | Universitaire Pers Maastricht 


\title{
Indolent lymphoma
}

\section{Diagnostic, prognostic and therapeutic paradoxes}

\author{
PROEFSCHRIFT \\ ter verkrijging van de graad van docttor \\ aan de Universiteit Maastricht, \\ op gezag van de Rector Magnificus, Prof. mr. G.P.M.F. Mols, \\ volgens het besluit van het College van Decanen, \\ in het openbaar te verdedigen \\ op donderdag 13 april 2006 om 14.00 uur
}

door

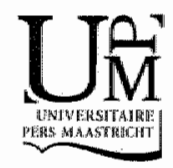


Promotores

Prof. dr. H.C. Schouten

Beoordelingscommissie

Prof. dr. Ph. Lambin (voorzitter)

Prof, dr M. Boogaerts, Katholieke Universiteit Leuven

Dr. G.M.J. Bos

Dr. F.J. Bot

Prof. dr. A. Hagenbeek, UMC Utrecht 
"Learns to say "I dont's know." If used when appropriate, it will be often." Donald Rumsfeld. 


\section{Contents}

Chapter 1 General introduction and outline of the thesis 9

Chapter 2 Allogeneic bone marrow transplantation for poor-prognosis 25 lymphoma: response, toxicity, and survival depend on disease histology

Chapter 3 Allogeneic bone marrow transplantation for refractory and recurrent low-grade lymphoma: the case for aggressive management

Chapter 4 Allogeneic transplantation for low-grade lymphoma: long-term follow-up

Chapter 5 Allogeneic bone marrow transplantation for low-grade lymphoma

Chapter 6 Comparison of autologous and allogeneic hematopoietic stem cell transplantation for follicular lymphoma

Chapter $7 \quad$ Myeloablative allogeneic hematopoietic stem cell transplantation in patients who experience relapse after autologous stem cell transplantation for lymphoma: a report of the international bone marrow transplant registry

Chapter 8 Management of lymphoma recurrence after allogeneic transplantation: the relevance of graft-versus-lymphoma effect

Chapter 9 Syngeneic hematopoietic stem-cell transplantation for nonHodgkin's lymphoma: a comparison with allogeneic and autologous transplantation-the lymphoma working committee of the International bone marrow transplant registry and the european group for blood and marrow transplantation

Chapter 10 General discussion: Stem cell transplantation in follicular lymphoma: progress at last?

Chapter 11 Conclusion

Samenvatting

Dankwoord 


\section{Chapter 1}

Introduction 
101 Chenter 


\section{Introduction}

Follicular lymphoma currently represents one of the most common and easily recognized variants of lymphoma. Great strides have been made in the understanding of its pathobiology, in determination of prognostic features and in its management. This review of its history illustrates the dramatic advances that have been made in biology and medicine, starting in the mid $19^{\text {th }}$ century.

\section{Initial descriptions of follicular lymphoma}

Rudolph Virchow, the leading German pathologist from the mid- to the late $19^{\text {th }}$ century, is generally considered the founder of cellular pathology, the discipline that relates disease processes to changes in cell physiology and morphology. Virchow's numerous contributions include the original description in 1845 of leukemia, a disease characterized by an increase in the "colorless corpuscles of the blood" and often associated with splenomegaly and lymphadenopathy. ${ }^{.}$The first descriptions of lymphoma came approximately 20 years later when Cohnheim, a pupil of Virchow, described a case of "pseudoleukemia". ${ }^{2}$ This case involved a 24 year old man who died after a short illness characterized by lympadenopathy and massive splenomegaly, but surprisingly, without leucocytosis. At autopsy, proliferating lymphocytes were found infiltrating most organs, but, surprisingly to the authors and in contrast to leukemia, involvement of the blood was absent.

Numerous other reports followed and, it was rapidly recognized that many different types of lymphoma exist, but the normal counterparts for lymphoma cells remained elusive. This resulted in complex, contradictory and perpetually changing classification systems and a bewildering variety of nomenclature. (For an excellent overview of the evolution of concepts of lymphoma classification, we refer to the excellent book chapter by Magrath. ${ }^{3}$ ) It is only in the past two decades, with an understanding of $T$ - and B-cell immunology and of cytogenetics that classifications of lymphoma have become more rooted in biology and increasingly logical. Amid the confusion of the late nineteenth and early twentieth century lymphoma classification two entities, Hodgkin's disease and follicular lymphoma were however relatively reliably recognized because of their unique morphological features.

The first systematic description of follicular lymphoma was by Brill et al in $1925{ }^{4}$ They reported two young patients, age 28 and 32 who presented with lymphadenopathy and massive splenomegaly. The lymph node biopsy showed giant follicular hyperplasia. One of the patients was icteric and might have had concomitant hemolyis. Both patients had dramatic and prolonged responses to radiation therapy, a treatment modality that had then already been in use for 
about twenty years. The authors recalled seeing one similar patient ten years earlier and referred to an additional case reported in 1901. Shortly thereafter, Symmers reported three additional cases, one of them occurring in a child. ${ }^{5}$ Both Brill and Symmers initially considered this giant follicular hyperplasia to represent a benign entity which became widely known as Brill-Symmers disease. But over the ensuing two decades; it was recognized that BrillSymmers disease did constitute a malignancy, and that transformation to more aggressive form of Hymphoma was possible. ${ }^{6}$ In 1941 Gall, Morrison and Scott published the first large series of 63 consecutive cases seen at the Massachusetts. General Hospital between 1917 and 1939 and thus contributed considerably to our understanding of the clinical features of follicular Iymphoma. ${ }^{7}$ Lymphadenopathy was often widespread at diagnosis in their patients and splenomegaly was commonly present. Involvement of extranodal organs was unusual. They did not seem aware of the frequent occurrence of bone marrow involvement in follicular lymphoma, probably because bone marrow aspiration and biopsy were not a routine procedures yet. ${ }^{8}$ They described the indolent course of, and prolonged survival in many cases of follicular lymphoma. Twenty percent of their patients had died within two years of diagnosis as compared with $56 \%$ of patients with other types of lymphoma. Eleven percent of patients were still alive ten years after diagnosis. The same authors also emphasized the exquisite radiosensitivity of follicular lymphoma and the frequent observation of very prolonged responses after treatment with kilovoltage radiation. Finally they recognized a histologic continuum from very low grade to histologically more aggressive follicular lymphoma. They recognized four subtypes, more or less akin to our current understanding of grades I, II and III follicular lymphoma.

Rappaport reported in 1956 the next large series of 253 cases reviewed at the Armed Forces Institute of Pathology. ${ }^{9}$ He essentially confirmed the observations of Gall, but attempted to explain them in the framework of a classification of Iymphoma that was based on cytology rather than on lymph node architecture. He questioned the concept of follicular lymphoma as a separate clinical and pathological entity, and emphasized the importance of cytological features, thus linking each cytological subtype of follicular lymphoma with a counterpart in the diffuse lymphomas. He suggested that "follicular lymphoma was not a distinct disease entity, but a variant of diffuse lymphoma of corresponding cellular composition" For every form of diffuse lymphoma, there was a nodular counterpart. His hypothesis and classification gained widespread acceptance in the US. Since then, new insights in biology have clearly established follicular lymphoma as an entity with a unique biology, quite different from large cell lymphoma. 
Thus, over the first half of the twentieth century, the morphology, clinical presentation and natural history of follicular lymphoma were defined. The sensitivity of follicular lymphoma to radiation was recognized almost immediately and radiation was the treatment of choice for more than half a century. Of interest, it appears that follicular lymphoma was a much less common neoplasm in the first half of the century than it is currently. For example, it constituted only $5 \%$ of all cases of lymphoma in the series reported by Gall and Mallory. ${ }^{10}$ The relative rarity of follicular lymphoma in the Western hemisphere during the first half of the century, is reminiscent of the current incidence of lymphoma in Asia and Africa. ${ }^{11}$ Its increased incidence in recent decades is likely in part related to increased recognition and to increases in life expectancy. But other unrecognized possibly environmental or dietary changes might also play a role.

\section{The biology of follicular lymphoma}

Our understanding of the pathobiology of lymphoma has dramatically increased over the past twenty years. This has affected diagnostic and therapeutic strategies and is starting to affect survival.

The recognition that the immune system is composed mainly of $\mathrm{T}$ - and B-cells and the development of monoclonal antibodies in the 1970's allowed a biological characterization of lymphomas ${ }^{12}$ and established the germinal center B-cell as the normal counterpart of the follicular lymphoma cell. ${ }^{13-15}$ The phenotype of follicular lymphoma cells is well characterized and a number of surface antigens have been exploited as therapeutic targets for drugs such as rituximab (anti-CD20), alemtuzumab (anti-CD52), and galiximab (anti-CD 80). Cytogenetic studies documented a consistent abnormality $t(14 ; 18)$ in the majority of follicular lymphomas. ${ }^{16}$ Shortly thereafter, the $\mathrm{t}(14 ; 18)$ breakpoint was cloned and the bcl-2 gene described. ${ }^{17} \mathrm{Bcl}-2$ turned out to be an antiapoptotic gene, with a central function in the regulation of cell survival. The study of bcl-2 led to a paradigm shift in the understanding of the role of apoptosis in cancer, and in follicular lymphoma in particular. ${ }^{18-20}$ Our current understanding of follicular lymphoma is that of a clonal disorder of follicle center cells, whose expansion is driven by overexpression of bcl-2, resulting in increased accumulation of cells rather than increased proliferation. But several observations suggest that bcl-2 overexpression is not sufficient, and possibly not even necessary for lymphomagenesis. First, in mouse models bcl-2 overexpression alone leads to lymphoid hyperplasia, but additional mutations seem necessary for development of lymphoma. ${ }^{24}$ In humans, the presence of complex karyotypic abnormalities is the rule in follicular lymphoma, ${ }^{22}$ Translocation $t(14 ; 18)$ is rarely the sole abnormality. The great majority of 
these secondary changes are unbalanced gains or losses of chromosomal material, with balanced translocations quite infrequent. The sequence by which these additional changes arise, whether certain alterations develop independently or in combination, and the influence these accumulating genetic changes exert individually or collectively on clinical behavior have not been determined, although certain models of karyotypic evolution have been proposed. ${ }^{22}$ Furthermore, a small number of cells carrying bcl-2 gene rearrangements are also found in lymphoid tissues or blood of a small percentage of healthy individuals suggesting that bcll-2 gene rearrangement does not always cause pathology. Finally, bcl-2 rearrangement negative follicular lymphomas are not uncommon raising the possibility of alternative molecular events that may give rise to follicular lymphoma. ${ }^{11}$

Much remains also to be learned about the factors underlying the marked heterogeneity in clinical course of follicular lymphomas. Some patients have an extremely indolent course and never require treatment or even experience spontaneous remissions. But others have a much more aggressive course and about ten percent of patients die within three years of diagnosis. Karyotypic, immunophenotypic or gene expression differences have only limited prognostic significance. Gene array technology has provided a novel platform for research. It was widely anticipated that specific gene expression profiles of the lymphoma cells would correlate with prognosis, as has been demonstrated in diffuse large B-cell lymphoma. ${ }^{23: 24}$ A recent study however suggests that clinical heterogeneity in follicular lymphoma is related to gene expression signatures of the non-malignant cells that infiltrate the tumor (T-cells, dendritic cells, macrophages), rather than to differences in the lymphoma cells. ${ }^{25}$ This suggests an important role for the immune system in controlling growth of follicular lymphoma and is consistent with a recent study in which a correlation was shown between the degree of macrophage infiltration into the lymphoma and patient survival. ${ }^{26}$ In a recent review, a model has been proposed in which the pathogenesis of follicular lymphoma is determined by cross-talk between the malignant population and the immune system. ${ }^{27}$ Different types of secondary cytogenetic lesions in the malignant population then determine specific immune response signatures.

As such, follicular lymphoma has evolved over the past twenty years from an entity defined by purely histological criteria into a malignancy with a partially elucidated biology and pathogenesis and an increasing array of diseasemodifying factors. New treatments have been envisioned based on the accumulating biologic information. Those based on anti-CD20 in particular have been spectacularly successful " and the recognition of the central role of $t(14 ; 18)$ and bcl-2 gene rearrangement has led to specific diagnostic and therapeutic strategies. 
Great gaps though remain in our knowledge of etiology and of risk factors for this disorder that occurs with increasing frequency in the western world. Geographical variation in incidence and the frequent occurrence of cases without detectable bcl-2 gene rearrangement in the Far East and Africa, raise important unresolved questions regarding the biology of the disease and its causative factors. ${ }^{11}$

\section{Treatment for follicular lymphoma}

From its earliest descriptions, follicular lymphoma was recognized as a radiotherapy sensitive disorder with an indolent course. This indolent behavior and the difficulty in predicting prognosis in individual patients have considerably complicated drug development. A substantial proportion of patients may never require treatment, and ideally, in order to demonstrate the benefit of a new approach, randomized studies are required. This is a difficult task in a rather uncommon disorder with a prolonged natural history, and nearly impossible when complex treatments such as bone marrow transplantation are concerned. In order to facilitate clinical studies, a number of surrogate markers of outcome have been proposed, but for none of them has a correlation with survival been validated. ${ }^{28}$

The development of an internationally validated prognostic index, the FLIPI provides some hope for improved categorization for patients in clinical studies. ${ }^{29}$ But the FLIPI is based on demographic and clinical information and is a somewhat limited instrument. Prognostic models that incorporate biologic information, such as those based on gene expression profiles, are potentially much more powerful, but require validation.

Still despite such limitations, progress has been made and in the past decade improvements in survival of follicular lymphoma patients have been repeatedly demonstrated in randomized studies and meta-analysis. ${ }^{30-32}$ This achievement is the result of decades of formal and informal, empirical, and more recently hypothesis-driven experimentation. A large number of therapeutic agents and modalities have been utilized.

\section{a. Radiation therapy}

$X$-rays were discovered by Conrad Roentgen in 1896 and by 1901 were used for therapy of cancers. The sensitivity of lymphoma to radiotherapy became rapidly apparent. ${ }^{40}$ Radiation became the treatment of choice for all types of lymphoma and the older literature states that "radiosensitivity was even utilized as a diagnostic criterion for tumors not accessible for histologic study". "In general, responses of lymphoma to radiation were incomplete and short lived, 
but follicular lymphoma was remarkable because of its higher incidence of complete and prolonged responses. ${ }^{4: 7}$ Even today, radiation rernains a valuable tool in the treatment of follicular lymphoma, particularly in stage $\|$ and $\|$ disease, where radiation, sometimes combined with chemotherapy, is considered a curative form of therapy $:^{3-36}$ Total lymphoid irradiation has also been studied in stage III disease. Five year progression-free survival rates range from $40 \%$ to $60 \%$.

\section{b. Chemotherapy}

Combination chemotherapy was initially studied in childhood ALL and many of the principles of modern day chemotherapy derive from these initial studies. ${ }^{40}$ The first trials of combination chemotherapy in lymphoma date back to the 70 's. Curative therapy for aggressive lymphoma and Hodgkin's disease was discovered, but in follicular lymphoma, initial optimism was followed by disappointment. With the possible exception of some small subgroups of patients, chemotherapy was not curative or did not seem to improve survival. ${ }^{42}$ CHOP chemotherapy did not seem much more effective than single agent chemotherapy and CVP or single agent chemotherapy did not extend life beyond what could be achieved with observation and treatment of symptoms (watchful waiting). (3-45 $^{3}$

Newer chemotherapeutic agents such as the nucleoside analogues have considerable activity in follicular lymphoma, but similarly were not shown to be superior in randomized studies. ${ }^{46}$

\section{c. Biological response modifiers}

The biological response modifier interferon alpha generated considerable excitement as a potential anti-cancer agent shortly after its purification. ${ }^{47-49}$ In phase II trials, purified and subsequently recombinant interferon was found to have considerable activity in follicular lymphoma, but was not curative..$^{50-53}$ Randomized studies were conducted with recombinant interferon in combination with chemotherapy or as maintenance therapy after completion of chemotherapy in patients with advanced follicular lymphoma. Several such trials did show a survival benefit, and interferon is approved for use in follicular lymphoma in the US as well as Europe ${ }^{54-57}$ Negative or disappointing results of other trials, ${ }^{58-64}$ toxicity of interferon, inconvenience of administration caused a decline in interest, ${ }^{65}$ and interferon is currently rarely used for treatment of follicular lymphoma in the US. Such a neglect may not be entirely justified as a recent meta-analysis confirms the significant survival benefit associated with appropriate interferon therapy. ${ }^{66}$ A survival advantage was associated with interferon in those studies in which it was given in rather high doses, in 
combination with intensive chemotherapy and as part of induction treatment, rather than merely as maintenance.

\section{d. Autologous and allogeneic transplantation}

High dose chemotherapy has been extensively studied in low grade lymphoma and also shows great promise. As opposed to all other types of therapy high dose chemotherapy with autologous or allogeneic transplant appears to be curative for a significant portion of younger patient with follicular lymphoma. ${ }^{67}$ Recent investigations have focused on elucidating the mechanisms of treatment failure in autologous transplantation and on dissecting the relative contributions of GVL vs chemotherapy effects in allogeneic transplantation. ${ }^{68-70}$ The complexity of the treatment and the associated side effects have limited widespread use of transplantation, though for certain patients with recurrent disease, allogeneic or autologous transplantation represent the best treatment options and are associated with a survival benefit. ${ }^{31}$ The use of autologous transplantation as consolidation therapy for high risk patients in first remission has also been investigated in three large randomized studies in Europe. It consistently has improved progression free survival when compared to intensive chemotherapy followed by interferon maintenance, but until now two of three randomized studies have failed to demonstrate a survival benefit. ${ }^{71.73}$

\section{e. Targeted therapy}

Targeted approaches, in particular humanized monoclonal antibodies directed against anti-CD20 have revolutionized the treatment of lymphoma. The development of these antibodies represents a fascinating chapter of hypothesis driven research, dating back to the late $19^{\text {th }}$ century when Ehrlich formulated his theory of the magic bullet in cancer. through the development of monoclonal antibody technology by Kohler and Milstein and the design of humanized antibodies over the past decade. ${ }^{74}$ The first murine monoclonals were used in human lymphoma patients in $1980 .{ }^{75}$ Rituximab was approved in the late 90 's and represents a great addition to the armamentarium in follicular lymphoma. ${ }^{76}$ As a single agent, it induces complete or partial responses in a large percentage of patients. ${ }^{77}$ In combination with commonly used chemotherapy regimens, it improves remission rates and duration of remission with minimal side-effects. ${ }^{78-80}$ It is widely expected that a considerable survival benefit will become apparent as the randomized studies mature. Rituximab may also have a role in combination with autologous or allogeneic stem cell transplantation where it may serve as a purging agent for stem cells and may prolong remissions when administered as maintenance therapy. ${ }^{81-83}$ The radiolabelled monoclonal antibodies Tositumomab (Bexxar) and ibritumomab tiuxetan (Zevalin) also target CD 20, but cause tumor destruction by radiation. 
These antibodies are currently approved for use in recurrent follicular lymphoma, but may ultimately find a role in the initial treatment of follicular lymiphoma. ${ }^{94-86}$ Other antibodies at various stages of development include antiCD22, anti-HLA DR and anti-CD80. ${ }^{87-89}$ Anti-idiotype antibodies are based on the principle of idiotype networks. Phase I and II developiment has been completed: ${ }^{90 ; 1}$ Two phase 111 studies are nearing completion.

Finally, anti-sense oligonucleotides are molecules directed against specific strands of messenger RNA. Anti-bcl-2 (genasense, oblimersen sodium) interrupts the action of bcl-2 and has activity in follicular lymphoma. ${ }^{92}$ "t is currently undergoing testing in combination with chemotherapeutic agents and monoclonal antibodies. ${ }^{93}$ In another exciting development, a peptide that specifically inhibits bel-2 shows great promise in clinical models. ${ }^{94}$ 


\section{References}

1. Virchow R. Cellular pathology as based upon physiological and pathological pathology. New York: Robert M. Dewitt; 1859.

2. Cohnheim. Ein Fall won Pseudoleukämie: Virchows Arch. 1862:33:451-4.

3. Magrath IT. Historical perspective: the evolution of modern concepts of biology and management. In: Magrath $\mid T$, ed. The Non-Hodgkin's Lymphomas: London-Sidney-Auckland: Arnold; 1997:47-76.

4. Brill NE, Baehr G, Rosenthal N. Generalized giant lymph follicle hyperplasia of lymph nodes and spleen. JAMA 1925;84:668-70.

5. Symmers D. Follicular lymphadenopathy with splenomegaly. Archives of Pathology \& Laboratory Medicine 1927;3:820.

6. Jackson $H$. The classification and prognosis of Hodgkin's disease and allied disorders. Surg.Gynecol.Obstet. 2005 ;lxiv:465.

7. Gall EA, Morrison HR, Scott AT. the follicular type of malignant lymphoma: a survey of 63 cases. Ann.Int.Med. 1941;14:2073-83.

8. Ryan DH, Cohen HJ. Bone marrow aspiration and morphology. In: Hoffman R, Benz EJ, Shattil $S J$ et al., eds. Hematology, basic principles and practice. New York: Churchill Livingstone; $2000: 2460-8$.

9. Rappaport H, Winter WJ, Hicks EB. Follicular lymphoma: a reevaluation of its position in the scheme of malignant lymphoma, based on a survey of 253 cases. Cancer 1956;9:792-821.

10. Gall EA, Mallory TB. Malignant lymphoma, a clinico-pathologic survey of 618 cases. Am.J.Pathol. 1942;18:381-429.

11. Biagi $\mathrm{JJ}$, Seymour JF. Insights into the molecular pathogenesis of follicular lymphoma arising from analysis of geagraphic variation. Blood 2002;99:4265-75.

12. Seligmann $M$, Grouet $J C$, Preud"homme $C$. The immunological diagnosis of human leukemias and lymphomas. An overview. In: Thierfelder $S$, Rodt $H_{\text {, }}$ Thiel $E_{1}$ eds. Immunolagical diagnosis of leukemias and lymphomas. Berlin: Springer Verlag; 1977:1-16.

13. Jaffe ES, Shevach EM, Frank MM, Berard CW, Green I. Nodular lymphoma-evidence for origin from follicular B lymphocytes. N.Engl.J.Med. 1974;290:813-9.

14. Glick $A D$, Leech $\mathrm{JH}$, Waldron $\mathrm{JA}$ et al. Malignant lymphomas of follicular center cell origin in man. II. Ultrastructural and cytochemicall studies. J.Nat.Cancer Inst. 1975;54:23-36.

15. Leech JH, Glick AD, Waldron JA et all. Malignant lymphomas of follicular center cell origin in man. I. Immunologic studies. J.Nat. Cancer inst. 1975;54:11-21.

16. Yunis $\mathrm{JJ}$, Oken MM, Kaplam ME et all. Distinctive chromosomal abnormalities in histologic subtypes of non-Hodgkin's lymphoma. N.Engl.J.Med. 1982;307:1231-6.

17. Cleary $M L$, Sklar J. Nucleotide sequence of a $t(14 ; 18)$ chromosomal brakapoint in follicular lymphoma and demonstration of a breakpoint-cluster region near a transcriptionally active locus on chromosome 18. Proc.Natl.Acad Sci.U.S.A 1985;82:7439-743.

18. Karsmeyer SJ, McDonnell TJ, Nunez G, Hockenbery D, Young R. Bcl-2: B cell life, dieath and neoplasia. Curr. Top. Microbiol.Immunal. 1990;166:203-7.

19. McDonnell $T J$, Nunez $G$, Platt $F M$ et al. Deregulated Bcl-2-immunoglobulin transgene expands a resting but responsive immunoglobulin $M$ and $D$-expressing $B$-cell population. Mol.Cell Biol 1990;10:1901-7.

20. McDonnell TJ, Deane N, Platt FM et al. bcl-2-immunoglobulin transgenic mice demonstrate extended B cell survival and follicular lymphoproliferation. Cell 1989;57:79-88.

21. McDonnell TJ, Korsmeyer SJ. Progression from lymphoid hyperplasia to high-grade malignant lymphoma in mice transgenic for the $t(14 ; 18)$. Nature $1991 ; 349: 254-6$.

22. Hoglund $M$, Sehn $L_{n}$ Connors JM et al. Identification of cytogenetic subgroups and karyotypic pathways of clonal evolution in follicular lymphomas. Genes Chromosomes.Cancer 2004:39:195-204.

23. Shipp MA Ross KN, Tamayo $P$ et al. Diffuse large B-cell lymphoma outcome prediction by gene-expression profiling and supervised machine learning. Nat.Med. 2002;8:68-74. 
24. Alizadieh $A_{4}$ Eisen $M B$, Davis $R E$ et al. Distinct types of diffuse large B-cell lymphoma identifed by gene expression profiling. Nature 2000;403:503-11.

25. Dave SS. Wright $G$. Tan $B$ et all. Prediction of survival in follicular lymphoma based on molecular features of tumor-infiltrating immune cells. N. Engl.J.Med. 2004:351:2159-69.

26. Farinha $P$, Masoudi $H_{*}$ Skinnider $B F$ et all: Analysis of multiple biomarkers shows that lymphomalassociated macrophage (LAM) content is an independent predictor of survival in follicular lymphoma (FL). Blooid 2005;106:2169-74

27. de Jong $D$. Molecular pathogenesis of follicular lymphoma a cross talk of genetic and immunologile factors. J. Clin Oncol 2005;23:6358-63.

28. MeLaughlin P. Progress and promise in the treatment of indolent lymphomas. Oncologist. 2002;7:217-25.

29. Solal-Celigny $\mathrm{P}$. Follicular ymphoma international prognostic project [abstract]. Ann.Oncol. 2002;13 Suppl. 2:\#54.

30. Rohatiner $A Z$, Gregory $W M_{\text {, Peterson }} B$ et al. Meta-analysis to evaluate the role of interferon in follicular lymphoma. J. Clin Oncoll $2005 ; 23: 2215-23$.

31. Schouten HC, Qian $W_{1}$ Kvaloy $S$ et al. High-dose therapy improves progression-free survival and survival in relapsed follicular non-Hodgkin's lymphoma: results from the randomized European CUP trial: J.Clin. Oncol. 2003;21:3918-27.

32. Fisher RI, LeBlanc $M$, Press OW et al. New Treatment Options Have Changed the Survival of Patients With Follicular Lymphoma. J.Clin Oncol 2005; 23:8447-52.

33. Peters MV. The Contribution of Radiation Therapy in the Control of Early Lymphomas. Am. A. Roentgenol Radium Ther Nucl.Med. 1963;90:956-67.

34. Paryani SB, Hoppe RT, Cox RS, Colby TV, Kaplan HS. the role of radiation therapy in the management of stage III follicular lymphomas. J.Clin. Oncol. 1984;2:841-8.

35. MoLaughlin $\mathbb{P}$, Fuller LM, Vellasquez WS et al. stage $1-11$ follicular lymphoma. Treatment results for 76 patients. Cancer 1986;58:1596-602.

36. Monfardini $S$, Banfi $A$ Bonnadonna $G$, al. Improved 5-year survival after combined radiotherapy-chemotherapy for Stage I-II non-hodgkin's lymphoma. Int.J.Radiat.Oncol Biol Phys. 1980;6:125-34.

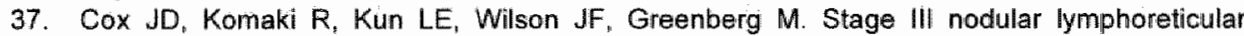
tumors (non-Hodgkin's lymphoma): Results of central lymphatic irradiation. Cancer $1981 ; 47: 2247-52$.

38. Glatstein E, Fuks $Z$, Goffinet DR, Kaplan HS. Non-Hodgkin"s lymphomas of stage lll extent. Is total lymphoid irradiation appropriate treatment? Cancer 1976;37:2806-12.

39. Ha CS, Kong JS, Tucker SL et al. Central lymphatic irradiation for stage I-III follicular lymphoma: report from a single-institutional prospective study. Int.J.Radiat.Oncol.Biol.Phys. $2003 ; 57: 316-20$

40. Frel E. Acute leukemia in children. Model for the development of scientific methodology for clinical therapeutic research in cancer. Cancer 1984;53:2013-25.

41. Frei $E$, III. Curative cancer chemotherapy. Cancer Res. 1985:45:6523-37.

42. Horning SJ. Treatment approaches to the low-grade lymphomas. Blood 1994;83:881-4.

43. Young $R C_{\text {. Longo }} \mathrm{DL}$, Glatstein $E$ et al. The treatment of indolent lymphomas: watchful waiting $v$ aggressive combined modality treatment. Semin. Hematol. 198:8;25:11:6.

44. Peterson BA, Petroni GR, Frizzera $G$ et al. Prolonged single-agent versus combination chemotherapy in indolent follicular lymphomas: a study of the cancer and leukemia group $B$. J.Clin. Oncol. 2003;21:5-15.

45. Ardeshna KM, Smith P. Norton $A$ et al. Long-term effect of a watch and wait policy versus immediate systemic treatment for asymptomatic advanced-stage non-Hodgkin lymphoma: a randomised controlled trial. Lancet 2003;362:516-22.

46. Coiffier $B$. Neidhardt-Berard EM, Tilly $H$ et al. Fludarabine alone compared to CHVP plus interferon in elderly patients with follicular lymphoma and adverse prognostic parameters: a GELA study. Groupe d'Etudes des Lymphomes de l'Adulte. Ann.Oncol. 1999;10:1191-7.

47. Krim M. Towards tumor therapy with interferons, part II. Interferons: in vivo effects. Blood $1980 ; 55: 875-84$.

48. Priestman TJ. Interferon: an anti-cancer agent? Cancer Treat.Rev. 1979;6:223-37. 
49. Borden EC. Interferons: rationale for clinical trials in neoplastic disease. Ann Intern.Med. $1979 ; 91: 472-9$

50. Gutterman JU, Blumenschein $G$, Alexanian $R$. Leucocyte interferon-induced tumor regression in human metastatic breast cancer; multiple myeloma and malignant lymphoma. Ann.Intern. Med. 1980;93:399-406.

51. Foon KA, Sherwin $S A$, Abrams $P G$, et al. Treatment of advanced non-Hodgkin's lymphome with recombinant leukocyte $A$ initerferon. N. Engl.J.Med. 1984:311:1148-52.

52. O'Connell MJ, Colgan JP, Oken MM, et al. Clinical trial of recombinant leukocyte A interferon as initial therapy for favorable histology non-Hodgkin's lymphoma and chronic lymphocytic leukemia. An ECOG pillot study: J Clin Oncol. 1986;4:128-36.

53. Wagstaff J, Loynds $P$, Crowther D. A phase III study of human recombinant DNA a2 interferon in patients with low-grade non-Hodgkin's lymphoma. Cancer Chemother.Pharmacol 1986;18:54-8.

54. Solal-Celigny $P$, Lepage $E$, Brousse $N_{n}$ et al. Recombinant interferon alfa-2b combined with a regimen containing doxorubicin in patients with advanced folliculat lymphoma. N.Engl.J.Med. 1993;329:1608-14.

55. Smalley RV, Andersen JW, Hawkins MJ et al. Interferon alfa combined with cytotoxic chemotherapy for patients with non-Hodgkin's lymphoma. N. Engl.J. Med. 1992;327:1336-41.

56. Andersen JW. Smalley RV. Interferon alfa plus chemotherapy for non-Hodgkin's lymphoma: Five-year follow-up. N.Engl.J.Med. 1993;329:1821-2.

57. Unterhalt $M$, Hermann $R$, Koch $P$ et al. Long term interferon alpha maintenance prolongs remission duration in advanced low grade lymphoma and is related to the efficacy of initial cytoreductive therapy [abstract]. Blood 1996;88 S1:453a.

58. Solal-Celigny $P$, Lepage $E$, Brousse $N$ et al. Recombinant interferon alfa- $2 \mathrm{~b}$ combined with a regimen containing doxarubicin in patients with advanced follicular lymplioma. Groupe d'Etude des Lymphomes de l'Adulte. N.Engl.J.Med. 1993;329:1608-14.

59. Aviles $A$, Duque $G$, Talavera $A$, Guzman $R$. Interferon alpha $2 b$ as maintenance therapy in low grade malignant lymphoma improves duration of remission and survival. Leuk.Lymphoma 1996;20:495-9.

60. Hagenbeek A, Carde $P$, Meerwaldt JH et al. Maintenance of remission with human recombinant interferon alfa-2a in patients with stages 111 and IV low-grade malignant nonHadgkin's lymphoma. European Organization for Research and Treatment of Cancer Lymphoma Cooperative Group. J.Clin Oncol 1998;16:41-7.

61. Arranz $R$. Garcia-Alfonso $P$, Sobrino $P$ et all. Role of interferon alfa-2b in the induction and maintenance treatment of low-grade non-Hodgkin's lymphoma: results from a prospective, multicenter trial with double randomization. J.Clin Oncoll 1998;16:1538-46

62. Fisher RI, Dana BW, LeBlanc $M$ et al. Interferon apha consolidation after intensiva chemotherapy does not prolong the progression-free survival of patients with low-grade nonHodgkin's lymphoma: results of the Southwest Oncology Group randomized phase III studly 8809. J.Clin Oncal 2000;18:2010-6.

63. Rohatiner $A$, Radford J, Deakin D et all. A randomized contralled trial to evaluate the role of interferom as initial and maintenance therapy in patients with follicular lymphoma. Br.J.Cancer 2001;85:29-35.

64. Peterson BA, Petroni GR, Oken MM, at al. Cyclophosphamide versuis cyclophosphamide plus interferon alfa- $2 \mathrm{~b}$ in follicular low-grade lymphomas: An intergroup phase III trial (CALGB 8691 and EST 7486) [abstract]. Proc Am Soc Clin Oncal 1997:16:14a (abstr 48).

65. Cheson BD. The curious case of the baffling biological. J.Clin Oncol 2000;18:2007-2009.

66. Rohatiner $A Z$, Gregory $\mathrm{WM}$, Peterson $\mathrm{B}$ et al. Meta-analysis to evaluate the role of interferon in follicular lymphoma. J.Clin Oncol 2005:23:2215-23.

67. Tse WW, Lazarus HM, van Besien K. Stem cell transplantation in follicular lymphoma: progress at last? Bone Marrow Transplant 2004,34:929-38.

68. Bierman PJ, Sweetenham JW, Laberiza FM et al. Syngeneic Hematopoietic Stem Cell Transplantation for Non-Hodgkin's Lymphoma: A Comparison with Allogeneic and Autologous Transplantation. لـ Clin. Oncol. 2003;21:37444-53. 
69. van Besien $K$, Loberiza $F R$, Bajorunaite $R$ et al. Comparison of autologous and allogeneic hematoposetic stem cell transplantation for follicular lymphoma. Blood 2003; 102:3521-9.

70. Corradini $P$, Latetto $M$, Zallio $F$ et al Long-term follow-up of indolent lymphoma patients treated with high-dose sequential chemotherapy and autografting: evidence that durable molecullar and dinical remission frequently can be attained only in follicular subtypes. J.Clin. Oncol: $2004 ; 22: 1460-8$.

71. Lenz $G$, Dreyling $M$, Schiegnitz $E$ et al." Myeloablative radiochemotherapy followed by autologous stem cell transplantation in first remission prolongs progression-free survival in follicular lymphoma - results of a prospective randomized trial of the German Low-Grade Lymphome Study Group (GLSG) Blood 2004;104:2667-74.

72. Deconinck $E$, Foussard $C_{i}$ Milpied $N$ et al. High-dose therapy followed by autologous purged stem-cell transplantation and doxorubicin-based chemotherapy in patients with advanced follicular lymphoma: a randomized multicenter study by GOELAMS. Blood 2005;105:3817-23.

73. Sebban $C$, Belanger $C$, Brousse $N$ et al. Comparison of CHVP + Interferon with CHOP Followed by Autologous Stem Cell Transplantation with a TBI Conditioning Regimen in Untreated Patients with High Tumor Burden Follicular Lymphoma: Results of the Randomized GELF94 Trial (G.E.L.A. Study Group) [abstract]. Blood 2003;102:\#354.

74. Dillman $\mathrm{RO}$. The history and rationale for monoclana antibodies in the treatment of hemattologic malignancy. Curr.Pharm.Biotechnol. 2001;2:293-300.

75. Nadler $L M_{1}$ Stashenko $P$. Hardy $R$ et al. Serotherapy of a patient with a monoclonal antibody directed against a human lymphoma-associated antigen. Cancer Res. 1980;40:3147-54.

76: Grillo-Lopez AJ. Rituximab: an insider's historical perspective. Semin. Oncol. 2000;27:9-16.

77. McLaughlin P, Grillo-Lopez A, Link BK et al. Rituximab chimeric anti-CD20 monoclonal antibody therapy for relapsed indolent lymphoma: half of patients respond to a four dose treatment program [abstract]. J.Clin. Oncol. 1998;16:28.25-33.

78. Marcus $R$, Imrie $K$. Bellch $A$ et al. CVP chemotherapy plus rituximab compared with CVP as first-line treatment for advanced follicular lymphoma. Blood 2005;105:1417-23.

79. Gandhi MK, Marcus RE. Follicular lymphoma: time for a re-think? Blood Rev. 2005; 19:16578 .

80. Hiddemann $W$, Kneba $M$, Dreyling $M$ et al. Front-line therapy with rituximab added to the combination of cyclophosphamide, doxorubicin, vincristine and prednisone (CHOP) significantly improves the outcome of patients with advanced stage follicular lymphomas as compared to CHOP alone - results of a prospective randomized study of the german low grade lymphoma study group (GLSG). 2005;106:3725-32.

81. Khouri IF, Saliba RM, Hosing $\mathrm{C}$ et al. Concurrent administration of high-dose rituximab before and after autologous stem-cell transplantation for relapsed aggressive B-cell non-Hodgkin's lymphomas. J.Clin Oncol 2005:23:2240-7.

82. Hoerr AL, Gao F, Hidlalgo J et al. Effects of pretransplantation treatment with rituximab on outcomes of autologous stem-cell transplantation for non-Hodigkin"s lymphoma. JiClin. Oncoll. $2004: 22: 4561-6$.

83. Horwitz SM, Negrin RS, Blume KG et al. Rituximab as adjuvant to high-dose therapy and autologous hematopoietic cell transplantation for aggressive non-Hodgkin lymphoma. Blood $2004 ; 103: 777-83$.

84. Gordon LI, Witzig T, Molina A et al. Yttrium 90-labeled ibritumomab tiuxetan radioimmunotherapy produces high response rates and durable remissions in patients with previously treated B-cell lymphoma. Clin. Lymphoma 2004:5:98-101.

85. Kaminski MS, Tuck $M$, Estes $J$ et al 1311-tositumomab therapy as initial treatment for follicular lymphoma. N. Engl.J.Med. 2005;352:441-9.

86. Kaminski MS, Zasadny KR, Francis IR et al. lodine-131 -anti B1 radioimmunotherapy for Bcell lymphoma. J.Clin Oncol. 1996;14:1974-81.

87. Czuczman MS, Thall A, Witzig TE et al. Phase I/II study of galiximab, an anti-CD80 antibody, for relapsed or refractory follicular lymphoma. J.Clin Oncol 2005;23:4390-8.

88. DeNardo GL. Concepts in radioimmunotherapy and immunotherapy: Radioimmunotherapy from a Lym-1 perspective. Semin. Oncol 2005; 32:S27-S35. 
89. Leonard JP, Coleman $\mathrm{M}$, Ketas $\mathrm{J}$ et al. Combination antibody therapy with epratuzumab and rituximab in relapsed/refractory non-Hodgkin's Iymphoma. J. Clin Oncol 2005:23:5044:51.

90. Hsu $F J$, Caspar $C B, C$ zerwinski $D$ et al. Tumor-specific idiotype vaccines in the treatment of patients with B-cell lymphoma-long-term results of a clinical trial. Blood 1997:89:3129-35.

91. Bendandi $M$, Gocke $C D$. Kobrin $C B$ et al. Complete molecular remissions induced by patientspecific vaccination plus granulocyte-monocyte colony-stimulating factor against lymphoma. Nat.Med. 1999;5:1171-7.

92. Waters $J S$, Webb $A$, Cunningham $D$ et al. Phase I clinical and pharmacokinetic study of bcll-2 antisense oligonucleotide therapy in patients with non-Hodgkin's lymphoma. $J$ Clin. Oncol. 2000;18:1812-23.

93. Klasa RJ. Targeting the proapoptotic factor $\mathrm{Bcl}-2$ in non-Hodgkin's lymphoma. Oncology (Huntingt) 2004:18:25-31.

94. Walensky LD. Kung AL. Escher I et al. Activation of apoptosis in vivo by a hydrocarbonstapled BH3 helix. Science 2004;305:1466-70. 


\section{Chapter 2}

Allogeneic bone marrow transplantation for poor-prognosis lymphoma: response, toxicity, and survival depend on disease histology

KW van Besien, RC Mehra, SA Giralt, HM Kantarjian, WC Pugh, IF Khouri, Y Moon, P Williams, BS Andersson, D Przepiorka, PL McCarthy, JL Gajewski, AB Deisseroth, FF Cabanillas, R Champlin 


\section{Abstract}

\section{Purpose}

To evaluate outcomess and identify prognostic factors in allogeneic bone marrow transplantation in patients with end-stage lymphoma.

\section{Patients and methods}

Data were retrospectively analyzed of 64 patients ( 42 men and 22 women) 18 to 48 years of age with recurrent or refractory lymphoma who underwent allogeneic bone marrow transplantation from matched sibling donors (or in 1 case from a one antigen-mismatched relative) between May 1981 and July 1994 .

\section{Results}

Twelve patients survived free of disease. They were 8 of 15 with low-grade lymphoma (diseasefree survival at 2 years $59 \pm 13 \%$ ); 3 of 25 with lymphoblastic lymphoma (disease-free survival $17 \pm 8 \%$ ); and 1 of 10 with diffuse small non-cleaved cell lymphoma (disease-free survival $10 \pm 29 \%$ ). Survivall and disease-free survival of patients with low-grade lymphoma were significantly superior compared to any other subgroup of patients $(P<0.01)$. Only 2 patients with low-grade lymphoma had disease progression ( $9 \pm 59 \%$ actuarial risk at 2 years) as opposed to 5 of 15 with intermediategrade lymphoma $(39 \pm 14 \%), 9$ of 25 with lymphoblastic lymphoma $(28 \pm 9 \%)$, and 8 of $10(80 \pm 13 \%)$ with diffuse small non-cleaved lymphoma. The actuarial risk for disease progression was significantly lower for patients with low-grade lymphoma than for any other histologic subgroup $(\mathcal{P} 0.02)$, It was significantly higher for those with diffuse small non-cleaved cell lymphoma than for other histologic subgroups ( $P \leq 0.003$ ).

\section{Conclusions}

Allogeneic bone marrow transplantation is an effective procedure in patients with refractory lowgrade lymphoma. It results in long-term remissions and should be considered in younger patients with recurrent disease who have a matched sibling donor. The late recurrence in 1 patient indicates the necessity af continued follow-up. A small fraction of patients with endstage intermediate- and high-grade lymphoma can obtain prolonged disease-free survival, but recurrence and regimenrelated toxicity remain major problems. The results could be improved by the development of conditioning regimens with less toxicity and by the use of bone marrow transplantation earlier in the course of the disease. 


\section{Introduction}

Fifty to $60 \%$ of patients with lymphoma achieve a complete remission with conventional treatments. ${ }^{1-3}$ Approximately $40 \%$ of those with intermediate- and high-grade lymphomas and a small percentage of those with low-grade lymphomas can be cured. Salvage treatment is effective in approximately $40 \%$ of patients, and some of these cases can be successfully consolidated with high-dose chemotherapy and bone marrow or stem cell rescue., The majority of patients ultimately fail both front-line and salvage regimens. Such patients only rarely benefit from autologous bone marrow transplantation (BMT) and ought to be considered for more aggressive treatment strategies.

Allogeneic BMT has been extensively evaluated in the treatment of recurrent lymphomas. A substantial portion of patients with recurrent or refractory lymphoma obtain prolonged disease-free survival after treatment with allogeneic BMT. ${ }^{5-13}$ In three series, the incidence of recurrence was lower among patients receiving allogeneic BMT compared with those receiving autologous BMT. ${ }^{11,13,14}$ This has been attributed to a graft versus lymphoma effect. Unfortunately, there is a higher risk of treatment-related mortality after allogeneic BMT, which has offset the impact of this graft versus lymphoma effect and obscured the identification of patients whose disease may be susceptible to such an effect. It has also led most centers to consider allogeneic BMT mainly for patients who do not qualify for autologous BMT because of bone marrow or peripheral blood involvement or the presence of refractory disease. This review of our institutional experience with allogeneic BMT focuses on patients with such high-risk features and highlights the importance of disease histology in determining the response to and outcome of allogeneic BMT.

\section{Patients and methods}

From May 1981 until July 1994, 64 patients with non-Hodgkin's lymphoma underwent allogeneic BMT at our institutions. Eligibility criteria included age $\leq 50$ years, Karnofsky performance status (KPS) $\geq 60 \%$, bilirubin $\leq 2 \mathrm{mg} / \mathrm{dl}$, creatinine $<1.5$ times normal, adequate pulmonary function (forced expiratory volume in 1 second and diffusing lung capacity $\geq 50 \%$ of predicted), and adequate cardiac function (left ventricular ejection fraction $\geq 50 \%$ ). Patients with HIV-related lymphoma were not eligible. Allogeneic BMT was considered for patients with primary chemotherapy- refractory disease and for those with recurrent disease, whether responsive or unresponsive to chemotherapy. Bone marrow involvement was allowed. Refractory disease was defined as a $<25 \%$ reduction in the sum of the products of the two greatest perpendicular 
diameters of measurable lesions despite treatment with combination chemotherapy regimens.

The histologic diagnosis was confirmed by review of the original biopsy specimens upon referral of the patient to our institution. Additional biopsies were performed at relapse, whenever possible, to rule out transformation.

Patients were categorized in the following histologic groups: low-grade Iymphoma (Working Formulation A-C), intermediate-grade lymphoma (Working Formulation $D-G$, but also including $H$, inummoblastic lymphoma), Iymphoblastic Iymphoma (Working Formulation 1), and diffuse small noncleaved cell Iymphoma (Working Formulation $J):^{15}$ One patient with a diffuse mantle zone lymphoma was included among those with low-grade lymphoma. ${ }^{16}$ One patient with a follicular large cell lymphoma was categorized as low-grade lymphoma, based on the indolent course of the disease, the preponderance of cleaved cells, and a low DNA index."

\section{Conditioning regimens, donor selection, and GVHD prophylaxis}

All patients provided written informed consent and were treated according to protocols approved by the institutional review boards. A number of different conditioning regimens were tested during the period covered by this report. Total body irradiation (TBl)-containing regimens included: cyclophosphamidle $120 \mathrm{mg} / \mathrm{kg}$ and TBI $(\mathrm{n}=10)$; cyclophosphamide $120 \mathrm{mg} / \mathrm{kg}$, etoposide 1,500 $\mathrm{mg} / \mathrm{m}^{2}$, and TBI $(\mathrm{n}=16)^{18,}$, mellphalan $140 \mathrm{mg} / \mathrm{kg}$ and TBI $(\mathrm{n}=4)^{19}$; cyclophosphamide $120 \mathrm{mg} / \mathrm{kg}, \mathrm{TBI}$, and total lymphoid irradiation $(n=5)^{20}$; carmustine $300 \mathrm{mg} / \mathrm{m}^{2}$, cytarabine $800 \mathrm{mg} / \mathrm{m}^{2}$, thioguanine $800 \mathrm{mg} / \mathrm{m}^{2}$, cyclophospharnide $200 \mathrm{mg} / \mathrm{m}^{2}$ and TBI $(\mathrm{n}=1)$, and piperazinedione $50 \mathrm{mg} / \mathrm{m}^{2}$ and TBI $(n=1){ }^{21}$ Twentyseven patients received high-dose chlemotherapy without TBI. Regimens included: busulfan $16 \mathrm{mg} / \mathrm{kg}$ and cyclophosphamide $(\mathrm{n}=3)^{6}$; thiotepa $750 \mathrm{mg} / \mathrm{kg}$, busulfan $10 \mathrm{mg} / \mathrm{kg}$, and cyclophosphamide 120 to $150 \mathrm{mg} / \mathrm{kg}$ (TBC) $(n=9)^{22}$; double consolidation with high-dose cyclophosphamide $5.25 \mathrm{~g} / \mathrm{m}^{2}$, etoposide $1,200 \mathrm{mg} / \mathrm{m}^{2}$, and platinum $135 \mathrm{mg} / \mathrm{m}^{2}$ followed by TBC $(\mathrm{n}=12)^{23}$; cyclophosphamide $6 \mathrm{~g} / \mathrm{m}^{2}$, carmustine $300 \mathrm{mg} / \mathrm{m}^{2}$, and etoposide $900 \mathrm{mg} / \mathrm{m}^{2}(\mathrm{n}=2)^{13}$; and carmustine $300 \mathrm{mg} / \mathrm{m}^{2}$, etopaside $1,600 \mathrm{mg} / \mathrm{m}^{2}$, cytarabine $1,600 \mathrm{mg} / \mathrm{m}^{2}$, and melphalan $140 \mathrm{mg} / \mathrm{m}^{2}(\mathrm{n}=1){ }^{24}$

Donors were human leukocyte antigen-identical siblings or, in 1 case, a one antigen-mismatched relative. Fifty-nine patients received unmanipulated marrow. Five patients received a T-cell depleted marrow after conditioning with etoposide, cyclophosphamide, TBl, and total lymphoid irradiation. ${ }^{20}$ Graft versus host disease (GVHD) prophylaxis consisted of cyclosporine alone $(n=5)$; cyclosporine and short-course methotrexate $(n=28)^{25}$ cyclosporine and corticosteroids $(n=19){ }^{26}$ cyclosporine and T-cell depletion $(n=5)$; and 
tacrolimus (FK506) and methotrexate $(n=1)$. Six patients treated in the early 1980 s received combinations of corticosteroids and methotrexate.

\section{Supportive care}

All patients were treated in laminar air flow rooms or in high-efficiency, particulate-free air rooms with strict reverse isolation. Infection prophylaxis changed considerably over the period covered by this report. The initial patients received nonabsorbable antibiotics and acyclovir prophyllaxis. More recently, patients received prophylaxis against Pneumocystis carinii, cytomegalovirus, and fungal infections. ${ }^{27-29}$ Irradiated blood products were administered to maintain a haemoglobin level $>8 \mathrm{~g} / \mathrm{dl}$ and platelet count $>20 \mathrm{x}$ $10^{9} /$. Patients treated after 1990 received growth factor support with recombinant human granulocyte colon stimulating factor, $5 \mathrm{mg} / \mathrm{kg}$ per day subcutaneously, beginning on day 0 until recovery of granulopoilesis.

\section{Post-transplant evaluation and response criteria}

Patients were evaluated for acute and chronic GVHD, and GVHD was scored and treated according to standard criteria. ${ }^{30,31}$

Response to therapy was evaluated by physical examination; blood counts: chest roentgenogram; computed tomography of the chest, abdomen, and pelvis; and bilateral marrow aspiration and biopsy.

Additionall tests such as immunophenotype analysis of the blood and bone marrow, lymph node aspiration, and biopsy were performed when clinically indicated. Response was evaluated at 6 weeks, 3 months, 6 months, and 1 year after transplant, and annually thereafter.

Complete remission was defined as disappearance of all disease and symptoms related to lymphoma for more than 1 month. Partial remission was defined as greater than $50 \%$ reduction in the sum of the products of the two greatest perpendicular diameters of measurable lesions for more than 1 month. All other outcomes were considered treatment failures.

\section{Statistical analysis}

The end points included: (1) survival (interval from the day of BMT until death or end of follow-up); (2) disease-free survival (interval from the day of BMT until disease progression, death due to disease or its treatment, or end of follow-up); and (3) time to progression (interval from BMT until disease progression.) Survival curves were estimated using the method of Kaplan and Meier. ${ }^{32}$ Survival curves were compared by the log rank test. ${ }^{33}$

The variables evaluated were: (1) histologic group, (2) conditioning (TBI versus non-TBI), (3) use of double consolidation versus single consolidation, (4) 
performance status at the time of BMT (KPS <80 versus $\geq 80$ ), and (5) decade of transplantation (BMT before 1990 versus BMT since 1990).

Because a poor performance status and the use of double consolidation were found to adversely affect survival and disease-firee survival, the analysis was repeated for those patients receiving single consolidation and with a good performance status (KPS $\geq 80)$ at $B M T(n=42)$.

\section{Results}

Patient characteristics, conditioning therapy, and GVHD prophylaxis are summarized in Table 2.1. As indicated, these were heavily pre-treated patients with refractory or multiply recurrent disease. The median follow-up for surviving patients is 38 months (range 10 to 171 ).

Figure 2.1 indicates actuarial survival and disease-free survival for patients according to histologic subtype. Ten of 15 patients with low-grade lymphoma were alive and 8 were free of disease at last follow-up (2-year survival $65 \pm 13 \%$; disease-free survival $59 \pm 13 \%$ ). One of 14 patients with intermediate- grade Iymphoma was alive at last follow-up (2-year survival $21 \pm 9 \%$ ). He relapsed 2 years after allogeneic BMT but underwent a successful second transplantation. Four of 25 patients with lymphoblastic lymphoma were alive at last follow-up (2year survival $21 \pm 9 \%$ ). Three were free of disease (2-year disease-free survival $17 \pm 8 \%$ ), but 1 had relapsed 38 months after BMT. One additional patient, who had central nervous system and testicular involvement at the time of transplantation, survived 6 years after BMT with mild GVHD but then died from fulminant sepsis. ${ }^{24}$ One of 10 patients with diffuse small non-cleaved cell (DSNCC) lymphoma is a long-term (>14 years) disease-free survivor (2-year survival and disease-free survival $10 \pm 9 \%$ ). The survival and disease-free survival for patients with low-grade lymphoma was significantly superior to any other subgroup of patients (log rank test $P<0.01$ ).

Table 2.2 shows the causes of death and Figure 2.2 the probability of disease progression associated with the different histologies. Two patients with lowgrade lymphoma had disease progression. One patient relapsed 6 months after transplantation with a transformed lymphoma. A second patient with chronic GVHD developed recurrent low-grade lymphoma 4 years after transplantation. Both appear to be responding to cyclosporine withdrawal.

Disease progression occurred in 5 patients with intermediate-grade Iymphoma (2-year risk of progression $39 \pm 14 \%$ ), 9 patients with Iymphoblastic lymphoma

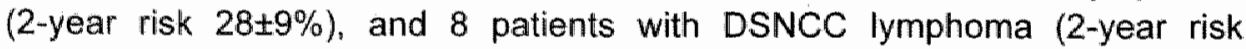
$80 \pm 13 \%$ ). The actuarial risk of progression was significantly higher in patients with DSNCC lymphoma than in any other subgroup of patients (log rank test $P<0.003$ ). Patients with DSNCC lymphoma tended to have extremely rapid 
disease progression after BMT. Seven of the 8 recurrences in this group occurred within 2 months. On the other hand, the actuarial risk for progression was significantly lower in patients with low-grade lymphoma than in any other histologic subgroup $(P<0.02)$.

Table 2.1 Patient characteristics, conditioning, regimens, and GVHD Prophylaxis by histologic subtype.

\begin{tabular}{|c|c|c|c|c|}
\hline & $\begin{array}{l}\text { Low } \\
\text { Gradie }\end{array}$ & $\begin{array}{l}\text { Intermediate } \\
\text { Grade }\end{array}$ & Lymphoblastic & DSNCO \\
\hline Number & $15^{\mathrm{a}}$ & $14^{6}$ & 25 & 10 \\
\hline Median age $(y)$ & 36 & 34 & 30 & 26 \\
\hline Range & $27-45$ & $22-48$ & $18-45$ & $12-43$ \\
\hline \multicolumn{5}{|l|}{ Sex } \\
\hline Men & 10 & 11 & 15 & 6 \\
\hline Women & 5 & 3 & 10 & 4 \\
\hline \multicolumn{5}{|l|}{ Disease state } \\
\hline First relapse, untreated & - & 4 & - & - \\
\hline First relapse, sensitive & 1 & 1 & 7 & 1 \\
\hline Refractory diaseas or $>1$ recurrence & 14 & 13 & 14 & 9 \\
\hline Median \# prior treatment regimens & 3 & 3 & 2 & 3 \\
\hline Range & $2-6$ & $1-5$ & $1-4$ & $2-6$ \\
\hline Median interval from diagnuasis to BMT (m) & 29 & 15 & 13 & 8 \\
\hline Range & $11-89$ & $5-182$ & $5-36$ & $3-21$ \\
\hline \multicolumn{5}{|l|}{ Performance status at BMT } \\
\hline $80-100$ & $13(87 \%)$ & $10(71 \%)$ & $19(76 \%)$ & $7(70 \%)$ \\
\hline$\leq 70$ & $2(23 \%)$ & $4(29 \%)$ & $6(24 \%)$ & $3(30 \%)$ \\
\hline \multicolumn{5}{|l|}{ Stage at conditioning } \\
\hline 0 & - & 2 & 6 & 2 \\
\hline II & - & 2 & 2 & - \\
\hline III & 2 & 3 & - & - \\
\hline IV & 13 & 7 & 17 & 8 \\
\hline \multicolumn{5}{|l|}{ Conditioning regimen } \\
\hline Witth TBI & 13 & 5 & 12 & 7 \\
\hline Without TBI & 2 & 9 & 13 & 3 \\
\hline \multicolumn{5}{|l|}{ GVHD prophylaxis } \\
\hline Cyclosporine & 13 & 14 & 16 & 9 \\
\hline Tacrolimus (FK506) & - & - & 1 & - \\
\hline No cyclosporine & 1 & 0 & 4 & 1 \\
\hline T-cell depletion + cyclosporine & 1 & 0 & 4 & 0 \\
\hline
\end{tabular}

ancludes 2 diffuse well differentiated lymphocytic lymphoma, 6 follicular small cleaved cell lymphoma, 5 follicular mixed cell lymphoma, 1 follicular large cell lymphoma, and 1 diffuse mantle zone lymphoma.

b Includes 9 diffuse large cell lymphoma, 1 diffuse mixed cell lymphoma, 3 primary mediastinal large cell lymphoma, and 1 transformed CLL.

GVHD=graft versus host disease; $D S N C C=$ diffuse small non-cleaved cell; $B M T=$ bone marrow transplantation; TBI=total body irradiation. 

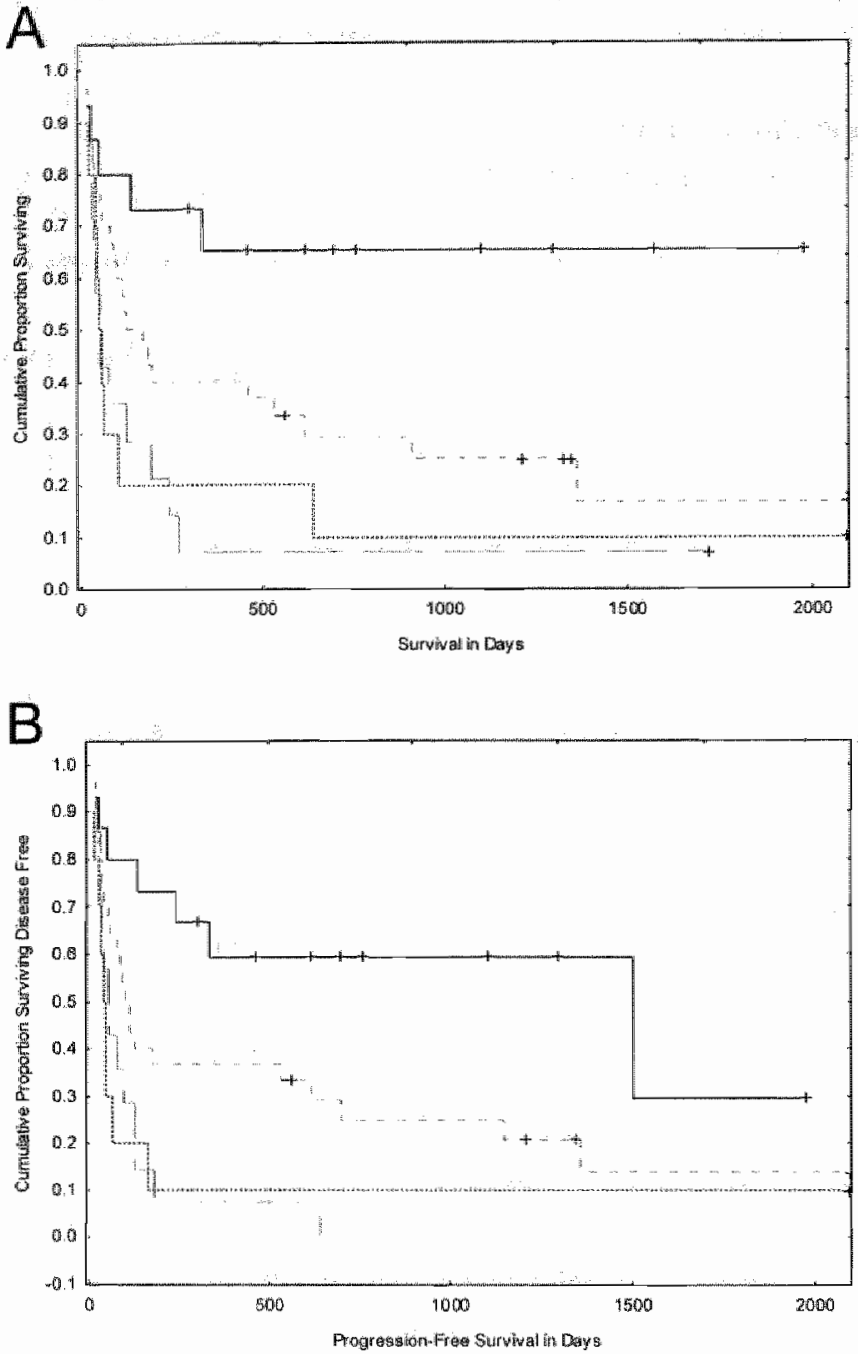

Figure 2.1 A. Survival after allogeneic BMT for lymphoma according to histologic subtype. B. Disease-free survival after allegeneic BMT for lymphoma according to histologic subtype. ( - ) Diffuse small non-cleaved, $(-\ldots)$ Intermediate grade, (.............") Lymphoblastic, $(\ldots-$.$) Low grade. BMT= bone marrow transplantation.$ 
Table 2.2 Causes of death after bone marrow transplantation.

\begin{tabular}{|c|c|c|c|c|}
\hline $\begin{array}{r}5 \\
\end{array}$ & $\begin{array}{l}\text { Low } \\
\text { Grade }\end{array}$ & $\begin{array}{c}\text { Intermediate } \\
\text { Grade }\end{array}$ & Lymphoblastic & DSNCC \\
\hline \multicolumn{5}{|l|}{ Toxicity } \\
\hline Hepatic & 1 & 1. & & \\
\hline Pulmonary & & $5^{a}$ & $2^{6}$ & \\
\hline Multiorgan & & 1 & 2 & \\
\hline Infection & & 1 & 3 & 1 \\
\hline Progression & & 4 & 8 & 8 \\
\hline Graft versus hast disease & 4 & 1 & 6 & \\
\hline
\end{tabular}

a Four pulmonary hemorrhages, 1 diffuse infiltrates

"One pulmonary hemorrhage, "interstitial pneumonitis

DSNCC $=$ diffuse small non-cleaved cell.

In univariate analysis, the use of double consolidation and a poor performance status at BMT were associated with a decreased survival and disease-free survival $(P<0.05)$. Therefore, the analysis was repeated, excluding patients with a poor performance status and those receiving double consolidation. In this subgroup of 42 patients, those with low-grade lymphoma still had significantly superior survival and disease-free survival compared to any other histologic group ( $P=0.04, P=0.05$, respectively). Their recurrence rate remained significantly lower than that in any other histologic group $(P<0.03)$

\section{Discussion}

The current report summarizes 13 years of experience with allogeneic BMT at our institutions. Because a high mortality was associated with this procedure in the past, it has mainly been offered to patients who did not qualify for autologous BMT. Therefore, the majority of patients in this series had advanced disease, extensive bone marrow involvement, and multiple high risk factors. Our results confirm that some such patients can be cured with allogeneic BMT. Many different subtypes of lymphoma are recognized in the Working Formulation ${ }^{15}$ or its recent successors, ${ }^{34}$ but for practical purposes, patients can be divided into four major subgroups: (1) low-grade lymphoma, (2) intermediate-grade and immunoblastic lymphoma, (3) lymphoblastic lymphoma, and (4) DSNCC lymphoma. Our results indicate the importance of disease histology in determining the outcome of allogeneic BMT for patients with recurrent or refractory lymphoma.

Allogeneic bone marrow transplantation was most effective in patients with lowgrade lymphoma. Three of 15 such patients were transplanted in the 1980 's without the benefit of cyclosporine and modern infection prophylaxis. They died from infectious complications of severe chronic GVHD. The other 12 underwent 
BMT after 1989. Ten of these were included in a previous report. ${ }^{35}$ At the time of this writing, 10 of the 12 are alive and 8 are in remission, with a median follow-up of 2 years, including 7 of the previously reported patients. In addition, 58 patients who had undergone allogeneic bone marrow transplantation for low-grade Iymphoma have been identified in the International Bone Marrow Transplant Registry. ${ }^{36}$ Kaplan-Meier disease-free survival at 3 years is $44 \%$ (range $31 \%$ to $58 \%$ ) for these patients. The probability of recurrence was only $24 \%$ despite the inclusion of 49 patients $(72 \%)$ with stage IV disease. These results, and anecdotal reports in the literature ${ }^{6,7,9,12,13}$ (see also Table 2.3) indicate that allogeneic bone marrow transplantation has a major impact in lowgrade lymphoma, regardless of the stage of the disease and its response to prior chemotherapy. Most of the patients in this series had bulky disease and extensive bone marrow involvement at the time of BMT. Responses were often slow to occur. The durability of remission was superior to that reported for autologous BMT, even with marrow purging, consistent with an active graft versus lymphoma effect. ${ }^{37-39}$. The occurrence of a late recurrence in 1 of our patients indicates the need for continued surveillance.

Patients with more aggressive histologies had a less favorable outcome with allogeneic BMT. Our results are similar to those of previously published series that incluide a majority of patients with intermediate- and high-grade Iymphomas. $10,11,13$ There is a high incidence of toxic deaths in patients with advanced disease, and disease-free survival was $10 \%$ to $20 \%$, with no significant difference in survival between intermediate grade and high-grade lymphoma. Not surprisingly, a poor performance status at BMT was predictive of a particularly ominous prognosis. There were, however, important differences in response rates and in the causes of treatment failure between those groups.

Table 2.3 Allogeneic bone marrow transplantation for recurrent low grade lymphoma, individually reported cases.

\begin{tabular}{|c|c|c|c|c|c|c|}
\hline Authoir & $\begin{array}{l}\text { Conditioning } \\
\text { regimen }\end{array}$ & $\begin{array}{c}\text { Number of } \\
\text { patients }\end{array}$ & Age (y) & $\begin{array}{c}\text { Disease-free } \\
\text { survival }\end{array}$ & Progression & $\begin{array}{l}\text { Treatment- } \\
\text { related death }\end{array}$ \\
\hline wan Besiem & See Text & 15 & $27-45$ & 8 & 0 & 5 \\
\hline Chopra et al. & NA & 1 & NA & 1 & 0 & 0 \\
\hline Appelbaum et al. ${ }^{9}$ & $\mathrm{BCNU}, \mathrm{Cy}, \mathrm{TBI}$ & 1 & 39 & 0 & 1 & 0 \\
\hline Copelan et al. & $\mathrm{Bu}, \mathrm{Cy}$ & 1 & 37 & 1 & 0 & 0 \\
\hline Lundberg et al. ${ }^{7}$ & Ara, Cy, TBI & 4 & $27-39$ & 3 & 0 & $1^{a}$ \\
\hline Tolal & & 22 & & $15(68 \%)$ & $1(5 \%)$ & $6(27 \%)$ \\
\hline
\end{tabular}

Matched unrelated donor. Na=not available; $B u=b u s u l f a n ; C y=c y c l o p h o s p h a m i d e ;$

Ara=cytarabine, $T B I=t o t a l$ body irradiation. For exact dosages see indicated references.

Twenty percent to $50 \%$ of cases of recurrent intermediate-grade lymphoma can be cured with high dose chemotherapy and autologous peripheral blood or marrow stem cell rescue. ${ }^{40-49}$ Patients with refractory disease or multiple 
recurrences have a poor prognosis with high-dose chemotherapy and autologous BMT. ${ }^{41,45,47.48}$ At our institutions, these patients were considered for allogeneic BMT. They often had bulky disease at the time of BMT and were debilitated by their disease and numerous previous treatments. Most had dramatic responses to treatment, and some obtained prolonged remissions, even though their disease was refractory to conventional-dose chemotherapy. Unfortunately, they tolerated the conditioning regimens poorly: this group, like previously reported cases, had a high rate of mortality from toxicity and infections (Table 2.4). Pulmonary hemorrhage and pulmonary toxicity were especially common and accounted for the majority of the deaths, even among patients who did not receive radiation.

Lymphoblastic lymphoma shares many characteristics with acute lymphoblastic leukemia The large majority of cases exhibit a T-cell phenotype. ${ }^{15,34}$ Most large series of patients undergoing BMT for recurrent non-Hodgkin's lymphoma include a small number of patients with lymphoblastic lymphoma, but their outcome is not generally specified. Five of the 25 patients who had lymphoblastic lymphoma in our series obtained prolonged disease-free survival after allogeneic BMT, including patients with chemotherapy refractory disease and 1 with central nervous system involvement. This is consistent with previously reported cases (Table 2.5) and with data from the European Bone Marrow Transplant registry, which suggest that allogeneic BMT is superior to autologous BMT for the treatment of this disease. ${ }^{42,53}$

Table 2.4 Allogeneic bone marrow transplantation for recurrent lintermediate grade and immunoblastic lymphoma, individually reported cases.

\begin{tabular}{|c|c|c|c|c|c|c|}
\hline Author & Conditioning regimen & $\begin{array}{c}\text { Number } \\
\text { of } \\
\text { patients }\end{array}$ & Age $(y)$ & $\begin{array}{l}\text { Disease- } \\
\text { free survival }\end{array}$ & Progression & $\begin{array}{l}\text { Treatment- } \\
\text { reilated } \\
\text { death }\end{array}$ \\
\hline Van Besien & See Text & 14 & $22-48$ & 0 & 5 & 9 \\
\hline Schmitz: & VP, TBI & 1 & 34 & 0 & 0 & 1 \\
\hline Philips $^{51}$ & Cy. TBI & 3 & $35,37,40$ & 1 & 0 & 2 \\
\hline Ernst $^{52}$ & $\begin{array}{l}\text { TBil + various } \\
\text { chemotherapy }\end{array}$ & 5 & $10-39$ & 2 & 2 & 1 \\
\hline Petersen ${ }^{10}$ & Ara, TBI & 3 & $36,38,43$ & 0 & 0 & 3 \\
\hline Sichouten $^{8}$ & Bu, Cy & 1 & 15 & 1 & 0 & 0 \\
\hline Copelan $^{6}$ & Bu, Cy & 1 & 29 & 1 & 0 & 0 \\
\hline Lundberg? & Ara, Cy, TBI & 9 & $46-44$ & $6^{b}$ & $2^{c}$ & 1 \\
\hline Appelbaum & Various & 9 & $5-62$ & 2 & 5 & 2 \\
\hline Total & & 46 & & $13(28 \%)$ & $14(30 \%)$ & $19(41 \%)$ \\
\hline
\end{tabular}

an some cases, additional inwolved field radiation or chemotherapy was given, for details see indicated references; ${ }^{b}$ In cludes 2 matched unrelated or mismatched related donors; ${ }^{e}$ Includes 1 matched unrelated or mismatched related donor. VP=otoposide; TBI=total body irradiation; $\mathrm{Cy}=$ cyclophosphamide; Ara $=$ cytarabine; $\mathrm{Bu}=$ busulfan; . For exact dosages see indicated references. 
Table 2.5: Results of allogeneic BMT in irecurrent or refractory lymphoblastic :lymphoma, individually reported cases.

\begin{tabular}{|c|c|c|c|c|c|c|}
\hline Author & Conditioning regimen & $\begin{array}{c}\text { Number } \\
\text { of } \\
\text { patients }\end{array}$ & Age $(y)$ & $\begin{array}{l}\text { Disease- } \\
\text { free } \\
\text { surwilual }\end{array}$ & Progressio & $\begin{array}{l}\text { on Treatment } \\
\text { related } \\
\text { death }\end{array}$ \\
\hline Lundberg & Cy-Ara-T & 2 & 22,28 & & 1 & 1 \\
\hline Emst & Vario & 8 & $7-28$ & 2 & 3 & 3 \\
\hline Philips: & Cy-TBU & 7 & $17-27$ & 1 & 2 & 4 \\
\hline Petersan ${ }^{40}$ & Ara TBH & 1 & 23 & & & 1 \\
\hline Appelbaum & $\begin{array}{l}C y-T B I(6) \\
C y-B C N U-T B \mid(1)\end{array}$ & 7 & $9-32$ & 2 & 1 & 4 \\
\hline $\begin{array}{l}\text { Copelan } \\
\text { van Besien } \\
\text { Total }\end{array}$ & $\begin{array}{l}\text { BurCy } \\
\text { see table } 2.1\end{array}$ & $\begin{array}{l}2 \\
25 \\
52\end{array}$ & $\begin{array}{c}18,36 \\
\text { see table } 2.1\end{array}$ & $\begin{array}{c}1 \\
4^{\mathrm{al}} \\
10(19 \%)\end{array}$ & $\begin{array}{c}1 \\
8 \\
17(33 \%)\end{array}$ & $\begin{array}{c}13 \\
25(48 \%)\end{array}$ \\
\hline
\end{tabular}

One patient died from sepsis 6 years after BMT.

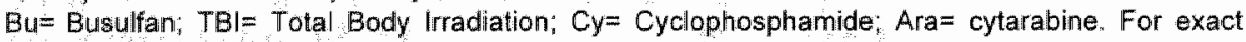
dosages see indicated references.

Although treatment-related mortality accounted for the majority of failures in intermediate-grade and lymphoblastic lymphoma, recurrence was the major problem in patients with DSNCC lymphoma. Most patients had no response, or only transient responses to allogeneic BMT, and tumor regrowth occurred upon hematologic recovery. An overview of individually published cases of BMT for recurrent DSNCC lymphoma in adults and children is presented in Table 2.6 , and is consistent with our results. In adults with recurrent or refractory DSNCC, both autologous and allogeneic bone marrow transplantation have yielded poor results, with very high recurrence rates. ${ }^{10,54}$

Table 2.6 Results of allegeneic BMT in recurrent of refractory DSNCC lymphoma (Burkitt's and mon-Burlkitt's), individually reported cases.

\begin{tabular}{|c|c|c|c|c|c|c|}
\hline Author & Conditioning regimen & $\begin{array}{l}\text { Number of } \\
\text { patients }\end{array}$ & Age $(y)$ & $\begin{array}{c}\text { Disease- } \\
\text { free } \\
\text { survival }\end{array}$ & $\begin{array}{c}\text { Outcome } \\
\text { progression }\end{array}$ & $\begin{array}{c}\text { Treatment- } \\
\text { related } \\
\text { death }\end{array}$ \\
\hline Schouten $^{\text {i }}$ & $\mathrm{BACT}$ & 1 & 29 & & & 1 \\
\hline Copelan ${ }^{3}$ & Bu-Cy & 3 & $15-43$ & & 3 & \\
\hline Philips $^{3+1}$ & Cy-TBI & 3 & $15-21$ & & 2 & 1 \\
\hline \multirow[t]{2}{*}{ Appelbaum ${ }^{9}$} & Mbu-Cy-TBI & 1 & 24 & & 1 & \\
\hline & Ara-Cy-TBI & 1 & 5 & & & 1 \\
\hline Schmitz ${ }^{601}$ & VP-TBI & 1 & 20 & 1 & & \\
\hline van Besien & See table 2.1 & 10 & $12-43$ & 1 & 8 & 1 \\
\hline Petersen $^{10}$ & Ara-TBI & 5 & $7-46$ & & 3 & 2 \\
\hline Total & & 25 & & $2(8 \%)$ & $17(68 \%)$ & $6(24 \%)$ \\
\hline
\end{tabular}

BACT= Carmustine, cytarabine, cyclophosphamide, 6-thioguanine; VP=etoposide; $T B \mid=$ total body

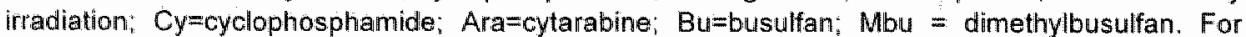
exact dosages see indicated references. 
The outcome of allogeneic BMT depends on the sensitivity of the disease to chemotherapy and to graft versus lymphoma effects. The results in patients with low-grade lymphoma are very promising and indicate a major impact of allogeneic BMT in this disease.

Sensitivity of low-grade lymphoma to graft versus lymphoma effects is not surprising, given the results of other immunomodulatory approaches such as administration of interferon or anti-idiotype antibodies. ${ }^{55-57}$

Graft versus lymphoma effects could explain the slow tumor regression after BMT that was observed in some of these patients. On the other hand, the high recurrence rates in patients with recurrent DSNCC lymphoma may be due in part to a decreased sensitivity to immune effects. This decreased sensitivity may be related to the lack of expression of adhesion molecules by the lymphoma cells. ${ }^{58.59}$ However, graft versus lymphoma effects are not completely absent in this disease. Graft versus lymphoma mediated regression of lymphoma has been reported, followed by relapse upon institution of immunosuppressive treatment. ${ }^{10}$ Promising results have also been obtained in high-risk patients in first complete remission. ${ }^{60}$

Selection of patients with less advanced disease may result in decreased toxicity and yield improved results with BMT in all types of lymphoma. Alogeneic BMT should be considered for younger patients with recurrent lowgrade lymphoma. Allogeneic BMT for patients with advanced intermediate- and high-grade lymphoma needs further evaluation with attention to measures to reduce toxicity. The use of novel cytokines and/or allogeneic peripheral blood stem cells are currently being explored as a means of reducing the incidence of early complications. In our experience, allogeneic peripheral blood stem cell transplantation has led to a reduction in time to hematopoietic recovery, ${ }^{58}$ and contributed to an improved early survival for such patients. ${ }^{59}$ The presence of mature T-lymphocytes in the graft could enhance the graft versus lymphoma effects and thereby further contribute to improved survival for these patients. 


\section{References}

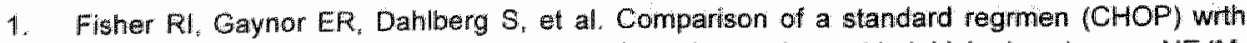
three intensive chemotherapy regimens for advanced non-Hodgkin's fymphoma NEJM. $1993 ; 328: 1002-6$.

2. Armitage JO. Drug therapy: treatment of non-Hodgkin's lymphoma. NEJM. 1993;328:1023-30

3. Gordon $\mathrm{L}$, , Harrington $D$, Andersen $J$, et al Comparison of a second generation combination chemotherapeutic regimen m-BACODJ with a standard regimen (CHOP) for advanced diffuse non-Hodgkin's lymphoma. NE.JM. 1992; 327:1342-3.

4. Velasquez WS, Mclaughilin P. Tucker $\$$, et al. ESHAP-an effective chemotherapy regimen in refractory and relapsing lymphoma: a 4-year follow up study. J Clin Oncol, 1994,12:1169-76.

5. Appelbaum $\mathrm{FR}_{i}$ Sullivan $\mathrm{KM}$, Buckner $\mathrm{CD}$, al. Treatment of malignant lymphoma in 100 patients with chemotherapy, total body irradiation and marrow transplantation. J Clin Oncol. $1987: 5: 1340$.

6. Copelan EA, Kapoor $\mathbb{N}$, Gibbins B, Tutschka PJ. Allogenerc marrow transplantation in nonHodgkin's lymphoma. Bone Marrow Transplant. 1990;5:47-50.

7. Lundberg $\mathrm{JH}$, Hansen $\mathrm{RM}$, Chitambar $\mathrm{CR}$, et al. Allogeneic bone marrow transplantation for relapsed and refractory lymphoma using genotypically HLA transplantation for relapsed and refractory lymphoma using genotypically HLA-identical and alternative donors. J Clin Oncal. 1991:9:1848 59.

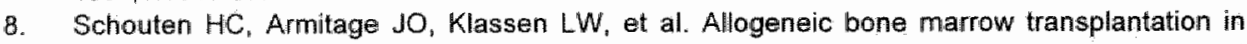
patients with lymphoma relapsing after autologous transplantation. Bone Marrow Transplant 1989:4:119-21.

9. Appelbaum $F R$. Thomas ED, Buckner $C D$, et al. Treatment of non-Hodgkin's lymphoma with chemoradiotherapy and allogeneic marrow transplantation. Hematol Oncoll: 1983;1:149-57.

10. Petersen FB, Appelbaum FR, Bigelow $\mathrm{CL}$, et al. High-dose cytosine arabinoside, total body irradiation and marrow transplantation for advanced malignant lymphoma. Bone Marrow Transplant. 1989;4:483-8.

11. Jones RJJ: Ambinder RF, Piantadosi $S_{\mathrm{i}}$ Santos GW. Evidence of a graft versus-lymphoma effect associated with allogeneic bone marrow transplantation. Blood. 1991;77:649-53.

12. Chopra $R$. Goldstone $A H$. Pearce $R_{8}$ et al. Autologous versus allogeneic bone marrow transplantation for non-Hodgkin's lymphoma: a case-controlled analysis of the European Bone Marrow Transplant Group registry data. J Clin Oncol. 1992;10:1690-5.

13. Ratanatharathorn $\mathrm{V}$. Uberti J, Karanes $\mathrm{C}$, et al. Prospective comparative trial of autologous versus allogeneic bone marrow transplantation in patients with non-Hodgkin's lymphoma. Blood 1994:84:4050-5.

14. Appeibaum FR. Treatment of aggressive non-Hodgkin's lymphoma with marrow transplantation. Marrow Transplantation Rev. 1993:3:1-16.

15. The Non-Hodgkin's Lymphoma Pathologic Classification Project. National Cancer Institute sponsored study of classifications of non-Hodgkin's lymphomas: summary and description of a working formulation for clinical usage. Cancer. 1982;49:2112-35.

16. Shivdasani FXA, Hess JL, Skarin AT, Pinkus GT. Intermediate lymphocytic lymphoma: clinical and pathologic features of a recently characterized subtype of non-Hodgkin's lymphoma. J Clin Oncol. 1993:11:802-11.

17. Longo DL. What's the deal with follicular lymphomas! J Clin Oncol. 1993;11:202-5.

18. Giralt SA, Vriesendorp HM, Andersson BS, et al. Etopaside, cyclophosphamide, total body irradiation and allogeneic bone marrow transplantation: an effective treatment for hematologic malignancies. J Clin Oncol. 1994:12:1923-30.

19. Spitzer $G$, Jagannath $S$, Dicke $K A$, et al. High dose melphalan and total body irradiation with bone marrow transplantation for refractory malignancies. Eur $J$ Cancer Clin Oncol. 1986:22:677-84.

20. Spinolo JA, Jagannath $S$, Zagars $G K$, et all. Occurrence of severe acute graft-versus-host disease with T-cell depletec allogeneic bone marrow transplantation In adilts with advanced or refractory haematological malignancies. Proc. Am Assoc Clin Oncol. 1988:7:47. Abstract. 


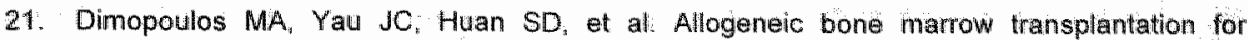
leukemia following piperazinediane and fractionated total body irradiation. Am J Hematol. $1994,46: 82-6$.

22. Przeplorka D, Ippoliti $C$, Giralt $S$, et al. A phase -11 study of high-dose thiotepa, busulfan and cyclophosphamide as a preparative regimen for allogeneic bone marrow transplantation: Bone Marrow Transplant. 1994:14:449-53.

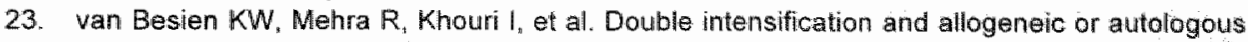
bone marrow transplantation for poor prognosis lymphoma. Blood: 1993;82(suppl 1):146a. Abstract:

24. van Besien $K W$. Demuynck $H_{1}$ LeMaistre CF, et al. High dose melphallan allows durable engraftment of allogeneic bone marrow. Bone Marrow Transplant. 1995;15:321-3.

25. Ferrara JLM, Deeg HJ. Mechanisms of disease: graft-versus-host disease. NEJM. 1991:324:667-74.

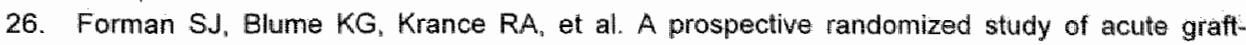
versus-host disease in 107 patients with leukemia: methotrexate/prednisone versus cyclosporine/prednisone. Transplant Proc. 1987;21:2605-7.

27. Goodrich JM, Bowden RA, Fisher $L$, et al. Ganclclovir prophylaxis to prevent cytomegalovirus disease after allogeneic marrow transplant. Ann Intern Med 1993:18:173-8.

28. Goodman JL, Winston DJ, Greenfield RA, et al. A controlled trial of fluconazole to prevent fungal infections in patients undergoing bone marrow transplantation. NEJM. 1992;326: 845-51.

29. Sullivan KM, Kopecky KJ, Jocom $J$, et al. Immunomodulatory and antimicrobial efficacy off intravenous immunoglobulin in bone marrow transplantation. NEJM. 1990;323:705-12.

30. Glucksberg H, Storb R, Fefer A. Clinical manifestations of graft-versus-lhost disease in human recipients of marrow fram HLA-identical sibling donors. Transplant 1974;18:295-304.

31. Atkinson $K_{\text {, Horowitz } M M}$ Gale RP, et al. Risk factors for chronic graft-wersus-host disease after HLA-identical sibling bone marrow transplantation. Bload. 1990;75:2459-64.

32. Kaplan EL, Meier P. Nonparametric estimation from incomplete observations. I Am Stat Assoc. 1958;53:457-81.

33. Armitage P. Berry G. Statfshcal Methods in Medical Research. Oxford: Blackwell Scientific Publications; $1987: 310-5$.

34. Harris NL, Jaffe ES, Stein $H_{\text {a }}$ et al. A revised European-American classification of lymphoid neoplasms: a proposal from the international lymphoma study group. Blood. 1994;84:1361-92.

35. van Besien $K W_{\text {, Khourl } I F}$, Giralt $S A$, et al. Allogeneic bone marrow transplantation for refractory and recurrent low grade lymphoma-the case for aggressive management. J Clin Oncol. 1995; 13:1096.

36. van Besien $K W$, Rowlings $P A$, Sobocinski $K A_{1}$ et al. Allogeneic bone marrow transplantation for low grade lymphoma. ASCO Proceedings. 1995;14:401.

37. Freedman AS, Nadler LM. Which patients with relapsed non-Hodgkin's Iymphoma benefit from high-dose therapy and hematopoietic stem-cell transplantation. J Clin Oncol. $1993 ; 11: 1841-3$.

38. Freedman AS, Ritz $J_{2}$ Neuberg $D$, et al. Autologous bone marrow transplantation in 69 patients with a history of low-grade B cell non-Hodgkin's lymphoma. Blood. 1991:77:2524-9.

39. Ronatiner AZS, Johnson PWM, Price CGA, et al. Myeloablative therapy with autologous bone marrow transplantation as consolidation therapy for recurrent follicular lymphoma. J Clin Oncol. 1994:12:1177-84.

40. Phillips GL, Fay JW, Herzig RH, et al. The treatment of progressive non-Hodgkin's lymphoma with intensive chemoradiotherapy and autologous marrow transplantation. Blood. 1990;75:831-8.

41. Philip $\mathrm{T}$, Armitage $\mathrm{JO}_{\mathrm{O}}$ Spitzer $\mathrm{G}$, et al. High-dose therapy and autologous bone marrow transplantation after failure of conventional chemotherapy in aduits with intermediate grade or high-grade-non-Hodgkin's lymphoma. NEJM. 1987;316:1493-8.

42. Takvorian T, Canellos CP. Ritz J, el al. Prolonged disease-free survival after autologous bone marrow transplantation in patients with non-Hodgkin's lymphoma with a poor prognosis. NEJM. 1987:316:1499-505. 
43. Petersen FB, Appelbaum $F R_{\text {, Hill }} \mathrm{R}_{\text {i }}$ et al. Autologous marrow transplantation for malignant lymphoma: a report of 101 cases from Seattle. J Clin Oncol. 1990;8:638-47.

44. Singer CRJ, Goldstone AH. Clinical studies of ABMT in non-Hodgkin's lymphoma. Clin Haematol. 1980;15:105-50.

45. Vose JM, Anderson $J R$, Kessinger $A$, al High-dose chemotherapy and autologous hematopoletlc stem-cell transplantation for aggressive non-Hodgkin's lymphoma. J Clim Oncol. 1993:11:1846:51.

46: Colombat $P$, Gorin $N C$, Lemannier $M-F^{\prime}$, et al. The role of autologous bone marrow transplantation in 46 adult patients with non-Hodgkin's lymphomas. J Clin Oncoll: 1990:8: B30-7

47. Rapoport AP. Rowe $\mathrm{JM}_{3}$ Kouides $\mathrm{PA}_{\text {, }}$ et al. One hundred autotransplants for relapsed or refractory Hodgkin's disease and Wmphoma: value of pretransplant disease status for predicting outcome. $\mathrm{J}$ Clin Oncoll 1993;14:2351-51.

48. wan Besien $K W$. Tabocoff $J$, Rodriguez $M A$, et al. Intensive chemotherapy with the BEAC regimen and autologous bone marrow transplantation in patients with refractory or recurrent intermediate grade and immunoblastic lymphoma: toxicity, long-term follow-up and identification of prognostic factors. Bone Marrow Transplant 1995:15:549-55.

49. Wheeler $C_{i}$ Straderman $M_{3}$. Ayash $L$, et al. Prognostic factors for treatment outcome in autotransplantation of intermediate-grade and high-grade non-Hodgkin's lymphoma with cyclophosphamide, carmustine, and etoposide. J Clin Oncol: 1983;11:1085-91.

50. Schmitz $N$, Gassmann W, Rister $M$, el al. Fractionated total body irradiation and high-dose VP15213 followed by allogeneic bone marrow transplantation in advanced leukemias. Blood. 1988:72:1567-73:

51. Phillips GL. Herzig RH, Lazarus $H M$, et al. High-dose chemotherapy, fractionated total-body irradiation, and allogeneic marrow transplantation for malignant lymphoma. I Clin Oncol. $1986: 4: 480=88$.

52. Ernst $P$, Maraninchi $D$, Jacobsen $N$, et al. Marrow transplantation for non Hodgkin's lymphoma: a multi-centre study from the European cooperative bone marrow transplant group. Bone Marrow Transplant. 1986; $4: 81-6$

53. Sweetenham JW, Liberti $G$, Pearce $R$, et al. High-dose therapy and autologous bone marrow transpiantation for adult patients with lymphoblastic lymphoma: results of the European group for bone marrow transplentation. J Clin Oncol. 1994;12:1358-6:5.

54. Ostronoff $M$, Soussain $G$, Zambon $E$, et al. Burkitt's lymphoma in adults: a retrospective study of 46 cases. Nouv Rev Fr Hematol: 1992;34:389-97.

55. McLaughlin $P$, Cabanillas $F$, Hagemeister $F B$ et al. CHOP-Bleo plus Interferon for stage $N$ lowgrade lymphoma. Ann Oncol. 1993;4:205-11.

56. Smalley RV. Andersen JW. Hawkins $\mathrm{MJ}_{\text {, }}$ et al. Interferon-a combined with cytotoxic chemotherapy for patients with non-Hodgkin's lymphome. NEJM. 1992;327:1336-41.

57. Kwak $L W$, Campbell MJ, Czerwinski DK, et al. Induction of immune responses in patients with $B$ ceil lymphoma against the surtace-immunoglabulin idiotype expressed by their tumors. NEJM. $1992 ; 327 ; 1209-15$.

58. Freedman AS. Expression and function of adhesion receptors on normal $B$ cells and $B$ cell nonHodgkin's lymphomas. Semin Hematol. 1993;30:318 28.

59. Guinan EC, Gribben JG, Boussiotis VA, al. Pivotal role of the B7:CD28 pathway in transplantation tolerance and tumor immunity. Blood. 1994:a4:3261-82.

60. Troussard $X$, Leblond $V$, Kuentz $M$, et al. Allogeneic bone marrowy transplantation in adults with Burkitt's lymphoma or acute lymphoblastic leukemia in first complete remission. J Clin Oncol. 1990;8:809-12.

61. Korbling M, Przepiorka D, Huh YO, et al. Allogeneic blood stem cell transplantation for refractory leukemia and lymphoma: potential advantage of blood over marrow allografts. Blood: $1995: 85: 1659-65$

62. van Besien $\mathrm{KW}$, Przepiorka $\mathrm{D}$, Champlin $\mathrm{R}$, et al. Allogeneic blood stem cell transplantation for endstage Iymphoma. Presented at the Meeting of The American Society of Blood and Marrow Transplantation, 1995. 


\section{Chapter 3}

Allogeneic bone marrow transplantation for refractory and recurrent low-grade lymphoma: the case for aggressive management

KW van Besien, IF Khouri, SA Giralt, P McCarthy, R Mehra, BS Andersson, D Przepiorka, JL Gajewski, N Bellare, R Nath, JE Romaguera, P McLaughlin, M Korbling, AB Deisseroth, FF Cabanillas, RE Champlin 


\section{Abstract}

\section{Purpose}

To evaluate the role of allogeneic bone marrow transplantation (BMT) in recurrent low-grade Iymphoma.

Patients and methods

Between 1989 and 1994,10 patients with chemotherapy-fefractory and recurrent low-grade lymphoma were treated with myeloablative therapy and allogeneic BMT. All patients had poor prognostic features and had been extensively pretreated.

\section{Regults}

Eight patients achieved a complete remission and none have relapsed at a median follow-up time of 816 days (range, 346 to 1,865 ). Two patients died of early complications. The actuarial survival and fallure-free survival rates are both $80 \%+12.6 \%$. For surviving patients, the duration of the current remission exceeds that of any previous remission achieved.

\section{Conclusions}

These results compare favorably with those for autologous BMT. Allogeneic BMT offers considerable promise for the treatment of patients with poor prognosis low-grade lymphoma. Its role should be further defined in prospective studies. 


\section{Introduction}

Low-grade lymphomas are indolent disorders with a high rate of initial response to treatment and a median survival duration of between 7 and 9 years. ${ }^{1.4}$ Radiation therapy or the combination of radiation and chemotherapy can produce durable remissions in some patients with stage I, II, or III disease. ${ }^{5-9}$ However, patients with advanced, recurrent, or refractory disease have a poor prognosis. ${ }^{1,10-12}$

Encouraging results have been reported with myeloablative therapy and autologous bone marrow transplantation (BMT) for patients with recurrent lowgrade llymphoma. ${ }^{13-16}$ Autologous BMT results in a 4-year disease-free survival rate of approximately $45 \%$ in patients with chemosensitive recurrences. ${ }^{13,14}$ For patients with extensive bone marrow involvement and for those with refractory disease, there is no effective therapy.

There have been anecdotal reports on the success of allogeneic BMT in patients with refractory disease, which indicate that prolonged disease-free survival can be obtained. ${ }^{7-20}$ Allogeneic BMT has not been widely applied to the treatment of low-grade lymphoma because of concern over transplant-related complications, particularly graft-versus-host disease (GVHD) and infections. However, important advances in supportive care, ${ }^{21}$ graft-versus-host prophylaxis, ${ }^{22}$ and infection prophylaxis, ${ }^{23}$ have reduced the risk of allogeneic BMT in the past decade.

Allogeneic BMT may have advantages over autologous transplantation. Donor marrow cells uninvolved by malignancy are used, avoiding the risk of infusing occult lymphoma cells, which, despite bone marrow purging, may contribute to relapse in many patients who undergo autologous BMT. ${ }^{24,25}$ In addition "donor lymphoid cells can potentially mediate a graft-versus-lymphoma effect. ${ }^{26}$ In view of the occurrence of spontaneous remissions ${ }^{27}$ and the sensitivity of the disease to interferon therapy ${ }^{28.29}$ and to anti-idiotype vaccines, ${ }^{30}$ low-grade lymphoma may be more susceptible than other subtypes to immune-mediated suppression by a graft-versus-lymphoma effect.

We report the results obtained with allogeneic BMT for low-grade lymphoma in 10 patients treated at our institutions since 1989.

\section{Patients and work-up}

Ten patients with low-grade lymphoma underwent allogeneic BMT between December 1989 and February 1994. Eligibility criteria included age $\leq 50$ years, performance status $\leq 1$, bilirubin level $\leq 2 \mathrm{mg} / \mathrm{dl}$, creatinine less than 1.5 times normal, adequate pulmonary function (forced expiratory volume in 1 second $\left[F E V_{1}\right]$ and diffusing capacity of carbon monoxide [DLCO] $\geq 50 \%$ of predicted) 
and adequate cardiac function (left ventricular ejection fraction [LVEF] $250 \%$ ). Patients with active CNS involvement or human immunodeficiency virus (HIV)related lymphoma were not eligible. Allogeneic BMT was considered for patients with primary chemotherapyrefractory disease or recurrent disease. whether responsive or unresponsive to chemotherapy. Bone marrow involvement was allowed.

Refractory disease was defined as a less than $25 \%$ reduction in the sum of the products of the two greatest perpendicular diameters of measurable lesions, despite treatment with combination chemotherapy regimens that contained an anthracycline, platinum, fludarabine, or combinations of these agents. ${ }^{31}$

All patients provided written, informed consent and were treated on protocols approved by the institutional review board. Pretransplant work-up included history and physical examination; blood counts; 12-element sequential multiplier analyzer (SMA-12); electrolytes; urinalysis; bilateral bone marrow aspirate and biopsy with immunophenotyping; chest $x$-ray and computed tomography of the chest, abdomen, and pelvis radionuclide cardiac scan, ECG; and pulmonary function tests; hepatitis, cytomegalovirus (CMV), and HIV serology; and pathology review. Additional tissue biopsies were obtained at relapse, whenever possible, to rule out transformation. Patients with tumor transformation to a higher histologic grade were not included in this analysis. One patient with a mantle-cell lymphoma was included; this disease has clinical features similar to those of low-grade lymphoma, but has a more aggressive course and a poor prognosis. ${ }^{32}$ Two patients were previously included in a report on conditioning for allogeneic BMT with cyclophosphamide, etoposide, and total-body irradiation (TBI). ${ }^{33}$

\section{Conditioning regimens, GVHD prophylaxis, and supportive care}

Eight patients underwent conditioning with TBI-containing regimens. Five received cyclophosphamide $(120 \mathrm{mg} / \mathrm{kg})$ and $\mathrm{TBI}$, and three received etoposide $\left(1,500 \mathrm{mg} / \mathrm{m}^{2}\right)$, cyclophosphamide $(120 \mathrm{mg} / \mathrm{kg})$, and TBI. TBI was administered twice daily using an $18-\mathrm{MeV}$ linear accelerator at a dose rate of $.25 \mathrm{~Gy} / \mathrm{min}$ in six fractions of $1.7 \mathrm{~Gy}$ for seven patients and in six fractions of 2.0 Gy for one patient.

Two patients were treated with two courses of high-dose chemotherapy. Course one consisted of cyclophosphamide $\left(5.25 \mathrm{~g} / \mathrm{m}^{2}\right)$, etoposide $(1,200$ $\left.\mathrm{mg} / \mathrm{m}^{2}\right)$, and cisplatin $\left(135 \mathrm{mg} / \mathrm{m}^{2}\right)(C V P)$. It was followed, after hematologic recovery, by course 2 , which consisted of thiotepa $\left(750 \mathrm{mg} / \mathrm{m}^{2}\right)$, busulfan (10 mg/kg), and cyclophosphamide (120 mg/kg) (TBC) plus bone marrow infusion. 34

Donors were human leukocyte antigen (HLA)-identical siblings or, in one case, a one-antigen-mismatched relative. All patients received unmanipulated 
marrow. GVHD prophylaxis consisted of cyclosporine and a short course of methotrexate in nine patients ${ }^{22}$ and cyclosporine and corticosteroids in one patient. $^{35}$

All patients were treated in laminar-air flow rooms or in high-efficiency particulate-free air rooms with strict reverse isolation. Infection prophylaxis consisted of acyclovir and fluconazole plus oral quinolones or nonabsorbable antibiotics during neutropenia. After granulocyte recovery, patients who were seropositive for CMV or who received bone marrow from a seropositive donor received prophylactic ganciclovir until day $100 .^{36}$ All patients received prophylaxis against Pneumocystis carinii with trimethoprim/sulfamethoxazole or aerosolized pentamidine for 1 year after BMT. Intravenous immunoglobulin ( 0.5 $\mathrm{g} / \mathrm{kg}$ ) was administered weekly for 100 days after transplant and then monthly for 1 year. Those with chronic GVHD continued to receive antibiotic prophylaxis indefinitely. ${ }^{23,37-39}$ Irradiated blood products were administered to maintain a haemoglobin level more than $8 \mathrm{~g} / \mathrm{dl}$ and platelet count more than $20 \times 10^{\circ} / \mathrm{l}$. Six patients received growth factor support with recombinant human granulocyte colony-stimulating factor ( $5 \mu \mathrm{g} / \mathrm{kg} / \mathrm{d}$ subcutaneously) beginning on day 0 until recovery of granulopoiesis.

\section{Posttransplant evaluation and response criteria}

Toxicity was assessed according to the criteria reported by Bearman et al. ${ }^{40}$ Hematopoietic chimerism was evaluated by conventional cytogenetic analysis for sex-mismatched patient-donor pairs or by restriction fragment-length polymorphisms at the $\mathrm{AY}-29$ or $\mathrm{YNH} 24$ loci. ${ }^{41}$ Patients were evaluated for acute and chronic GVHD 28 days and 100 days, respectively, after marrow infusion, and GVHD was scored and treated according to standard criteria. ${ }^{42,43}$

Response to therapy was evaluated at 6 weeks, 3 months, 6 months, and 1 year after transplant, and annually thereafter. Evaluation consisted of physical examination; blood counts; chest x-ray and computed tomography of the chest, abdomen, and pelvis; and bilateral marrow aspirate and biopsy. Additional tests, such as immunophenotyping of the blood and bone marrow, lymph node aspiration "or biopsy, were performed when clinically indicated.

Complete remission was defined as the disappearance of all disease and symptoms related to lymphoma for more than 1 month. Partial remission was defined as more than $50 \%$ reduction in the sum of the products of the two greatest perpendicular diameters of measurable lesions for more than 1 month. All other outcomes were considered treatment failures.

In keeping with published eligibility criteria for autologous BMT, bulky lymphadenopathy was defined as any lymph node mass more than $2 \mathrm{~cm}$ in its greatest diameter. ${ }^{13.24}$ Anemia was defined as a hemoglobin level $\leq 12 \mathrm{~g} / \mathrm{dll} .{ }^{31}$ 


\section{Statistical considerations}

The end points included the following: (1) response, (2) survival (interval from the day of BMT until death or end of follow-up period), and (3) time to treatment failure (interval from the day of BMT until relapse, disease progression, death due to disease or its treatment, or end of follow-up). Survival curves were estimated using the Kaplan-Meier product-limit method. ${ }^{44}$

\section{Results}

\section{Patient characteristics}

The median age at transplant was 36 years (range, 23 to 45 ). There were eight men and two women. Characteristics for each patient are listed in Table 3.1.

All patients had poor prognostic features and had been extensively pretreated. Eight patients had refractory disease, five had primary refractory disease, and three had refractory relapses (one had experienced disease relapse after a previous autologous BMT). Six patients had extensive $(>20 \%)$ bone marrow involvement at the time of transplantation. Eight patients had bulky disease, four had increased lactate dehydrogenase levels, four had constitutional symptoms, and six had anemia.

\section{Early deaths, toxicity, and infections}

Data on early deaths, toxicity and infections are listed in Table 3.2. Two patients died early, one on day 16 of venoocclusive disease after receiving the CVP/TBC regimen, and one on day 26 of multiorgan failure and grade IV acute GVHD.

The second patient, who received the CVP/TBC regimen, had experienced a relapse after a previous autologous BMT with a conditioning regimen of etoposide, cyclophosphamide, and TBI. She received a one-antigenmismatched bone marrow transplant from her son and developed grade III hemorrhagic cystitis, and grade II cardiac, renal, and CNS toxicity, but eventually recovered.

Toxicity was generally mild among patients who received TBI-containing conditioning regimens. There was one case of transient renal failure, and all patients who received methotrexate developed grade 11 mucositis. One patient developed a small subarachnoid hemorrhage, which was successfully managed with platelet transfusions and tranexamic acid.

Viral, fungal, and bacterial infections occurred, but all were successfully treated. No infection-related deaths occurred. 
Allogenero Bnt hor hohomat
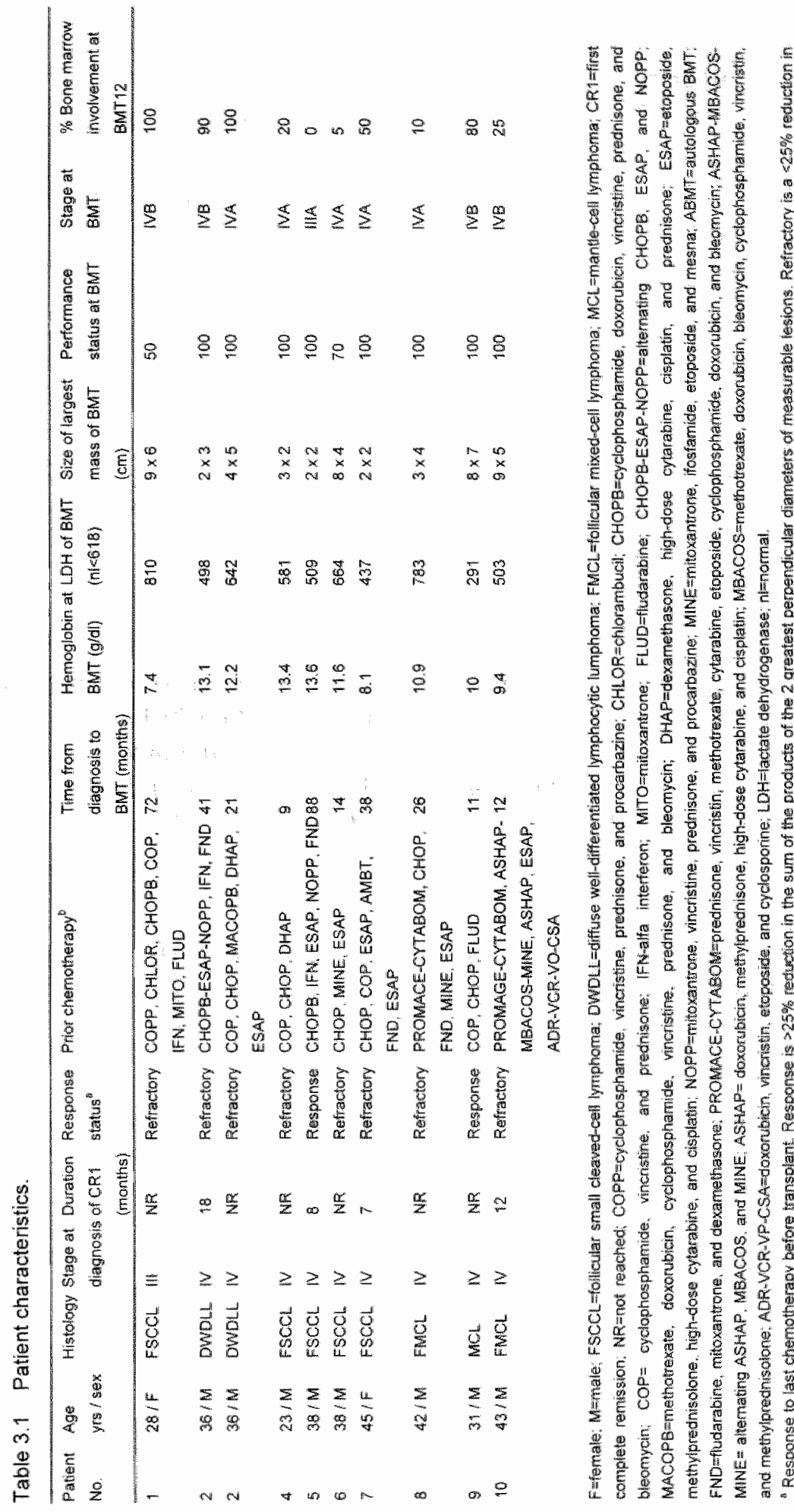

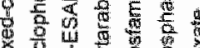

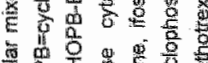

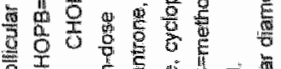

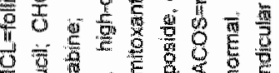

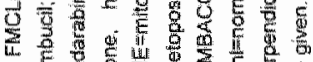

w.

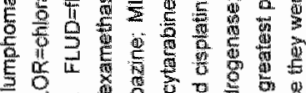

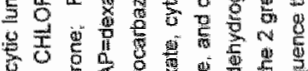

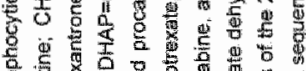

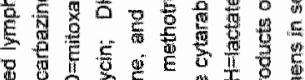

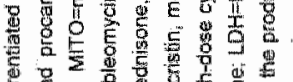

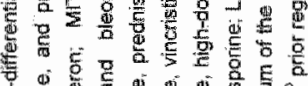

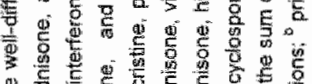

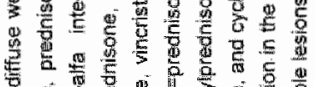

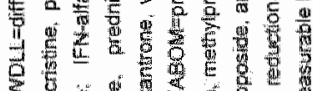

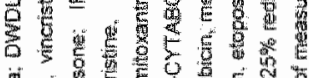

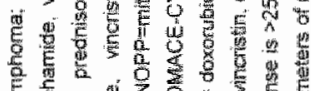

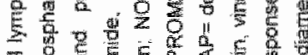

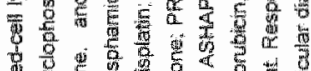

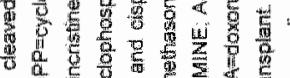

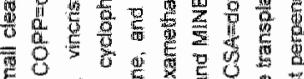

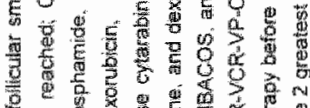

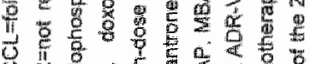

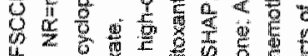

i

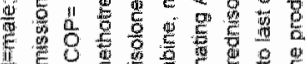

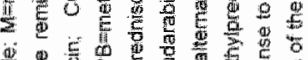
क

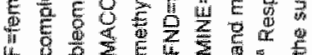


Table 3.2 Clinical toxicity

\begin{tabular}{lc}
\hline Toxicity & No. of patients \\
\hline Treatment-related deaths & 1 \\
Venoocclusive disease & 1 \\
GVHD & \\
Grade II-IV toxicity & 1 \\
Cardiac & 3 \\
Renal & 1 \\
Hepatic & 1 \\
Bladder & 9 \\
Mucositis & \\
Infections & 2 \\
Bacterial sepsis & 2 \\
Fungal sepsis & 1 \\
CMV preumonia & 1 \\
Respiratory syncytial virus infection & 1 \\
Herpes simplex II &
\end{tabular}

\section{Engraftment and GVHD}

Seven of eight assessable patients achieved complete hematopoietic engraftment. One patient continues to require platelet transfusions, 11 months after transplantation. The median time to reach an absolute granulocyte count more than $0.5 \times 10^{\circ} /$ was 16 days (range, 14 to 21 ). The median time to reach a platelet count more than $20 \times 10^{9} /$ was 25 days (range, 15 to $>346$ ). Acute GVHD (grade II to IV) developed in five patients. One patient had fatal grade IV acute GVHD. Four patients developed chronic GVHD. Two of them continue to require treatment for lichenoild skin lesions. Six patients have a Karnofsky performance status of $100 \% .45$ One patient with chronic GVHD of the skin and one patient who underwent BMT recently have a performance status of $90 \%$.

\section{Response}

Antitumor responses after BMT are listed in Table 3.3. Eight patients achieved a complete remission. Maximal cytoreduction may take several months to occur. In one patient, bone marrow biopsy still showed involvement on day 75 . but was persistently negative thereafter. One patient with chronic GVHD had polyclonal lymphoid nodules in the bone marrow up to 820 days after BMT. No rearrangement of the immunoglobulin heavy-chain gene could be demonstrated in bone marrow samples from this patient. One patient has residual splenomegaly. 
Table 3.3 Conditioning outcome.

\begin{tabular}{|c|c|c|c|c|c|c|c|c|c|}
\hline $\begin{array}{l}\text { Patient } \\
\text { no. }\end{array}$ & $\begin{array}{l}\text { DRR } \\
\text { Sex }\end{array}$ & $\begin{array}{l}\text { Donor } \\
\text { type }\end{array}$ & $\begin{array}{r}\text { Condlioning } \\
\end{array}$ & GVHDPRophylaxis & $\begin{array}{l}\text { Acute } \\
\text { SUHD }\end{array}$ & Chronic GWHO & $\begin{array}{r}\text { Responge } \\
\end{array}$ & KPS & $\begin{array}{c}\text { Falure Froe } \\
\text { fas }\end{array}$ \\
\hline 1 & $F / F$ & ID-SIB & CYNPIGTBI & CYCLOSP MTX & No & Sikin \& Wouth & $\mathrm{CR}^{\prime}$ & $\infty 0$ & $1,459+$ \\
\hline 2 & $F / M$ & $\mathrm{D}-\mathrm{SIB}$ & CrTB & GYCLOSP MTX & it & Sikin \&otitt? & $\mathrm{CR}$ & 100 & 6,474 \\
\hline 3 & MIM & D-SIB & CWNPIGITE! & CYCLOSP MTX & \|l! & Skin & $\mathrm{GR}$ & 100 & 1,865 \\
\hline 4 & $F / M$ & ND-SIB: & CYлEI & CYCLOSP NTX & No & No & $\mathrm{CR}^{2}$ & 100 & 1,1804 \\
\hline 5 & FIM & $\mathrm{D}-\mathrm{SIO}$ & CWNP 6 TBU & CYCLOSPMTX & No & Skin & $\mathrm{CR}$ & 100 & 9904 \\
\hline 6 & $F / M$ & $\mathrm{D}-\mathrm{StB}$ & CVPITBC & CYCLOSP MTX & NA & NA & NA & 100 & Diad day 6 VOD \\
\hline 7 & MiF & IAGMM & CVPTTSC & CYCLOSP MTX & 11 & $\mathrm{Ho}$ & $\mathrm{CR}$ & 100 & $585+$ \\
\hline 8 & MIM & D-SIE & critai & CYCLOSP MTX & No & $\mathrm{NA}$ & $\mathrm{CR}$ & 90 & 3464 \\
\hline 9 & MIM & ID-SIB & $\mathrm{CY} / \mathrm{TBI}$ & OYCLOSP PDN & $\|$ & No & $\mathrm{CR}$ & 100 & $502+$ \\
\hline 10 & $M M$ & ID-SUB & CY/TBI & CrCLOSP MTX & $\mathrm{V}$ & NA & NA & & Died daY 26 AGVHD \\
\hline
\end{tabular}

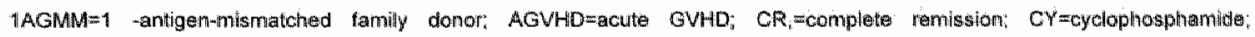

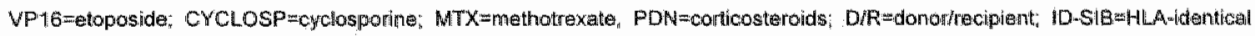
sibling; KPS, Kanofsky performance score: NAwnot assessable; PR=partial remission; VOD=venoocclusive disease.

${ }^{3}$ Lymphoid nodules in bone marrow until day 820 .

${ }^{2}$ Persistent splenomegaly.

\section{Failure-free survival}

Eight patients are alive a median of 816 days (range, 346 to 1,865) after BMT. No patients have had relapses. The actuarial survival and failure-free survival rates are both $80 \% \pm 12.6 \%$ (Figure 3.1 ). For surviving patients, the duration of the current remission exceeds the duration of any prior remission achieved.

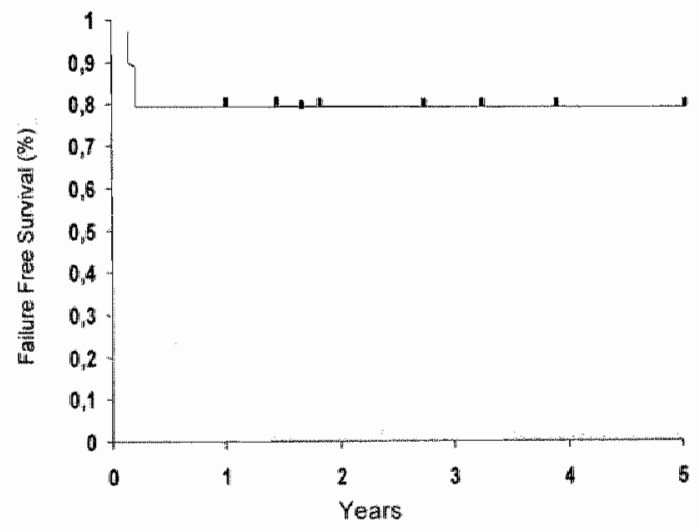

Figure 3.1 Survival and failure-free survival curves. The curves are identical. 


\section{Discussion}

Our results with allogeneic BMT for low-grade lymphoma indicate a high rate of complete responses and a prolonged remission duration in a group of patients with end-stage disease, only one of whom would have qualified for an autologous BMT. With conventional chemotherapy, the median survival duration for a group of patients with similar disease characteristics, treated at the same institution, was only 5 months. ${ }^{31}$ Our data compare favourably with autologous BMT results, despite the inclusion of patients with advanced disease. As in autologous BMT, the high response rate is due to the intensive conditioning, but an immune-mediated graft-versus-lymphoma effect probably contributes as well. The slow regression of residual lymph node and bone marrow involvement is reminiscent of the gradual disappearance of leukemic cells observed after allogeneic BMT for chronic myelogenous leukemia. ${ }^{4647}$

Most studies of allogeneic BMT for lymphoma have included primarily intermediate-grade and high-grade subtypes. Although a graft-versuslymphoma effect has been reported in patients with aggressive disease, ${ }^{26,48,49}$ any benefit of allogeneic BMT has been offset by an increased treatmentrelated death rate. Overall results are similar to those achieved with autologous $\mathrm{BMT}^{20,26,49,50}$ Low-grade lymphoma patients, on the other hand, have more indolent disease. They are usually in better condition and more likely to survive intensive conditioning therapy, thereby allowing the graft-versus-lymphoma effect to have its full impact.

Consistent with our data, favorable outcomes have been reported with allogeneic BMT for refractory chronic lymphocytic leukemia, another indolent Iymphoid malignancy. ${ }^{51-53}$

Our data were obtained in patients who had experienced multiple relapses or who had refractory disease. Performing allogeneic BMT earlier in the course of the disease might improve the results, ${ }^{54,55}$ and this option could be offered to patients with a poor prognosis. Several features, such as refractory disease, male sex, short duration of remission, and extensive tumor burden, allow the identification of such patients. ${ }^{3,11,31,56}$ In our situation, the median survival duration for males with stage IV disease and a high tumor burden is only 43 months. ${ }^{3}$ For patients with recurrent follicular lymphoma, the median survival duration ranges from 20 months $^{311}$ to almost 6 years,56 but patients with unfavorable characteristics have a median survival time of only 5 months. 31 This is substantially worse than for patients with chronic myelogenous leukemia, a disease for which allogeneic BMT is routinely recommended. ${ }^{57}$

Considerable attention has focused on autologous BMT for patients with recurrent low-grade lymphoma and chemotherapy-sensitive disease. The early treatment-related mortality rate of autologous BMT is less than $5 \%$, which indicates that it might be a safer treatment. ${ }^{13,14}$ However, with prolonged follow- 
up time, there has been a continued pattern of relapse after autologous BMT, and it is not entirely certain whether the survival of transplanted patient is better than that of patients with similar characteristics who do not undergo autologous BMT. ${ }^{14.56 .58}$ Another potential problem is the occasional occurrence of posttransplant leukemia or myelodysplastic syndrome following autologous BMT, possibly related to the heavy exposure of the patient and the infused marrow to alkylating agents, epipodophyllotoxins, and other cytotoxic drugs. ${ }^{13.24,59,60}$ Secondary leukemias have been reported only rarely as a complication of allogeneic BMT. ${ }^{61,63}$

The indications for allogeneic BMT in low-grade lymphoma need to be further defined in prospective studies. Given the encouraging results in patients with advanced and refractory disease, we consider it reasonable to offer allogeneic BMT to all patients younger than 55 years with recurrent disease who have an HLA-compatible sibling, regardless of their response to chemotherapy. The median age at diagnosis for low-grade lymphoma is between 50 and 60 years ${ }^{64-66}$; hence, many patients should be eligible for the procedure. Recent studies suggest that the use of allogeneic BMT may be extended to older patients as well, further increasing the number of patients who could benefit. ${ }^{67}$ For patients with particularly poor prognostic features, the procedure could be considered as a component of their initial therapy. For younger patients with a poor prognosis who lack an HLA-identical sibling donor and who do not qualify for autologous BMT, the role of unrelated-donor transplantation should be explored. 


\section{References}

1. Armitage JO: Drug therapy: Treatment off non-Hodgkin's lymphoma. $\mathrm{N}$ Engl J Med. $1993 ; 328: 1023-30$.

2. Portlock CS: Management of the low-grade non-Hodgkin's lymphomas. Semin Oncol. $1990 ; 17: 51-9$

3. Romaguera JE, McLaughin $P$, North $L$, ef al: Multivariate analysis of prognostic factors in itage IV follicular low-grade ilymphoma: A risk model. J Clin Oncoll 1991;9:762-9.

4. Homing SJ: Treatment approaches to the low-grade lymphomas. Blood 1994;83:881-4.

5. Paryani SB, Hoppe RT, Co* RS, et al: The role of radiation therapy in the management of stage Ill follicular lymphomas. J Clin Oncol. 1984;2:841-8.

6. Paryani SB, Hoppe RT, Cox RS et al: Analysis of non-Hodgkin's tymphomas with nodular and favorable histologies, stages I and II. Cancer, 1983;52:2300-7.

7. Cox JD, Komaki R, Kun LE, al: Stage III nodular lymphoreticular tumors (non-Hodgkin"s lymphoma): Results of central lymphatic irradiation. Cancer 1981;47:2247-52.

8. Mclaughtlin P, Fuller LM, Velasquez WS, et al: Stage III follicular lymphoma: Durable remissions with a combined chemotherapy-radiotherapy regimen. J Clin Oncol . $1987 ; 5$ : 867-74.

9. McLaughlin P, Fuller LM, Velasquez WS, et al: Stage 1-ll follicular lymphoma. Treatment results for 76 patients. Cancer. 1986;58:1596-602.

10. Young $\mathrm{RC}$, Longo $\mathrm{DL}$. Glatstein $\mathrm{E}$, et al: The treatment of indolent lymphomas: Watchful waiting versus aggressive combined madality treatment. Semin Hematol. 1988; $25: 11-6$,

11. Gallagher $C J$, Gregory $W M$, Jones $A E_{\text {, }}$ et al: Follicular lymphoma: Prognostic factors for response and survival. $J$ Clin Oncol, 1986;4:1470-80.

12. Ezdinli EZ, Anderson JR, Melvin $F$, al: Moderate versus aggressive chemotherapy of nodular lymphocytic poorly differentiated lymphoma. J Clin Oncol 1985;3:769-75.

13. Freedman $A S$, Ritz $d$ Neuberg $D$, et al: Autologous bone marrow transplantation in 69 patients with a history of low-grade B-cell non-Hodgkin's lymphioma. Blood. 1991;77:2524-9.

14. Rohatiner AZS, Johnsom PWM, Price CGA et al: Myeloablative therapy with autologous bone marrow transplantation as consolidation therapy for recurrent follicular lymphoma. $\rfloor C l i n$ Oncol. 1994;12:1177-84.

15. Schouten HC, Bierman PJ, Vaughan WP, et al: Autologous bone marrow transplantation in follicular non-Hodgkin's lymphoma before and after histologic transformation. Blood $.71989: 4: 2579-84$

16. Colombat $\mathrm{P}$, Binet $\mathrm{C}$, Linassier $\mathrm{C}$, et al: High dose chemotherapy with autologous marrow transpllantation in follicular lymphomas. Leuk Lymphoma. 1992;57:3-6.

17. Appelbaum FR, Thomas ED, Buckner CD, et al: Treatment of non-Hodgkin's lymphoma with chemoradiotherapy and allogeneic marrow transplantation. Hematol Oncol. 1983;1:149-57.

18. Lundberg $J H$, Hansen RM, Chitambar $C R$, et al: Allogeneic bone marrow tramsplantation for relapsed and refractory lymphoma using genotypically HLA-identical and alternative donors. J Clin Oncol. 1991:9:1848-59.

19. Copelan EA, Kapoor N, Gibbins B, et al: Allogeneic marrow transplantation in non-Hodgkin's Iymphoma. Bone Marrow Transplant. 1990;5:47-50

20. Chopra R, Goldstone AH, Pearce R, et al: Autologous versus allogeneic bone marrow transplantation for non-Hodgkin's lymphoma: A case-controlled analysis of the European Bone Marrow Transplant Group registry data. J Clin Oncol. 1992;10:1690-5.

21. Sullivan KM, Kapecky KJ, Jocom J, al: Immunomodulatory and antimicrobial efficacy of intravenous immunoglobulin in bone marrow transplantation. N Engl J Med. 1990;323:705-12.

22. Ferrara JLM, Deeg HJ: Mechanisms of disease: Graft-versushost disease. N Engl $J$ Med 1991:324:667-74.

23. Goodrich JM, Bowden RA, Fisher $L_{\text {, }}$ et al: Ganciclovir prophylaxis to prevent cytomegalovirus disease after allogeneic marrow transplant. Ann Intern Med. 1993;1:8:173-8. 
24. Johnson PWM, Price CGA, Smith $T$, of al Detection of cells bearing the $t(14 ; 18)$ translocation following myeloablative treatment and aútologeus bone marrow transplantation for follicullar lymphoma. J Clin Oncol. 1994:12:798-805.

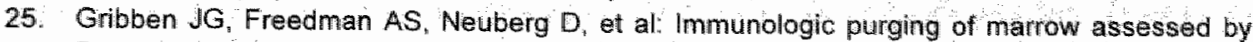
PCR before autologous bone marrow transplantation for $\mathrm{B}$-cell lymphoma. $\mathbb{N}$ Engl $\mathrm{J}$ Med. 1991;325:1525-33.

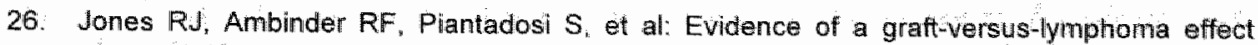
associated with allogeneic bone marrow transplantation. Blood. 1991;77:649-53.

27. Krikorian JG, Portlock CS, Cooney $P_{\text {v }}$ et al: Spontaneous regression of non-Hodgkin Hymphoma: A report of nine cases. Cancer. 1980;46:2093-6.

28. McLaughlin $P$. Cabanillas. F. Hagemeister FB, at: CHOP Bleo plus interferon for stege $\mathrm{V}$ law-grade lymphoma. Ann Oncol. 1993;4:205-11.

29. Smalley RV: Aindersen JW, Hawkins MJ, et al: Interferon alfa combined with cytotoxic chemotherapy for patients with non-Hodgkin's lymphoma. N Engl J Med. 1992;327:1336-41.

30. Kwak LW, Campbell MJ, Czerwinski DK, et al: Induction of immune responses in patients with B-cell lymphoma against the surface-immunoglabulin idiotype expressed by their tumors. $\mathrm{N}$ Engl a Med. 1992;327:1209-15.

31. Spinolo JA, Cabanillas F, Dixon DO, et al: Therapy of relapsed or refractory low-grade follicular lymphomas: Factors assaciated with complete remission, survival and time to treatment failure. Ann Oncol. 1992;3:227-32.

32. Shivdasani RA, Hess $J$. Skarin AT, el al: Intermediate lymphocytic lymphoma: Clinical and pathologic features of a recently characterized subtype of non-Hodgkin's lymphoma. J Clin Oncol. 1993;11:802-11.

33. Giralt SA, Vriesendorp HM, Andersson BS, et al: Etoposide, cyclophosphamide, totall body irradiation and allogeneic bone marrow transplantation: An effective treatment for hematologic malignancies. J Clin Oncol. 1994;12:1923-30.

34. Van Besien KW, Mehra R, Khouri I, et al: Double intensification and allogeneic or autologous bone marrow transplantation for poor prognosis lymphoma. Blood. 1993;82 S1:146a.

35. Forman $S J$, Blume KG, Krance RA, et al: A prospective randomized studly of acute graftversus-host disease in 107 patients with leukemia: Methotrexate/prednisone versus cyclosporine/prednisone. Transplant Proc. 1987,21:2605-7.

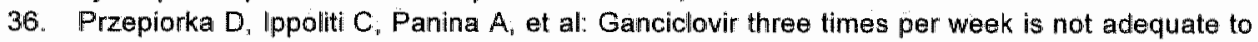
prevent cytomegalovirus reactivation after T-cell depleted marrow transplantation. Bone Marrow Transplant. 1994:13:461-4.

37. Winston DJ, Ho WG, Bartoni K, et al: Ganciclovir prophylaxis of cytomegalovirus infection and disease in allogeneic bone marrow transplant recipients: Results of a placebo-controlled, double-blind trial. Ann Intern Med. 1993:118:179-84.

38. Masur H: Drug therapy: Prevention and treatiment of pneumocystis pneumonia. $N$ Engl $J$ Med. 1992;327:1853-60.

39. Przepiorka D, Selwaggi $K$, Rosenzweig $P Q$, et al: Aerosolized pentamidine for prevention of Pneumocystis pneumonia after allogeneic marrow transplantation. Bone Marrow Transplant. 1991;7:324-5.

40. Bearman SI, Appelbaum FR, Buckner $C D$, et al: Regimenrelated toxicity in patients undergoing bone marrow transplantation. J Clin Oncol. 1988;6:1562-8.

41. Yam PY, Petz LD, Knowiton RG, et al: Use of DNA restriction fragment length polymorphisms to document marrow engraftment and mixed hematopoietic chimerism following bone marrow transplantation. Transplantation. 1987:43:399-407.

42. Glucksberg $H_{n}$, Storb $R_{r}$ Fefer $A$ : Clinical manifestations of graft-versus-host disease in human recipients of marrow from HLAidentical sibling donors. Transplantation. 1974;18:295-304.

43. Atkinson $K_{v}$ Horowitz MM, Gale RP, et al: Risk factors for chronic graft-versus-host disease after HLA-identical sibling bone marrow transplantation. Blood. 1990,75:2459-64.

44. Kaplan EL, Meier P: Nonparametric estimation from incomplete observations. J Am Stat Assoc. 1958;53:457-81.

45. Mor V. Laliberte $L$, Morris $J \mathbb{N}$, et al: The Karnofsky performance status scale. Cancer. 1984:53:2002-7. 
46. Weiden PL, Sullivan KM. Flournoy N, et al: Antileukemic effect of chronic graft-versus-host disease: Contribution to improved survival after allogeneic marrow transplantation. $N$ Engl J Med. 1981:304:1529-32.

47. Lee $M$, Khouri I, Champlin $R_{n}$ et al: Detection of minimal residual disease by polymerase chain reaction of bcrab/transcripts in chronic myelogenous leukaemia following allogeneic bone marrow transplantation. Br J Haematol. 1992;82:708-14.

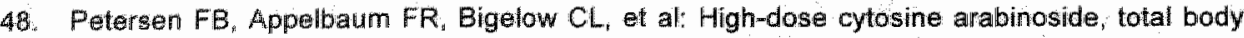
irradiation and marrow transplantation for advanced malignant lymphoma. Bone Marrow Transplant. 1989:4:483-8.

49. Ratanatharathom $\mathrm{V}$, Uberti $\mathrm{J}$, Karanes $\mathrm{C}$, et al: Prospective comparative trial of autologous versus allogeneic bone marrow transplantation in patients with non-Hodgkin's lymphoma. Bloodi. 1994;84:1050-5

50. Appelbaum FR, Sullivan $\mathrm{KM}$, Buckner $\mathrm{CD}$, et al: Treatment of malignant lymphoma in 100 patients with chemotherapy, total body irradiation and marrow transplantation. $J$ Clin Oncol. $1987 ; 5 ; 1340-7$.

51. Michallet $M_{4}$ Corront $B$, Hollard $D$, et al: Allogeneic bone marrow transplantation in chronic lymphocytic leukemia: 17 cases. Report from the EBMTG. Bone Marrow Transplant. 1991;7:275-9.

52. Rabinowe $S N$, Soiffer RJ, Gribben $J G$, et al: Autologous and allogeneic bone marrow transplantation for poor prognosis patients with B-cell chronic lymphocytic leukemia. Blood. 1993;82:1366-76.

53. Khouri IF, Keating M/J, Vriesendorp HM, et al: Autologous and allogeneic bone marrow transplantation for chronic lymphocytic leukemia. J Clin Oncol. 1994;12:748-58.

54. Thomas ED, Clift RA: Indications for marrow transplantation in chronic myelogenous leukemia. Blood. 1989;73;861-4.

55. Goldman $J M_{x}$ Szydio $R$, Horowitz $M M_{1}$ et al: Choice of pretransplant treatment and timing of transplants for chronic myelogenous leukemia in chronic phase. Blood. 1993;82:2235-8.

56. Weisdorf DJ, Andersen JW, Glick JH, et al: Survival after relapse of low-grade non-Hodgkin's Iymphoma: Implications for marrow transplantation. J Clin Oncol. 1992;10:942-7.

57. Kantarian $H M$, Deisseroth $A$, Kurzrock $R$, at al: Chronic myelogenous leukemia: $A$ concise update. Blocd. 1993;82:691-703.

58. Freedman AS, Nadler LM: Which patients with relapsed non-Hodgkin's lymphoma benefit from high-dose therapy and hematopoietic stem-cell transplantation. $J$ Clin Oncol. 1993;11:1841-3.

59. Stone RM: Myelodysplastic syndrome after autologous bone marrow transplantation for Iymphoma: The price of progress? Blood. 1994;83:3437-40.

60. Miller JS, Arthur DC, Litz CE, et al: Myalodysplastic syndrome after autologous bone marrow transplantation: An additional late complication of curative cancer therapy. Blood. $1994 ; 83: 3780-6$

61. McCann SR, Lawler $M_{*}$ Bacigalupo A: Recurrence of Philadelphia chromosome-positive leukemia in donor cells after bone marrow transplantation for chronic granulocytic leukemia. Leuk Lymphoma. 1993:10:419-25.

62. Stein J. Zimmerman PA, Kochera $M_{0}$ et al: Origin of leukemic rellapse after bone marrow transplantation: Comparison of cytogenetic and molecular analyses. Bload. 1989;73:2033-40.

63. Witherspoon RP, Fisher LD, Schoch G, et al: Secondary cancers after bome marrow transplantation for leukemia or aplastic anemia. N Engl J Med. 1989:321:784-9.

64. Harrington DS, Yuling $Y E_{*}$ Weisenburge $D D$, et al: Malignant lymphoma in Nebraska and Guangzhou, China: A comparative study. Hum Pathol. 1987;18:924-8.

65. Cutler SJ, Young JL: Third National Cancer Survey: Incidence data, NCI Monogr. 1975:41:102.

66. The Non-Hodgkin's Lymphoma Pathologic Classification Project: National Cancer Institute sponsored study of classifications of non-Hodgkin's lymphomas: Summary and description of a working formulation for clinical usage. Cancer. 1982;49:2112-35.

67. Clift RA, Appelbaum FR, Thomas ED: Treatment of chronic myeloid leukemia by marrow transplantation. Blood. 1993;82:1954-6. 


\section{Chapter 4}

Allogeneic transplantation for low-grade lymphoma: long-term follow-up 
56 Chapter

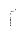


In 1995 we reported on 10 patients with a history of advanced, refractory lowgrade lymphoma who had undergone allogeneic transplantation. Seven patients had follicle-center lymphomas, two had small lymphocytic lymphomas; and one had a mantle cell lymphoma. Two patients had died from transplantrelated toxicity and eight had obtained remissions. With a median follow-up of 27 months (range, 11 to 62 months), no recurrences had occurred. Figure 4.1 shows the survival and disease-free survival of this patient cohort as of October 1999. Currently, the median follow-up is 6 years after transplantation (range, 5 to 9 years), and only one patient has developed disease progression. That patient is currently in remission 8 years after the initial transplant and 4 years after a second allogeneic transplantation. That same patient developed extensive chronic graft-versus-host disease after transplantation and developed disease recurrence while receiving chronic immunosuppression. Two additional patients have developed limited chronic graft-versus-host disease, and one patient has developed aseptic hip necrosis. No other posttransplant complications have occurred.

Since our initial publication, several groups have confirmed the ability to induce remissions of low-grade lymphoma with allogeneic transplantation, but the median follow-up in these studies was, at best, 3 years. ${ }^{2-5}$ Hence, the possibility remained that , as with autologous transplantation, late recurrences and complications such as secondary MDS would affect long-term outcome. ${ }^{6}$ However, our data, admittedly obtained on a small patient sample, indicate the possibility of durable remissions in the majority of survivors of allogeneic transplantation. Confirmation of these data in larger studies with long follow-up is necessary.

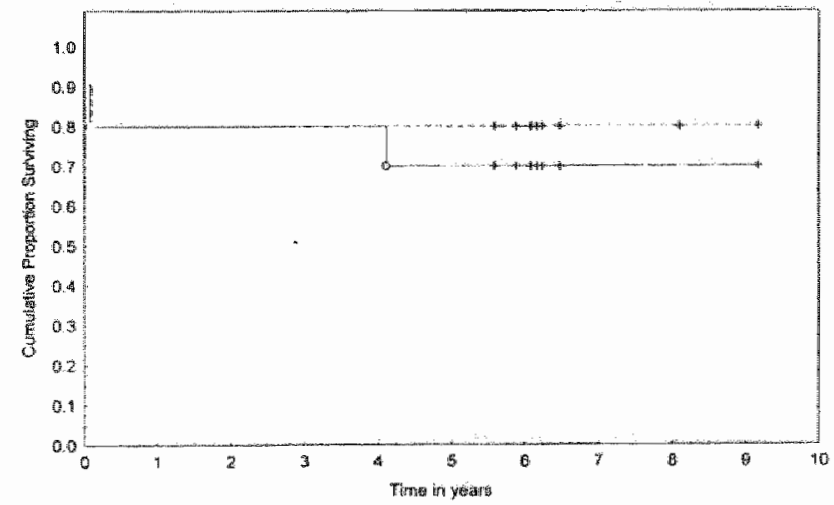

Figure 4.1 Survival and disease-free survival. 


\section{References}

1. wan Besien KW, Khouri IF, Giratt $S A$, et al: Allogeneic bone marrow transplantation for refractory and recurrent low grade lymphoma: The case for aggressive management. J Clin Oncoll. 1995:131096-102.

2. Verdonck LF. Allogeneic versus autologous bone marrow transplantation for refractory and recurrent low-grade non-Hodgkin's Iymphoma. Updated results of the Utrecht experience. Leuk Lymphoma, 1999;34:129-36.

3. van Besien $K$, Sobocinski $K$, Rowlings $P$, al: Allogeneic bone marrow transplantation for low grade lymphoma, Blood. 1998;92:1832-6.

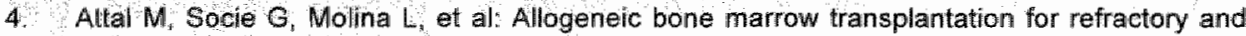
recurrent follicular lymphoma: Acase-matched analysis with autologous transplantation from the French bone marrow transplant group registry data. Blood. 1997:90 S1:1120A.

5. Peniket AJ, Ruiz de Elvira MC. Taghipour $G$, et al: Allogeneic transplantation for lymphoma produces a lower relapse rate than autologous transplantation but survival has not risen because of higher treatment-related mortality: A report of 764 cases from the EBMT Iymphoma registry. Blood. 1997;90 S1:1121A.

6. Freedman AS, Neuberg D, Mauch P, et al: Long-term follow-up of autologous bone marrow transplantation in patients with relapsed follicular lymphoma. Blood. 1999;94:3325-33. 


\section{Chapter 5}

Allogeneic bone marrow transplantation for lowgrade lymphoma

KW van Besien, KA Sobocinski, PA Rowlings, SC Murphy, JO Armitage, MR Bishop, O Chaekal, RP Gale, JP Klein, HM Lazarus, PL McCarthy Jr, JMM Raemaekers, J Reiffers, GL Phillips, AVMB Schattenberg, LF Verdonck, JM Vose, MM Horowitz 


\section{Abstract}

Advanced low-grade lymphomas are usually incurable with conventional-dose chemotherapy. It is uncertain whether cures are possible with high-dose therapy and bone marrow transplant from a human leukocyte antigen (HLA)-identical sibling. We sought to determine the outcome of HLAidentical sibling bone marrow transpiants in advanced low-grade lyniphoma in an obsenvational study of 113 patients conducted at 50 centers participating in the International Bone Marrow Transplant Registry (IBMTR). The median patient age was 38 years (range, 15 to 61). Eighty percent had stage IV disease at the time of transplantation. The median number of prior chemotherapy regimens was two (range, 0 to 5). Thirty-eight percent had refractory disease and $29 \%$ a Karnofsky performance score (KPS) less than $80 \%$. All patients underwent allogeneic bone marrow transplantation firom a HLA-identical sibling donor. The conditioning regimen included totalbody irradiation (TB1) in $82 \%$ of patients; cyclosporine was used for graft-versus-host disease prophylaxis in $74 \%$. Survival, disease-free survival, recurrence rate, treatment-related mortality, and causes of death were deternined. Three-year probabilities of recurrence, survival, and disease-free survival were $16 \%$ (95\% confidence interval [Cl], $9 \%$ to $27 \%$ ), $49 \%(95 \% \mathrm{Cl}, 39 \%$ to $60 \%)$, and $49 \%(95 \% \mathrm{Cl}, 39 \%$ to $59 \%)$, respectively. Higher survival was associated with pretransplant KPS $\geq 90 \%$, chemotherapy-sensitive disease, use of a TBI-containing conditioning regimen, and age less than 40 years. We conclude that high-dose therapy followed by transplantation from a HLA-identical sibling leads to prolonged survival in some patients with advanced low-grade lymphoma. Most mortality is treatment-related, and recurrences are rare 


\section{Introduction}

Advanced-grade lymphomas are relatively indolent, but are incurable with conventional treatments. ${ }^{t-4}$ The median survival duration from diagnosis is 7 to 9 years. High-dose therapy and a blood cell or bone marrow autotransplant reportedly results in sustained remission in some patients. ${ }^{5-9}$ Recurrences are common and there is concern about posttransplant myelodysplastic syndromes. ${ }^{5,10-12}$ Prolonged remissions have been reported in small numbers of patients treated with allogeneic bone marrow transplantation. ${ }^{13-19}$ We studied 113 patients with advanced low-grade lymphoma who received a bone marrow transplant from a human leukocyte antigen (HLA)-identical sibling.

\section{Patients and methods}

\section{Patients}

We reviewed all HLA-identical sibling transplants for low-grade lymphoma performed between 1984 and 1995 and reported to the International Bone Marrow Transplant Registry (IBMTR) by 50 centers worldwide. The study included 113 patients with a diagnosis of low-grade lymphoma at diagnosis and at the time of transplant. This included patients with diffuse well-differentiated lymphocytic lymphoma (Working Formulation group A), follicular small cleavedcell lymphoma (Working Formulation group B), and follicular mixed-cell lymphoma (Working Formulation group $\mathrm{C}$ ). ${ }^{20}$ Patients initially diagnosed with low-grade lymphoma, but whose disease transformed to intermediate-grade or high-grade lymphoma before transplantation, were excluded.

Pathology reports confirming the diagnosis of low-grade lymphoma were reviewed by Koen van Besien. Discrepancies in nomenclature among centers were resolved using the recent publication on the Revised European-American Lymphoma (REAL) classification. ${ }^{21}$

\section{IBMTR}

The IBMTR is a voluntary working group of more than 300 transplant teams worldwide that contribute detailed data on their allogeneic bone marrow transplants to the Statistical Center at the Medical College of Wisconsin. Participants are required to report all consecutive transplants; compliance is monitored by on-site audits. Approximately two thirds of all active transplant centers report their data to the IBMTR. The IBMTR database includes $40 \%$ to $45 \%$ of all allogeneic transplant recipients since 1970. Patients are monitored 
longitudinally. Computerized error checks, physician review of submitted data, and on-site audits of participating centers ensure data quality.

\section{Statistical methods}

Primary outcomes were survival, disease-free survival (survival without lymphoma posttransplant), recurrence, and treatment-related mortality (nonrelapse death). For treatment-related mortality, patients were considered treatment failures at the time of death from any cause in the first 28 days posttransplant or at time of death in continuous remission for those surviving more than 28 days posttransplant; patients with recurrent lymphoma were censored at the time of relapse and those alive in remission were censored at the last follow-up evaluation. For disease-free survival, patients were considered treatment failures at the time of relapse or death from any cause; patients alive in continuous remission were censored at the last follow-up evaluation. Patients who never achieved remission were analyzed as having recurrent lymphoma on day 28.

Other outcomes examined were acute graft-versus-host disease (GVHD), chronic GVHD, and survival. Acute GVHD was defined as moderate to severe (grade II to IV) disease using established criteria; patients surviving more than 21 days with evidence of engraftment were considered at risk. ${ }^{22}$ Chronic GVHD was determined by clinical criteria in patients surviving more than 90 days with evidence of engraftment. ${ }^{23}$

Probabilities of outcomes were calculated using the Kaplan-Meier product-limit estimate and expressed as probabilities with a 95\% confidence interval (Cl) computed using the arcsine-square root transformation. Patient-, disease-, and transplant-related variables were studied for associations with survival. Univariate comparisons used the log-rank test. Multivariate analyses used Cox proportional hazards regression with stepwise forward variable selection. As disease-free survival was nearly identical to survival, multivariate analyses were performed only for survival. The incidence of lymphoma relapse was too low to allow a multivariate analysis of this parameter.

\section{Results}

\section{Patient characteristics}

Patient-, disease-, and transplant-related characteristics are listed in Table 5.1. Fifty-eight percent of patients were male. The median age was 38 years (range, 15 to 61). Twenty-nine percent had a Karnofsky performance score (KPS) less than $90 \%$. 
Table 5.1 Patient-, disease-, and transplant-related characteristics of 113 recipients of HLAidentical sibling bone marrow transplants for low-grade non-Hodgkin"s lymphonia reported to the IBMTR by 50 centers worldwide:

\begin{tabular}{|c|c|c|c|}
\hline \multirow{2}{*}{$\begin{array}{l}\text { Variable } \\
\text { Patient characteristics }\end{array}$} & \multirow[t]{2}{*}{ No. assessable } & \multicolumn{2}{|c|}{ Patients No. $\%$} \\
\hline & & \multirow{3}{*}{66} & \multirow{3}{*}{58} \\
\hline Male gender & 113 & & \\
\hline Age at transplant (yr) & 113 & & \\
\hline Median & & 38 & \\
\hline Range & & $15-61$ & \\
\hline$<40$ & & 63 & 56 \\
\hline 240 & & 50 & 44 \\
\hline KPS $\leq 80 \%$ & 143 & 33 & 29 \\
\hline \multicolumn{4}{|l|}{ Disease characteristics at diagnosis } \\
\hline Histology & 113 & & \\
\hline Small lymphocytic & & 20 & 18 \\
\hline Follicular small cleaved & & 52 & 46 \\
\hline Follicular mixed & & 41 & 36 \\
\hline Disease stage & $\$ 13$ & & \\
\hline 1 & & 2 & 2 \\
\hline II & & 9 & 8 \\
\hline 眦 & & 10 & $\dot{9}$ \\
\hline IV & & 92 & 81 \\
\hline Extranodal involvement & 110 & & \\
\hline None & & 19 & 17 \\
\hline Bone marrow & & 6.6 & 60 \\
\hline Bone marnow + other ${ }^{\text {n }}$ & & 13 & 12 \\
\hline Othera & & 12 & 11 \\
\hline \multicolumn{4}{|l|}{ Disease characteristics at transplant } \\
\hline Disease stage & 113 & & \\
\hline Complete remission & & 16 & 14 \\
\hline 1 & & 2 & 2 \\
\hline II & & 7 & 6 \\
\hline III & & 7 & 6 \\
\hline $1 \mathrm{~V}$ & & 80 & 71 \\
\hline Unknown & & 1 & 1 \\
\hline Extranodal involvement & 110 & & \\
\hline None & & 30 & 27 \\
\hline Bone marrow & & 64 & 58 \\
\hline Bone marrow + other & & 11 & 10 \\
\hline Other ${ }^{6}$ & & 5 & 5 \\
\hline Response to chemotherapy & 105 & & \\
\hline Sensitive & & 66 & 63 \\
\hline Resistant & & 39 & 37 \\
\hline No. of prior chemotherapy regimens & 110 & & \\
\hline Median & & 2 & \\
\hline Range & & $1-5$ & \\
\hline Prior complete remission & 112 & 46 & 41 \\
\hline
\end{tabular}




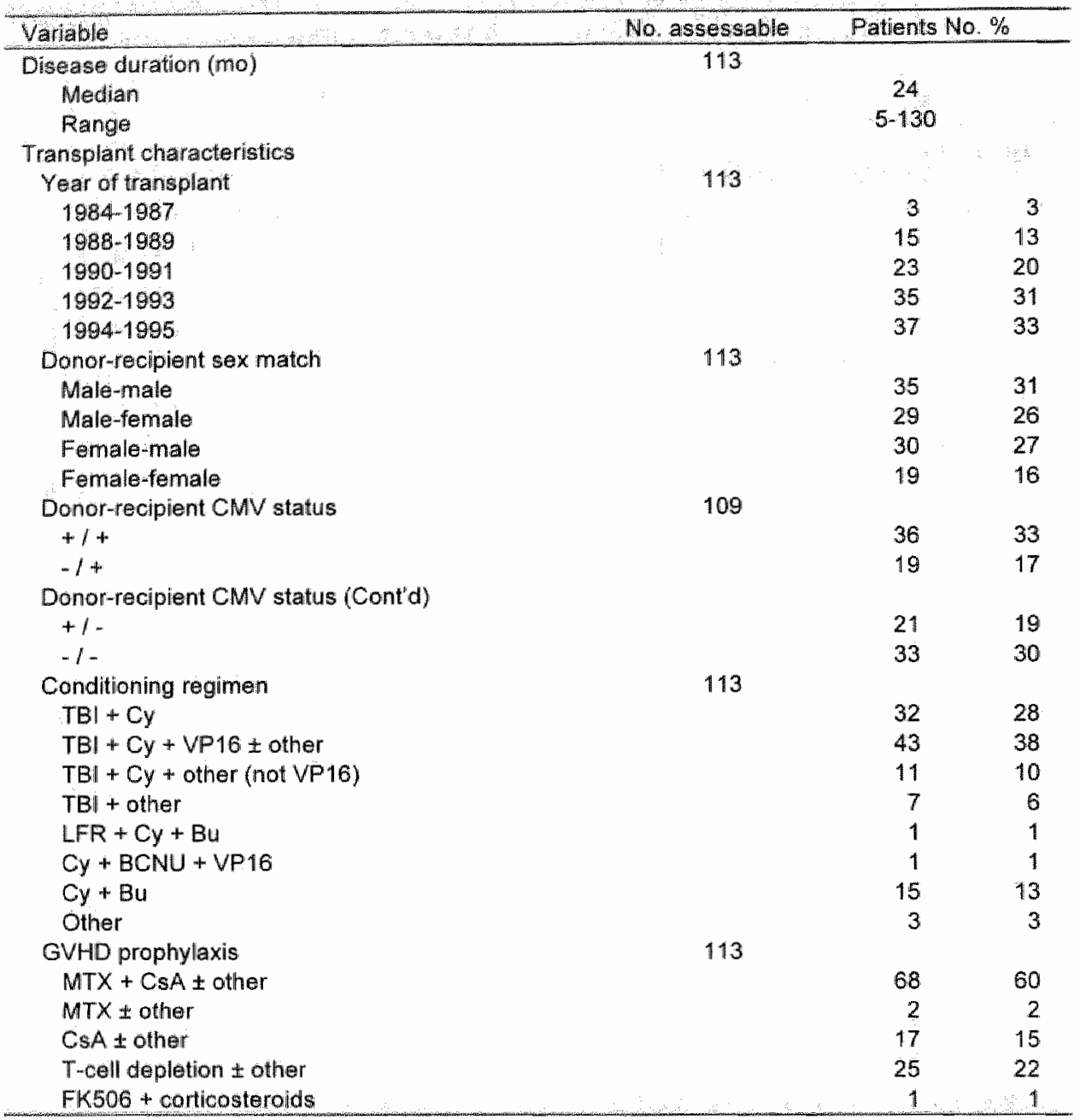

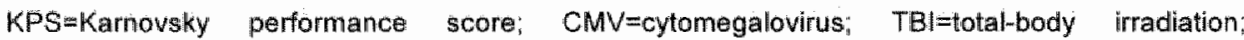
$C y=c y c l o p h o s p h a m i d e ; \quad V P 16=$ etoposide: $L F R=$ limited-field radiation; $B u=b u s u l f a n ; \quad B C N U=$ nitrosurea; $M T X=$ methotrexate; $C s A=$ cyclosporine.

"Other 5 pleura, liver, bone, skin, lung, kidney, epidural space: ${ }^{\text {b }}$ Other 5 pleura, liver, kidney, bone, lung, brain.

Eighteen percent of patients had small lymphocytic lymphoma, $46 \%$ had follicular small cleaved-cell lymphoma, and $36 \%$ had follicular mixed-cell lymphoma. Eighty-one percent were diagnosed with stage IV disease, most commonly due to bone marrow involvement. Only $14 \%$ were in complete remission at transplant. Seventy-one percent had stage IV disease at transplant, despite a median of two prior chemotherapy regimens. Diverse 
chemotherapy regimens were used pretransplant; $37 \%$ of patients were felt to have chemotherapy-resistant lymphoma (i.e.. they had achieved less than a partial remission to the last chemotherapy regimen administered before transplant).

Eighty-four percent of the transplants were performed after 1990. The median interval from diagnosis to transplant was 24 months (range, 5 to 130). The pretransplant conditioning regimen included total-body irradiation (TBI) in $82 \%$ of cases. Among the 20 patients $(18 \%)$ not receiving TBI for conditioning regimens, only three had received prior radiation. Twenty-two percent of patients received T-cell-depleted transplants.

\section{Outcomes}

Outcomes are summarized in Table 5.2. The median follow-up duration of surviving patients was 25 months (range, 4 to 95 ). Three-year probabilities of recurrence and treatment-related mortality were $16 \%(95 \% \mathrm{Cl}, 9 \%$ to $27 \%)$ and $40 \%\left(95 \% \mathrm{Cl}_{1} 30 \%\right.$ to $\left.50 \%\right)$, respectively (Figure 5.1$)$. Three-year probabilities of survival and disease-free survival were both $49 \%(95 \% \mathrm{Cl}, 39 \%$ to $59 \%$ ) (Figure 5.2). Among 33 patients monitored for more than 2 years after transplantation, only one relapse was documented.

Table 5.2 Probabilities $( \pm 95 \% \mathrm{Cl}$ ) of transplant outcomes (at 3 years unmess otherwise stated).

\begin{tabular}{lcr}
\hline & $3-$ Yeair probability (\%) & No. assessable \\
\hline Graft failure $^{a}$ & $1(0-5)$ & 104 \\
Relapse $^{a}$ & $16(9-27)$ & 93 \\
Treatment-related mortality $^{b}$ & $40(30-50)$ & 413 \\
Acute GVHD (at 100 days) & $27(19-37)$ & 99 \\
Chronic GVHD $^{C}$ & $66(53-77)$ & 67 \\
Survivall & $49(39-60)$ & 113 \\
Disease-free survival & $49(39-59)$ & 113 \\
\hline
\end{tabular}

Among patients surviving $\geq 28$ days posttransplant" Among patients surviving $\geq 21$ days with evidence of engraftment; ${ }^{\circ}$ Among patients surviving $\geq 90$ days with evidence of engraftment.

In multivariate analysis, KPS, chemotherapy-resistance, conditioning regimen " and age significantly predicted survival (Table 5.3).

Fifty-one patients died; causes of death are summarized in Table 5.4. Pulmonary complications were most common, including interstitial pneumonitis $(n=7)$, acute respiratory distress syndrome $(n=5)$, and pulmonary hemorrhage $(n=1)$. Two patients died of acute GVHD and three of chronic GVHD. 


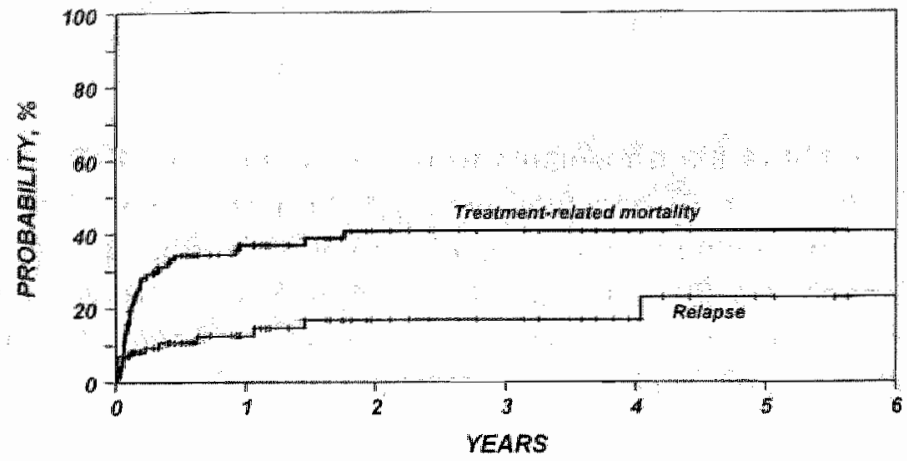

Figure 5.1 Probability of relapse and treatment-related mortality after HLA-identical sibling bone marrow transplant for low-grade non-Hodgkin's lymphoma.

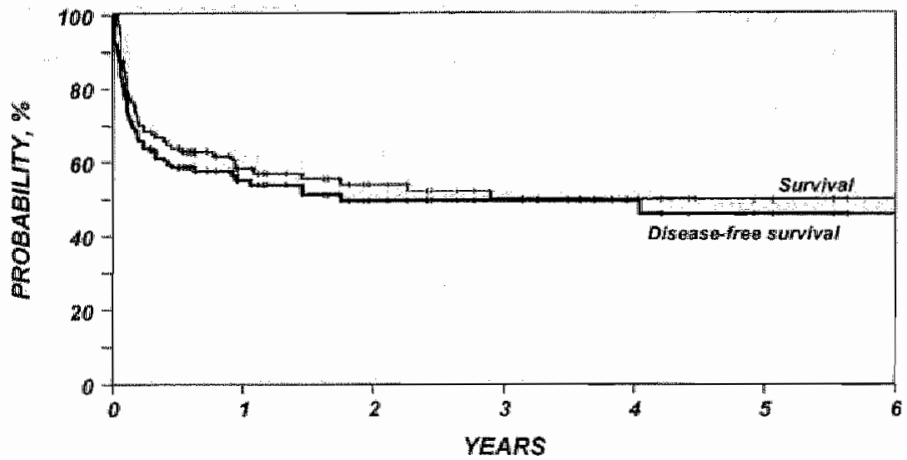

Figure 5.2 Probability of survival and disease-free survival after HLA-identical sibling bone marrow transplant for low-grade non-Hodgkin's lymphoma.

Table 5.3 Factors significantly associated with survival in multivariate analysis of 1113 recipients of HLA-identical sibling bone marrow transplants for low-grade non-Hodgkin's lymphoma reported to the IBMTR by 50 centers worldwide.

\begin{tabular}{llllll}
\hline Covariate & & No. & RR of death & $95 \% \mathrm{Cl}$ & Pvalue \\
\hline KPS pretransplant & $490 \%$ & 33 & 1.00 & & - \\
& $290 \%$ & 80 & 0.42 & $(0.23-0.77)$ & 0.005 \\
Conditioning regimen & Chemotherapy alone & 20 & 1.00 & & - \\
TBI 1 chemotherapy & & 93 & 0.47 & $(0.24-0.93)$ & 0.03 \\
Sensitivity to chemotherapy & Resistant & 66 & 1.00 & & - \\
Sensitive & & 39 & 0.50 & $(0.27-0.91)$ & $0.02^{*}$ \\
Unknown & & 8 & 1.02 & $(0.35-2.99)$ & $0.97^{*}$ \\
Age at transplant (yr) & $<40$ & 63 & 1.00 & & - \\
& 240 & 50 & 1.85 & $(1.05-3.24)$ & $0.03^{*}$ \\
\hline
\end{tabular}

$\mathrm{RR}=$ relative risk.

avalue for pairwise comparison of specific category with the reference (baseline) group. 
Table 5.4 Causes of death of 5 il recipients of HLA-identical sibling bone marrow transplants for low-grade non-Hodgkin's lymphoma.

\begin{tabular}{lcc}
\hline Cause of Death & Patients & \\
\hline Persistant or recurrent iymphoma & No & 22 \\
Interstitial pneumonia & 11 & 20 \\
VOD & 10 & 14 \\
GVHD (chronic or acute) & 7 & 12 \\
Aduit respiratory distress syndrome & 6 & 10 \\
Sepsis & 5 & 8 \\
Organ failure & 4 & 4 \\
Hemornage & 2 & 4 \\
Unknown & 2 & 4 \\
Pulmonary embolism & 2 & 2 \\
Stroke & 1 & 2 \\
\hline
\end{tabular}

VOD=veno-occlusive disease.

\section{Discussion}

This report evaluates the outcome of HLA-identical sibling bone marrow transplants for advanced low-grade lymphomas among centers reporting consecutive patients to the IBMTR. Not surprisingly, the data indicate that transplants are mainly offered to younger patients with advanced disease. Most patients in this study received extensive prior therapy. Many had chemotherapy-resistant disease and low performance scores. Most were not candidates for autotransplants because of extensive bone marrow involvement. Characteristics of these patients and their outcomes are consistent with those reported in three smaller single-institution series. ${ }^{13,18,19}$ Only 22 of the patients in this study were included in those series. Given the unfavorable characteristics of this population, the observed lymphoma-free and overall survival rates of $49 \%$ and the recurrence rate of only $16 \%$ are encouraging. Interestingly, there was only one recurrence among 33 patients monitored for more than 2 years. This seems lower than has been reported for autotransplants and is consistent with other recent reports.24.25 The low recurrence rate, if true, may be due to graft-versus-lymphoma effects as suggested by some,26-28 or, alternatively, to lack of tumor contamination of the allogeneic graft. ${ }^{29,30}$ Our results should be interpreted cautiously. Although we tried to obtain current information on all patients, follow-up methods and accuracy of restaging varies considerably among reporting centers; failure to detect early recurrences may at least partially explain the results.

Multivariate analyses identified poor KPS and chemotherapy-resistance as adverse prognostic factors. Better patient selection and earlier transplants 
could improve outcome. Use of TBI for pretransplant conditioning was also associated with better survival. Radiation is effective in low-grade lymphoma and is frequently used in autotransplant conditioning regimens. However, in a recent analysis of autotransplants for low-grade lymphoma, there was a trend ( $P=0.09$ in multivariate analysis) for poorer survival among patients receiving TBI ${ }^{31}$ Only $18 \%$ of the patients in this series received non-TBI regimens and it is possible that such patients differed for unknown but important (latent) covariates.

The 3-year probability of treatment-related mortality was $40 \%(95 \% \mathrm{Cl}, 30 \%$ to $50 \%$ ). Most treatment-related deaths were from pulmonary complications, similar to observations in allogeneic transplants for Hodgkin's disease. ${ }^{32}$ This high incidence of pulmonary complications may be related to the use of busulfan or TBI. Chronic GVHD, though common, was a rare cause of death.

In conclusion, this analysis establishes the potential of allogeneic transplantation to achieve survival in patients with advanced low-grade lymphoma. Our data provide a rationale for prospective studies of allogeneic transplants earlier in the course of the disease. 


\section{References}

1. Armitage 10 . Drug therapy: Treatment of non-Hodgkin's lymphoma. N Engl $j$ Mled. 1993;328:1023-30.

2. Portlock CS. Management of the low-grade non-Hodgkin"s yymphomas. Semin Oncol. $1990 ; 17: 51-9$.

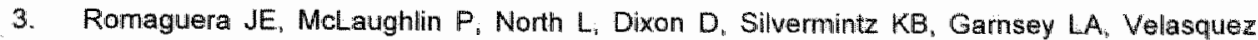
WS, Hagemeister FB, Cabanillas F. Multivariate analysis of prognostic factors in stage $N$ follicular low-grade lymphoma:Arisk model. J Clin Oncol. 1991;9:762-9.

4. Horning SJI. Treatment approaches to the low-grade lymphonnas. Blood: 1994:83:881 1-4.

5. Freedman AS, Ritz J, Neuberg D, Anderson KC, Rabinowe SN, Mauch P. Takvorian $T_{\text {, }}$ Soiffer R, Blake K, Yeap B, Coral F, Nadler LM. Autologous bone marrow transplantation in 69 patients with a history of low-grade B-cell non-Hodgkin's lymphoma. Blood. 1991;77: 2524-9.

6. Rohatiner AZS, Johnson PWM, Price CGA, Arnott SJ, Amess JAL, Norton AJ, Dorey E, Adams K, Whelan JS, Matthews J, MacCallum PK, Oza AM, Lister TA. Myeloablative therapy with autologous bone marrow transplantation as consolidation therapy for recurrent follicular Iymphoma. J Clin Oncol. 1994:12:1177-84.

7. Schouten HC, Bierman PJ, Vaughan WP. Kessinger $A_{n}$ Vose JM, Weisenburger DD, Armitage JO. Autologous bone marrow transplantation in follicular non-Hodgkin's lymphoma before and after histologic transformation. Blood. 1989;74:2579-84.

8. Colombat $\mathbb{P}$, Binet $C$, Linassier $C$, Desbois I, Lamagnere JP, Biron P, Philip T. High dose chemotherapy with autologous marrow transplantation in follicular lymphomas. Leuk Lymphoma: 1992; $51: 3-6$ :

9. Bierman PJ, Vose JM, Anderson JR, Bishop MR, Kessinger A, Armitagle JO. High-dose therapy with autologous hematopoietic rescue for follicular low-grade non-Hodgkin's lymphoma. J Clin Oncol. 1997:15:445-50.

10. Johnson PWM, Price CGA, Smith $T$, Cotter FA, Meerabux J, Rohatiner AZS, Young BD, Lister TA. Detection of cells bearing the $t(14 ; 18)$ translocation following myeloablative treatment and autologous bone marrow transplantation for follicular lymphoma. $J \mathrm{Clin}$ Oncoll. 1994:12:798-805.

11. Stone RM. Myelodysplastic syndrome after autologous bone marrow transplantation for lymphoma: The price of progress? Bload. 1994:83:3437-40.

12. Miller JS, Arthur DC "Litz CE, Neglia JP, Miller WJ, Weisdorf DJ. Myelodysplastic syndrome after autologous bone marrow transpllantation: An additional late complication of curative cancer therapy. Blood. 1994;83:3780-6.

13. van Besien KW, Khouri IF, Giralt SA, McCarthy P. Mehra R, Andersson BS, Przepiorka D. Gajewski JL, Bellare N, Nath R, Romaguera JE, McLaughlin P, Korbling M, Deisseroth AB, Cabanillas FF, Champlin RE. Allogeneic bone marrow transplantation for reffractory and recurrent low grade lymphoma: The case for aggressive management. $\mathrm{J}$ Clin Oncol. 1995;13:1096-102.

14. Appelbaum FR, Clift RA, Buckner CD, Stewart $P$, Storb $R$, Sullivan KM, Thomas ED. Allogeneic bone marrow transplantation for non-lymphoblastic leukemia after first relapse. Blood. 1983;61:949-53.

15. Lundberg $\mathrm{JH}$, Hansen RM, Chitambar $C R$, Lawton $C A$, Gottlieb $M$, Anderson $T$, Ash RC. Allogeneic bone marrow transplantation for relapsed and refractory lymphoma using genotypically HLA-identical and alternative donors. J Clin Oncol. 1991,9:1848-59.

16. Copelan EA, Kapoor $N$, Gibbins B. Tutschka PJ. Allogeneic marrow transplantation in nonHodgkin's lymphoma. Bone Marrow Transplant, 1990;5:47-50.

17. Chopra R, Goldstone AH, Pearce $F_{3}$, Philip T, Petersen F, Appelbaum F, De Vol E, Ernst P. Autologous versus allogeneic bone marrow transplantation for non-Hodgkin's lymphoma: $A$ case controlled analysis of the European Bone Marrow Transplant Group registry data. I Clin Oncal. 1992;10:1690-5. 
18. Mandigers $C_{n}$ Raemaekers $J_{\text {; }}$ Schattenberg $A$, Bogman $J_{x}$ Mensink $E$, de Witte $\mathbb{T}$. Allogeneic bone marrow transplantation in patients with relapsed low-grade follicullar non-Hodgkin's Iymphoma. Blood. 1995;86 51:208a.

19. Molina I, Nicolirï F, Viret F, Pegourie-Bandelier B, Le ger $J$, Solto JJ. Allogeneic bone marrow trarisplantation for refractory and recurrent low grade non-Hodgkin's lymphoma. Blood. 1995; 86 \% $\$ 1: 209 a$.

20. The Non-Hodgkin's Lymphoma Pathologic Classification Project. National Cancer Institute sponsored study of classificalions of non-Hodlgkin's lymphomas: Summary and description of a working formulation for clinical usage. Cancer 1982,49:2112.

21. Harris $\mathrm{NL}_{\text {, Jaffe }} \mathrm{ES}$, Stein $\mathrm{H}$, Banks PM, Chan JKC, Cleary ML, Delsol $\mathrm{G}$, De Wolf-Peeters $\mathrm{C}$, Falin $B$, Gatter KC, Grogan TM, Isaacson PG, Knowles DM, Mason DY, Muller-Hermelink H$K$. Pileri $S A_{i}$ Piris $M A_{i}$ Ralfkiaer $E$ and Warnke RA. A revised European- American classification of lymphoid neoplasms: A proposal from the international lymphoma study group. Blood. 1994;84:1361-92.

22. Przepiorka $D$, Weisdorf $D$, Martin $P$, Klingemann H-G, Beatty $P$, Hows J Thomas ED. Consensus conference on GVHD grading. Bone Marrow Transplant. 1995:15:825-8.

23. Atkinson $K_{1}$ Horowitz MM, Galle RP, van Bekkum DW, Gluckman $E$, Good RA, Jacobsen N,

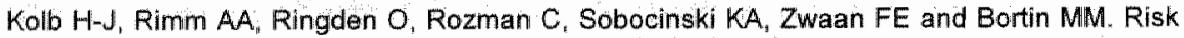
factors for chronic graft-versus-host disease after HLA-identical sibling bone marrow transplantation. Blood 1 190; 75:2459-64.

24. Altal M, Socle $G$, Molina L, Jouet JP, Pico J, Kuentz M, Blaise D, Milpied N, Ifrah $N$, Payen $C_{n}$ Tanguy ML: Allogeneic bone marrow transplantation for refractory and recurrent follicular lymphoma: A case-matched analysis with autologous transplantation from the French bone marrow transplant group registry data. Blood. 1997;20 S1:1120a.

25. Pleniket AJ, Ruiz de Elvira MC, Taghipour $G$, de Witte $T$, Tazelaar PJ, Carella A, Vernant JP, Schaefer UW, Cleeven $M$, Boogaerts MA, Gluckman $E_{n}$ Goldstone A.H. Allogeneic transplartation for lymphoma produces a lower relapse rate than autologous transplantation but survival has not risen because of higher treatment-related mortality-A report of 764 cases from the EBMT Iymphoma registry. Bload. 1997;51:1121a.

26. Ratanatharathorn $V$, Uberti $J$, Karanes $C$, Abella $E$, Lum $L G_{n}$ Momin $F$, Cummings $G$, Sensenbrenner $L L$. Prospective comparative trial of autologous versus allogeneic bone mairrow transplantation in patients with non-Hodgkin"s lymphoma. Blood. 1994;84:1050-5.

27. Jones RJ, Ambinder RF, Plantadosi $S$, Santos GW. Evidence of a graft-versus-lymphama effect associated with allogeneic bone marrow transplantation. Blood. 1991;77:649-53.

28. van Besien KW, de Lima Mi; Giralt SA, Moore DF Ji., Chouri IF, Rondon G, Mehra R, Andersson BS, Dyer $\mathrm{C}$, Cleary K, Przepiorka D, Gajewsiki JL, Chemplin RE. Management of Iymphoma recurrence after allogeneic transplantation: The relevance of graft-yersuslymphoma ffect. Bone Marrow Transplant. 1997;19:977-82.

29. Gribben JG, Freedman AS, Neuberg D, Roy DC, Blake KW, Woo SD, Grossbard ML, Rabinowe $S N_{i}$ Coral F. Freeman GJ, Ritz J Nadler LM. Immunologic purging of marrow assessed by PCR before autologous bone marrow transplantation for B-cell lymphoma. $N$ Engl J Med. 1991;325:1525-33.

30. Sharp JG, Joshi SS, Armitage JO, Bierman P, Coccia PF, Harrington DS, Kessinger $A_{\text {, }}$ Crouse DA, Mann SL, Weisenburger DD. Significance of detection of occult non-Hodgkin's lymphoma in histologically uninvolved bone marrow by a culture technique. Blood. 1992;79:1074-80.

31. Williams CD, Goldstone AH, Pearce RM, Philip T, Hartmann $O$, Colombat $P$, Santini $G$, Foulard $\mathrm{L}$, Gorin NC. Purging of bone marrow in autologous bone marrow transplantation for non-Hodgkin's lymphonna: A case-matched comparison with unpurged cases by the European Blood and Marrow Transplant Lymphoma Registry. J Clin Oncol. 1996;14:2454-64.

32. Gajewski JL, Phillips GL, Sobocinski KA Armitage JO, Gale RP, Champlin RE, Herzig RH, Hurd DD, Jagannath $S$, Klein JP. Lazarus HM, MicCarthy PL Jr, Pavlovsky S, Peterson FB, Rowlings PA, Russell JA, Silver SM, Vose JM, Wiernik PH, Bortin MM, Horowitz MM. Bone marrow transplants from HLA-identical siblings in advanced Hodgkin's disease. $J$ Clin Oncol. $1996 ; 14: 572-8$. 


\section{Chapter 6}

Comparison of autologous and allogeneic hematopoietic stem cell transplantation for follicular lymphoma

$K$ van Besien, FR Loberiza Jr, $\mathbb{R}$ Bajorunaite, JO Armitage, A Bashey, LJ Burns, CO Freytes, J Gibson, MM Horowitz, DJ Inwards, DI Marks, R Mino, RT Maziarz, A Molina, S Pavlovsky, AL Pecora, HC Schouten, TC Shea, HM Lazarus, J Douglas Rizzo, JM Vose 


\section{Abstract}

In this article, we report on 904 patients undergoing transplantation for follicular lymphoma. A total of $176(19 \%)$ received allogeneic, $131(14 \%)$ received purged autologous, and $597(67 \%)$ received unpurged astologous transplants. Five-year treatment-related mortality (TRM) rates were $30 \%$, $14 \%$, and $8 \%$ and 5 -year recurrence rates were $21 \%, 43 \%$, and $58 \%$ after allotransplantation. purged autotransplantation, and unpurged autotransplantation, respectively. In multivariate analyses, allotransplantation had higher TRM and lower disease recurrence. Purged autotransplantation had a $26 \%$ lower recurrence risk than unpurgled autotransplantation. Five-year probabilities of survival were $51 \%, 62 \%$, and $55 \%$ after allogenelc, purged autotransplantation, and unpurged autolransplantation, respectively. Advanced age, prolonged interval from diagnosis to transplantation, high lactate dehydrogenase $(\mathrm{LDH})$, refractory disease, bone marrow involvement. low performance scores, and transplantation between 1990 and 1993 were associated with adverse outcomes. Total body irradiation was associated with higher TRM but lower recurrence. There was no association between acute or chronic graft-versus-host disease and recurrence after allotransplantation. We conclucle that both allogeneic and autologous transplantation can induce durable remissions. There may be a benefit to graft purging in autologous transplantation. The decreased recurrence after allotransplantation is offset by increased TRM. We did not detect a correlation between graft-versus-host disease (GVHD) and recurrence. Finally, outcomes of transplantation for follicular lymphoma show improvement over the past decade. 


\section{Introduction}

Follicular lymphoma is considered an indolent disorder but can have an unpredictable and often relentless course..$^{4-5}$ Treatments such as chemotherapy, biologic response modifiers, and monoclonal antibodies are not considered curative and, with the possible exception of interferon, do not prolong survival. ${ }^{6,7}$ In contrast, autologous hematopoietic stem cell transplantation is shown in several phase 2 studies to induce remissions in patients with recurrent or newly diagnosed disease ${ }^{8-21}$ Although recurrence rates are high in some of these studies, some patients have very durable remissions and may be cured. ${ }^{22}$ Allogeneic hematopoietic stem cell transplantation is also a potentially curative approach. Recurrence rates after allogeneic transplantation are low, but treatment-related mortality (TRM) is high, related, in part, to a tendency to use this therapy in patients with very advanced disease. ${ }^{23-32}$ To evaluate the roles of allogeneic versus autologous transplantation, as well as to gather additional insights into mechanisms of disease control, we studied 904 patients undergoing allogeneic or autologous transplantation for follicular lymphoma between 1990 and 1999 who were reported to the International Bone Marrow Transplant Registry (IBMTR) or the Autologous Blood and Marrow Transplant Registry (ABMTR).

\section{Patients and methods}

\section{Data sources}

The IBMTR is a voluntary working group of more than 350 transplantation centers worldwide that contribute detailed data on consecutive allogeneic hematopoietic stem cell transplantations to a statistical center at the Health Policy Institute of the Medical College of Wisconsin in Milwaukee. The ABMTR is a voluntary organization of more than 250 transplantation centers primarily in North and South America that report data on consecutive autotransplantations to the same statistical center. On the basis of data collected in the Centers for Disease Control Hospital Surveys and the U.S. Government Accounting Office and worldwide surveys of transplantation activity, approximately $35 \%$ of allogeneic transplantations worldwide and more than $50 \%$ of autotransplantations in North and South America are registered with the IBMTR/ABMTR. Participating centers are required to register all transplants consecutively; compliance is monitored by on-site audits. Patients are followed longitudinally, with yearly follow-up. Computerized checks for errors "physician 
reviews of submitted data, and on-site audits of participating centers ensure data quality. The IBMTR/ABMTR collects data at 2 levels: registration and research. Registration data include disease type, age, sex, pretransplantation performance status, disease stage and chemotherapy responsiveness, date of diagnosis, donor and graft type (bone marrow-and/or blood-derived stem cells), high-dose conditioning regimen, posttransplantation engraftment, graftversus-host disease, disease recurrence and survival, development of a new malignancy, and cause of death. Requests for data on disease or death for registered patients are at 6-month intervals. All IBMTR/ABMTR teams contribute registration data on all patients. Research data are collected on subsets of registered patients selected by using a weighted randomization scheme, including comprehensive pretransplantation and posttransplantation clinical information.

\section{Patients}

We reviewed all HLA-identical sibling transplantations and autologous transplantations for follicular lymphoma performed between 1990 and 1999 and reported to the IBMTR/ABMTR. A total of 2459 registered cases were identified. Of these cases, 904 patients with follicular lymphoma both at diagnosis and at the time of transplantation had full research data and were included in the analysis. This analysils included patients with follicular small cleaved-cell lymphoma (Working Formulation group B), follicular mixed-cell lymphoma (Working Formulation group C), and follicular large cell lymphoma (Working Formulation group D). Patients initially diagnosed with follicular Iymphoma, but whose disease transformed to intermediate-grade or high-grade

lymphoma before transplantation, were excluded. Patients receiving nonmyeloablative conditioning regimens for allogeneic transplantation were excluded. To ensure that the research patients were representative of all registered patients, demographics, relapse rates, and survival rates between research and registered patients were compared; no differences were noted. Patients were considered to have "early" disease if they received their transplant in first or second complete remission or at the time of first relapse. All other patients were considered to have advanced disease.

\section{Endpoints}

Primary outcomes were survival, disease-free survival (DFS; survival without lymphoma after transplantation), recurrence, and TRM (treatmentrelated or nonrelapse mortality). Any death occurring within 28 days after transplantation was considered a TRM. Additionally, any death occurring 28 days or more after transplantation in a patient in continuous remission was considered treatment related. Patients with recurrent lymphoma were censored at the time of 
relapse, and those patients alive in remission were censored at the last followup evaluation. For DFS, patients were considered treatment failures at the time of relapse or death from any cause; patients alive in continuous complete remission were censored at the last follow-up evaluation. Patients who never achieved complete remission were analyzed as having recurrent lymphoma on day 28. Other outcomes examined were acute graft-versus-host disease (GVHD) and chronic GVHD. Acute GVHD was defined as moderate to severe (grades II to IV) disease using established criteria; patients surviving more than 21 days with evidence of engraftment were considered at risk. Chronic GVHD was determined by clinical criteria in patients surviving more than 90 days with evidence of engraftment.

\section{Statistical analysis}

Univariate comparisons were done by using the Kruskal-Wallis test for continuous data and the chi-square test for categorical variables. Probabilities of survival and DFS were calculated by using the Kaplan-Meier product-limit estimate. Probabilities of relapse and TRM were calculated by using cumulative incidences to allow for competing risks. The 95\% confidence intervals (Cls) were computed by using the arc sine-square root transformation. TRM, relapse, DFS, and survival after autologous (purged/unpurged) versus HLAidentical sibling transplantation were evaluated in multivariate analyses by using Cox proportional hazards regression to adjust for other potentially confounding differences between the cohorts. Variables considered in multivariate analysis are as follows: type of transplant ${ }_{\text {age, sex, Karnofsky }}$ performance score at transplantation, disease stage at transplantation, chemosensitivity, bone marrow involvement at diagnosis and transplantation, histology type, presence of B symptoms at diagnosis, serum lactate dehydrogenase (LDH) at transplantation, initial chemotherapy given, interval from diagnosis to transplantation, use of total body irradiation (TBI) or other field radiation, use of growth factors, graft source, and year of transplantation. Each model contained the main effect (type of transplant: unpurged autologous transplant versus purged autologous transplant versus HLA-identical sibling transplant). We tested the proportional hazards assumption for each factor in the Cox model by using time-dependent covariates. When this statistic indicated differential effects over time (nonproportional hazards), models were constructed to break the posttransplantation time course into 2 periods, using the maximized partial likelihood method to find the most appropriate breakpoint. Interactions between the type of transplant and all covariates were tested prior to stepwise modeling. After modeling time-varying effects and interactions, the final multivariate model was built by using a forward stepwise model selection approach. Factors significantly associated with the outcome 
variable at a $5 \%$ o level were kept in the final model. First-order interactions were again examined between the type of transplant and all significant prognostic factors. Examination for center effects used a random effects or frailty model. No statistically significant center effect was noted. All $P$ values are 2-sided:

\section{Results}

\section{Patient and transplant characteristics}

Patient-, disease-, and transplant-related characteristics are listed in Table 6.1 and compared across the 3 treatment groups. A total of 176 patients underwent allogeneic transplantation and 728 underwent autologous transplantation; 131 of the autologous grafts were treated in vitro to remove residual lymphoma cells (purged). There was a slight majority of men in each of the groups, reflective of the slightly higher incidence of follicular lymphoma in men.

Table 6.1 Patient-, disease, and transplantation-related characteristics

\begin{tabular}{|c|c|c|c|}
\hline \multirow[t]{2}{*}{ Variables } & \multicolumn{3}{|c|}{ Type of trainsplant } \\
\hline & $\begin{array}{l}\text { HLA-identical } \\
\text { sibling }\end{array}$ & $\begin{array}{l}\text { Autologous } \\
\text { purged }\end{array}$ & $\begin{array}{c}\text { Autologous } \\
\text { unpurged }\end{array}$ \\
\hline $\mathrm{N}$ & 176 & 131 & 597 \\
\hline Median age, y (range) & $42(22-64)$ & $49(29-64)$ & $49(18-71)$ \\
\hline Men $(\%)$ & $95(54)$ & $83(63)$ & $320(54)$ \\
\hline \multicolumn{4}{|c|}{ Karnofsky performance score at transplantation $(\%)^{a}$} \\
\hline No more than $80 \%$ & $60(34)$ & $17(13)$ & $183(31)$ \\
\hline $90 \%-100 \%$ & $116(66)$ & $114(87)$ & $414(69)$ \\
\hline \multicolumn{4}{|l|}{ CMV status at transplantation $(\%)^{a}$} \\
\hline Negative & $85(48)$ & $16(12)$ & $153(26)$ \\
\hline Positive & $88(50)$ & $32(25)$ & $205(34)$ \\
\hline Unknown & $3(2)$ & $83(63)$ & $239(40)$ \\
\hline \multicolumn{4}{|l|}{ Disease status at transplantation $(\%)^{\text {alo }}$} \\
\hline Early & $85(48)$ & $69(53)$ & $350(59)$ \\
\hline Advanced & $91(52)$ & $62(47)$ & $247(41)$ \\
\hline \multicolumn{4}{|c|}{ Bone marrow involvement at diagnosis $(\%)$} \\
\hline Absent & $102(58)$ & $71(54)$ & $355(59)$ \\
\hline Present & $74(42)$ & $60(46)$ & $242(41)$ \\
\hline \multicolumn{4}{|c|}{ Bone marrow involvement at transplantation $(\%)^{a}$} \\
\hline Absent & $119(68)$ & $103(79)$ & $486(81)$ \\
\hline Present & $57(32)$ & $28(21)$ & $111(19)$ \\
\hline \multicolumn{4}{|l|}{ Histology $(\%)^{\mathrm{a}}$} \\
\hline Follicular, small cleaved & $91(52)$ & $67(51)$ & $218(36)$ \\
\hline Follicular, mixed small and large & $72(41)$ & $52(40)$ & $242(41)$ \\
\hline Follicular, large cell & $13(7)$ & $12(9)$ & $137(23)$ \\
\hline
\end{tabular}




\begin{tabular}{|c|c|c|c|}
\hline \multirow[t]{2}{*}{ Variables } & \multicolumn{3}{|c|}{ Type of transplant } \\
\hline & $\begin{array}{l}\text { HLA-identical } \\
\text { sibling }\end{array}$ & $\begin{array}{l}\text { Autologous } \\
\text { purged }\end{array}$ & $\begin{array}{l}\text { Autologous } \\
\text { unpurged }\end{array}$ \\
\hline \multicolumn{4}{|l|}{ Disease stage at diagnosis $(\%)$} \\
\hline$|-| \mid$ & $22(13)$ & $23(17)$ & $113(19)$ \\
\hline III-IV & $152(86)$ & $107(82)$ & $476(80)$ \\
\hline Unknown & $2(1)$ & $1(1)$ & $8(1)$ \\
\hline \multicolumn{4}{|l|}{ B symptoms at diagnosis $(\%)$} \\
\hline Absent & $116(66)$ & $94(72)$ & $367(62)$ \\
\hline Present & $48(27)$ & $33(25)$ & $182(30)$ \\
\hline Unknown & $12(7)$ & $4(3)$ & $48(8)$ \\
\hline \multicolumn{4}{|l|}{ Chemosensitivity $(\%)^{\tilde{a}}$} \\
\hline Sensitive & $118(67)$ & $111(B 5)$ & $488(82)$ \\
\hline Resistant & $31(18)$ & $14(11)$ & $66(11)$ \\
\hline Untreated/unknown & $27(15)$ & $6(4)$ & $43(7)$ \\
\hline \multicolumn{4}{|l|}{ Serum $L D H$ at diagnosis $(\%)^{a}$} \\
\hline Normal & $117(67)$ & $55(42)$ & $389(65)$ \\
\hline Abinormall & $44(25)$ & $27(21)$ & $174(29)$ \\
\hline Unknown & $15(8)$ & $49(37)$ & $34(6)$ \\
\hline \multicolumn{4}{|l|}{ Initial chemotherapy $(\%)^{a}$} \\
\hline $\mathrm{CHOP} \pm$ other & $44(25)$ & $57(44)$ & $206(34)$ \\
\hline Fludarabine \pm other & $29(16)$ & $7(5)$ & $63(11)$ \\
\hline Other & $44(25)$ & $32(24)$ & $221(37)$ \\
\hline Unknown & $59(34)$ & $35(27)$ & $107(18)$ \\
\hline \multicolumn{4}{|c|}{ Interval from diagnosis to transplantation $(\%)$} \\
\hline Less than $1 \mathrm{y}$ & $26(15)$ & $27(21)$ & $115(19)$ \\
\hline $1-2 y$ & $56(32)$ & $32(24)$ & $156(26)$ \\
\hline More than $2 y$ & $94(53)$ & $72(55)$ & $326(55)$ \\
\hline \multicolumn{4}{|l|}{ Graft type $(\%)^{2}$} \\
\hline Bone marrow & $135(77)$ & $100(76)$ & $89(15)$ \\
\hline Peripheral blood/both & $41(23)$ & $31(24)$ & $508(85)$ \\
\hline \multicolumn{4}{|l|}{ Year of transplantation $(\%)^{a}$} \\
\hline $1990-1993$ & $50(28)$ & $70(54)$ & $181(30)$ \\
\hline $1994-1996$ & $64(37)$ & $41(31)$ & $269(45)$ \\
\hline $1997-1999$ & $62(35)$ & $20(15)$ & $147(25)$ \\
\hline \multicolumn{4}{|l|}{ Conditioning regimen $(\%)^{g}$} \\
\hline TBI & $120(68)$ & $44(34)$ & $184(34)$ \\
\hline Non-TBi & $56(32)$ & $87(66)$ & $413(69)$ \\
\hline \multicolumn{4}{|c|}{ Use of involved field radiation $(\%)$} \\
\hline No & $169(96)$ & $128(98)$ & $576(96)$ \\
\hline Yes & $7(4)$ & $3(2)$ & $21(4)$ \\
\hline GVHD prophylaxis (\%) & & & \\
\hline T-cell depletion & $28(16)$ & - & - \\
\hline MTX \pm other & $113(64)$ & - & - \\
\hline CSA \pm otherlother or none & $35(20)$ & - & - \\
\hline \multicolumn{4}{|l|}{ AGVHD $(\%)$} \\
\hline None-mild & $108(61)$ & - & - \\
\hline Moderate-severe & $65(37)$ & - & - \\
\hline Unknown & $3(2)$ & - & - \\
\hline
\end{tabular}




\begin{tabular}{|c|c|c|c|}
\hline \multirow[t]{2}{*}{ Variables } & \multicolumn{3}{|c|}{ Type of transplant } \\
\hline & $\begin{array}{l}\text { HLA-identical } \\
\text { sibling }\end{array}$ & $\begin{array}{l}\text { Autologous } \\
\text { purged }\end{array}$ & $\begin{array}{c}\text { Autologous } \\
\text { unpurged }\end{array}$ \\
\hline \multicolumn{4}{|l|}{ Chronic GVHD (\%) } \\
\hline None & $131(74)$ & - & - \\
\hline Mild-3evere & $42(24)$ & - & - \\
\hline Unknown & $3(2)$ & - & - \\
\hline Number of centers & 56 & 21 & 98 \\
\hline
\end{tabular}

$C M V=c y t o m e g a l o v i r u s ; \quad C H O P=C y c l o p h o s p h a m i d e$ Hydroxydaunomycin Oncovin Prednisone;

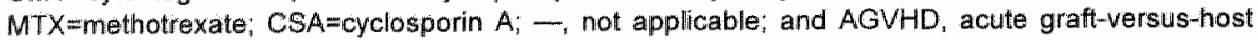
disease.

${ }^{a}$ P<0.01 for difference between transplant groups: Early disease indicates patients whose disease status at transplantation is in first or second complete remission, or in first relapse; advanced disease, patients whose disease status at transplantation is in second or greater relapse, in third complete remission, or with primary induction failure.

The median age of those patients receiving allogeneic transplants was 42 versus 49 years for those patients receiving autologous transplants. This difference was not statistically significant. There were statistically significant imbalances among the 3 treatment groups in several other characteristics. Allograft recipients were more likely to have poor performance status, advanced disease, increased $\mathrm{LDH}$, and bone marrow involvement at transplantation and to have chemotherapy-resistant disease. Autograft recipients were more likely to have follicular large cell lymphoma.

Transplantation regimens also varied significantly. Bone marrow grafts and TBI conditioning were most commonly used for allogeneic transplantation. Chemotherapy conditioning was more commonly used for autologous transplantation. Bone marrow was more commonly used for purged autologous grafts, whereas peripheral blood was the preferred stem cell source for unpurged autologous transplantations. Purged autologous transplantation was performed more commonly at the beginning of the decade, whereas allogeneic transplantation was increasingly used toward the late $1990 \mathrm{~s}$.

The median follow-up of survivors was 36 months for allograft recipients, 49 months for purged autograft recipients, and 41 months for unpurged autograft recipients.

The types of purging used are summarized in Table 6.2. A variety of methodologies were reported, but purging by in vitro exposure to 4hydroperoxycyclophosphamide was the most common, accounting for $50 \%$ of purged grafts. 
Table 6.2 Purging methods used for autologous transplantation $(\mathbb{N}=931$.

\begin{tabular}{lc}
\hline$n(\%)$ \\
\hline Monoclonal antibody & $14(11)$ \\
4-hydroperoxycyclophosphamide & $65(50)$ \\
Positive stem cell selection & $28(21)$ \\
Drugs & $24(18)$ \\
4-hydroperoxy cyclophosphamide & 65 \\
Etoposide + methylprednisolone & 18 \\
Vincristine + methylprednisolone & 6 \\
\hline
\end{tabular}

\section{Outcomes}

Outcomes are summarized in Table 6.3. TRM after allogeneic transplantation was $24 \%$ at 1 year and $30 \%$ at 5 years. TRM after autologous transplantation was $4 \%$ to $8 \%$ at 1 year and $8 \%$ to $14 \%$ at 5 years. The recurrence rate after allogeneic transplantation was $19 \%$ at 1 year with very few relapses thereafter. The recurrence rate after unpurged autologous transplantation was $36 \%$ at 1 year and $58 \%$ at 5 years. The recurrence rate after purged autologous transplantation was $25 \%$ at 1 year and $43 \%$ at 5 years.

These marked differences in recurrence rates and TRM resulted in a higher treatment failure (relapse or death) among patients who received allogeneic transplants in the first year after transplantation. But the results were almost identical for disease-free and overall survival after autologous or allogeneic transplantation by 5 years after transplantation.

Table 6.3 Univariate outcome probabilities.

\begin{tabular}{|c|c|c|c|c|}
\hline \multirow{2}{*}{\multicolumn{2}{|c|}{ Outcomes }} & \multirow{2}{*}{\multicolumn{3}{|c|}{ Type of transplant probability $\%(95 \% \mathrm{Cl})$}} \\
\hline & & & & \\
\hline Treatment-related mortality ${ }^{2}$ & & \multirow{2}{*}{$\begin{array}{l}\text { HLA-identical } \\
\text { sibling } \\
24(18-32)\end{array}$} & $\begin{array}{l}\text { Autologous } \\
\text { purged } \\
\frac{8(5-15)}{}\end{array}$ & $\begin{array}{l}\text { Autologous } \\
\text { unpurges } \\
4(3-6)\end{array}$ \\
\hline I reatment-related mortality & $\begin{array}{l}1 y \\
3 y\end{array}$ & & $\begin{aligned} 8(5-15) \\
10(6-17)\end{aligned}$ & $\begin{array}{l}4(3-6) \\
6(4-8)\end{array}$ \\
\hline & $5 y$ & $30(23-40)$ & $14(8-22)$ & $8(6-11)$ \\
\hline \multirow[t]{3}{*}{ Ralapse ${ }^{1}$} & $1 y$ & $19(14-26)$ & $25(18-34)$ & $36(32-40)$ \\
\hline & $3 y$ & $21(15-28)$ & $40(32-50)$ & $52(48-57)$ \\
\hline & $5 y$ & $21(15-28)$ & $43(35-54)$ & $58(53-63)$ \\
\hline \multirow[t]{3}{*}{ Disease-free survival $^{b}$} & $1 y$ & $55(48-62)$ & $66(58-74)$ & $59(55-63)$ \\
\hline & $3 y$ & $48(40-55)$ & $48(39-57)$ & $41(37-45)$ \\
\hline & $5 y$ & $45(36-53)$ & $39(30-48)$ & $31(27-36)$ \\
\hline \multirow[t]{3}{*}{ Overall survival $^{b}$} & $1 y$ & $61(54-68)$ & $82(76-89)$ & $81(78-84)$ \\
\hline & $3 y$ & $54(47-62)$ & $71(63-79)$ & $6561-69)$ \\
\hline & $5 y$ & $51(43-60)$ & $62(53-72)$ & $55(50-60)$ \\
\hline
\end{tabular}

a Cumulative indicence;" Kaplan-Meier estimate. 


\section{Multuariate analysis}

Multivariate analyses allowed comparisons among the 3 main groups, taking into accourit the potentially confounding effects of other important patient, disease, and treatment-related variables. Results are summarized in Tables 6.4-7.

Table 6.4 Mutivariate analysis of treatment-related mortality.

\begin{tabular}{|c|c|c|}
\hline Variables & $\begin{array}{l}\text { Relative risk of treatment- } \\
\text { related mortality }(95 \% \mathrm{Cl})\end{array}$ & $p$ \\
\hline Type of transplant & & $<0.001^{\mathrm{b}}$ \\
\hline Autologous unpurged, $n=596$ & 1.00 & - \\
\hline Autologous purges, $n=130$ & $0.98(0.52-1.87)$ & 0.96 \\
\hline Allogeneic, $n=175$ & $4.44(2.84-7.02)$ & $<0.001$ \\
\hline Chemoserisitivity & & $<0.001^{b}$ \\
\hline Sensitive, $n=714$ & 1.00 & - \\
\hline Resistant, $n=111$ & $2.71(1.69-4.36)$ & $<0.001$ \\
\hline Untreated/unknown, $n=76$ & $1.78(0.99-3.19)$ & 0.06 \\
\hline Serum LDH at transplantation & & $<0.001^{\circ}$ \\
\hline Notmal, $n=561$ & 1.00 & - \\
\hline Abnormall, $n=243$ & $2.03(1.32-3.14)$ & 0.001 \\
\hline Unknown $n=97$ & $2.69(1.43-5.04)$ & 0.002 \\
\hline Age at transplantation & & - \\
\hline No older than 40 y, $n=198$ & 1.00 & - \\
\hline Older than 40 y, $n=703$ & $1.98(1.21-3.26)$ & 0.007 \\
\hline \multicolumn{3}{|l|}{ Conditioning regimen } \\
\hline Non-TBI, $n=553$ & 1.00 & - \\
\hline TBI. $N=3448$ & $1.80(1.16-2.77)$ & 0.008 \\
\hline Year of transplantation & & $0.03^{b}$ \\
\hline $1990-1993, n=300$ & 1.00 & - \\
\hline $1994-1996, n=373$ & $0.67(0.42-1.06)$ & 0.09 \\
\hline $1997-1998, n=228$ & $0.49(0.28-0.87)$ & 0.01 \\
\hline
\end{tabular}

-Indicates reference group; $L D H=l a c t a t e$ dehydrogenase; $T B \mid=t o t a l$ body irradiation.

it Allegeneic versus autologouw-purged (relative risk (RIR), 4.52;95\%,Cl, 2.29-8.92; $P<0.001$

"Determoned by 2-degree of freedom test.

After adjustment for other covariates, the risk of TRM (Table 6.4) was 4.4 times higher after allogeneic than after autologous transplantation $(P<0.001)$. There was no statistically significant difference in TRM after purged versus unpurged autotransplantation. Other factors significantly associated with higher TRM were age older than 40 years, chemotherapy-resistant disease, high serum $\mathrm{LDH}$ at transplantation, TBI for conditioning, and transplantation between 1990 and 1993. Figure 6.1 shows the cumulative incidence of TRM by type of transplant. 
Table 6.5 Multivariate analysis of relapse.

\begin{tabular}{|c|c|c|}
\hline Variables & Refative risk of relapse $/ 95 \%$ oll & p \\
\hline Type of transplan ${ }^{2}$ & & $<0.001^{\circ}$ \\
\hline Autologous unpurged, $n=596$ & 1.00 & - \\
\hline Autologous purged, $n=130$ & $0.74(0.55-0.99)$ & 0.04 \\
\hline Allogeneic, $n=175$ & $0.46(0.33 \cdot 0.66)$ & $<0.001$ \\
\hline Disease stage at transplantation ${ }^{b}$ & & - \\
\hline Earty, $n=501$ & 1.00 & - \\
\hline Advanced, n= 400 & $1.29(1.06-1.58)$ & 0.01 \\
\hline Chemosensitivity & & $0.004^{2}$ \\
\hline Sensitive, $n=714$ & 1.00 & - \\
\hline Resistant, $n=111$ & $1.69(1.27 \cdot 2.23)$ & $<0.001$ \\
\hline Untreated/unknown, $n=76$ & $0.98(0.58 \cdot 1.42)$ & 0.93 \\
\hline Serum LDH at transplantation & & $<0.001^{\mathrm{a}}$ \\
\hline Normal, $n=561$ & 1.00 & - \\
\hline Abnormal, $n=243$ & $4.51(1.21-1.87)$ & $<0.001$ \\
\hline Unknown, $n=97$ & $1.00(0.69-1.43)$ & 0.98 \\
\hline Karnorsky performance score at transplantation & & - \\
\hline $90 \%-100 \%, n=641$ & 1.00 & - \\
\hline No more than $80 \%, n=260$ & $1.31(1.07-1.61)$ & 0.01 \\
\hline Conditioning regimen & & - \\
\hline Non-TBI, $n=553$ & 1.00 & - \\
\hline TBI, $n=348$ & $0.77(0.62-0.95)$ & 0.02 \\
\hline Interval from diagnosis to transplantlation & & $0.05^{\circ}$ \\
\hline Less than $1 y, m=168$ & 1.00 & - \\
\hline $1-2 y_{n}=244$ & $1.37(1.01-1.87)$ & 0.05 \\
\hline More than 2 y, $n=489$ & $1.40(1.06-1.84)$ & 0.01 \\
\hline Bone marrow involvement at transplantation & & - \\
\hline No, $n=705$ & 1.00 & - \\
\hline Yes, $n=196$ & $1.31(1.04-11.65)$ & 0,02 \\
\hline
\end{tabular}

- Indicates reference group; $L D H=l a c t a t e$ dehydrogenase; $T B \mid=t o t a l$ body irradiation.

- Allogeneic versus autologous purgied transplantation $\left(\mathrm{RR}_{11} 0.63 ; 95 \%, 01,0.41-0.97 ; P<0.03\right)$;

- Early disease indicates complete remission (1st or 2 nd) or relapse (1st); advanced disease, complete remission (3rd) or relapse ( $>2$ nd) or primary induction failure.

- Determined by 2 -degree of freedom test.

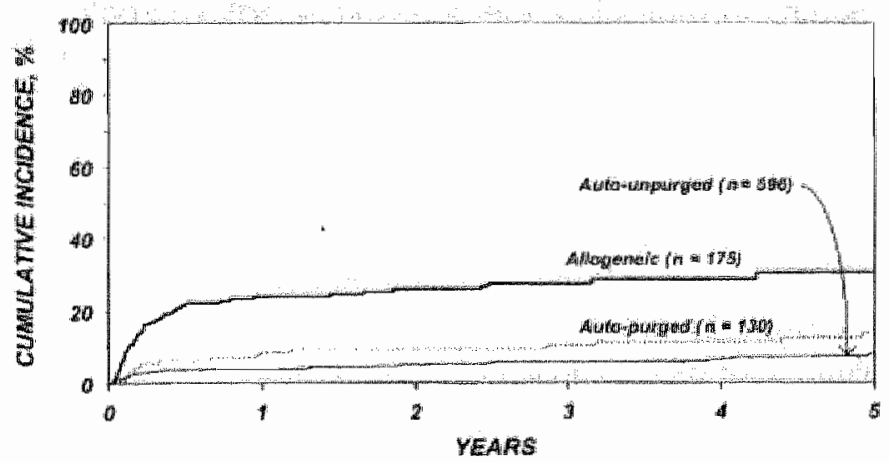

Figure 6.1 Cumulative incidences of treatment-related mortality by type of transplant. 
The risk for disease recurrence (Table 6.5) was $54 \%$ lower in recipients of allogeneic transplants $(P<0.001)$ and $26 \%$ lower in recipients of purged autotransplants $(P=0.04)$ than in recipients of unpurged autotransplants. Other factors associated with higher risk of relapse were advanced disease, high serum LDH at transplantation, chemotherapy-resistant disease, poor Karnofsky performance score, bone marrow involvement, and an interval greater than 1 year between diagnosis and transplantation. The use of TBI was associated with a lower risk of disease recurrence. Figure 6.2 shows the cumulative incidence of relapse by type of transplant.

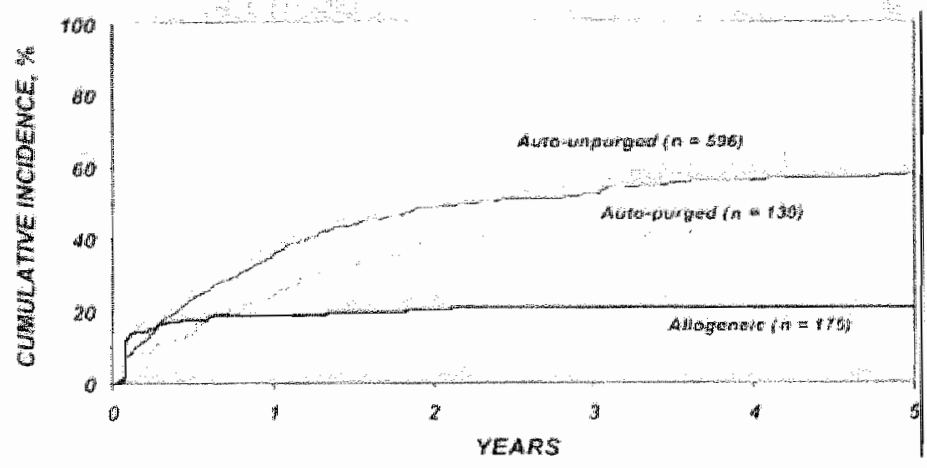

Figure 6.2 Cumulative incidences of relapse by type of transplant.

The risk of treatment failure (relapse or death) (Table 6.6) was higher after purged autologous than unpurged autologous transplantation, although this difference was not statisticaliy different $(P=0.14)$. In the first 6 months after transplantation, the risk of treatment failure was higher among patients who received allotransplants than autotransplants $(P<0.001)$. Among patients surviving 6 months in remission, the subsequent risk of treatment failure was significantly lower among patients who received allotransplants than autotransplants $(\mathcal{P}<0.001)$. Again, advanced disease stage, chemotherapyresistant disease, high $\mathrm{LDH}$ at transplantation, age older than 40 years, poor performance status, and prolonged delay between diagnosis and transplantation were associated with lower DFS. We failed to detect statistical difference in DFS by year of transplantation; however, this could be due to lack of statistical power. Figure 6.3 shows the probability of DFS by type of transplant adjusted for other significant covariates. 


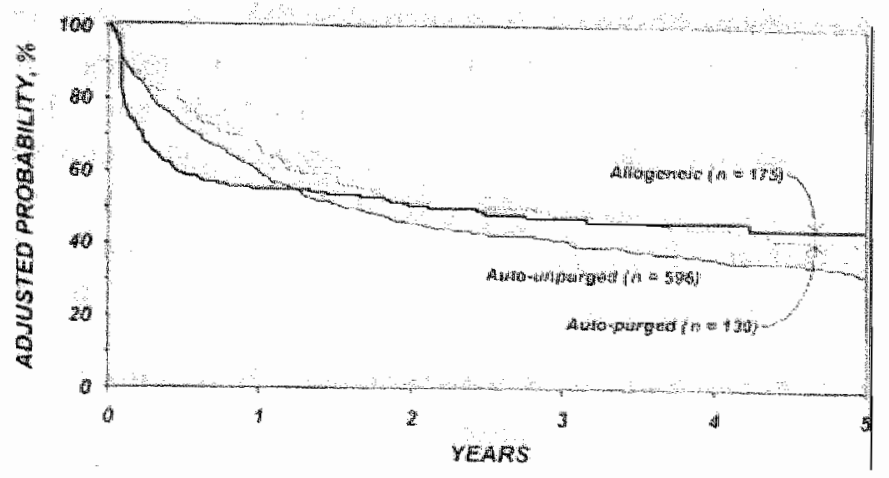

Figure 6.3 Probabilities of disease-free survival by type of transplant ${ }_{s}$ adjusted for other significant covariates listed in Table6.6.

Table 6.6 Multivariate analysis of disease-free-survival.

\begin{tabular}{|c|c|c|}
\hline Variables & Relative risk of treatment failure $(95 \% \mathrm{Cl})$ & $P$ \\
\hline Type of transplant ${ }^{2}$ & & $<0.001^{d}$ \\
\hline Autologous unpurged, $n=596$ & 1.00 & - \\
\hline Autolegous purged, in=130 & $0.82(0.63-1.07)$ & 0.14 \\
\hline Allogeneic $n=175^{\text {ib }}$ & & $\dot{-}$ \\
\hline First 6 mo after transplantation & $1.77(1.34-2.34)$ & $<0.001$ \\
\hline 6 mo after transplantation & $0.35(0.22 \cdot 0.57)$ & $<0.001$ \\
\hline Disease stage at transplantation ${ }^{\circ}$ & & - \\
\hline Early $(n=501)$ & 1.00 & - \\
\hline Advanced $(n=400)$ & $1.27(1.07-1.52)$ & 0.007 \\
\hline Chemosensitivily & & $<0.0010$ \\
\hline Sensitive, $n=714$ & 1.00 & - \\
\hline Resistant, $\mathrm{n}=111$ & $1.92(1.52-2.44)$ & $<0.001$ \\
\hline Untreated/unknown, $m=76$ & $1.12(0.83-1.53)$ & 0.45 \\
\hline Serum LDH at transplantation & & $<000110$ \\
\hline Normall, $n=561$ & 1.00 & - \\
\hline Abnormal, $n=243$ & $1.58(1.30-1.93)$ & $<0.0001$ \\
\hline Unknown, in=97 & $0.95(0.70-1,30)$ & 0.76 \\
\hline Kannofsky perhormance score at transplantation & & - \\
\hline $90 \%-100 \%, n=641$ & 1.00 & - \\
\hline No more than $80 \%, n=260$ & $1.31(9.09-1.57)$ & 0.004 \\
\hline Interval from diagnosis to trainsplantaiton & & $0.05^{16}$ \\
\hline Less than $1 y^{\prime} n=\| 68$ & 1.00 & - \\
\hline $1-2 \times n=244$ & $1.37(1.04 \times 1.80)$ & 0.03 \\
\hline More than $2 y, n=4.89$ & $1.35(1.06-1.72)$ & 002 \\
\hline Age at transplantation & & - \\
\hline No older than $40 y_{0} n=198$ & 1.00 & - \\
\hline Older than $40 y, n=703$ & $1.31(1.04-1.64)$ & 0.02 \\
\hline
\end{tabular}

- Indicates reference group: LDH=lactate dehydrogenase.

"Time-dependent covariate; such that risk of death before and after 6 months after transplantation varies; ${ }^{*}$ Allogeneic ( $\leq 6$ months) wersus autalogous-purged transplantation $\left(R R_{i} 2.15 ; 95 \% \mathrm{Cl}, 1.50\right.$ 3.08; $P<0.001$ ); allogeneic (>6 months) versus autologous-purged transplantation ( $R R, 0.43 ; 95 \%$ $\mathrm{Cl}, 0.26-0.73 ; \quad P<0.001) ; "$ Early disease indicates complete remission (1st or 2nd) or relapse (1st): advanced disease, complete remission (3rd) or relapse ( $>2 \mathrm{nd}$ ) or primary induction failure; ${ }^{\circ}$ Determined by 3-degree of freedom test: ${ }^{*}$ Determined by 2 -degree of freedom test. 
The risk of mortality (Table 6.7) was lower after purged versus unpurged autotransplantation $(P=0.03)$. In the first 6 months after transplantation, the risk of death was higher among patients who received allogeneic transplants than autologous transplants $(P<0.001)$. Among patients who survived the first 6 months, there was a slightly lower risk of death in the allotransplant group $(P=0.14)$. Advanced disease stage, chemotherapy-resistant disease, high serum LDH at transplantation, age older than 40 years, poor performance status, and prolonged delay between diagnosis and transplantation were associated with worse survival as was transplantation in the first 3 years of the decade. Figure 6.4 shows the probability of survival by type of transplant adjusted for other significant covariates. The 5-year adjusted probabilities of survival after allotransplantations, purged autologous transplantations, and unpurged autologous transplantations were $51 \%$ (95\% confidence interval [Cl], $43 \%-60 \%), 62 \%(95 \% \mathrm{Cl}, 53 \%-72 \%)$, and $55 \%(95 \% \mathrm{Cl}, 50 \%-60 \%)$, respectively.

In a separate multivariate analysis restricted to recipients of allogeneic transplants, we evaluated the effect of acute and chronic GVHD on the probability of disease recurrence by using a time-dependent covariate. The risk of relapse for patients with acute GVHD was not significantly different from that of patients without acute GVHD. The risk of relapse for patients with chronilc GVHD after transplantation was not significantly different from that of patients without chronic GVHD.

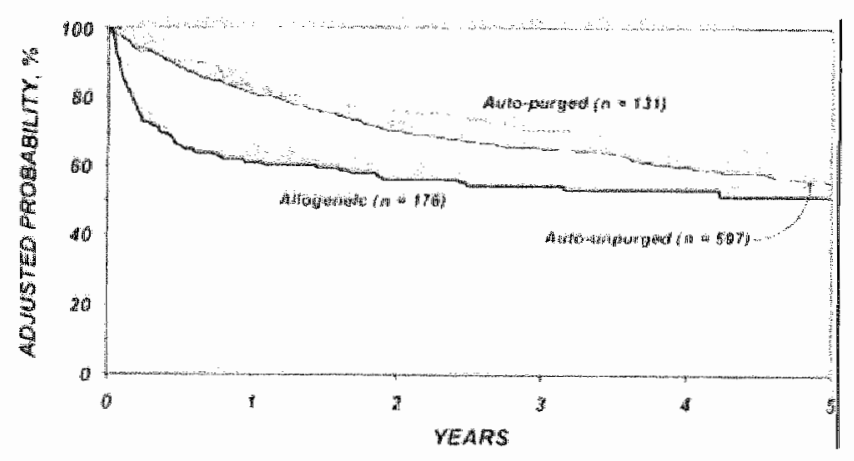

Figure 6.4 Probabilities of survival by type of transplant adjusted for ather significant covariates Histed in Table 6.7. 
Table 6.7. Multivariate analysis of overall survival.

\begin{tabular}{|c|c|c|}
\hline Variables & Relative fisk of dedh 195 o & $\rho$ \\
\hline Type of transplant ${ }^{3}$ & & $20.0011^{\circ}$ \\
\hline Astlologous unpurged, $n=59$ ? & 100 & - \\
\hline Auttologous purged, $n=131$ & $0.67(0.48-0.95)$ & 0.08 \\
\hline Allogeneic $n=176^{2}$ & & - \\
\hline First 6 mo after transplantation & $3.59(2.52-5.10)$ & $<0.001$ \\
\hline 6 mo after transplantation & $0.71(0.84-9.13)$ & 0.14 \\
\hline Disease stage at transplantation ${ }^{*}$ & & - \\
\hline Early, $m=504$ & 1.00 & $\div$ \\
\hline Advanced, $n=400$ & $1.26(4.04-4.57)$ & 0.04 \\
\hline Chemosensitivily & & $<0,001^{1}$ \\
\hline Sensitive, $n=717$ & 100 & - \\
\hline Resistant, $n=111$ & $2.63(2.01-3.44)$ & $<0,001$ \\
\hline Untreated/unknown, $n=76$ & $1.42(1.00-2.02)$ & 0.06 \\
\hline Serum LDH at transplantation & & $<0.001^{e}$ \\
\hline Normal, $n=561$ & 1.00 & - \\
\hline Abnormal, $n=245$ & $2.26(1.79-2.84)$ & $<0.001$ \\
\hline Unknown, $n=98$ & $2.11(1.48-3.01)$ & $<0.001$ \\
\hline Karnofsky performance score at transplantation & $\because$ & - \\
\hline $90 \%-1.00 \%, \mathrm{n}=644$ & 1.00 & - \\
\hline No more than $80 \%, n=260$ & $1.5 \pi(1.21-1.88)$ & $<0.001$ \\
\hline Interval from diagnosis to transplantation & & $0.001^{\circ}$ \\
\hline Less than $1 y, n=168$ & 1.00 & - \\
\hline $1-2 y, n=244$ & $1.71(1.20-2.42)$ & 0.003 \\
\hline More than 2 y, $n=492$ & $1.38(1.01-1.90)$ & 0.05 \\
\hline Age at transplantation & & - \\
\hline No older tham 40 y, $n=199$ & 1.00 & anomer \\
\hline Older than 40 y, $m=705$ & $1.42(1.07-4.88)$ & 0.01 \\
\hline Year of transplantation & & $0.007^{\circ}$ \\
\hline $1990-1993, n=301$ & 1.00 & - \\
\hline $1994 \times 1996, n=374$ & $0.71(0.55-0.90)$ & 0.006 \\
\hline $1997-1998, n=229$ & $0.67(0.49-0.2)$ & 0.01 \\
\hline
\end{tabular}

- Indicates reference group; LDH=lactate dehydrogenase.

a Time-dependent covariate; such that risk of death before and after 6 months after transplantation varies; "Allogeneic ( $\leqslant 6$ months) versus autologous-purged transplantation ( $R R, 5.33 ; 95 \% \mathrm{Cl}, 3.34$ 8.50; $P<0.001$ ); allogeneic ( $\leq 6$ months) versus autologous-purged transplantation ( $R R, 1.05 ; 95 \%$ $\mathrm{Cl}, 0.60-1.83 ; P<0.87$ ): "Early disease indicates complete remission (1st or 2 nd) or relapse (1st); advanced disease ${ }_{1}$ complete remission (3rd) or relapse $(>2$ nd) or primary induction failure; " Determined by 3-degree of freedom test; ${ }^{*}$ Determined by 2-degree of freedom test.

\section{Discussion}

Follicular lymphoma, although unpredictable and often associated with a prolonged course, is in most cases a fatal illness. ${ }^{1}$ Although numerous treatment modalities are effective, very few are shown to prolong survival, and none are curative, with the possible exception of autologous or allogeneic transplantation. ${ }^{22}$ A recently reported randomized study of 89 patients with a 
median follow-up of 6 years indicates a considerable benefit in disease-free survival $(P=0.0037)$ and survival $(P=0.079)$ of autologous transplantation compared with conventional chemotherapy for patients with recurrent follicular ymphoma. 33

The identification of patient- or disease-related prognostic variables in a large group of patients undergoing these procedures constituted a major purpose of the current analysis. We hoped to identify patient populations that might specifically benefit from allogeneic versus autologous transplantation and studied the effect of conditioning (TBI versus non-TBI), stem cell source (peripheral blood versus bone marrow), and stem cell manipulation (purged versus unpurged) on outcome. In a separate analysis restricted to recipients of allogeneic transplants, we evaluated the relationship between acute and chronic GVHD and disease recurrence. We excluded patients receiving nonmyeloablative regimens because few of such reported patients have yet achieved sufficient follow-up for meaningful analysis. ${ }^{22}$

We confirmed that both autologous and allogeneic transplantation induce longterm disease control in a proportion of patients. Disease-free survival at 5 years is approximately $50 \%$ with both procedures, a result consistent with previous studies. As in most previous studies a continuous pattern of treatment failure was observed after autologous transplantation, suggesting that cure may be achieved in only a small minority of patients. Most late failures were due to disease recurrence, but some were also related to the occurrence of secondary hematologic malignancy, a well-known complication following autologous transplantation. ${ }^{34-36}$ (Table 6.8). The pattern of treatment failure after allogeneic transplantation was markedly different from that after autologous transplantation. The recurrence rate was only $20 \%$, with almost all recurrences occurring within the first year after transplantation. This recurrence rate was virtually identical to that observed in our previous report that included many fewer patients with follicular lymphoma and covered, in part, an earlier time period. $^{27}$ Long-term outcome after allogeneic transplantation was, however, adversely affected by a high early TRM rate.

Table 6.8 Causes of nonrelapse mortality.

\begin{tabular}{lcccc}
\hline & \multicolumn{3}{c}{ Type of transplant, } \\
\cline { 2 - 4 } Cause of death & $\begin{array}{c}\text { HLA-identical } \\
\text { sibling, }\end{array}$ & $\begin{array}{c}\text { Autologous purged } \\
n=18\end{array}$ & $\begin{array}{c}\text { Autologous unpurged, } \\
n=45\end{array}$ \\
\hline New malignancy & - & 5 & 9 \\
GVHD & 10 & - & - \\
Interstitial pneumonitis & 28 & 20 & 28 \\
Infection & 18 & 24 & 22 \\
Organ failure & 24 & 22 & 18 \\
Other causes & 16 & 17 & 13 \\
Unknown & 4 & 12 & 10 \\
\hline
\end{tabular}

- indicates no events. 
Patient-and disease-related covariates that adverselly affected overall outcome included advanced age, poor performance status, an interval between diagnosis and transplantation of more than 1 year, chemotherapy-refractory disease, and increased serum LDH at transplantation. Patients with any of these features had lower overall survival regardless of the type of transplant they received. Age, ${ }^{12}$ serum $\angle D H_{,}^{16}$ chemotherapy refractory disease, ${ }^{12,13,16,17}$ and bone marrow involvement ${ }^{10}$ have all been previously correlated with adverse outcome of autologous transplantation. In our prior report on allogeneic transplantation, patient age older than 40 years and chemotherapy refractory disease were associated with a worse outcome. ${ }^{27}$ Of note, neither disease histology (or llymphoma "grade," by World Health Organization [WHO] cllassification37), stem cell source (bone marrow versus peripheral blood stem cells), nor use of posttransplantation myeloid growth factors correlated with outcome in multivariate analysis.

The Dana-Farber group initially reported a correllation between outcome of transplantation and optimal purging of the stem cell product.38 In an update of their experience, patients receiving transplants of stem cell products devoid of lymphoma cells had up to $80 \%$ DFS at 8 years after transplantation. ${ }^{10}$ Those patients receiving cells that were contaminated with Iymphoma had a very high recurrence rate. These results are confirmed in some, ${ }^{14,39}$ but not all studies, ${ }^{8,12,13,33,40,41}$ and the clinical benefits of stem cell purging remain a matter of ongoing study. Our analysis is the first controlled comparison between the outcomes of purged versus unpurged transplantation in a large patient group. In multivariate analyses, an effect of stem cell purging on recurrence rates and overall survival was found. As indicated by the relapse curve, there is a decrease in early as well as late recurrences associated with purging. These data suggest that graft purging, even with current technical limitations, might be of clinical benefit in patients with follicular lymphoma undergoing autologous transplantation. This observation is consistent with our observation of a markedly reduced recurrence rate after syngeneic versus autologous transplantation in follicular lymphoma, because syngeneic transplantation may be considered the equivalent of an optimally purged autologous transplantation. ${ }^{42}$

Allogeneic transplantation was associated with a low early recurrence rate and near absence of documented recurrences beyond 1 year after transplantation. The lack of late recurrences confirms the curative potential of allogeneic transplantation. Whether cure results from graft-versus-lymphoma (GVL) effects $^{28,43-48}$ or from the complete eradication of tumor by high-dose chemotherapy followed by infusion of uncontaminated stem cells (a "purging" effect) 10,42 or from a combination of both is unclear. In the current study, we were unable to detect a GVL effect of either acute or chronic GVHD. Because 
of sample size limitations, is possible we lacked the power to detect such an effect.

The use of TBI was associated with increased TRM, but with decreased recurrence rates. In our previous analysis of allogeneic transplantation for follicular lymphoma, the use of TBI was associated with an improved outcome. ${ }^{27}$ By contrast, a European analysis of patients undergoing autologous transplantation indicated a worse overall survival for patients with low-grade Iymphoma receiving $\mathrm{TBI}^{41}$ Although these data must be interpreted with caution, they may indicate that TBI is a highly effective although toxic treatment for follicular lymphoma. They may also suggest that less toxic methods of administration of radiation, perhaps in the form of radiolabeled antibodies, may improve transplantation outcomes. 49

Figures 6.5 and 6.6 show survival rates after autologous and allogeneic transplantation during successive 3-year periods. It is reassuring that, independent of other covariates, TRM after transplantation, particularly after allogeneic transplantation, declined over the past decade. This decline is probably related to selection of patients with more favorable characteristics, improvements in supportive care, and improvements in early diagnosis and treatment of opportunistic infections.

This analysis confirms that transplantation has its major benefit when performed early in the course of disease. Transplantation for refractory disease is associated with a dismal course and should probably be avoided. When comparing the patient characteristics of patients in this study with those of our previous report on allogeneic transplantation for low-grade lymphoma, it is apparent that this is the approach increasingly favored by most physicians. Patients in the current study had, on average, far less advanced disease than those in our previous report that included patients receiving transplants between 1985 and 1995 .

Whether to recommend autologous or allogeneic transplantation for patients who have an HLA-matched sibling donor remains, at present, a matter of physician and patient preference. We had hoped to identify variables that would have a differential effect on allogeneic versus autologous transplantation but were unable to do so. Adverse prognostic features had similar effects on long-term outcome of both allogeneic and autologous transplantation.

If autologous transplantation is performed, consideration should be given to the use of in vitro or in vivo stem cell purging. Novel in vitro purging methods continue to be explored and are of considerable interest. ${ }^{5,51}$ Data undicating that administration of rituximab results in highly efficient purging of peripheral blood stem cell products require testing in larger cohorts of patients.52 Whenever one recommends autologous transplantation, the considerable risk for secondary myelodysplastic syndrome (MDS) should be taken into account. ${ }^{34-36}$ Allogeneic transplantation has an increased risk of early TRM, but, 
as shown in Figure 6.5, survival has improved in recent years. In the most recent patient cohorts, 1-year survival after transplantation is approximately $80 \%$. The rapid development of new transplantation technologies may further reduce recurrence rates as well as TRM and, thus, affect the risk-benefit ratios of these procedures. Reduced intensity conditioning, which relies on graftversus-lymphoma effects, is one of the strategies currently under study. Our analysis failed to identify a beneficial effect of GVHD on the incidence of relapse, thus raising some concerns about the ultimate effect of reduced intensity conditioning. However, with highly effective high-dose conditioning, an otherwise effective GVL reaction may have been difficult to detect. A plethora of novel agents and approaches are now available or are under study for management of follicular lymphoma. These agents include rituximab, its radiolabeled equivalent ibritumomab, and other monoclonal antibodies, as well as vaccine approaches. High-dose chemotherapy and autologous and allogeneic transplantation constitute a different, but possibly complementary, approach. Future studies integrating various approaches might render curative therapy for all patients with follicular lymphoma a realistic goal. 


\section{References}

1. Armitage J0. Drug therapy: treatment of non-Hodgkin's lymphoma. N Engl $d$ Med $1993 ; 328: 1023-30$.

2. Portlock CS. Management of the low-grade non-Hodgkin's lymphomas Semin Oncol. $1990,17,51-9$.

3. Romaguera JE, McLaughlin $P_{i}$ North L, el al. Multivariate analysis of prognostic factors in stage JV follicular low-grade lymphomat a risk model. J Clin Oncol, 1991;9:762-9.

4. Horning s. Treaiment approaches to the lowgrade lymphomas. Blood. 1994;83:881-4.

5. Solal-Celigny $P$. Follicular lymphoma international prognostic project [abstract]. Ann Oncol. $2002 ; 13$ (suppl 2),54.

6. Horning SJ. Follicular lymphoma: have we made any progress? Ann Oncol. 2000;11(suppl 1):23-7.

7. Rohatiner A, Gregory W, Peterson B, et al. A meta-analysis of randomized trials evaluating the role of interferon as treatment for follicular lymphoma [abstract]. Proc Am Soc Clin Oncol. $1998: 17: 11$.

8. Ladetto $M_{i}$ Corradini $P$, Vallet $S$, et al. High rate of clinical and molecular remissions in follicular lymphoma patients receiving high-dose sequential chemotherapy and autografting at dliagnosis: a muticenter, prospective study by the Gruppo Italiano Trapianto Midollo Osseo (GITMO): Blood 2002;100:1559-65.

9. Horning SJ, Negrin RS, Hoppe RT, et al. Highdose therapy and autologous bone marrow transplantation for follicular lymphoma in first complete or partial remission: results of a phase Il clinical trial. Blood. 2001;97:404-9.

10. Freedman AS, Neuberg $D$, Mauch $P$, et al. Longterm follow-up of autologous bone marrow transplantation in patients with relapsed follicular lymphoma. Blood. 1999;94:3325-33.

11. Rohatiner AZS, Johnson PWM, Price CGA, et al. Myeloablative therapy with autologous bone marrow transplantation as consolidation therapy for recurrent follicular lymphoma. $₫$ Clin Oncol. 1994:12:1177-84.

12. Bierman PJ, Vose JM, Anderson JR, Bishop MR, Kessinger A, Armitage JO. High-dose therapy with autologous hematopoietic rescue for follicular low-grade non-Hodgkin's lymphoma. J Clin Oncol 1997;15:445-50.

13. Bastion $Y$, Brice $P$, Haioun $C$, et al. Intensive therapy with peripheral blood progenitor cell transplantation in 60 patients with poor-prognosis follicular lymphoma. Blood. 1995;86: $3257-62$.

14. Fouillard $L$, Laporte JP, Labopin $M$, et al. Autologous stem-cell transplantation for nonHodgkin's lymphomas: the role of graft purging and radiotherapy posttransplantation-results of a retrospective analysis on 120 patients autografted in a single institution. J Clin Oncol. $1998 ; 16: 2803-16$

15. Colombat $P$, Donadio $D_{1}$, Fouillard $L_{\text {n }}$ et al. Value of autologous bone marrow transplantation in follicular Iymphoma: a France Autogreffe retrospective study of 42 patients. Bone Marrow Transplant. 1994:13:157-62.

16. Cervantes $F$. Shu $X O$, McGlave $\mathrm{PB}$, ef al. Autologous bone marrow transplantation for nontransformed low-grade non-Hodgkin's tymphoma. Bone Marrow Transplant. 1995;16:387-92.

17. Vaso MT, Martin S, Hohaus S, et al. Prognostic factors for the clinical outcome of patients with follicular fymphoma following high-dose therapy and peripheral blood stem cell transplantation (PBSCT). Bone Marrow Transplant. 2000;25:957-64.

18. Apostolidis J, Gupta RK, Grenzelias D, et al. High-dose therapy with autologous bone marrow support as consolidation of remission in follicular lymphoma: Iong-term clinical and molecular follow-up. J Clin Oncol. 2000:18:527-36.

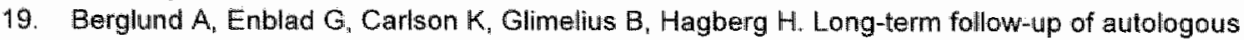
stem cell transplantation for follicular and transformed follicular lymphoma. Eur $\mathrm{J}$ Haematol. $2000 ; 65: 17-22$ 


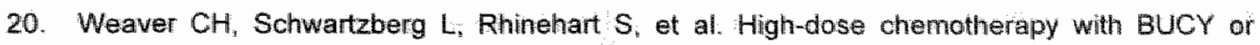
$B E A C$ and unpurged peripheral blood stem cell infusion in patients with low-grade non* Hodgkin's lymphoma. Bone Marrow Transplant. 1998;21:383-9.

21. Brice $P$, Simon $D$, Bouabdallah $R$, et al. Highdose therapy with autologous stem-cell transplantation. (ASCT) after first disease prolonged surviwal of follicular lymphoma patients included in the prospective GELF 86 protocol. Ann Oncol. 2000;11:1585-90.

22. Hunault-Berger $M_{i}$ Ifrah $N$, Solal-Celigny $P$. Intensive therapies in follicular non-Hodgkin lymphomas. Blood: 2002;100:1141-52.

23. Aftal $M$, Socie $G$, Molina $L$, et al. Allogeneic bone marrow transplantation for refractory and recurrent follicular lymphoma: a case-matched analysis with autologous transplantation from the French bone marrow transplant group registry data [abstract]. Blood. 1997;90(suppl 1):255a.

24. Verdonck LF, Dekker AW, Lokhorst HM, Petersen EJ, Nieuwenhuis HK. Allogeneic versus autollogous bone marrow transplantation for refractory and recurrent low grade non Hodgkin's lymphoma. Blood. 1997;90:4201-5.

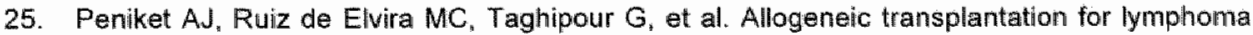
produces a lower relapse rate than autologous transplantation but survival has not risen because of higher treatment-related mortality-a report of 764 cases from the EBMT lymphoma registry [abstract]. Blood. 1997;90(suppl 1):255a.

26. van Besien KW, Khouri IF, Giralt SA, et al. Allogeneic bane marrow transplantation for refractory and recurrent low grade lymphoma--the case for aggressive management. $J$ Clin Oncol. 1995;13:1096-102.

27. van Besien $K_{n}$ Sobacinski $K_{n}$ Rowlings $P$, et al. Allogeneic bone marrow transplantation for lowgrade lymphoma. Blood. 1998;92:1832-6.

28. Khouri IF. Saliba RM, Giralt SA, et al. Nonablative allogeneic hematopoietic transplantation as adoptive immunotherapy for indolent lymphoma: low incidence of toxicity, acute graftversus-host disease, and treatment-related mortality. Blood. 2001:98:3595-9.

29. Toze $\mathrm{Cl}$, Shepherd $\mathrm{JD}$, Connors $\mathrm{JM}$, et al. Allogeneic bone marrow transplantation for lowgrade tymphoma and chronic lymphocytic leukemia. Bone Marrow Transplant. 2000;25: 605-12.

30. Cull $G M$, Haynes $A P$, Byrne $J L$, et al. Preliminary experience of allogeneic stem cell transplantation for lymphoproliferative disorders using BEAMCAMPATH conditioning: an effective regimen with low procedure-rellated toxicity. Br J Haematol. 2000;108:754-60.

31. Mandigers CM, Raemaekers JM, Schattenberg AV, at Allogeneic bone marrow transplantation with T-cell-depleted marrow grafts for patients with poor-risk relapsed lowgrade non-Hodgkin"s lymphoma. Br J Haematol. 1998;100:198-206.

32. Stein RS, Greer JP, Goodman S, Kallianpur A, Ahmed MS, Wolff SN. High-dose therapy with autologous or allogeneic transplantation as salvage therapy for small-cleaved cell lymphoma of follicular center cell origin. Bone Marrow Transplant. 1999;23:227-33.

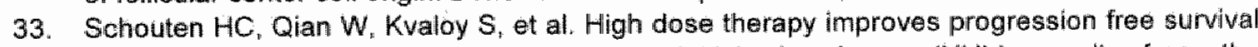
and survival in relapsed follicular non-Hodgkin's lymphoma (NHL): results from the randomized European CUP trial. J Clin Oncol. In press.

34. Friedberg JW. Neuberg $D_{\text {. }}$ Stone RM, al. Outcome in patients with myelodysplastic syndrome after autologous bone marrow transplantation for non-Hodgkin's lymphoma. J Clin Oncol. 1999:17:3128-35.

35. Traweek ST, Silovak ML, Nademanee AP, Brynes RK, Niland JC, Forman S. Myelodysplasia and acute myeloid leukemia occurring after autologous bone marrow transplantation for Iymphoma. Leuk Lymphoma. 1996;20:365-72

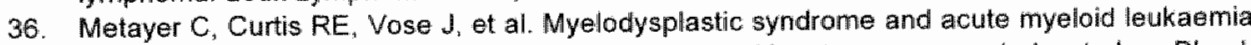
after autotransplantation for lymphoma: a multicenter case-control study. Blood. 2003:101:2015-23.

37. Jaffe ES, Harris NL, Stein H, Vardiman JW. Pathology and genetics of tumours of haematopoietic and lymphoid tissues. In: Kleihues $P$, Sobin LH, eds. World Health Organization Classification of Tumours. Lyon, France: IARC Press; 2001:1-35\%. 
38. Gribben JC, Freedman AS, Neuberg D, el al. limmunotogic purging of marrow assessed by $\mathrm{PCR}$ before autologous bone marrow transpiantation for B-cell tymphoma. $\mathrm{N}$ Engl $J$ Medl. $1991 ; 325: 1525-33$

39. Corradini $P$, Astoffi $M_{*}$ Cherasco $C$, et al Molecular monitoring of minimal residual disease in follicifar and mantte cell non-Hodgkin's lymphomas treated with high-dose chemotherapy and peripheral blood progenitor cell autografting. Blood. 1997:89:724-31.

40. Johnson PWM ${ }_{i}$ Price CGA, Smith $T$, et al. Detection of cells bearing the $t(14 ; 18)$ translocation following myeloablative treatment and witologous bone marrow transplantation for follicular lymphoma. J Clin Oncol: 1994,12:798-805.

41. Willams $\mathrm{CD}$, Goldstone $\mathrm{AH}$, Pearce $\mathrm{RM}_{1}$ et al. Purging of bone marrow in autologous bone marrow tranisplantation for non-Hodgkin's lymphoma: a case-matched comparison with unpurged cases by the European Blood and Marrow Transplant Lymphoma Registry. $\mathrm{J}$ Clin Oncol 1996;14:2454-64.

42. Bierman PJ, Sweetenham JW, Loberiza FM, et al. Syngeneic hematopoietic stem cell transplantation for non-Hodgkin's lymphoma (NHL): comparison with allogeneic and autologous trainsplants suggests a role for purging [abstract]. ASCO Proc. 2001;20:187.

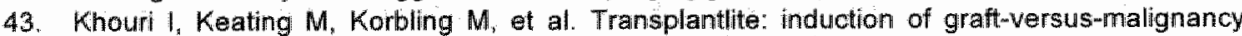
using fludarabine-based nonablative chemotherapy and allogeneic blood progenitor-cell transplantation as treatment for lymphoid malignancies. J Clin Oncol. 1998;16:2817-24.

44. van Besien $K W$, de Lima $M$, Giralt $S A$, et al. Management of lymphoma recurrence after allogeneic transplantation: the relevance of graftversus-lymphoma effects. Bone Marrow Transplant. 1997;19:977-82.

45. Corradini $P$, Talella $C$. Olivieri $A$, al. Reducedintensity conditioning followed by allografting of hematopoietic cells can produce clinicall and molecular remissions in patients with poor-risk heimatologic malignancies. Blood. 2002;99:75-82.

46. Mohty $\mathrm{M}_{1}$ Fegueux $\mathrm{N}_{\mathrm{i}}$ Exbrayat $\mathrm{C}$, at al. Reduced intensity conditioning: enhanced graftversustumor effect following dose-reduced conditioning and allogeneic transplantation for refractory lymphoid malignancies after high-dose therapy. Bone Marrow Transplant. $2001 ; 28: 335-9$

47. McSweeney PA, Niederwieser D, Shizuru JA, et al. Hematopoietic cell transplantation in older patients with hematologic malignaricies: replacing high-dose cytotoxic therapy with graftversustumor effects. Blood. 2001;97:3390-400.

48. Mandigers $C_{t}$ Meijerink $J P$, Raemaekers $J M$, Schattenberg $A$, Mensink EJ. Graft vs lymphoma effect of donor leucocyte infusions shown by realtime quantitative PCR analysis of $1(14: 18)$. Lancet. 1998;352:1522-3.

49. Press OW, Eary JF, Gooley T, et al. A phase I/II trial of iodine-131-tositumomab (anti-CD20) etoposide; cyclophosphamide, and autologous stem cell transplantation for relapsed B-cell lymphomas. Bloodl. 2000;96:2934-42.

50. Vose $\mathrm{JM}$, Bierman PJ, Lynch $\mathrm{JG}_{\text {n }}$ at al. Transplantation of highly purified CD34 + Thy-1 + hembtopaietic stem cells in patients with recurrent indolent nan-Hodgkin's lymphoma. Biol Blood Marrow Transplant. 2001;7:680-7.

51. Koehl U, Zimmermann $S$, Esser $R$, et al. Autologous transplantation of CD133 selected henuatopoietic progenitor cells in a pediatric patient with relapsed leukemia. Bone Marrow Transplant. 2002;29:927-30

52. Magini $M$, Di Nicola $M$, Devizzi $L$, et al. Successful in vivo purging of CD34-containing peripheral blood harvests in mantle cell and indolent lymphoma: evidence for a rolle of both chemotherapy and rituximab infusion. Blood. 2000,96:864-9. 


\section{Chapter 7}

Myeloablative allogeneic hematopoietic stem cell transplantation in patients who experience relapse after autologous stem cell transplantation for lymphoma: a report of the international bone marrow transplant registry

CO Freytes, FR Loberiza, JD Rizzo. A Bashey, CN Bredeson, MS Cairo, RP Gale, MM Horowilz, TR Klumpp, R Martino, PL McCarthy, A Molina, S Pavlowsky, AL Pecora, DS Serna, T Tsai, MJ Zhang, JM Vose, HM Lazarus, $K$ van Besien 


\section{Abstract}

Myeloablative allogeneic hematopoietic stem cell transplantation (allo-HSCT) is increasingly used in patients with lymphoma who experience disease relapse after autologous hematopoietic stem cefl transplantation (auto-HSCT) because the allograft is tumor free and may induce a graft-versustumor effect. We analyzed 114 patients treated with this approach from 1990 to 1999 to assess diseage progression, progression-free survival (PFS), and overall survival (OS). Cumulative incidence of disease progression at 3 years was $52 \%$, whereas treatment related mortality was $22 \%$, lower than previously reported. Three-year probabilities of OS and PFS were $33 \%$ and $25 \%$, respectively. With prolonged follow-up, however, nearly all patients experienced disease progression, and 5-year probabilities were $24 \%$ and $5 \%$, respectively. Complete remission at the time of allo-HSCT and use of total body irradiation (TBI) in patients with non-Hodgkin lymphoma (NHL) were associated with lower rates of disease progression and higher rates of OS. In summary, allo-HSCT is feasible for patients with lymphoma who have relapses after auto-HSCT and can result in prolonged survival for some, but it is usually not curative. Most likely to benefit are patients who have HLA-matched sibling donors, are in remission, and have good performance status. 


\section{Introduction}

High-dose chemotherapy with autologous hematopoietic stem cell transplantation (auto-HSCT) has an established role in the treatment of patients with lymphoid malignancies. ${ }^{1-3}$ Unfortunately, relapse or progression of lymphoma is common after auto-HSCT, and the prognosis for patients who experience relapse is poor. ${ }^{4-6}$ Conventional-dose chemotherapy can induce remission in a small proportion of these patients, but the remissions are usually short. ${ }^{4}$ Second auto-HSCT is sometimes performed, but it is most likely to benefit patients in prolonged remission after the initial auto-HSCT. 7,8

Another therapeutic approach for patients who experience relapse after autoHSCT is to perform myeloablative allogeneic hematopoietic stem cell transplantation (allo-HSCT) ${ }^{9}$ Potential advantages of allo-HSCT include the use of a tumor-free graft and immune-mediated graft-versus-tumor effects. ${ }^{10,11}$ Information is limited regarding the outcome for patients who undergo alloHSCT after autologous transplantation for lymphoma fails. Published reports include small numbers of patients and show conflicting results. ${ }^{8.12-17}$ To more precisely determine outcomes and to further identify prognostic variables for patients who undergo allo-HSCT after failed auto-HSCT, we undertook an analysis of patients treated between 1990 and 1999 and reported to the International Bone Marrow Transplant Registry (BMTR) and the Autologous Blood and Marrow Transplant Registry (ABMTR).

\section{Patients and methods}

\section{Data sources}

The IBMTR/ABMTR is a voluntary working group of more than $400 \mathrm{HSCT}$ centers worldwide that contribute detailed data on consecutive allogeneic or autologous HSCT recipients to a Statistical Center at the Health Policy Institute of the Medical College of Wisconsin in Milwaukee. Approximately $40 \%$ of alloHSCTs worldwide and more than $50 \%$ of auto-HSCTs in North and South America are registered with the IBMTR/ABMTR. Participating centers are required to report all transplantations consecutively; compliance is monitored by on-site audits. Patients are followed up longitudinally, with yearly follow-up. Computerized checks for errors, physician reviews of submitted data, and onsite audits of participating centers ensure data quality. Requests for data on disease progression or death for registered patients are at 1-year intervals. IBMTR observational studies are conducted with a waiver of informed consent 
and in compliance with HIPAA regulations as determined by the institutional review board and the privacy officer of the Medical College of Wisconsin.

\section{Patients}

We reviewed the records of all patients with lymphoma reported to the IBMTR/ABMTR who underwent allo-HSCT after relapse from auto-HSCT. We included patients with Hodgkin lymphoma (HL) or non-Hodgkin lymphoma (NHL), including low-, intermediate-, and high-grade lymphomas according to the Working Formulation for the Classification of Lymphomas. ${ }^{8}$ The allo-HSCT had to have been performed between 1990 and 1999. Patients who received nonmyeloablative conditioning regimens were excluded.

\section{Study end points}

Primary outcomes studied were disease progression, progression-free survival (PFS), and overall survival (OS). Progression was defined as any increase in size of sites of disease, development of new sites of disease, or recurrence of disease after an initial complete response. OS was defined as the time from transplantation to death from any cause. PFS was defined as time from transplantation to relapse, progressive disease, or death from any cause. Other outcomes examined were transplant-related mortality (TRM), defined as death from any cause in the first 28 days or, thereafter, death without progression, and the incidence and severity of acute and chronic graft-versus-host disease (GVHD). Acute GVHD was defined as moderate to severe (grades II-IV) using established criteria; patients surviving more than 21 days with evidence of engraftment were considered at risk. Chronic GVHD was determined by clinical criteria in patients surviving more than 90 days with evidence of engraftment.

\section{Statistical analysis}

Probabilities of OS and PFS were calculated using the Kaplan-Meier product limit estimate, and probabilities of progression, TRM, and acute and chronic GVHD were calculated using cumulative incidence to allow for competing risks. Associations between patient-, disease-; and transplantrelated factors and the outcomes of interest were assessed using multivariate cox proportional hazards regression. Variables included in the model building are listed in Table 7.1. For most patients, we had few data about details of auto-HSCT or treatment before auto-HSCT and, hence, could not examine these factors in model building. $\mathrm{HL}$ and NHL are different biologically ${ }_{i}$ and initial treatment for HL commonly involves radiation, limiting the choices for allo-HSCT conditioning in HL. Consequently, we forced the factor HL versus NHL in all the models built and examined interactions between this factor and other significant covariates 
identified. If the interaction term was significant, indicating differential effects in $\mathrm{HL}$ and NHL, the final model subdivides patients according to this interaction term. For example, Tables 7.4,7.5, and 7.6 subdivide patients into 4 groups: NHL with or without total body irradiation (TBI) and $\mathrm{HL}$ with or without TBI. All computations used the procedure PHREG in the SAS statistical package. Forward stepwise variable selection at a 0.05 significance level was used to identify covariates associated with outcomes. All variables were tested for the assumption of proportional hazards using a time-dependent covariate. All variables satisfied the proportionality assumption. First-order interactions were tested for all significant covariates. Overall covariate effects were tested using the Wald test.

\section{Results}

\section{Patient and transplant characteristics}

Patient-, disease-, and transplant-related characteristics are listed in Table 7.1. One hundred fourteen patients from 54 different centers underwent allo-HSCT foliowing relapse after auto-HSCT. Their median age at the time of allo-HSCT was 34 years (range, $15-65$ years). Sixty-five (57\%) patients were male. Fifty (44\%) patients had Karnofsky performance scores of $80 \%$ or less at the time of allo-HSCT.

Seventy-nine $(69 \%)$ patients had NHL, and $35(31 \%)$ had $\mathrm{HL}$. Among patients with $\mathrm{NHL}, 44(56 \%)$ had intermediate-grade, $16(20 \%)$ had low-grade, and 8 $(10 \%)$ had high-grade lymphomas; $11(14 \%)$ had other types of NHL not defined in the Working Formulation. ${ }^{18}$

The median time interval from diagnosis to auto-HSCT was 14 months (range, 3-130 months). Forty-three (38\%) patients underwent auto-HSCT less than 1 year after the diagnosis of lymphoma. The median interval between auto-HSCT and allo-HSCT was 16 months (range, 2-66 months). Only 24 (21\%) patients were in complete remission at the time of allo-HSCT. Seventy $(61 \%)$ patients received transplants from an HLA-identical sibling, $17(14 \%)$ from a haploidentical sibling, and $27(25 \%)$ from an unrelated donor. Seventy-seven $(68 \%)$ patients received bone marrow as the source of allogeneic stem cells; the remaining $37(32 \%)$ patients received peripheral blood. TBI was used as part of the conditioning regimen for allo-HSCT in $45(39 \%)$ patients. Eighty-four $(74 \%)$ patients received hematopoietic growth factors (HGFs) within 7 days of allo-HSCT. GVHD prophylaxis included methotrexate and cyclosporine in 74 $(65 \%)$ patients, combinations of cyclosporine with other agents in $24(21 \%)$ patients, and T-cell depletion of the graft in $16(14 \%)$ patients. 
Table 7.1 Patient-, disease-, and transplantrelated characteristics of patients with HL or NHL who underwent allo-HSCT following relapse after autologous transplantation, 1990 to 1999, reported to IBMTR.

\begin{tabular}{|c|c|}
\hline Variables & $N(\%)^{\mathrm{a}}$ \\
\hline $\mathbb{N}$ & 114 \\
\hline Age, y, median (range) & $34(15-65)^{b}$ \\
\hline Male & $65(57)$ \\
\hline \multicolumn{2}{|l|}{ Kannofsky performance score at allo-HSCT } \\
\hline $90 \%-100 \%$ & $64(56)$ \\
\hline $80 \%$ & $29(25)$ \\
\hline $70 \%$ & $16(14)$ \\
\hline$\therefore \quad \cdots$ & $2(2)$ \\
\hline $50 \%$ or lower & $3(3)$ \\
\hline \multicolumn{2}{|l|}{ Disease type } \\
\hline NHL & $79(69)$ \\
\hline Low grade & $16(20)$ \\
\hline Intermediate grade & $44(56)$ \\
\hline High grade & $8(10)$ \\
\hline Otheri & $11(14)$ \\
\hline HL & $35(31)$ \\
\hline Interval from diagnosis to first, autologous transplantation, mo, median (range) & $14(3-130)^{6}$ \\
\hline 12 or less & $43(38)$ \\
\hline More than 12 & $71(62)$ \\
\hline Interval from auto-HSCT to allo-HSCT, mo, median (range) & $16(2-66)^{b}$ \\
\hline 12 or less & $44(39)$ \\
\hline More than 12 & $70(61)$ \\
\hline \multicolumn{2}{|l|}{ Disease staltus before allo-HSCT } \\
\hline Complete remission & $24(21)$ \\
\hline Relapse or persistent disease, chemosensitive & $39(35)$ \\
\hline Relapse or persistent disease, chemoresistant & $23(20)$ \\
\hline Relapse or persistent, untreated after atuto-HSCT & $28(24)$ \\
\hline \multicolumn{2}{|l|}{ Donor type for allo-HSCT } \\
\hline HLA-identical sibling & $70(61)$ \\
\hline Haploidentical sibling & $17(14)$ \\
\hline Unirelated & $27(25)$ \\
\hline \multicolumn{2}{|l|}{ Graft type used for allo-HSCT } \\
\hline Bone marrow & $77(68)$ \\
\hline Perlpheral blood & $37(32)$ \\
\hline TBI for allo-HSCT & $45(39)$ \\
\hline Posttransplantation use of growth factors, within $7 \mathrm{~d}$ & $84(74)$ \\
\hline \multicolumn{2}{|l|}{ GVHD prophylaxis } \\
\hline MTX + CSA t others & $74(65)$ \\
\hline CSA \pm others & $24(21)$ \\
\hline T-cell depletion \pm others & $16(\| 4)$ \\
\hline \multicolumn{2}{|l|}{ Years of allo-HSCT } \\
\hline $1990-1996$ & $56(49)$ \\
\hline $1997-1999$ & $58(51)$ \\
\hline No. centers reporting & 54 \\
\hline Follow-up time of survivors, mo, median (range) & $43(3-89)^{b}$ \\
\hline 75th percentile & 21 \\
\hline 25th percentle & 58 \\
\hline
\end{tabular}

$M T X=$ methotrexate; $\mathrm{CSA}=\mathrm{cyclosporine;} \mathrm{Categorical} \mathrm{variable;}{ }^{\circ}$ Continuous variable; " Includes NHL composite, mantle cell, and peripheral T-cell lymphomas. 
Fifty-eight $(51 \%)$ allo-HSCTs were performed in the 3 years between 1997 and 1999, whereas the remaining procedures were performed in the previous 7 years, 1990 to 1996 . Median follow-up of survivors was 43 months.

\section{Outcomes}

Estimated outcomes are summarized in Table 7.2. Of the 114 patients studied, $79(69 \%)$ died, $31(27 \%)$ were alive with lymphoma, and $4(4 \%)$ were alive without evidence of lymphoma at last follow-up. The 100-day mortality rate was $21 \%(95 \%$ confidence interval [ $95 \% \mathrm{Cl}], 14 \%-29 \%)$. TRM after allo-HSCT was $22 \%(95 \% \mathrm{Cl}, 16 \%-31 \%)$ at 1 year and $25 \%(95 \% \mathrm{Cl}, 17 \%-33 \%)$ at 5 years. Twenty-four of $90(27 \%)$ patients not in complete remission at the time of alloHSCT achieved complete remission after allo-HSCT.

Table 7.2 Outcome probabilities.

\begin{tabular}{lccccc}
\hline & $100 d$ & $1 y$ & $3 y$ & $5 y$ \\
\hline Grade II-IV acute GVHD $^{\mathrm{a}}$ & $29(21-37)$ & - & - & - \\
Chronic GVHD $^{\mathrm{a}}$ & - & $11(6-18)$ & $12(7-20)$ & $13(7-20)$ \\
TRM $^{\mathrm{a}}$ & $21(14-29)$ & $22(16-31)$ & $22(16-31)$ & $25(17-33)$ \\
Progression $^{3}$ & - & $45(36-54)$ & $52(43-61)$ & $70(61-76)$ \\
Progression-free survival $^{\mathrm{b}}$ & - & $32(24-41)$ & $25(18-33)$ & $5(2-10)$ \\
Survival $^{\mathrm{b}}$ & - & $37(28-46)$ & $33(24-42)$ & $24(14-37)$ \\
\hline
\end{tabular}

Values in parentheses represent $95 \% \mathrm{Cl}$; - indicates not applicable; ${ }^{\text {a }}$ Cumulative incidence rate;

Kaplan-Meier estimate.

Disease-progression rate was $45 \%(95 \%, \mathrm{Cl}, 36 \%-54 \%)$ at 1 year and increased to $70 \%(95 \% \mathrm{Cl}, 61 \%-76 \%)$ at 5 years after transplantation. Figure 7.1 illustrates the cumulative incidences of progression and TRM. The probability of OS at 11 year was $37 \%(95 \% \mathrm{Cl}, 28 \%-46 \%)$ and decreased to $33 \%(95 \% \mathrm{Cl}, 24 \%-42 \%)$ at 3 years and $24 \%(95 \% \mathrm{Cl}, 14 \%-37 \%)$ at 5 years after transplantation (Figure 7.2). PFS was 32\% (95\% Cl, 24\%-41\%), 25\% $(95 \% \mathrm{Cl}, 18 \%-33 \%)$, and $5 \%(95 \% \mathrm{Cl}, 2 \%-10 \%)$ at 1,3, and 5 years after transplantation, respectively.

The 100-day probability of developing grades II to IV acute GVHD was $29 \%$ $(95 \% \mathrm{Cl}, 21 \%-37 \%)$. The 3-year probability of developing chronic GVHD was $12 \%(95 \% \mathrm{Cl}, 7 \%-20 \%)$. There was no difference in the risk for disease progression between patients who developed grades II to IV acute GVHD and those who did not. For patients who experienced engraftment and survived at least 21 days ( $n=99$ ), the relative risk (RR) of disease progression for patients with grades $\|$ to IV acute GVHD compared with those without acute GVHD using time-dependent Cox models was $0.93(95 \% \mathrm{Cl}, 0.58-1.49 ; \quad P=0.76)$. Additionally, there was no difference in the risk for progression between patients in whom chronic GVHD developed and those in whom it did not among 
patients who experienced engraftment and survived at least 90 days $(n=62)$, with an $\mathrm{RR}$ of $\left.0.81(95 \% \mathrm{Cl}, 0.40-1.67)^{\circ} \mathrm{P}=0.57\right)$. There were no differences in OS, PFS, or TRM between patients with HL and NHL. In addition, there were no differences in outcome among patients with low-. intermediate-, or highgrade $\mathrm{NHL}$ (data not shown).

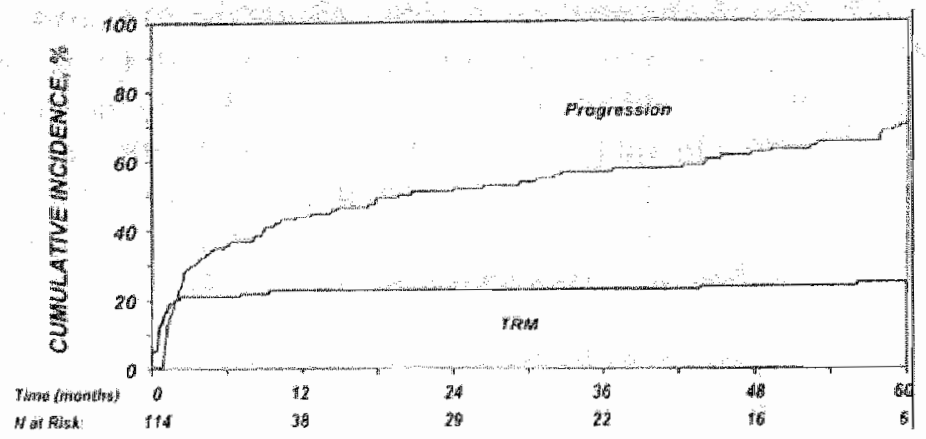

Figure 7.1 Cumulative incidences of TRM and disease progression after allo-HSCT in patients who experience relapse after auto-HSCT for HL or NHL.

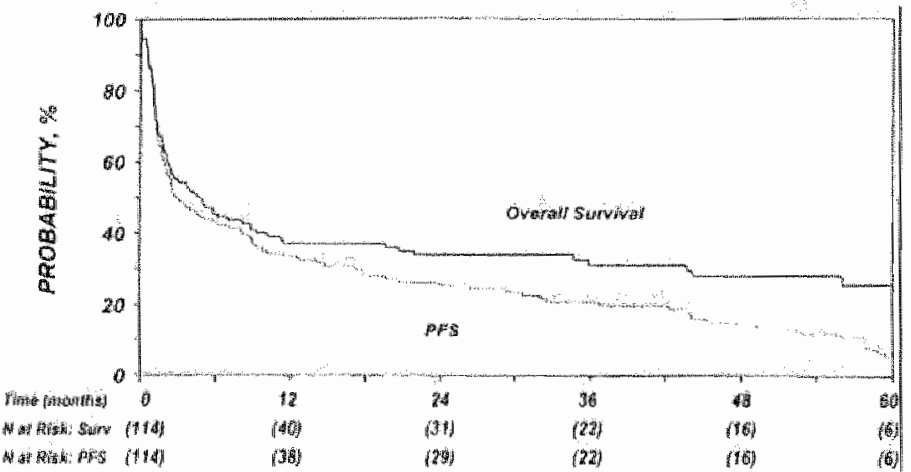

Figure 7.2 Probabilities of PFS and OS after allo-HSCT in patients who experience relapse after auto-HSCT for HL or NHL

\section{Multivariate analysis}

The only factor signifficantly correlated with TRM risk was donor type. Patients with haploidentical sibling donors had a 3 -fold increased risk for TRM (RR, $3.17 ; 95 \% \mathrm{Cl}, 1.04-3.31 ; P=0.02)$, and those with unrelated donors had a 2 -fold increased risk for TRM (RR, 2.15;95\% Cl, 0.90-5.12; $P=0.08$ ) compared with recipients of transplants from HLA-identical siblings. 
Table 7.3 shows the multivariate analysis of disease progression. Rate of disease progression was associated with type of conditioning regimen and disease status at allo-HSCT. The effect of conditioning was dependent on the type of lymphoma. Patients with NHL who underwent non-TBI-conditioning HSCT had a 3 -fold increased rate of disease progression compared with patients who received TBI. Patients with $\mathrm{HL}$ had an increased rate of recurrence compared with the risk in NHL patients receiving TBI. However, among $\mathrm{HL}$ patients, we failed to detect any effect of $T B \mathrm{Bl}$ on recurrence. Patients who had active disease before allo-HSCT also had an increased rate of progression compared with patients who underwent transplantation while in remission. Using patients in complete remission as the reference group, the RR for progression ranged from 1.38 for patients with chemosensitive relapse to 2.90 for patients with chemotherapy-refractory relapse and 3.45 for patients with untreated relapse.

Table 7.3 Multivariate analysis of progression.

\begin{tabular}{|c|c|c|}
\hline Variables & $\begin{array}{c}\text { RR of progression } \\
(95 \% \mathrm{Cl})\end{array}$ & $P$ \\
\hline Disease type and use of TBI & & $0.002^{b}$ \\
\hline NHL with $T B I_{1} n=37$ & 1.00 & - \\
\hline NHL no TBI, $n=42$ & $3.02(1.71-5.32)$ & $<0.001$ \\
\hline HL with TBI, $n=8^{a}$ & $2.18(0.86-5.52)$ & 0.10 \\
\hline HL no TBI, $n=27$ & $2.15(1.14-4.05)$ & 0.02 \\
\hline Disease status before second transplantation & & $<0.004^{13}$ \\
\hline Complete remission, $n=24$ & 1.00 & - \\
\hline Relapse/primary induction failure, chemosensitive, $n=39$ & $1.38(0.77-2.46)$ & 0.28 \\
\hline Relapse/primary induction failure, chemoresistant, $n=23$ & $2.90(1.38-6.08)$ & 0.005 \\
\hline Relapse/primary induction failure, untreated, $n=28$ & $3.45(1.74-6.87)$ & $<0.001$ \\
\hline
\end{tabular}

- Indicates not applicable; "Pairwise comparison: HL with TBI versus HL with no TBI $(P=0.93) ;{ }^{b} 3$ degrees of freedom test.

Table 7.4 shows the multivariate analysis of PFS (treatment failure, death, or progression), Patients with NHL who received non-TBI conditioning for alloHSCT had an approximately 2.5 -fold increased rate of treatment failure compared with patients who received TBI. Patients with $\mathrm{HL}$ had a higher rate of treatment failure than did patients with $\mathrm{NHL}$ who received TBI. However, among patients with $\mathrm{HL}$, there was no association between TBI and treatment failure. Patients who had active disease before allo-HSCT also had an increased rate of treatment failure compared with patients who underwent iransplantation in remission. Using patients in complete remission as the reference group, the relative risk for treatment failure ranged from 1.74 for patients with chemosensitive relapse to 3.91 for patients with chemotherapy 
refractory relapse and to 3.68 for patients with untreated relapse. Patients who received transplants from haploidentical siblings or from unrelated donors had a higher rate of treatment failure than those who received transplants from HLAidentical siblings.

Table 7.4 Multivariate analysis of PFS.

\begin{tabular}{|c|c|c|}
\hline Variables: & $\begin{array}{l}\text { RR of treatment } \\
\text { failure }(95 \% \mathrm{CD}) \\
\end{array}$ & $P$ \\
\hline Disease type and use of TBI: & & $0.002^{b}$ \\
\hline NHL with TBI, $n=37$ & 1.00 & - \\
\hline NHL no TBI, $n=42$ & $2.45(1.49-4.02)$ & $<0.001$ \\
\hline HL with $T B 1, n=8^{\text {a }}$ & $1.77(0.78-4.01)$ & 0.17 \\
\hline HL no TBI, $n=27$ & $1.97(1.14-3.41)$ & 0.01 \\
\hline Disease status before second transplantation & & $<0.001^{b}$ \\
\hline Complete remission, $n=24$ & 1.00 & - \\
\hline Relapse/primary induction fallure, chemosensitive, $n=39$ & $1.74(0.99-3.03)$ & 0.06 \\
\hline Relapse/primary induction failure, chemoresistant, $n=23$ & $3.91(2.05-7.44)$ & $<0.001$ \\
\hline Relapse/primary induction fallure, untreated, $n=28$ & $3.68(1.97-6.84)$ & $<0.001$ \\
\hline Donor type & & $0.05^{\mathrm{c}}$ \\
\hline HLA-identical sibling, $n=70$ & 1.00 & - \\
\hline Haploidentical sibling, $n=17$ & $1.85(1.04-3.31)$ & 0.04 \\
\hline Unrelated $n=27$ & $1.47(0.92-2.34)$ & 0.11 \\
\hline
\end{tabular}

Treatment failure indicates disease progression or death; - indicates not applicable; " painwise comparison: HL with TBI versus HL with no TBI $(P=0.82) ;{ }^{b} 3$ degrees of freedom test; ${ }^{\circ} 2$ degrees of freedom test.

Table 7.5 shows the multivariate analysis of overall mortality. Patients with NHL who received non-TBI conditioning for allo-HSCT had a 2-fold increased mortality rate compared with patients who received $\mathrm{TB}$. The mortality rate for patients with $\mathrm{HL}$ was similar to that of patients with $\mathrm{NHL}$ receiving TBI. Among patients with $\mathrm{HL}$, we failed to detect any association between TBl and mortality rate. Patients with low Karnofsky performance scores (80\%) at the time of alloHSCT died at an approximately 2 -fold increased rate. Patients who had active disease before allo-HSCT also had a higher mortality rate than did patients who underwent transplantation while in remission. Finally, the mortality rate was higher in patients who received transplants from haploidentical siblings or from unrelated donors than in patients who received transplants from HLAidentical siblings. Figures 7.3-7.6, and 6 show probabilities of OS according to the identified risk factors.

In summary, multivariate analyses showed that $T B \mid$ was associated with a decreased rate of disease progression and higher rates of PFS and OS in patients with NHL, but no such effect was shown in a smaller group of patients with HL. Chemotherapy responsiveness was also associated with decreased rate of disease progression and higher PFS and OS rates. Transplants from donors other than HLA-matched siblings were associated with higher TRM and 
lower PFS and OS rates, and good performance status was associated with higher OS rate.

Table 7.5 Multivariate analysis of ris for death.

\begin{tabular}{|c|c|c|}
\hline Variables & $\begin{array}{c}\text { RR of death } \\
(95 \% \mathrm{Cl})\end{array}$ & $\rho$ \\
\hline Disease type and use of TBI & & $0.001^{6}$ \\
\hline NHL with TBI, $n=37$ & 1.00 & - \\
\hline NHL no TBI, $n=42$ & $2.11(1.19-3.77)$ & 0.01 \\
\hline HL with $\mathbb{T B}$, $n=8^{\mathrm{a}}$ & $0.98(0.33-2.85)$ & 0.96 \\
\hline HL no $T B I_{1} n=27$ & $1.44(0.76-2.76)$ & 0.26 \\
\hline Karnofsky performance score at transplantation & & - \\
\hline $90 \%-100 \%, n=64$ & 1.00 & - \\
\hline $80 \%$ or less, $n=50$ & $1.76(1.10-2.82)$ & 0.02 \\
\hline Disease status before second transplantation & & $0.006^{\mathrm{b}}$ \\
\hline Complete remission, $n=24$ & 1.00 & $\longrightarrow$ \\
\hline Relapse/primary induction failure, chemosensitive, $n=39$ & $2.76(1.27-5.96)$ & 0.01 \\
\hline Relapse/primary induction failure, chemoresistant, $n=23$ & $3.95(1.70-9.15)$ & 0.001 \\
\hline Relapse/primary induction failure "untreated, $n=28$ & $3.74(1.67-8.41)$ & 0.001 \\
\hline Donor type & & $0.004^{\circ}$ \\
\hline HLA-identical sibling, $n=70$ & 1.00 & - \\
\hline Haploidentical sibling, $n=17$ & $2.40(1.24-4.66)$ & 0.009 \\
\hline Unrelated, $n=27$ & $2.14(1.24-3.68)$ & 0.006 \\
\hline
\end{tabular}

- Indicates not applicable " pairwise comparison: HL with TBI versus HL with no TBI $(P=0.47)^{\circ}{ }^{\circ} 3$ degrees of freedom test; " 2 degrees of freedom test.

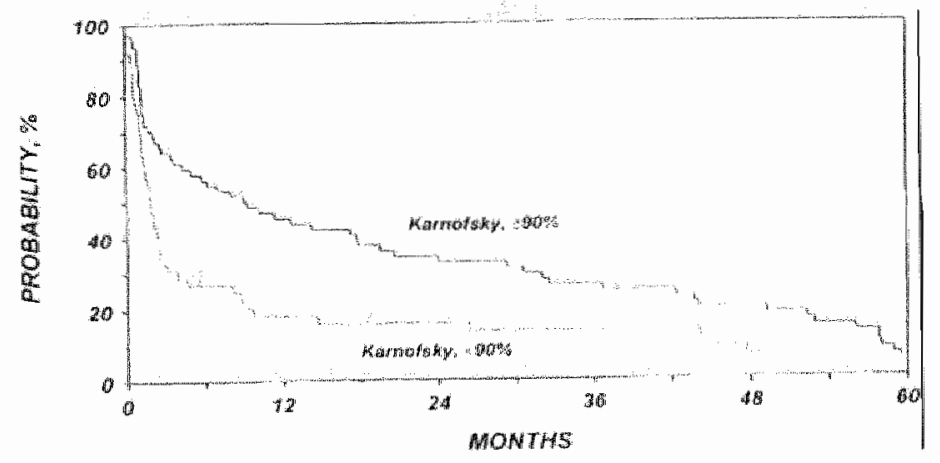

Figure 7.3 Probability of surviwal after allo-HSCT in patients who experience relapse after autoHSCT for $H L$ or NHL, accoirding to Karnofsky performance score at allo-HSCT. 


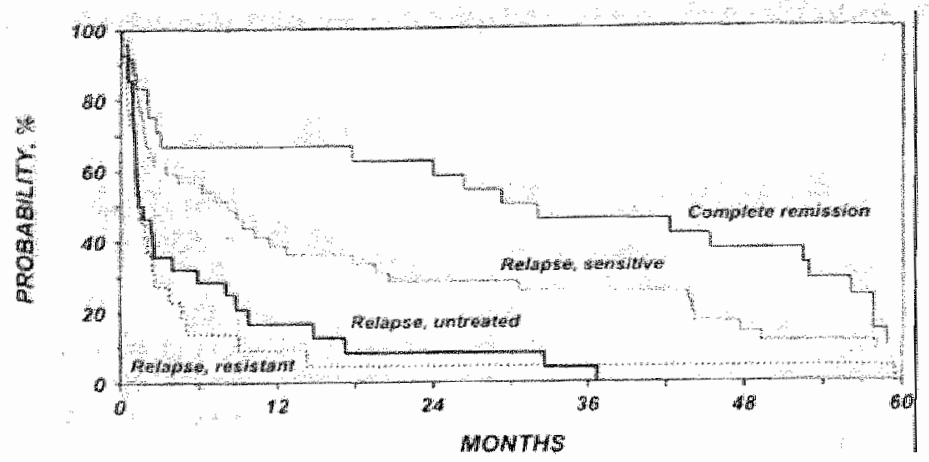

Figure 7.4 Probability of survival after allo-HSCT in patients who experience relapse after autoHSCT for HL or NHL according to disease status at allo-HSCT.

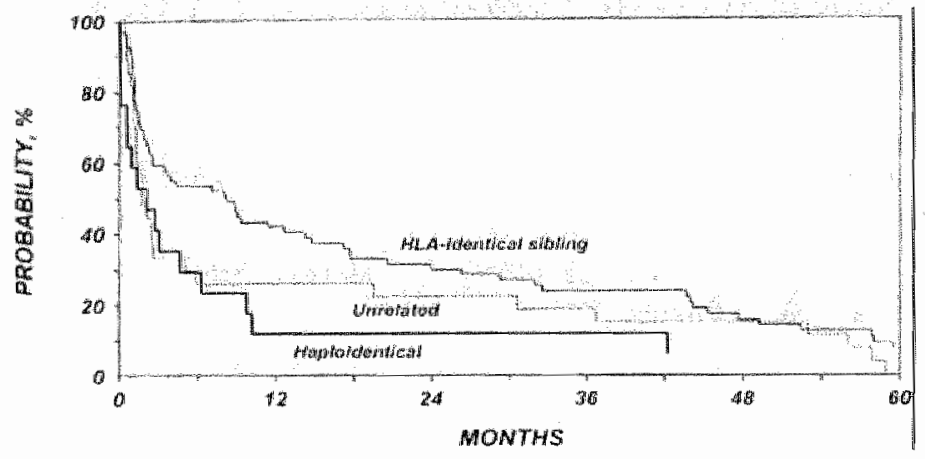

Figure 7.5 Probability of survival after allo-HSCT in patients who experience relapse after autoHSCT for HL or NHL according to type of donor.

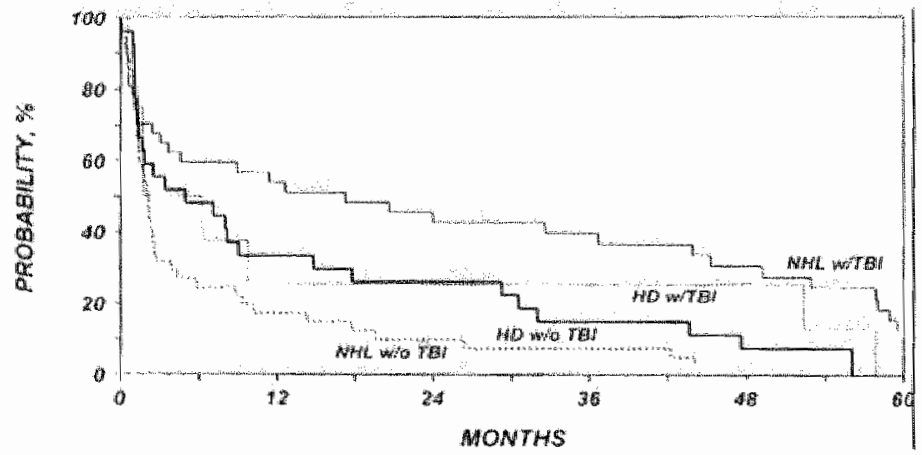

Figure 7.6 Probability of survival after allo-HISCT in patients who experience relapse after autoHSCT for HL or NHL according to disease type and use of TBI as part of conditioning regimen. NHL with TBI versus NHL with no TBI $(P=0,01)$. HL with TBI versus. HL with no TBI $(P=0.47)$. 


\section{Discussion}

Recurrence occurs relatively frequently after auto-HSCT for lymphoma, and managing patients who experience relapse is difficult: Allo-HSCT is increasingly used because it has the potential advantages of a graft-versustumor effect and a tumor-free graft. Despite increasing use, reports describing the results of allo-HSCT are few and include small numbers of patients. ${ }^{8,12-17}$ Identifying patient- or disease-related prognostic variables in a large group of patients undergoing allo-HSCT after failure of auto-HSCT was the major purpose of this analysis. We excluded patients who underwent nonmyeloablative therapy because this technique was introduced recently and the follow-up of patients receiving nonmyelaablative regimens has been short. Diverse lymphoma histology findings were included in this analysis, but most patients had $\mathrm{HL}$ or aggressive NHL.

The TRM rate was relatively low $(22 \%)$ and suggests that with current supportive care, allo-HSCT is feasible for this group of patients. This finding is in apparent contrast to results of several previous studies. Tsai et al. ${ }^{12}$ report $85 \%$ TRM among 14 patients. Radich et al. ${ }^{13}$ summarize the Seattle experience and report $78 \%$ TRM among patients with lymphoma at 2 years after second transplantation. Bierman et al. ${ }^{15}$ report 16 patients with a TRM rate of $44 \%$ at 100 days. Reports of other small studies also demonstrate high TRM rates. ${ }^{14,17}$ Possible explanations for the low TRM rate in our report compared with previous ones include changes in patient selection over time and improvements in supportive care over the past decade. All patients included in our analysis underwent transplantation after 1990, and half underwent transplantation between 1997 and 1999. The reports by Tsai et al. ${ }^{12}$ and by Radich et al. ${ }^{13}$ include considerable numbers of patients who underwent transplantation before 1990, when growth factor support, prevention and management of opportunistic cytomegalovirus (CMV) infections, and donor selection strategies based on high-resolution HLA typing were less optimal. In addition, 15 of 18 patients reported by Radich et al. ${ }^{13}$ had active disease at the time of transplantation, and 7 had HLA-mismatched or unrelated donors, features that in our current study are associated with high risk for TRM. Three of the 14 transplantations in the series by Tsai et al. ${ }^{12}$ also involved donors other than HLA-matched siblings. By contrast, in the small series by de Lima et al., ${ }^{8}$ most patients had chemotherapy-responsive disease and HLA-matched sibling donors. Three of 5 patients in that series obtained durable remissions. Our data are also in agreement with those of Seropian et al. ${ }^{19}$ who recently reported a $55 \%$ PFS rate among 11 patients undergoing allo-HSCT after previous auto-HSCT failed. The comparatively low TRM in our report may also be partly explained by methodological differences from other studies, such as the use of cumulative incidence rather than Kaplan-Meier estimates. 
Although TRM was within acceptable limits for allo-HSCT, there was a high rate of disease progression in this cohort. The risk for progression was $45 \%$ at 1 year after transplantation and $52 \%$ at 3 years, with a continued risk for relapse beyond 3 years. At 5 years, almost all survivors experienced lymphoma recurrence or progression, suggesting that allogeneic transplantation is rarely curative in patients for whom autologous transplantation fails. Similarly, in the study by Radich ef al., ${ }^{13}$ the 4 patients who did not die of treatment-related causes experienced relapse. In the report by Tsai et al. ${ }^{12}$ only 2 of 14 patients were alive and in remission 2 years after the second transplantation, and de Lima et al. ${ }^{8}$ report only 3 of 8 patients were alive and disease free at 25,22 , and 7 months after transplantation. In the report by Bierman et al., ${ }^{15}$ the OS and disease-free survival rates were estimated to be $42 \%$ at 2 years. In their experience, longer intervals between autologous and allogeneic transplantation were associated with better outcomes, a finding that was not replicated in our analysis.

Although not curative, prolonged survival was observed in a substantial proportion of patients in this study. The study then provided a unique opportunity to determine the effects of donor selection, disease type, performance score, disease stage, conditioning regimen, and potential effect of graft-versus-tumor effects and disease histology on transplantation outcome, specifically on the duration of allotransplantation-induced remissions and survival.

Not surprisingly, recipients of transplants from HLA-identical siblings had better outcomes than those with unrelated donors or related haploidentical donors, and poor performance status was associated with worse outcome. Patients with NHL who received TBI for conditioning had only one third the rate of disease progression of patients who did not receive TBI. This unexpected role of $\mathrm{TBI}$ in prolonging remission is consistent with our previous observations in follicular lymphoma ${ }^{20}$ and with recent data in autologous transplantation. ${ }^{21,22}$ On the other hand, it remains possible that TBI conditioning represents a surrogate for other undetected prognostic variables. No effect of TBI on recurrence rates was observed among patients with HL. The latter data should be interpreted with caution because the number of $\mathrm{HL}$ patients receiving $\mathrm{TBI}$ was small. Undergoing allo-HSCT while in remission was also associated with a decreased rate of disease progression. Among patients who underwent transplantation with active disease, the rate of disease progression was lower if the disease was chemosensitive. This is consistent with multiple previous observations in studies of allogeneic or autologous transplantation. ${ }^{2,23}$

Clinical observations of patients undergoing myeloablative and nonmyeloablative allo-HSCT suggest that the graft-versus-tumor effects may be important in inducing prolonged remission in patients with lymphoma ${ }^{24-27}$ and that it constitutes one of the rationales for considering allogeneic 
transplantation. Nevertheless; we were unable to clearly demonstrate a graftversus-lymphoma effect of GVHD in this study. The rate of progression in patients with acute or chronic GVHD was similar to that in patients without GVHD. Several previous registry analyses, including a recent study of first transplantation for follicular Iymphoma ${ }^{20}$ and an analysis of syngeneic transplantation, ${ }^{28}$ have similarly failed to demonstrate such an effect. However, given that only $30 \%$ of patients acquired GVHD, even our relatively large study (and other registry analyses) might not have been large enough to detect a significant graft-versus-iymphoma effect. Additionally, the lack of benefit from graft-versus-tumor effect in this group of patients at very high risk does not rule out that such effects might be operative in patients at standard risk.

We also did not observe any differences in overall outcomes among patients with low-, intermediate-, and high-grade NHL. The outcome for patients with HL was worse than that for patients with $\mathrm{NHL}$ receiving $\mathrm{TBI}$ for most outcome variables, but it was similar to that for patients with NHL receiving chemotherapy conditioning. It was previously reported that the outcome of allogeneic transplantation depends on disease histology, ${ }^{29}$ and we have shown that relapse rates after transplantation for low-grade lymphoma in particular are low. ${ }^{23}$ The failure to observe an effect of disease histology in the current study is likely attributable to the fact that study patients had disease that was resistant to numerous previous therapies, including high-dose chemotherapy, and, therefore, regardless of histology, was high risk. The small sample sizes of the subgroups of patients whose disease was of indolent histology migint also have contributed to the lack of discernible histology related effects.

The OS rate of patients included in this study appears to be superior to the reported OS rate of patients treated with conventional therapy after failed autologous transplantation. Vose et al. reviewed the outcomes of 169 patients at the University of Nebraska who had malignant Iymphoma and experienced relapse after auto-HSCT. With a median follow-up of only 1 year, $18(11 \%)$ of these 169 patients remained alive, off therapy, and without evidence of disease progression. By contrast, in our study, $33 \%$ of patients were projected to be alive at 3 years after allo-HSCT, and $25 \%$ were projected to be alive and free of disease. This is impressive given the fact that only one fifth of the patients in our study were in remission at the time of allo-HSCT and that almost half had Karnofsky scores lower than $90 \%$. Additionally, nearly $40 \%$ of patients received grafts from unrelated or HLAmismatched sibling donors.

In summary, it is apparent from this study that with modern supportive care, selected young patients with Iymphoma who experience relapse after autologous transplantation may benefit from allogeneic transplantation, though few will ultimatelly be cured. Patients who continue to exhibit disease responsiveness and who have HLA identical siblings have relatively good 3-year survival. Conditioning with TBI should be consilered for patients with 
NHL because it seems to be associated with prolonged duration of remission. In contrast, patients with refractory disease and poor performance status scores and who lack HLA-identical sibling donors have poorer outcomes. Our observations of the impact of $\mathrm{TBI}$ in NHL patients and the lack of detectable GVL effects suggest that nonmyeloablative transplantation, with its emphasis on dose reduction, may not constitute an optimal long-term strategy for these patients. Recent reports using nonmyeloablative allo-HSCT after auto-HSCT demonstrate the feasibility of this approach,30-33 but longer follow-up is necessary to demonstrate its effectiveness in achieving long-term disease control. 


\section{References}

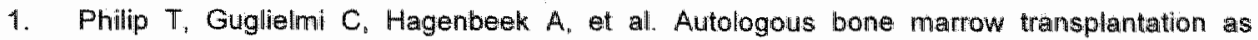
compared with salvage chemotherapy in relapses of chemotherapy-sensitive non-Hodgkin"s. Iymphoma. N Engl J Med. 1995;333:1540-5.

2. Vose $J M$, Zhang $M-J$, Rowlings $P A$, al. Autologous transplantation for diffuse aggressive non-Hodgkin's lymphoma in patients never achieving remission: a report from the Autologous. Blood and Marrow Transplant Registry (ABMTR). J Clin Oncol. 2001:19:406-13.

3. Lazarus HM, Loberiza FR Jr, Zhang M-J, et all. Autotransplants for Hodgkin's disease in first relapse or second remission: a report from the Autologous Blood and Marrow Transplant Registry (ABMTR). Bone Marrow Transplant. 2001;27:387-96.

4. Vose JM, Bierman PJ, Anderson JR, et al. Progressive disease after high-dose therapy and autologous transplantation for lymphoid malignancy: clinical course and patient follow-up. Blood. 1992;80:2142\%8.

5. Shamash J, Lee SM, Radford JA, et al. Patterns of relapse and subsequent management following high-dose chemotherapy with autologous haematopoietic support in relapsed or refractory Hodgkin's lymphoma: a two centre study. Ann Oncol. 2000;11:715-9.

6. Petersen FB, Appelbaum FR, Hill $R$, al. Autologous marrow transplantation for malignant lymphoma: a report of 101 cases from Seattle. J Clin Oncol. 1990;8:638 47 .

7. Vandenberghe $E$, Pearce $R$. Taghipour $G$, Fouillard $L$, Goldstone AH. Role of a second transplant in the management of poor-prognosis. lymphomas: a report from the European Blood and Marrow Registry. J Clin Oncol. 1997;15:1595-600.

8. de Lima M, van Besien $K W$, Giralt $S A$, et al. Bone marrow transplantation after failure of autologous transplant for non-Hodgkin's lymphoma. Bone Marrow Transplant. 1997; 19:121-7.

9. Freytes CO, Loberiza FR, Rizzo JD, et al. Allogeneic transplantation in patients that relapsed after autologous transplantation for Iymphoma: a report from the International Bone Marrow Transplant Registry [abstract]. J Clin Oncol. 2002;21:414.

10. Horowitz MM, Gale RP, Sondel PM, et al. Graftversus-leukemia reactions after bone marrow transplantation. Blood. 1990;75:555-62.

11. Brenner MK, Rill DR, Moen RC, et al. Genemarking to trace origin or relapse after autologous bone marrow transplantation. Lancet. 1993;341:85-6.

12. Tsai $T$, Goodman $S$, Saez $R$, et al. Allogeneic bone marrow transplantation in patients who relapse after autologous transplantation. Bone Marrow Transplant. 1997;20:859-63.

13. Radich JP, Gooley T, Sanders JE, Anasetti $C$, Chauncey $T$, Appelbaum FR. Second allogeneic transplantation after failure of first autologous transplantation. Biol Blood Marrow Transplant: 2000;6:272-9.

14. Schouten $\mathrm{HC}_{1}$. Armitage JO, Klassen $\mathrm{LW}_{\text {, }}$ et al. Allogeneic bone marrow transplantation in patients with lymphoma relapsing after autologous marrow transplantation. Bone Marirow Transplant, 1989:4:119:21.

15. Bierman $P$, Kottaridis $P$, Kollath $\mathrm{J}$, et al. Allogeneic transplantation following failure of autologous transplantation for lymphoma [abstract]. Blood. 1998:92:321.

16. Shah A.J, Kapoor $\mathrm{N}$, Weinberg KI, ef all. Second hematopoietic stem cell transplantation in pediatric patients: overall survival and long-term followup. Biol Blood Marrow Transplant. 2002;8:221-8.

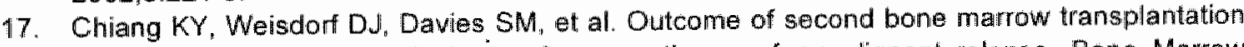
following a uniform conditioning regimen as therapy for malignant relapse. Bone Marrow Transplant. 1996;17:39-42

18. National Cancer Institute-sponsored study of classifications of non-Hodgkin"s lymphoma: summary and description of a working formulation for clinical usage: the Non-Hodgkin's Lymphoma Pathologic Classification Project. Cancer. 1982;49:2112-35.

19. Seropian S. Bahceci $E$. Cooper DL. Allogeneic peripheral blood stem cell transplantation for high-risk non-Hodgkin's lymphoma. Bane Marrow Transplant. 2003;32:763-9.

20. van Besien $K$, Loberiza FR. Jr, Bajorunaite $R$, et al. Comparison of autologous and allogeneic hematopoietic stem cell transplantation for follicular lymphoma. Biload. 2003;102:3521-9. 
21. Stiff PJ, Unger JM, Forman SJ, et al. The value of augmented preparative regimens combined with an autologous bone marrow transplant for the management of relapsed on refractory Hodgkin disease: a Southwest Oncology Group phase II trial. Biol Blood Marrow Transplant: $2003: 9.529-39$.

22. Stif PJ, Dahiberg S, Foreman SJ, et al. Autologous bone marrow transplantation for patients with relapsed ar refractory diffuse aggressive non-Hodgkin's lymphoma value of augmented preparatfve regimens-a Southwest Oncology Group Trial J Clin Oncol 1998;16:48-55.

23. van Beslen $K$, Sobocinski $K A$, Rowlings $P A$, et al. Allogeneic bone marrow transplantation for lowgrade lymphoma. Blood 1998;92;1832-6.

24. van Besien KW, de Lima M, Giralt SA, et al. Management of lymphoma recurrence after allogeneic transplantation the relevance of graftversus-lymphoma effects. Bone Marrow Transplant: $1997 ; 19: 977-82$.

25. Khouri IF, Keating Marbling $M$, et al. Transplant tite: induction of graft-versus-malignancy using fludarabine-based nonablative chemotherapy and allogeneic blood progenitor-cell transplantation as treatment for lymphoid malignancies. J Clin Oncol. 1998;16:2817-24.

26. Corradini $P$. Tarella $C$, Olivien $A_{\text {a }}$ et al. Reducedintensity conditioning followed by allografting of hematopoietic cells can produce clinical and molecular remissions in patients with poor-risk hematologic malignancies. Blood. 2002;99:75-82.

27. McSweeney PA, Niederwieser D, Shizuru JA, et al. Hematopoietic cell transplantation in older patients with hematologic malignancies: replacing high-dose cytotoxic therapy with graftversustumor effects. Blood. 2001:97:3390-400

28. Bierman $\mathrm{PJ}$, Sweetenham $\mathrm{JW}$, Loberiza $\mathrm{FR} J r_{\text {, }}$ et al. Syngeneic hematopoietic stem cell transplantation for non-Hodgkin's lymphoma: a comparison with allogeneic and autologous transplantation-the Lymphoma Working Committee of the International Bone Marrow Transplant Registry and the European Group for Blood and Marrow Transplantation. $\mathrm{J}$ Clin Oncol. 2003;21:3744-53.

29. van Besien $K W_{\text {, Mehra }} \mathrm{RC}$, Giralt SA, et al. Allogeneic bone marrow transplantation for poorprognosis lymphoma: response, toxicity and survival depend on disease histology. Am J Merd. 1996;100:299-307.

30. Sllavin S, Nagler A, Naparstek E, et al. Nonnyeloablative stem cell transplantation and cell therapy as an altemative to conventional bone marrow transplantation and with lethal cytoreduction for the treatment of malignant and non-malignant hematologic diseases. Blood. 1998:91:756-63.

31. Nagler A, Or R, Naparstek E, Varadi G, Slavin S. Second allogeneic stem-cell transplantation using nonmyeloablative conditioning for patients who relapsed or developed secondary malignancies following autologous transplantation. Exp Hematol. 2000;28:1096-104.

32. Branson $K_{0}$ Chopra $R$, Kottaridis $P D_{i}$ et al. Role of nonmyeloablative allogeneic stem cell transplantation after failure of autologous transplantation in patients with lymphoproliferative malignancies. J Clin Oncol. 2002;20:4022-31

33. Feinstein $L C$, Sandmaier $B M$ Maloney $D G$, et al. Allografting after nonmyeloablative conditioning as a treatment after a failed conventional hematopoietic stem cell transplant. Biol Blood Marrow Transplant. 2003;9:266-72. 


\section{Chapter 8}

Management of lymphoma recurrence after allogeneic transplantation: the relevance of graftversus-lymphoma effect

KW van Besien, M de Lima, SA Giralt, DF Moore Jr, IF Khouri, G Rondón, R Mehra, BS Andersson, C Dyer, K Cleary, D Przepiorka, JL Gajewski, RE Champlin 


\section{Abstract}

Donior lymphocyte infusions, by virtue of a graft-wersus tumor effect, have been shown to induce remissions in leukemia that recurs after allogeneic bone marrow transplantation. Similar effects have been postulated to contribute to the decreased recurrence rate observed after allogeneic transplantation in non-Hodgkin's lymphoma. This lower recurrence rate may be due to a variety of other mechanisms. We aimed to evalualte the role of graft-versus-lymphoma effects in patients in whom lymphomas recur after allogeneic transplantation. At the time of recurrence, immunosuppressive therapy was withiheld. Patients with non-responding disease received an infusion of donor lymphocytes. Patients were observed for response and graft-versus-host disease. Disease in four of nine patients responded to withdrawal of immunosuppressive therapy. A minor response was observed in one of three recipients of donor lymphocyte infusions. Responses were observed among two patients with follicular lymphoma, one with large cell lymphoma and one with lymphoblastic lymphoma. A minor response was abserved in a patient with prolymphocytic leukemia/lymphoma. We conclude that withdrawal of immunosuppressive therapy and donor lymphocyte infusion can induce durable remissions in patients with recurrent lymphoma after allogeneic transplantation. 


\section{Introduction}

Bone marrow transplantation has been commonly used in treatment of hematologic malignancies. Considerable data indicate that a graft-versusleukemia effect occurs after allogeneic transplantation and that it contributes to the achievement of durable remissions in leukemia. ${ }^{1,2}$ Syngeneic transplants and $T$ cell-depleted allografts are associated with an increased relapse rate, indicating that $T$ cells participate in the graft-versus-leukemia effect. ${ }^{3}$ Allogeneic transplantation has also been used to treat non-Hodgkin's lymphoma, and several studies report lower relapse rates than those achieved with autologous transplants ${ }^{4,5}$ The concept of a graft-versus-lymphoma effect, however, remains unproven, because of the inclusion of heterogeneous patient populations in lymphoma studies and a high treatment-related mortality rate.

Discontinuation of immunosuppressive therapy or donor lymphocyte infusions have been successfully used to induce remissions in patients in whom disease has recurred after allogeneic transplantation for chronic or acute myelogenous leukemia. ${ }^{6}$ Similar observations have been reported for patients with multiple myeloma. ${ }^{7}$ We have used immunologic manipulations in several patients with non-Hodgkin's lymphoma in whom disease recurred after allogeneic transplantation; complete or partial responses have been observed in four of nine patients.

\section{Patients and methods}

\section{Patients}

Between April 1991 and July 1996, 77 patients with lymphoma underwent allogeneic bone marrow or stem cell transplantation at the MD Anderson Cancer Center. Two had diffuse small non-cleaved cell lymphoma, 10 lymphoblastic lymphoma, 26 low-grade lymphoma, 32 had de novo intermediate grade lymphoma and seven transformed lymphoma. Fifteen patients developed disease recurrence.

One, with Burkitt's disease, died within a day of the diagnosis of disease recurrence. Two patients had graft failure prior to disease recurrence. They were treated with conventional chemotherapy and radiation. Three patients were cared for by their local physician at the time of recurrence. Nine fully engrafted patients were cared for at the MD Anderson Cancer Center at the time of disease recurrence. They form the subject of this report. 
Details on conditioning, stem cell procurement and prophylaxis for graft-versushost disease and infections have been previously reported. ${ }^{8-11}$ Two patients received conditioning consisting of cyclophosphamide, etoposide (VP-16) and total body irradiation, ${ }^{8}$ six patients received high-dose thiotepa, busulfan and cyclophosphamide, 10 and one received $B C N U$, etoposide, cytarabine and melphalan. Prophylaxis for graft-versus-host disease consisted of cyclosporine and short-course methotrexate $(n=3)$, cyclosporine and methylprednisolone $(n=5)$ or tacrollimus and methotrexate $(n=1) . T$ cell depletion was not used.

\section{Immunologic manipulations at recurrence}

Upon diagnosis of recurrence, several immunologic manipulations were attempted. If the patient was receiving cyclosporine or tacrolimus, it was discontinued. If the disease continued to progress after discontinuation of immunosuppression, and the patient remained in good condition, lymphocytes were collected from the allogeneic donor and infused into the patient without further prophylaxis for graft-versus-host disease. If a partial or complete response was obtained, this procedure could be repeated.

\section{Case report}

Patient characteristics and details on treatment and outcome are provided in Table 8.1. Response to withdrawal of cyclosporine or tacrolimus was observed in four patients: three patients who failed to respond to cyclosporine withdrawal, then received an infusion of donor lymphocytes; a minor response was observed in one patient. The case histories of patients with a response to immunologic manipulations are detailed below. Patient numbers in the case report refer to numbers assigned in Table 8.1.

\section{Pationt $y$}

A 33-year-old man, presented in January 1991 with $T$ cell lymphoblastic lymphoma. After an initial response to combination chemotherapy, the patient developed leptomeningeal disease. He received combined systemic and intrathecal treatment and obtained a partial response.

He underwent allogeneic BMT from his HLA-identical sister, after conditioning with thiotepa, busulfan, and cyclophosphamide. Prophylaxis for graft-versushost disease consisted of cyclosporine and methylprednisolone. A complete response was achieved. Acute and chronic graft-versus-host disease of the skin developed and required treatment with steraids and cyclosporine. 


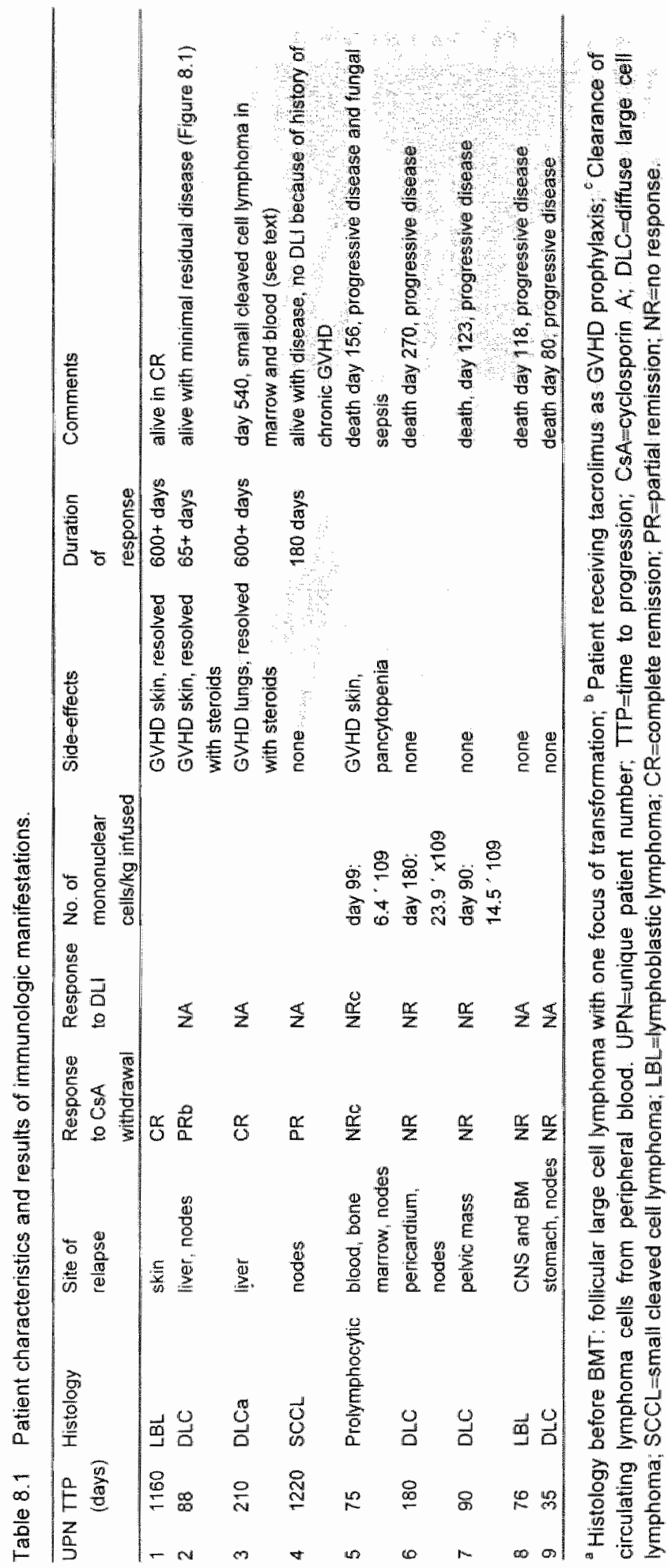


Thirty-eight months after BMT, he presented with a biopsy-confirmed, isolated recurrence of lymphoblastic lymphoma in the skin. Cyclosporine was stopped and steroids were tapered. This resulted in a transient flare-up of graft-versushost disease of the skin and cornplete resolution of the skin lesions. Twentyfour months after cessation of cyclosporine therapy, the patient's disease continues to be in remission.

\section{Patient 2}

A 41-year-old male was diagnosed with T cell-rich B cell large cell lymphoma in May 1995. He failed treatment with two consecutive chemotherapy regimens. He underwent allogeneic stem cell transplantation from his HLA-identical brother after conditioning with BCNU, etoposide, cytarabine and melphalan (BEAM). Prophylaxis for graft-versus-host disease consisted of tacrolimus and methotrexate. After a transient response, the patient's disease progressed in the liver, mediastinal and retroperitoneal lymph nodes on day 88 after transplant. Fine-needle aspiration demonstrated the original disease histology. Tacrolimus was stopped after which disease regression occurred in all sites of involvement (Figure 8.1). The patient has developed GVHD of the gut and liver which is controlled with steroids. His disease continues to be in remission 140 days after withdrawal of tacrolimus.

\section{Patient 3}

A 35-year-old man with common variable immunodeficiency and autoimmune hemolytic anemia, was diagnosed with stage IV follicular large cell lymphoma in October 1992. Only transient disease responses were obtained with the administration of several chemotherapeutic regimens.

He underwent allogeneic BMT from his HLA-identical brother after conditioning with cyclophosphamide, etoposide and total body irradiation. Prophylaxis for graft-versus-host disease consisted of cyclosporine and methotrexate. The patient's disease entered complete remission. Seven months after BMT, he presented with increasing liver function tests and paratracheal and retroperitoneal adenopathy; a liver biopsy showed B cell large-cell lymphoma. Cyclosporine was stopped. 
a
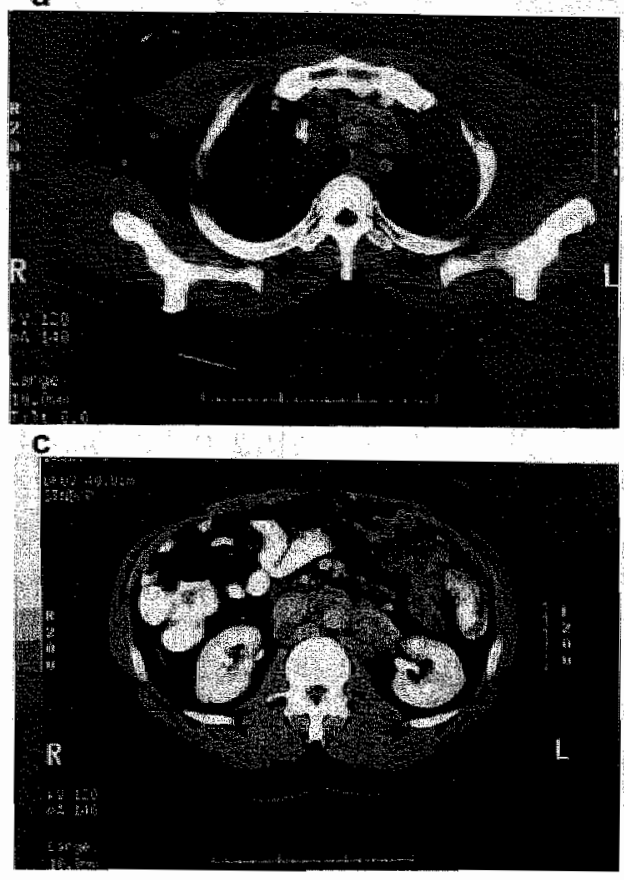

b
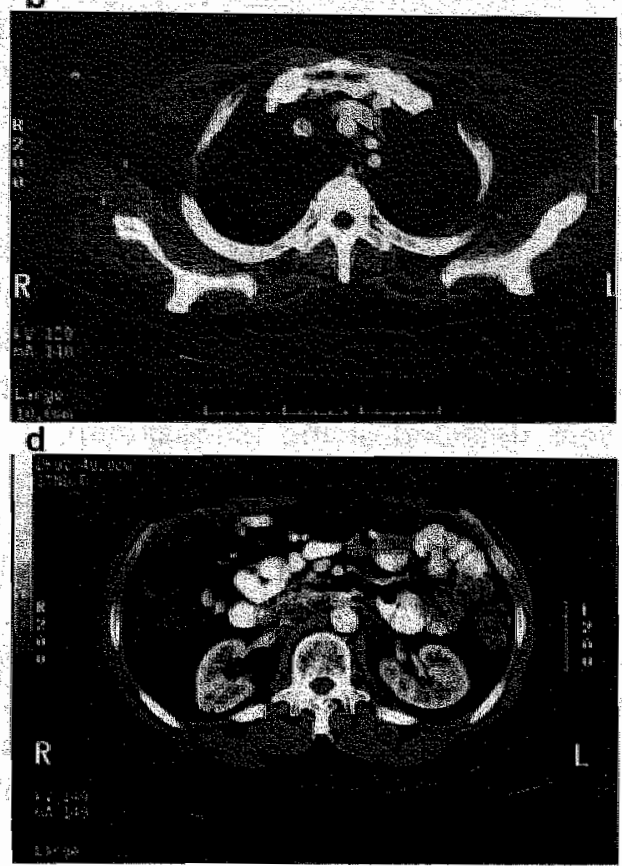

Figure 8.1 Patient 2 (a) mediastinal adenopathy 88 days after transplantation; (b) mediastinal adenopathy 143 days after transplantation and 55 days after withdrawal of tacrolimus: (c) retroperitoneal adenopathy 88 days after transplantation. Active disease was demonstrated by fine needle aspiration. (d) Retroperitoneal adenopathy 143 days after transplantation and $\mathbf{5 5}$ days after withdrawall of tacrolimus. 
The patient's bilirubin level decreased from 4.3 to $1.1 \mathrm{mg} / \mathrm{dll}$, but serum SGPT remained elevated A repeat liver biopsy showed acute hepatitis with polyclonal lymphoid aggregates in the parenchyma oligonucleotide in situ hybridization did not reveal the presence of Epstein-Barr virus RNA (EBER). An assay for hepatitis C RNA in the serum was positive, and interferon was started at 3 million units subcutaneously three times a week; all liver function tests normalized. Interferon was stopped after 6 months of therapy, but a relapse of hepatitis occurred that was documented by a liver biopsy. There was no evidence of Iymphoma. His liver function tests normalized after the reinstitution of interferon, One year after cyclosporine withdrawal, atypical lymphocytes were detected in the bloodstream, and a bone marrow biopsy revealed an interstitial lymphoid infitrate that was suspicious for lymphoma. Flow cytometry was non-diagnostic, but cytogenetic analysis of the marrow revealed the following karyotype in $25 \%$ of the analyzed cells $45, \times Y$, dell $(2)(\mathrm{p} 21),-2$, $1(7)(q 11.1),-7,-9,-11,+\operatorname{del}(14)(q 21)$, +mar1, The remainder of the cells had a normal karyotype. Oligonucleotide in situ hybridization on sections of the marrow did not show Epstein-Barr virus RNA, rendering the diagnosis of an EBV-related lymphoproliferation unlikely. Twenty months after cyclosporine withdrawal, the patient remains asymptomatic and has not undergone further treatment

\section{Patient 4}

A 31-year-old woman was diagnosed with stage IV follicular small cleaved-cell Iymphoma in May 1985. Only transient disease responses were obtained with the administration of several chemotherapeutic regimens.

She then underwent allogeneic BMT from her HLA-ildentical brother after conditioning with cyclophosphamide, etoposide, and total body irradiation. Prophylaxis for graft-versus-host disease consisted of cyclosporine and methotrexate. Acute grade 1 graft-versus-host disease of the skin developed and required treatment with steroids.

Three months after allogeneic BMT, her bone marrow showed persistent lymphoma, but subsequent biopsies revealed decreasing involvement. One year after BMT she presented with extensive chronic graft-versus-host disease of the skin and esophagus, which was controlled with cyclosporine and methylprednisolone. Several attempts at. tapering the medications resulted in flare-ups of graft-versus-host disease.

Four years after BMT, a fine-needle aspiration of an enlarged lymph node in the left crus of the diaphragm showed recurrent small cleaved-cell lymphoma. Cyclosporine was stopped, resulting in a decrease in the lymphadenopathy without recurrence of graft-versus-host disease in the skin. Although a spontaneous remission of low-grade lymphoma could explain the decrease in adenopathy, ${ }^{4 / 3}$ the tempioral association with withdrawal of cyclosporine 
indicates a graft-versus-lymphoma effect. Nine months later, progression of adenopathy was documented. The patient did not respond to treatment with interferon. Donor lymphocyte infusion was not considered for fear of provoking recurrent graft-versus hast disease. Currently the patient is receiving monocionall antibody treatment.

\section{patiens}

A 53-year-old man was diagnosed in August 1994 with prolymphocytic leukemia. He presented with massive adenopathy, blood and bone marrow involvement and failed treatment with two consecutive chemotherapy regimens.

He underwent allogeneic peripheral blood stem cell transplant from his HLAidentical sister after conditioning with thiotepa, busulfan and cyclophosphamide. Prophylaxis for graft-versus-host disease consisted of cyclosporine and methylprednisolone. After initial tumor reduction, disease progression was documented in the bone marrow, lymph nodes and peripheral blood on day 75 .

Cyclosporine was stopped, resulting in a transient clearing of circulating lymphoma cells. No effect on the bone marrow or lymph nodes was observed. On days +99 and +100 after allogeneic BMT, he received a donor lymphocyte infusion, after which clearance of lymphoma cells from the blood was documented. Graft-versus-host disease of the skin and profound pancytopenia developed. The patient received a boost of G-CSF-mobilized donor stem cells on day +139 . Despite the response in the peripheral blood, no response was documented in the bone marrow or other disease sites, and the patient died at day +156 after allogeneic BMT as a result of disease progression and Candida kruseisepsis.

\section{Discussion}

The high incidence of aggressive Iymphoid malignancy in AIDS patients ${ }^{14}$ and among organ transplantation recipients ${ }^{15}$ indicates that immune deficiency plays a pivotal role in the pathogenesis of these malignancies. The susceptibility of lymphoma to host defense mechanisms is further illustrated by the observation of spontaneous remissions ${ }^{13}$ and response to interferon ${ }^{16}$ or anti-idiotype antibodies. ${ }^{17}$ Presumably, Iymphoid cells are also targets of graftversus-host disease, and an associated graft-versus-lymphoma effect may occur after allogeneic BMT. In accordance with this hypothesis, favorable outcomes have been reported after allogeneic BMT in patients with low-grade lymphoma, ${ }^{9,18-21}$ and several studies indicate a lower incidence of recurrence 
after allogeneic BMT compared with autologous BMT. ${ }^{5,22}$ There have also been reports of successful BMT after failure of autologous BMT in patients with nonHodgkin's lymphoma. ${ }^{23,24}$

While such findings are suggestive of graft-versus-lymphoma effects, they could conceivably be due to the lack of bone marrow contamination in recipients of allogeneic bone marrow or potentially to the antitumoral effects of drugs utilized as prophylaxis for graft-versus-host disease. More convincing evidence for graft-versus-lymphoma effects can be obtained by the correlation of graft-versus-host disease with recurrence rates1 or by the observation of lymphoma regression after immunomodulatory treatments. There are only two previous reports of tumor regression induced by immunologic manipulations in patients with recurrent non-Hodgkin's lymphoma after allogeneic BMT. Petersen et al. ${ }^{25}$ reported on a patient with Burkitt's disease that recurred after allogeneic BMT, but went into complete remission after cyclosporine was discontinued. Graft-versus-host disease then developed in this patient, which necessitated the reinstitution of immunosuppressive therapy; Burkitt's disease promptly recurred again. Kolb et al. ${ }^{26}$ reported a transient response in one of two lymphoma patients treated with donor lymphocyte infusion for recurrence after allogeneic BMT.

In an attempt to investigate this concept further, we have explored the use of withdrawal of immunosuppressants and donor lymphocyte infusions for patients in whom disease recurs after allogeneic BMT. Withdrawal of cyclosporine or tacrolimus was effective in four of nine patients studied. It resulted in two complete and two partial responses. Donor lymphocyte infusions were administered to three patients who did not respond to cyclosporine withdrawal. A minimal response was observed in one of the three. We have previously also reported a complete response to donor lymphocyte infusion in a patient with refractory chronic lymphocytic leukemia, a similar disease. ${ }^{27.28}$ Among leukemia patients, the response to donor lymphocyte infusion depends on disease histology. ${ }^{6}$ Based on the low recurrence rates after allogeneic BMT for low-grade lymphoma, similar differences in sensitivity to GVL effects may be true among lymphoma subtypes. ${ }^{9}$ Our observations on the effect of cyclosporine withdrawal however are currently too limited to allow such conclusions.

In conclusion, immune modulations may induce graft-versus-lymphoma effects that result in tumor regression in different histologic subtypes of lymphoma. Therapeutic strategies aimed at exploiting such effects should be further evaluated in a systematic fashion. 


\section{References}

1 Fefer A. Graft-versus-tumor responses: adoptive cellular therapy in bone marrow transplantation. In: Forman SJ, Blume KG, Thomas ED (eds). Bone Marrow Transplantation. Blackwell Scientific Publications: Oxford, 1994:231-41.

2 Weiden $P L$, Flournoy $N$, Thomas $E D$ at al. Antileukemic effect of graft-versus-host disease in human recipients of allogeneic marrow grafts. New Engl J Med 1979;300:1068-73.

3 Marmont AM, Horowitz MM, Gale RP et al. T-cell depletion of HLA-identical transplants in leukemia. Blood 1991; 78:2120-30.

4 Appelbaum FR. Treatment of aggressive non-Hodgkin's lymphoma with marrow transplantation. Marrow Transplant Rev 1993;3:1-16:

5 Ratanatharathorn $\mathrm{V}$, Uberti $\mathrm{J}$, Karanes $\mathrm{C}$ et al. Prospective comparative trial of autologous versus allogeneic bone marrow transplantation in patients with non-Hodgkin"s Iymphoma. Blood 1994;84:1050-5.

6. Kolb H, Schattenberg $A_{3}$ Goldman J et al. Graft-versus leukemia effect of donor lymphocyte transfusion in marrow grafted patients. Blood 1995;86:2041 -50.

7 Tricot $\mathrm{G}$, Vesole $\mathrm{DH}_{1}$ Jagannath $S$ et al. Graft-versus-myeloma effect: proof of principle. Blood 1996;87:1196-8.

8 Giralt SA, LeMaistre CF, Vriesendorp HM et al. Etoposide, cyclophosphamide, total-body irradiation, and allogeneic bone marrow transplantation for hematologic malignancies. $J$ Clin Oncol 1994:12:1923-30.

9 van Besien KW, Khouri IF, Giralt SA et al. Allogeneic bone marrow transplantation for refractory and recurrent low grade lymphoma - the case for aggressive management. $J$ Clin Oncol 1995; 13:1096-102.

10 Przepiorka D, Ippoliti C, Giralt S et al. A phase I-II study of high-dose thiotepa, busulfan and cyclophosphamide as a preparative regimen for allogeneic bone marrow transplantation. Bone Marrow Transplant 1994:14:449-53.

11 Korbling $M$, Przepiorka $D$, Huh $Y O$ et al. Allogeneic blood stem cell transplantation for refractory leukemia and lymphoma: potential advantage of blood over marrow allografts. Blood 1995;85:1659-65.

12 van Besien $\mathrm{KW}$, Demuynck $\mathrm{H}$, LeMaistre $\mathrm{CF}$ et al. High dose melphalan aliows durable engraftment of allogeneic bone marrow. Bone Marrow Transplant 1995;15:321-3.

13 Krikorian JG, Portlock CS, Cooney P. Rosenberg SA: Spontaneous regression of nonHodgkin lymphoma: a report of nine cases. Cancer 1980;46:2093-6.

14 Gaidano $G$, Carbone A. Aids-related lympomas: from pathogenesis to pathology. $\mathrm{Br} J$ Haematol 1995;90:235-43.

15 Levine AM. Lymphoma complicating immunodeficiency disorders. Ann Oncol 1994:5:529. \$35.

16 Smalley RV: Andersen JW, Hawkins MJ et al. Interferon alfa combined with cytotoxic chemotherapy for patients with non-Hodgkin"s Iymphoma. Now Engl J Med 1992;327: 1336-41.

17 Kwak LW, Campbell MJ. Czerwinski DK et al. Induction of immune responses in patients with B-cell lymphoma against the surface-immunoglobulin idiotype expressed by their tumors. New Engl J Med 1992;327:1209-15

18 Molina 1, Nicolini $F_{\mathrm{n}}$ Viret $F$ et al. Allogeneic bone marrow transplantation for refractory and recurrent low grade non Hodgkín's lymphoma. Blood 1995;86:209a (Abstr.).

19 van Besien $K$, Rowlings PA, Sobocinski KA et al. Allogeneic bone marrow transplantation for low grade lymphoma. Blood 1995:86:209a (Abstr.).

20 Mandigers C, Raemaekers J, Schattenberg A el al. Allogeneic bone marrow transplantation in patients with relapsed low-grade follicular non-Hodgkin's lymphoma. Blood 1995;86:208a (Abstr.).

21 Fielding $A K_{v}$ de Witte $T$, Reiffers $\downarrow$ et al. Allogeneic bone marrow transplantation for low-grade non-Hodgkin's lymphoma. Bone Marrow Transplant 1995; 15:S96 (Abstr.). 
22 Jones $\mathrm{RJ}_{1}$ Ambinder RF. Plantadosi $S$, Santos GW. Evidence of a graft-wersus-lymphoma effect associated with allogeneic bone marrow transplantation. Blood $1991_{1}, 77: 649-53$.

23 Schouten $\mathrm{HC}$, Armitage $\mathrm{JO}$, Klassen LW et al. Allogeneic bone marrow transplantation in patients with Yymphoma relapsing after autologous transplantation. Bone Marrow Transpllant $1989.4: 119.21$.

24 de Lima $M_{\text {s }}$ van Besien $K$. Giralt $S A$ et al Bone marrow transplantation affer failure of autologous transplant for non-Hodgkin's lymphoma. Bone Marrow Transplant 1997; 19:121-7.

25 Petersen $F B_{i}$ Appelbaum $F R$, Bigelow $C$ et al. High-dose cytosine arabinoside, total body irradiation and marrow transplantation for advanced malignant lymphoma. Bone Marrow Transplant 1989:4:483-8.

26 Kolb HJ, de Witte T, Mittermueller $J$ et al. Graft-versus leukemia effect of donor buffy coat transfusion on recurrent leukemia after marrow transplantation. Blood 1993;82:214a (Abstr).

27 Rondón $G$, Giralt $S$, Huh $Y$ et al. Complete remission due to graft-versus-leukemia effect against chronic lymphocytic leukemia. Bone Marrow Transplant 1996;18:669-72.

28 Rondón $G_{i}$ Khouri I. Giralt $S$ et al. Chimerism following sex-mismatched allogeneic BMT in chronic lymphacytic leukemia (CLL). Blood 1994,84:208a (Abstr). 


\section{Chapter}

Syngeneic hematopoietic stem-cell

transplantation for non-Hodgkin's lymphoma: a comparison with allogeneic and autologous transplantation-the lymphoma working committee of the International bone marrow transplant registry and the European group for blood and marrow transplantation

PJ Bierman, JW Sweetenham, FR Loberiza Jr, G Taghipour, HM Lazarus, JD Rizzo, N Schmitz, K van Besien, JM Vose, M Horowitz, A Goldstone 


\section{Abstract}

\section{Purpose}

To compare resuits of syngeneic allogeneic, and autologous hematopoletic stem-cell transplantation for non-Hodgkin's lymphoma (NHL)

\section{Patients and Methodis}

The databases of the Internationa Bone Marrow Transplant Registiry (IBMTR) and the European Group for Blood and Marrow Transplantation were used to identify 89 NHL patients who received symgeneit transplants. These patients were compared with NHL patients identifed from the UBMTR and the Autologous Blood and Warrow Transplant Registry who received allogeneic (T-cell depleted aind $T$-cell replete) and autologous (purged and unpurged) transplants.

\section{Results}

No significant differences in relapse rates were observed when results of allogeneic transplantation were compared with syngeneic transplantation for any histology. T-cell depletion of allografts was not associated with a higher relapse risk, but was associalted with improved overall survival for patients: with low-grade and intermediate grade histology. Patients who received unpurged autografts for low-grade $N H L$ had a fiwe-fold $(P=0,008)$ greater risk of relapse than recipients of syngenelic transplants, and recipients of unpurged autografts had a two-fold $(P=0.0009) \mathrm{greater}$ relapse risk than patients who received purged autografts. Among low-grade NHL patients, the use of purging was associated with signifi- cantly better disease-free survival ( $P=0.003$ ) and overall survival $(P=0.04)$ when compared with patients who received unpurged autografts.

\section{Conclusion}

These analyses failed to find evidence of a graft-versus-lymphoma effect, but do provide indirect evidence to support the hypothesis that tumor contamination may contribute to lymphoma relapse, and that purging may be beneficial for patients undergoing autologous hematopoietic stem-cell transplantation for low-grade NHL. 


\section{Introduction}

Several studies have shown lower relapse rates after allogeneic transplantation for non-Hodgkin's lymphoma (NHL) when compared with autologous transplantation. These results could be explained by lack of tumor contamination, or by selection bias favoring patients with better prognostic characteristics. However, many investigators have hypothesized that a graftversus-lymphoma effect is the most likely explanation for this finding.

High-dose therapy followed by autologous hematopoletic stem-cell transplantation has become accepted therapy for certain NHL patients. However, autologous transplantation is associated with the potential risk of reinfusing malignant cells. This has led to trials involving removal of contaminating cells from the autograft. Several of these methods of manipulation (purging) can eliminate significant numbers of tumor cells from the graft. There is indirect evidence for a clinical benefit from purging, although benefits have not been conclusively demonstrated.

Comparisons of syngeneic and allogeneic bone marrow transplantation for leukemia support the existence of a graft-versus-leukemia effect. We reasoned that a comparison of syngeneic and allogeneic NHL transplants could also provide insights into whether a similar graft-versus-lymphoma effect exists. We also reasoned that a syngeneic transplant is representative of an uncontaminated autograft, and consequently, a comparison of syngeneic and autologous transplants could provide indirect evidence regarding the potential contribution of tumor contamination to relapse after autologous transplantation for NHL. This study was undertaken to compare relapse rates after syngeneic, autologous, and allogeneic hematopoietic stem-cell transplantation for NHL.

\section{Patients and methods}

\section{Data sources}

The International Bone Marrow Transplant Registry (IBMTR) comprises more than 400 transplantation centers that contribute data on allogeneic and syngeneic hematopoietic stem-cell transplantations to a Statistical Center at the Health Policy Institute of the Medical College of Wisconsin. The Autologous Blood and Marrow Transplant Registry (ABMTR) comprises more than 250 transplant centers that report data on autotransplantations to the same institution. Approximately $40 \%$ of allogeneic transplantations worldwide and more than $50 \%$ of autologous transplantations in North and South America are 
registered with the IBMTR/ABMTR.' Consecutive transplantations are reported and compliance is monitored with on-site audits. The European Group for Blood and Marrow Transplantation (EBMT) comprises 436 transplantation centers in Europe and associated members from non-European countries. Data are checked by the Statistical Office of the EBMT at the University College of London Hospitals and at random site visits. The registry accrues data on transplantations from participating centers, and requests basic patient and clinical information and annual follow-up on all patients. Additional data are requested if patients are included in a study. Institutions were contacted on three occasions to obtain data for this study before the variable was coded as missing or unknown.

\section{Patients}

This study included NHL patients who received high-dose therapy followed by syngeneic, autologous, or HLA-matched sibling allogeneic transplants between 1985 and 1998 , and were reported to the $I B M T R$, ABMTR, or EBMT. Syngeneic transplants reported to the IBMTR and EBMT were checked for overlap. These patients were then compared with autologous and allogeneic transplant reciplents from the IBMTR/ABMTR. Nonmyeloablative allogeneic transplants were excluded.

Lymphoma classification evolved during the study period and specific histologic criteria were applied to ensure comparability of diagnoses. Only patients with a descriptive histologic classification conforming to the Working Formulation were included. ${ }^{3}$ Entities such as mantle-cell lymphoma and marginal zone lymphoma that are only recognized in the Revised European-American Lymphoma or WHO classification systems were excluded. 4,5 Follicular large-cell lymphoma and large-cell immunoblastic lymphoma were classified as intermediate grade.

\section{End points}

The primary end point was relapse, defined as persistent or recurrent NHL in patients surviving at least 28 days after transplantation. Patients were also analyzed for disease-free survival and overall survival. Disease-free survival was defined as survival without evidence of NHL. Patients with persistent disease were classified as experiencing relapse at day 28 , even if they did not subsequently progress. Overall survival was defined as the interval between transplantation and death from any cause. Surviving patients were censored at the date of last contact. 


\section{Statistical analysis}

Patient-, disease-, and transplantation-related variables for cohorts were compared using the $\chi^{2}$ statistic for categorical variables and the Kruskal-Wallis test for continuous variables. Univariate probabilities of disease-free and overall survival were calculated using the Kaplan-Meier estimator. ${ }^{6}$ The logrank test was used for univariate comparisons of survival curves.

Probabilities of relapse and transplantation-related mortality were calculated using cumulative incidence curves to accommodate competing risks. . $^{\text {. }}$ Transplantation-related mortality, defined as death during continuous remission or death in the first 28 days after transplantation, was used as a competing risk factor for estimation of relapse. Ninety-five percent $\mathrm{Cls}$ for all probabilities and $P$ values of pairwise comparisons were derived from pointwise estimates and calculated using standard techniques. ${ }^{9}$

Cox proportional hazards models were constructed for each histologic subtype. The primary covariate analyzed was graft type (syngeneic, allogeneic T-cell depleted, allogeneic T-cell replete, autologous purged, and autologous unpurged). The following factors were also analyzed in the multivariate analyses for their association with relapse and their potential confounding effect on the associations between relapse and type of transplantation. The first set of categories were patient-related factors at the time of transplantation: age $<40 \mathrm{v} \geq 40$ years) and sex. The second set of categories were disease-related factors at diagnosis: histology (low grade $v$ intermediate grade $v$ high grade). The third set of categories were diseaserelated factors at the time of transplantation: disease sensitivity (chemotherapy sensitive $v$ resistant $v$ unknown or untested), presence of bone marrow involvement at diagnosis or transplantation, and disease status (first remission $v$ never in remission $v$ second remission $v$ first relapse $v$ second relapse $v$ unknown). The fourth set of categories were transplantation-related factors: year of transplantation (1985 to $1989 \vee 1990$ to $1995 \vee 1996$ to 1998), conditioning regimen (containing totalbody irradiation [TBI] $\vee$ not containing $T B I$ ), graft source (blood $v$ marrow), and use of hematopoietic growth factors within 7 days of transplantation. A separate category for missing data was created for each covariate included in the multivariate analysis whenever applicable. Allogeneic transplants were analyzed for the effects of acute graft-versus-host disease (GVHD) and chronic GVHD entered as time-dependent covariates. We tested the proportional hazards assumption for each factor in the Cox model using time-dependent covariates. ${ }^{10}$ When this indicated differential effects over time (nonproportional hazards), models were constructed that broke the postiransplantation course into two periods using the maximized partial likelihood method to find the most appropriate breakpoint. After time-varying effects were modeled, the final multivariate model was built using a forward stepwise model selection approach. Each model contained the main effect (syngeneic las the reference 
groupl, allogeneic T-cell depleted, allogeneic T-cell replete, autologous purged, or autologous unpurged transplant). The inclusion of the main effect allowed us to examine differences in the outcome risk by type of transplant while controlling for other significant covariates. Factors significantly associated with the outcome variable at the $5 \%$ level were kept in the final model First-order interactions were examined between the type of transplant and all significant prognostic factors. Examination for center effects used a random effects or frailty model. We found no evidence of correlation between transplantation center and any outcomes. All Pvalues are two-sided.

\section{Results}

Patient characteristics are presented in Table 9.1. Allogeneic transplant recipients were younger. All groups had a higher percentage of males. Allogeneic recipients were more likely to have high-grade histology and autologous transplant recipients were more likely to have intermediate-grade and low-grade histology. Allogeneic transplant recipients were also more likely to have a history of marrow involvement. The groups were similar with respect to systemic symptoms at diagnosis, stage at diagnosis, and disease status at transplantation. Allogeneic recipients were more likely to have untested or unknown sensitivity and were more likely to have received TBI conditioning. Bone marrow was used for most of the allogeneic transplants and purged autografts, whereas most unpurged autografts were performed with peripheral blood. A variety of purging and T-cell-depletion methods were used.

Among patients receiving purged autografts, 214 grafts $(57 \%)$ were purged with 4-hydroperoxycyclophosphamide or mafosfamide, 44 grafts (12\%) were purged with positive selection techniques, 31 grafts $(8 \%)$ were purged with monoclonal antibodies, and 87 grafts $(23 \%)$ were purged with other pharmacologio agents. Among patients receiving T-cell-depleted allografts, 40 grafts (34\%) were T-cell depleted with elutriation, 31 grafts $(26 \%)$ were T-cell depletted with sheep red cells and/or soybean lectin, 29 grafts (24\%) were T-cell depleted with monoclonal antibodies, and 19 grafts (16\%) were T-cell depleted with other methods.

The median follow-up for syngeneic transplants, unpurged autologous transplants, purged autologous transplants, T-cell-replete allogeneic transplants, and T-cell- depleted allogeneic transplants was 44 months (range, 4 to 186 months), 36 months (range, $<1$ to 125 months), 46 months (range, 3 to 128 months), 48 months (range, 2 to 174 months), and 60 months (range, 3 to 159 months), respectively. The interval between diagnosis and transplantation was not significantly different when syngeneic transplants were compared with other transplant types. 
Table 9:1 Patient characteristics.

\begin{tabular}{|c|c|c|c|c|c|c|c|c|c|c|}
\hline \multirow[b]{2}{*}{ Characterigtic: } & \multicolumn{2}{|c|}{ Syrgeneic } & \multicolumn{2}{|c|}{$\begin{array}{l}\text { Autologous } \\
\text { Unpunged }\end{array}$} & \multicolumn{2}{|c|}{$\begin{array}{c}\text { Autologous } \\
\text { purgatid }\end{array}$} & \multicolumn{2}{|c|}{$\begin{array}{l}\text { Allogenelo } \\
\text { Acrell-woplete }\end{array}$} & \multicolumn{2}{|c|}{ 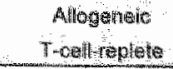 } \\
\hline & No. & $\%$ & 40 & $\%$ & No. & $\%$ & No. & $\%$ & No & $\%$ \\
\hline No of patients & 89 & & 2,018 & & 376 & & 774 & & 118 & \\
\hline Median & \multicolumn{2}{|c|}{42} & \multicolumn{2}{|c|}{48} & \multicolumn{2}{|c|}{$4 \pi$} & \multicolumn{2}{|c|}{33} & \multicolumn{2}{|c|}{$37:$} \\
\hline Range & \multicolumn{2}{|c|}{$4-68$} & \multicolumn{2}{|c|}{$11-68$} & \multicolumn{2}{|c|}{$6-79$} & \multicolumn{2}{|c|}{2.62} & \multicolumn{2}{|c|}{$5-62$} \\
\hline Male & 5 肖 & 57 & 1,232 & 61 & 230 & 61 & 495 & 64 & 69 & 56 \\
\hline \multicolumn{11}{|c|}{ Karnofsky pertormance status } \\
\hline $290 \%$ & 30 & 34 & 1,203 & 60 & 272 & 72 & 440 & 57 & 92 & 77 \\
\hline$<90 \%$ & 27 & 30 & 712 & 35 & 55 & 15 & 313 & 40 & 16 & 13 \\
\hline Unkmown & 32 & 36 & 103 & 5 & 49 & 13 & 24 & 3. & 11 & 10 \\
\hline \multicolumn{11}{|l|}{ Histology } \\
\hline Low-grade & 30 & 34 & 427 & $2 \pi$ & 160 & 42 & 189 & 24 & 36 & 30 \\
\hline Intermedliate-grade & 31 & 35 & 1.417 & 70 & 180 & 48 & 194 & 25 & 26 & 22 \\
\hline Migh-grade & 28 & 31 & 1174 & 9 & 36 & 10 & 391 & 51 & $5 \pi$ & 48 \\
\hline "B" symptoms at dilagrosis & & & & & & & & & & \\
\hline Absent & 39 & 44 & 1.191 & 59 & 244 & 65 & 402 & 52 & 55 & 46 \\
\hline Priesent & 24 & 27 & 787 & 39 & 124 & 33 & 255 & 33 & 39 & 33 \\
\hline Uniknown & 26 & 29 & 40 & 2 & 8 & 2 & 117 & 15 & 25 & 21 \\
\hline Stage at diagnosis & & & & & & & & & & \\
\hline$\|$ to $\|$ & 18 & 20 & 578 & 29 & 97 & 26 & 137 & 12 & 25 & 21 \\
\hline 津 to $\mathrm{W}$ & 57 & 64 & $1_{n} 417$ & 70 & 277 & 73 & 566 & 73 & 73 & 61 \\
\hline Linknown & 14 & 16 & 23 & 1 & 2 & -1 & 71 & $\theta$ & $2 \pi$ & 8 \\
\hline $\begin{array}{l}\text { Bone marrow involvement } \\
\text { diagnosis or lransplantation }\end{array}$ & & & & & & & & & & \\
\hline Absent & 57 & 64 & $1,8 \pi 6$ & 90 & 285 & 76 & 255 & 33 & 32 & 27 \\
\hline Present & 9 & 10 & 121 & 6 & 20 & 5 & 186 & 24 & 16 & 13 \\
\hline Uniknown & 23 & 26 & 81 & 4 & 71 & 10 & 333 & 43 & 74 & 60 \\
\hline Sensitivity to chemotherapy & & & & & & & & & & \\
\hline Sensitive & 50 & 56 & 1,464 & 72 & 280 & 7.4 & 308 & 40 & 31 & 20 \\
\hline Resistant & 13 & 15 & 316 & 16 & 63 & 17 & $\$ 10$ & 14 & 13 & 11 \\
\hline Untreated or unknown: & 26 & 29 & 238 & 12 & 33 & 9 & 356 & 46 & 75 & 63 \\
\hline $\begin{array}{l}\text { Discase stallus at } \\
\text { transpitantation }\end{array}$ & & & & & & & & & & \\
\hline Primary induction failure & 22 & 25 & 4.49 & 22 & 64 & 17 & 194 & 25 & 27 & 23 \\
\hline CRI & 18 & 20 & 238 & 12 & 53 & 14 & 150 & 19 & 32 & $2 \pi$ \\
\hline $\mathrm{CF} 2$ & 14 & 16 & 319 & 116 & 74 & 20 & 140 & 18 & 19 & 16 \\
\hline Rell 1 & 24 & 27 & 650 & 32 & 82 & 22 & 160 & 22 & 14 & 12 \\
\hline $\operatorname{Rel} 2$ & $\theta$ & 7 & 471 & 是 & 30 & 8 & 53 & 7 & 11 & $\theta$ \\
\hline Wat assess.able & 6 & 5 & 蜔1 & 10 & 73 & 19 & 69 & $y$ & 16 & 14 \\
\hline TEI for conditioning & 25 & 28 & 557 & 28 & 225 & 60 & 559 & 72 & 107 & 90 \\
\hline Type of graft & & & & & & & & & & \\
\hline Peripheral stemucell & 23 & 26 & 1,359 & 67 & 48 & 13 & 92 & 12 & - & - \\
\hline Bonie marrow & 66 & 74 & 659 & 33 & 328 & 87 & 682 & 88 & 110 & 100 \\
\hline $\begin{array}{l}\text { Growth factor given within } 7 \\
\text { days posttiransplantataion }\end{array}$ & 26 & 30 & 1.156 & 64 & 146 & 4.4 & 2465 & 33 & 24 & 2 \\
\hline Year of transplantation & & & & & & & & & & \\
\hline $1985-1989$ & $\| \pi$ & 19 & 86 & 5 & 31 & 9 & 177 & 23 & 36 & 30 \\
\hline $1990-1992$ & 23 & 26 & 392 & 19. & 137 & 36 & 255 & 33 & 20 & 17 \\
\hline $1993-1995$ & 22 & 25 & 884 & 44 & 945 & 38 & 193 & 25 & 56 & 47 \\
\hline $1996-1998$ & 27 & 30 & 656 & 32 & 63 & 17 & 149 & 19 & 7 & $B$ \\
\hline
\end{tabular}

$C R=$ complete remission; Rel=relapse; $T$ TIItotal body irradiation 


\section{Relapse}

The cumulative incidence of relapse for each type of transplant is displayed in Figure 9.1. Results of the multivariate analysis of factors independently associated with relapse risk are listed in Table 9.2 .
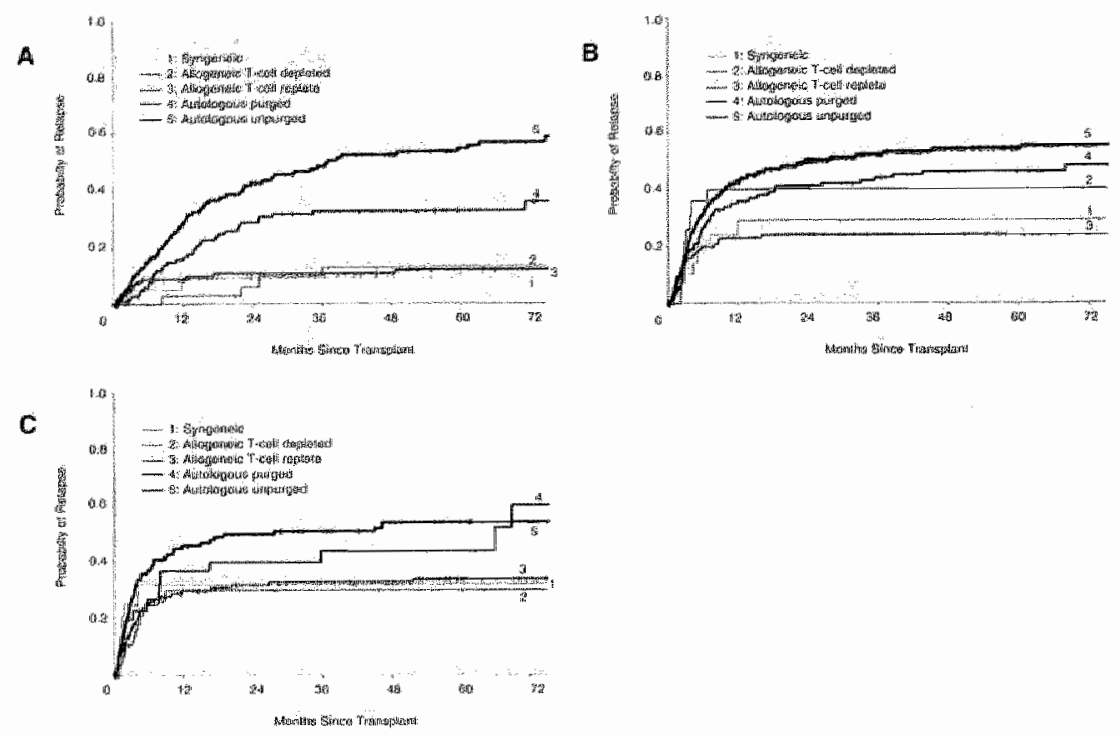

Figure 9.1 Cumulative incidence of relapse after transplantation for all patients according to type of transplant. (A) Low-grade histology, (B) intermediate-grade histology, (C) high-grade histology.

Low-grade NHL patients who received allogeneic transplants did not have a significantly lower relapse risk than patients who received syngeneic transplants. Furthermore, there were no significant differences in relapse probability between patients who received T-cell-depleted and T-cell-replete allografts (relative risk $[R R], 0.98 ; P=0.97$ ). When compared with syngeneic transplants, unpurged autologous transplant recipients had a significantly higher risk of relapse ( $R R, 4.93 ; P=0.008)$.

Reciplents of purged autologous transplants had a three-fold higher relapse risk than syngeneic transplant recipients, although this difference was not statistically different $(P=0.10)$. Recipients of unpurged autografts had a significantly greater risk of relapse than patients who received purged autologous transplants (RR, 1.82; $P=0.0009$ ). 
Table 9.2 Multivariate analysis relapse:

\begin{tabular}{|c|c|c|c|c|}
\hline & No of patients & Relative risk of relapse & $95 \% \mathrm{Cl}$ & $P$ \\
\hline \multicolumn{5}{|l|}{ Low-grade } \\
\hline Syngeneic $^{\text {ab }}$ & 26 & 1.00 & & \\
\hline Allogeneic $T$-cell-depleted & 34 & 1.49 & 0.32 to 6.88 & 0.61 \\
\hline Allogeneic T-cell-replete & 165 & 1.46 & 0.41 to 5.13 & 0.56 \\
\hline Autologous purged & 143 & 2.70 & 0.81 to 9.02 & 0.10 \\
\hline $\begin{array}{l}\text { Autologous unpurged } \\
\text { Intermediate-grade }\end{array}$ & 394 & 4.93 & 1.52 to 15.94 & 0.008 \\
\hline Syngeneic & 30 & 1.00 & & \\
\hline Allogeneic T-ceil-depleted & 23 & 1.80 & 0.68 to 4.75 & 0.24 \\
\hline Allogeneic T-cell-replete & 173 & 1.12 & 0.52 to 2.42 & 0.78 \\
\hline Autologouls purged & 154 & 1.04 & 1.53 to 3.22 & 0.26 \\
\hline Autologous unpurged & 1,399 & 1.88 & 0.93 to 3.82 & 0.08 \\
\hline \multicolumn{5}{|l|}{ Hilgh-grade ${ }^{\text {ad }}$} \\
\hline Syngeneic & 28 & $\$ .00$ & & \\
\hline Allogieneic T-cell-depleted & 57 & 1.01 & 0.41 to 2.46 & 0.99 \\
\hline Allogeneic $T$-cell-replete & 373 & 0.99 & 0.46 to 2.12 & 0.98 \\
\hline Autologous purged & 36 & 1.60 & 0.62 to 4.13 & 0.33 \\
\hline Autologous unpurged & 169 & 1.68 & 0.78 to 3.61 & 0.19 \\
\hline
\end{tabular}

"Model stratified by disease status at transplantation and year of transplantation; ${ }^{\text {a }}$ other significant variable: chemotherapy-sensitive versus chemotherapy-resistant to initial chemotherapy (relative risk [RR], $1.99 ; 95 \% \mathrm{Cl}, 1.39$ to $2.83 ; P=0.0002$ ). Pairwise comparison between $T$-cell-replete versus T-cell-depleted allogeneic transplants; $\left.R R_{n} 0.98 ; P=0.97\right)$; autologous unpurged versus purged ( $R R, 1.82 ; P=0.0009$ ); "other significant variable: chemotherapy-sensitive versus chemotherapy-resistant to initial chemotherapy $\left(R R_{n} 1.84 ; 95 \% \mathrm{Cl}, 1.52\right.$ to $\left.2.23 ; P=0.0001\right)$. Pailiwise comparison between $T$-cell-replete versus $T$-cell-depleted allogeneic transplants; $R R$, $0.62 ; P=0.21$ ); autologous unpurged versus purged (RR, $1.23 ; P=0.12) ;{ }^{\text {d }}$ other significant variable: chemotherapy-sensitive versus chemotherapy-resistant to initial chemotherapy, $(\mathbb{R R}, 2.49$; $95 \% \mathrm{Cl}$, 1.56 to $3.97 ; P=0.0001)$. Pairwise comparison between T-cell-replete versus T-cell-depleted allogeneic transplants (RR, $0.99 ; P=0.97)$; autologous unpurged versus purged $(R R, 1.05 ; P=0.89)$.

No significant differences in relapse risk were identified when allogeneic transplants for intermediate-grade NHL were compared with syngeneic transplants. An increased risk of relapse was not associated with T-cell depletion. Patients who received unpurged autografts had a higher risk of relapse than did syngeneic transplant recipients, although this difference was not statistically significant $(P=0.08)$. Among patients with intermediate-grade $\mathrm{NHL}$, there were no significant differences in relapse risk when results of unpurged and purged autologous transplants were compared (RR, 1.23; $P=0.12$ ).

Among patients with high-grade histology, there were no significant differences in relapse risk when allogeneic, autologous, and syngeneic transplants were compared. There were no significant differences when T-cell-depleted and Tcell-replete allogeneic transplants were compared, and no significant differences between unpurged and purged autografts. 
For allogeneic transplant recipients who survived at least 90 days, the relapse rate at 1 year was estimated to be $20 \%(95 \% \mathrm{Cl}, 14 \%$ to $26 \%)$ for patients who developed chronic GVHD, as compared with $17 \%(95 \% \mathrm{Cl}, 13 \%$ to $22 \%)$ for patients without chronic GVHD $(P=0.41)$. When time-dependent Cox regression was used, the RR of relapse for patients with chronic GVHD was $0.82 .(95 \% \mathrm{Cl}, 0.52$ to $1.28 ; P=0.39)$ when compared with patients without chronic GVHD. There was no evidence of graft-versus-lymphoma effects associated with acute GVHD or chronic GVHD, and this was true for all grades of lymphoma.

\section{Disease-free Survival}

The actuarial disease-free survival for each type of transplant is shown in Figure 9.2. Results of the multivariate analysis of factors independently associated with disease-free survival are listed in Table 9.3.
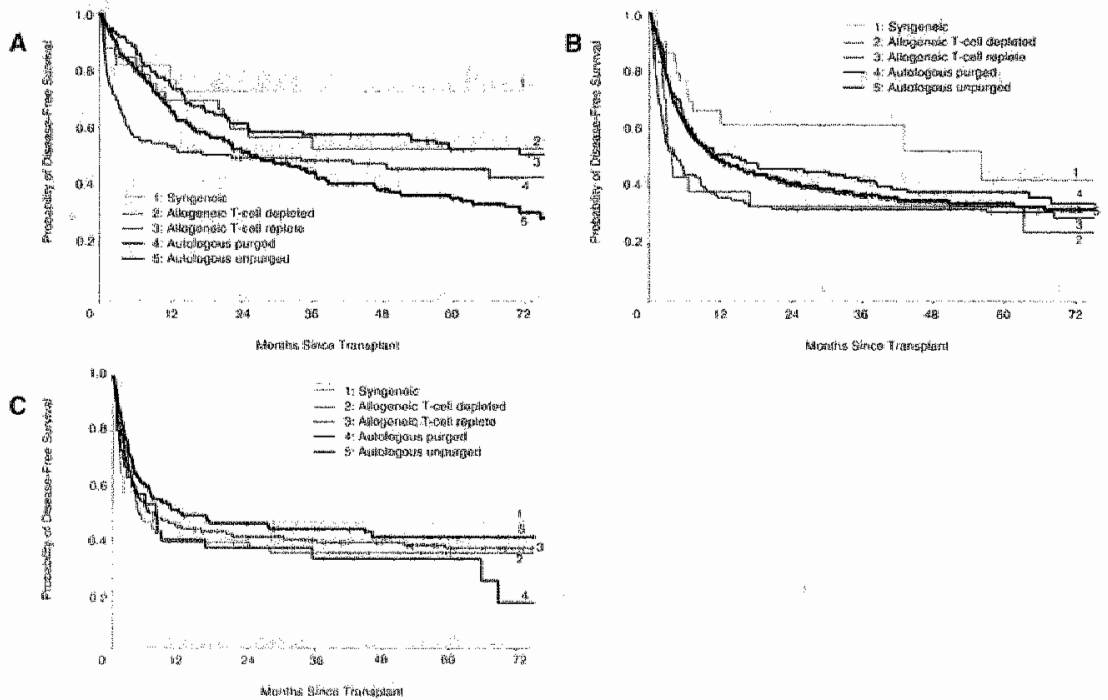

Figure 9.2 Actuarial probability of disease-free survivall after transplantation for all patients according to type of transplant. (A) Low-grade histology. (B) intermediate-grade histology, (C) high-grade histology.

Low-grade NHL patients who received allogeneic transplants who were not $\mathrm{T}$ cell depleted had significantly worse disease free survival than did syngeneic transplant recipients (RR, 3.12; $P=0.006$ ). The former also had a trend toward poorer disease free survival, when compared with patients who received $T$ cell-depleted allografts (RR, $1.70 ; P=0.08$ ). Patients who received unpurged 
autologous transplants had significantly worse disease free survival than those who received syngeneic transplants ( $R R, 228, P=0.04)$. When compared with patients who received purged autografts, patients who received unpurged autologous transplants also had significantly lower disease-free survival (RR, 1.59; $P=0.003)$.

Table 9.3 Multivariate analysis: disease-free survival.

\begin{tabular}{|c|c|c|c|c|}
\hline & No of patients & Relative risk of treatment failure & $95 \% \mathrm{Cl}$ & $P$ \\
\hline \multicolumn{5}{|l|}{ Low grade } \\
\hline Syngeneic & 26 & 1.00 & & \\
\hline Allogeneic T-cell-depleted & 34 & 1.83 & 0.72 to 4.64 & 0.20 \\
\hline Allogeneic T-cell-replete & 165 & 3.12 & 1.40106 .98 & 0.006 \\
\hline Autologous purged & 143 & 9.43 & 0.63 .303 .24 & 0.39 \\
\hline Autologous unpurged & 394 & 2.28 & 1.04104 .99 & 0.04 \\
\hline \multicolumn{5}{|l|}{ Intermediate-grade } \\
\hline Syngeneic & 30 & 1.00 & & \\
\hline Allogeneic T-cell-depleted & 23 & $\$ 60$ & 0.75 to 3.38 & 0.22 \\
\hline Allogeneic T-cell-teplete & 173 & 1.85 & 1.05 to 3.26 & 0.03 \\
\hline Autologous purged & 154 & 1.21 & 0.68 to 2.14 & 0.52 \\
\hline Autologous unpurged & 1,399 & 1,32 & 0.77102 .25 & 0.32 \\
\hline \multicolumn{5}{|l|}{ High-grade ${ }^{\text {atcl }}$} \\
\hline Syngeneic & 28 & 1.00 & & \\
\hline Allogeneic T-cell-depleted & 57 & 1.17 & 0.60102 .27 & 0.64 \\
\hline Allogeneic T-cell-replote & 373 & 1.04 & 0.58 to 1.84 & 0.00 \\
\hline Autologous purged & 36 & 1.31 & 0.63 to 2.75 & 0.47 \\
\hline Autologous unpurged & 169 & 0.98 & 0.54 to 1.79 & 0.96 \\
\hline
\end{tabular}

a Modell stratified by disease status at transplantation and year of transplantation; "other significant variable: chemotherapy-sensitive versus chemotherapy-resistant to initial chemotherapy (relative risk $[R R], 1.58 ; 95 \%, C l, 1.17$ to 2.13; $P=0.003$ ). Pairwise comparison between T-cell-replete versus $T$-cell-depleted allogeneic transplants $(R R, 1.70 ; \quad P=0.08)$, autologous unpurged versus purged $(R R, 1.59 ; \quad P=0.003)$; " other significant variable: chemotherapy-sensitive versus chemotherapy-resistant to initial chemotherapy (RR, $1.84 ; 95 \% \mathrm{Cl}, 1.55$ to $2.18 ; P=0.0001$ ). Patrwise comparison between T-cell-replete versus T-cell- depleted allogeneic transplants (RR, 1.16; $P=0.61$ ); autologous unpurged versus purged $(R R, 1.09 ; P=0.46)$; other significant variable: chemotherapy-sensitive versus chemotherapy-resistant to initial chemotherapy $\left(R^{2}, 1.91 ; 95 \% \mathrm{Cl}_{\text {, }}\right.$ 1.29 to 2.82; $P=0.001)$. Pairwise comparison between T-cell-replete versus T-celladepleted allogeneic transplants $\left(R R_{n}, 0.88 ; P=0.80\right)$; autologous unpurged versus purged $(\mathbb{R} R, 0.75 ; P=0.56)$.

Patients with intermediate-grade NHL who received allogeneic transplants that were not T-cell depleted had significantly poorer disease-free survival than recipients of syngeneic transplants ( $R R, 1.85 ; P=0.03$ ). No significant differences in disease-free survival were observed when recipients of T-cellreplete and $T$-cell- depleted allogeneic transplants were compared $(R R, 1.16$; $P=0.61$ ). No significant differences in disease-free survival were seen when results of autologous and syngeneic transplants were compared, or when purged and unpurged autologous transplants were compared (RR, 1.09; $P=0.46$ ). 
Among patients with high-grade histology, no significant differences in diseasefree survival were noted when autologous or allogeneic transplants were compared with syngeneic transplants. No advantages were associated with $T$ cell depletion or purging.

\section{Overall Survival}

The actuarial survival for each type of transplant is shown in Figure 9.3. Results of the multivariate analysis of factors independently associated with survival are listed in Table 9.4 .

A
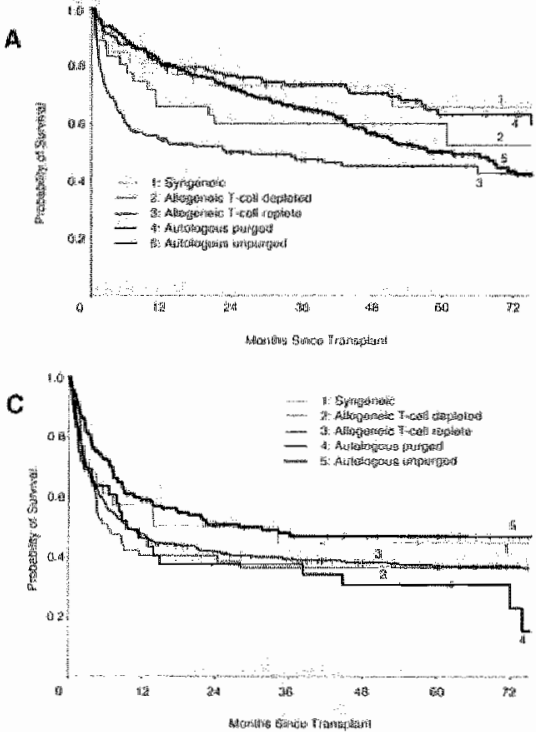

$\mathbf{B}$

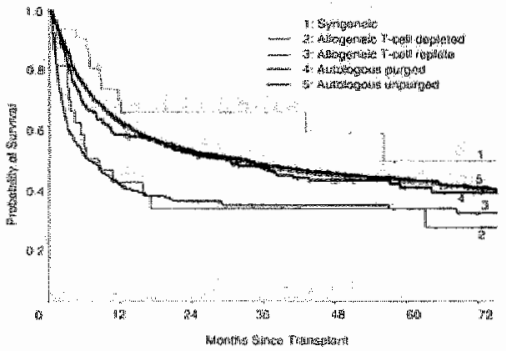

Figure 9.3 Actuarial probability of overall survival after transplantation for all patients according to type of transplant. (A) Low-grade histology, (B) intermediate-grade histology, (C) highgrade histology.

Low-grade NHL patients who received allogeneic transplants that were not Tcell depleted had significantly worse survival than patients who received syngeneic transplants (RR, 2.87; $P=0.006$ ). These patients also had significantly poorer survival than patients receiving T-cell-depleted allogeneic transplants $\left(R R_{n} 1.88 ; P=0.005\right)$. No survival differences were seen when autologous and syngeneic transplants were compared, although lack of purging was associated with poorer survival when purged and unpurged autologous transplants were compared (RR, $1.55 ; P=0.04)$. 
Table 9.4 Multivariate analysis: overall survival.

\begin{tabular}{|c|c|c|c|c|}
\hline & No. of patients & Relative risk of death & $95 \% \mathrm{Cl}$ & $P$ \\
\hline \multicolumn{5}{|l|}{ Low-grade $^{\text {ab }}$} \\
\hline syngeneic & 30 & 1.00 & & \\
\hline Allogeneic T-cell-depleted & 36 & 1.52 & 0.63 to 3.69 & 0.35 \\
\hline Allogeneic T-cell-replete & 189 & 2.87 & 1.36 to 6.06 & 0.006 \\
\hline Autologous purged & 160 & 0.80 & 0.37109 .74 & 0.57 \\
\hline $\begin{array}{l}\text { Autologous unipurged } \\
\text { Intermediate-grade }\end{array}$ & 427 & Intermediate-grade ${ }^{a c}$ & 0.60 to 2.57 & 0.57 \\
\hline Syngeneic & 31 & 1.00 & & \\
\hline Allogeneic T-cell-depleted & 26 & 1.85 & 0.88 to 3.92 & 0.41 \\
\hline Allogeneic T-cell-reptete & 194 & 2.19 & 1.22 to 3.91 & 0.008 \\
\hline Autollogous purged & 180 & 1.33 & 0.74 to 2.40 & 0.34 \\
\hline Autalogous unpurged & 1,417 & 1.25 & 0.71 to 2.18 & 0.44 \\
\hline \multicolumn{5}{|l|}{ High-grade ${ }^{a d}$} \\
\hline Syngeneic & 28 & 9.00 & & \\
\hline Allogeneic T-cell-depleted & 57 & 1.47 & 0.76 to 2.86 & 0.27 \\
\hline Allogeneic T-cell-replete & 391 & 1.30 & 0.73 to 2.31 & 0.37 \\
\hline Autologous purged & 36 & 1.47 & 0.72 to 3.00 & 0.29 \\
\hline Autologous unpurged & 174 & 0.92 & 0.50 to 1.68 & 0.79 \\
\hline
\end{tabular}

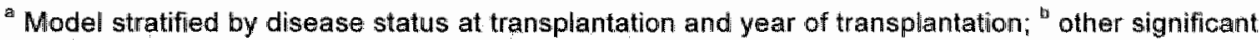
variable: chemotherapy-sensitive versus chemotherapy-resistant to initial chemotherapy (relative risk $[R R], 1.70 ; 95 \%, C l, 1.26$ to $2.29 ; p=0,0004$ ). Pairwise comparison between T-cell-replete versus $T$-cell-depleted allogeneic transplants $(R R, 1.88 ; P=0.005)$; autologous unpurged versus purged (RR, 1.55, $P=0.04) ;$ other significant variable: chemotherapy-sensitive versus chemotherapy-resistant to initial chemotherapy (RR, $1.92 ; 95 \% \mathrm{Cl}, 1.63$ to $2.26 ; P=0.0001$ ). Pairwise comparison between T-cell-replete versus $T$-cell-depleted allogleneic transplants (RR, $1.18 ; P=0.03)$; autologous unpurged versus purged $(R R, 0.94 ; P=0.61) ;$ th other significant variable: chemotherapy-sensitive versus chemotherapy-resistant to initial chemotherapy $\left(\mathrm{RR}_{2}, 1.50 ; 95 \% \mathrm{Cl}\right.$, 1.02 to $2.20 ; \quad P=0.04$ ). Pairwise comparison between T-cell-replete versus T-cell-depleted allogeneic transplants $(R R, 0.88 ; P=0.55)$; autologous unpurged versus puirged ( $R R, 0.63 ; P=0.06)$.

Patients with intermediate-grade NHL who received allogeneic transplants that were not T-cell depleted had significantly poorer survival than syngeneic transplant recipients ( $R R, 2.19 ; P=0.008$ ). In addition, a comparison of $T$-cellreplete and $T$-cell-depleted allogeneic transplants showed poorer survival when $T$-cell depletion was not used $(R R, 1.18 ; P=0.03)$. No significant survival differences were observed when autologous and syngeneic transplants were compared, and no survival advantage was associated with purging.

There were no significant survival differences when autologous or allogeneic transplants were compared with syngeneic transplants. No survival advantages were associated with T-cell depletion or purging. 


\section{Discussion}

The first part of this study was designed to look for evidence of a graft-versuslymphoma effect. Relapse rates after allogeneic hematopoietic stem-cell transplantation for NHL are lower than relapse rates after autologous transplantation. ${ }^{12-17}$. However, survival advantages are not seen with allogeneic transplantation because of higher transplantation-related mortality. Lower relapse rates following allogeneic transplantation suggest that a graft-versuslymphoma effect exists. However, these differences might also be explained by other factors such as lack of tumor contamination in the allograft.

We reasoned that comparing syngeneic transplantation with allogeneic transplantation would eliminate the confounding variable of tumor contamination and provide more definitive evidence for the existence of a graftversus-lymphoma effect, in the same way that graft-versus-leukemia effects were demonstrated. ${ }^{18}$ Studies of syngeneic transplantations for NHL are limited. Investigators from Seattle compared autologous, allogeneic, and syngeneic bone marrow transplantations in 100 lymphoma patients. ${ }^{19}$ No significant differences in relapse rate or disease-free survival were identified, but only 13 syngeneic transplantations were studied and two of these patients had Hodgkin's disease.

The multivariate analyses in our study failed to show a lower risk of relapse when allogeneic and syngeneic transplants were compared. Furthermore, there were no significant differences in relapse between T-cell-depleted and non-Tcell-depleted allografts, although T-cell depletion was associated with survival advantages in patients with low-grade and intermediate-grade histology. The analyses also failed to show a lower relapse rate in patients who developed GVHD.

Our failure to find evidence of a graft-versus-lymphoma effect must be examined in light of clinical evidence supporting this effect derived from comparisons of autologous and allogeneic transplants and the fact that graftversus-lymphoma effects have been demonstrated in some animal models. ${ }^{20}$ The existence of a graft-versus-lymphoma effect is also supported by reports of lymphoma regression when immunosuppression is withdrawn following relapse after allogeneic transplantation, ${ }^{21-23}$ and by reports of response to donor leukocyte infusion. ${ }^{24,25}$ Finally, lower rates of relapse or progression have been reported in patients who develop chronic GVHD after allogeneic transplantation for $\mathrm{NHL}^{26}$

Although this study does not provide evidence for a graft-versus-lymphoma effect, it is possible that this analysis lacked statistical power to show a difference in rates of relapse between allogeneic and syngeneic transplants. However, no trends in favor of this association were noted. A graft-versuslymphoma effect might be obscured by an increased frequency of adverse 
prognostic factors; such as chemotherapy resistance, in recipients of allogeneic transplants, although adjustment for prognostic factors in the multivariate analyses did not alter the results. Our analysis is also hampered by missing data, which made it impossible to include certain variables in the multivariate analyses. However, statistical adjustments for missing data did not indicate that this accounted for the results. For known prognostic factors, such as performance status, we included a category for missing data in the models. This allowed us to make adjustments to the fullest extent of the data available to us and to ensure that no patient cases were discarded, as would be necessary in a matched-pair analysis. Moreover, even with a more complete database, the use of case-matching does not improve statistical power when compared with regression analysis using all available patients. ${ }^{27,28}$ Although important variables such as history of marrow involvement, disease status, and chemotherapy sensitivity were included in the analyses, it is possible that allogeneic transplant recipients were more likely to have unidentified adverse prognostic features because this is not a randomized study.

Our results raise the hypothesis that lower relapse rates after allogeneic transplantation for NHL may be largely explained by other factors such as lack of tumor contamination of the autograft, and that graft-versus-lymphoma effects may not be as powerful as previously suspected. If true, an obvious implication is that the utility of nonmyeloablative allogeneic transplantations may need to be reconsidered. ${ }^{29}$ However, it must also be noted that the 5-year cumulative incidence of relapse after syngeneic transplantation was only $9 \%$ for patients with low-grade histology. This result is similar to the relapse rate after allogeneic transplantation in this series, as well as other reports of allogeneic transplantation for low-grade NHL. ${ }^{15,16,30}$ The similarly low rate of relapse after syngeneic and allogeneic transplantation suggests that long-term disease-free survival may be a result of the high-dose preparative regimen. This observation also suggests that graft-versus-lymphoma effects might be difficult to detect after high-dose therapy, and that effects could become more evident with less intensive conditioning regimens.

The second part of this study was a comparison of syngeneic and autologous hematopoietic stem-cell transplantation for NHL. Gene marking studies have shown that tumor contamination may contribute to relapse after autologous transplantation for acute myelogenous leukemia, chronic myelogenous leukemia, and neuroblastoma. ${ }^{31-33}$ Although this has not been demonstrated for $\mathrm{NHL}$, indirect evidence suggests that tumor contamination might also contribute to relapse.

The first evidence comes from reports of rapid disseminated relapse after autologous bone marrow transplantation for aggressive $\mathrm{NHL}^{34.35}$ Other evidence comes from studies showing lower relapse-free survival after autologous marrow transplantation in NHL patients whose marrow contains 
clonogenic tumor cells. ${ }^{36}$ Additional evidenice supporting the importance of tumor contamination comes from studies showing better survival in patients who received autografts that did not contain detectable tumor cells after purging. Another analysis showed a lower incidence of relapse after autologous hematopolietic stem-cell transplantation for NHL when more aggressive purging was used..$^{38}$ Finally, a case-matching study comparing purged and unpurged autologous transplants showed that low-grade $\mathrm{NHL}$ patients who received purged autografts had significantly better survival ${ }^{39}$

We reasoned that a syngeneic transplant is similar to an uncontaminated autograft and a comparison would provide another way to indirectly study whether tumor contamination contributes to relapse. A previous comparision of syngeneic and autologous bone marrow transplantations found no significant differences in relapse or disease-free survival in lymphoma patients. ${ }^{10}$

The multivariate analyses in our study showed a five-fold greater risk of relapse when results of unpurged autologous transplantations were compared with syngeneic transplantations for low-grade $\mathrm{NHL}$. In addition, recipients of unpurged autologous transplants had a significantly greater risk of relapse than those who received purged autografts. In low-grade NHL, purging was also associated with improved disease-free and overall survival. Among patients with intermediate-grade histology, those receiving unpurged autografts had a two-fold higher risk of relapse than did recipients of syngeneic transplants, although this difference was of borderline statisticall significance, and was no associated with improved survival.

Only one trial has prospectively studied the value of purging autologous transplants for $\mathrm{NHL} .{ }^{40}$ A preliminary analysis showed no significant differences in disease progression or survival between purged and unpurged transplants. Other analyses also failed to show a benefit from purging. ${ }^{39,41,42}$ Most relapses after autologous transplantlation for NHL occur at sites of prior disease, suggestimg that treatment failure most likely is due to inadequacy of high-dose therapy, rather than tumor contamination.

Nevertheless, our analyses provide additional indirect evidence that tumor contamination of the autograft may contribute to relapse after autologous hematopoietic stem-cell transplantation for low-grade, and possibly intermediate-grade, NHL. It is possible that a syngeneic graft-versus-lymphoma effect could explain these results. ${ }^{43}$ However, it seems unlikely that this effect is important given the lack of evidence for an allogeneic graft-versus-lymphoma effect in our study, although a potent syngeneic graft-versus-lymphoma effect might make it impossible to identify an allogeneic graftversus-lymphoma effect in this analysis. A syngeneic graft-versus-lymphoma effect could also explain the observed differences in relapse rate between syngeneic and autologous transplants. 
In summary, this analysis failed to show evidence of a graft-versus-lymphoma effect. In contrast, this analysis provides additional evidence to suggest that tumor contamination can contribute to relapse after autologous hematopoietic stem-cell transplantation for low-grade, and possibly intermediate-grade, NHL. Although registry-based analyses are hindered by treatment heterogeneity and missing data, our results suggest the possibility that absence of tumor contamination accounts for some of the differences in relapse that have been attributed to a graft-versus-lymphoma effect when autologous and allogeneic transplants for NHL have been compared. Our results suggest that in vitro purging, positive selection, ${ }^{44}$ or in vivo purging ${ }^{45}$ may be beneficial, although randomized trials are the only way to prove the value of these approaches. In rare instances when a syngeneic donor is available, this may be the preferred type of transplant. 


\section{References}

1. National Hospital Discharge Survey for 1990 and 1991. US Department of Health and Human Services, Public Health Service, Centers for Disease Control Hyattsville, MD, National Center for Health Statistics, Hospital Care Statistics Branch

2. Graves EJ: Detailed diagnoses and procedures, National Hospital Discharge Survey, 1991. Vital Health Stat $131994: 115: 1-290$.

3. The Non-Hodgkin's Lymphoma Classification Project National Cancer Institute sponsored study of classifications of non-Hodgkin's lymphomas - Summary and description of a working formulation for clinical usage. Cancer 1982;49:2112-35.

4. Harris NL, Jaffe ES, Stein $\mathrm{H}_{\text {}}$ et al: A Revised European-American Classification of Lymphoid Neoplasms: A proposal from the International Lymphoma Study Group. Blood 1994:84:136192

5. Harris NL, Jaffe ES, Diebold J, et al: World Health Organization Classification of neoplastic diseases of the hematopoietic and lymphoid tissues: Report of the Clinical Advisory' Committee Meeting-Airlie House, Virginia, November 1997. J Clin Oncol 1999:17:3835-49.

6. Kaplan EL, Meier P: Non parametric estimation from incomplete observations. J Am Stat Assoc 1958:53:457-81.

7. Mantel N: Evaluation of survival data and two new rank order statistics arising in its. consideration. Cancer Chemother Rep 1966;50:163-70.

8. Gooley TA, Leisenring W, Crowley $\downarrow_{\text {, }}$ et al: Estimation of failure probabilities in the presence of competing risks: New representations of old estimators. Stat Med 1999;18:695-706.

9. Klein JP, Moeschberger ML: Survival Analysis: Techniques for Censored and Truncated Data. New York, NY, Springer, 1997:334-6.

10. Cox DR: Regression madels and life-tables. J R Stat Soc 1972;34:187-220.

11. Andersen PK, Klein JP, Zhang M-J: Testing for centre effects in multi-centre survival studies: A Monte Carlo comparison of fixed and random effects tests. Stat Med 1999;18:1489-500.

12. Jones RJ, Ambinder RF, Piantadosi $S$, et al: Evidence of a graftversus-lymphoma effect associated with allogeneic bone marrow transplantation. Blood 1991;77:649-53.

13. Ratanatharathorn $V$, Uberti $J$, Karanes $C$, et al: Prospective comparative trial of autologous versus allogeneic bone marrow transplantation in patients with non-Hodgkin's lymphoma. Blood 1994:84:1050-5.

14. Peniket A. "Ruiz de Elvira MC. Taghipour $G$, et al: Allogeneic transplantation for lymphoma produces a lower relapse rate than autologous transplantation but survival is worse because of higher treatment ralated montality: A report of 764 cases from the EBMT lymphoma registry. Blood 1997;90:255a.

15. Attal M, Socie $G$, Molina $L$, et al: Allogeneic bone marrow transplantation for refractory and recurrent follicular lymphoma: A case-matched analysis with autologous transplantation from the French bone marrow transplant group registry data. Blood 1997:90:255a.

16. Verdonck $L F$ : Allogeneic versus autologous bone marrow transplantation for refractory and recurrent llow-grade non-Hodgkin's Iymphoma: Updated results of the Utrecht experience. Leuk Lymphoma 1999:34:129-36.

17. Schimmer AD, Jamal $S$, Messner $H_{1}$ el al: Allogeneic or autologous bone marrow transplantation (BMT) for non-Hodgkin's lymphoma (NHL): Results of a provincial strategy. Bone Marrow Transplant 2000;26:859-64.

18. Horowitz MM, Gale RP, Sondel PM, al: Graft-versus-leukemiä reactions after bone marrow transplantation. Blood 1990;75;555-62.

19. Appelbaum FR, Sullivan KM, Buckner $C D$, et al: Treatment of malignant lymphoma in 100 patients with chemotherapy, total body irradiation, and marrow transplantation. J Clin Oncol $1987 ; 5: 1340-7$.

20. Ito $M$. Shizuru JA: Graft-vs.-lymphoma effect in an allogeneic hematopoietic stem-cell transplantation model. Biol Blood Marrow Transplant 1999;5:357-68. 


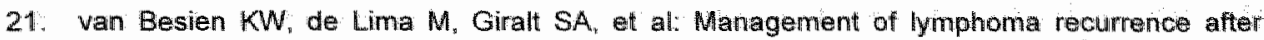
allogeneic transplantation: The relevance of graft-versus-lymphoma effect. Bone Marrow Transplant 1997:19:977-82.

22. Petersen FM, Appelbaum FR, Bigelow $\mathrm{CL}$, et al: High dose cytosine arabinoside, total body irradiation and marrow transplantation for advanced malignant lymphoma. Bone Marrow Transplant 1989;4:483-8.

23. Grigg $A$, Bardy $P$, Byron $K$, et al: Fludarabine-based non-myeloablative chemotherapy followed by infusion of HLA-identical stem cells for relapsed leukaemia and lymphoma. Bone Marrow Transplant 1999;23:107 -10.

24. Bernard $M_{1}$, Dauriac $C$. Dre'nou $B$, et at: Long-term follow-up of allogeneic bone marrow transplantation in patients with poor prognosis non-Hodgkin's lymphoma. Bone Marrow Transplant 1999;23:329-33.

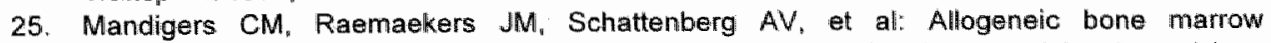
transplantation with T-cell depleted marrow grafts for patients with poor-risk relapsed lowgrade non-Hodgkin's lymphoma. Br J Haematol 1998:100:198:206.

26. Chopra R, Goldstone AH. Pearce $R$, et al: Autologous versus allogeneic bone marrow transplantation for non-Hodgkin's. lymphoma: A case-controlled analysis of the European Bone Marrow Transplant Group registry data. J Clin Oncol 1992;10:1690-5.

27. Klein J, Zhang $M$. Statistical challenges in comparing chemotherapy and bone marrow transplantation as a treatment for leukemia, in Jewell NP (ed): Lifetime Data: Models in Reliability and Survival Analysis. Boston, MA, Kluwer Academic, 1996:175-85.

28. Klein JP, Rizzo JD, Zhang M-J, et al: Statistical methods for the analysis and presentation of the results of bone marrow tramsplants: Part 2. Regression modeling. Bone Marrow Transplant 2001;28:1001-11.

29. Khouri IF, Saliba RM, Giralt SA, et al: Nonablative allogeneic hematopoietic transplantation as adoptive immunotherapy for indolent lymphoma: Low incidence of toxicity, acute graftversus-host disease, and treatment-related mortality. Bload 2001;98:3595-9.

30. van Besien K, Sobocinski KA, Rowlings PA, et al: Allogeneic bone marrow transplantation for low-grade lymphoma. Blaod 1998;92:18:32-6.

31. Rill DR, Santana VM, Roberts $W M$, et al: Direct demonstration that autologous bone marrow transplantation for solid tumors can return a multiplicity of tumorigenic cells. Blood 1994:84:380-3.

32. Deisseroth $A B, Z u Z$, Claxton $D_{n}$ et al: Genetic marking shows that $P h$ cells present in autologous transplants of chronic myelogenous leukemia $(\mathrm{CML})$ contribute to relapse after autologous bone marrow in CML. Blood 1994;83:3068-76.

33. Brenner MK, Rill DR, Moen RC, et al: Gene-marking to trace origin of relapse after autologous bone-marrow transplantation. Lancet 1993;341:85-6.

34. Vaughan WP, Weisenburger DD, Sanger W, et al: Early leukemic recurrence of non Hodgkin lymphoma after high-dose anti-neoplastic therapy with autologous marrow rescue. Bone Marrow Transplant 1987;1:373-8.

35. Rossetti F, Deeg HJ, Hackman RC: Early pulmonary recurrence of non-Hodgkin's lymphoma after autologous marrow transplantation: Evidence for reinfusion of lymphoma cells? Bone Marrow Transplant 1995:15:429-32.

36. Sharp JG, Kessinger $A$, Mann $S$, et al: Outcome of high-dose therapy and autologous transplantation in non-Hodgkin's lymphoma based on the presence of tumor in the marrow or infused hematopoietic harvest. J Clin Oncol 1996;14:214-9.

37. Gribben JG, Freedman AS, Neuberg D, et al: Immunologic purging of marrow assessed by PCR before autologous bone marrow transplantation for Bi-cell lymphoma. $N$ Engl $J$ Med $1991 ; 325: 1525-33$.

38. Fouillard L, Laporte JP, Labopin $M$, et al: Autologous stem-cell transplantation for nonHodgkin's lymphomas: The role of graft purging and radiotherapy posttransplantation-results of a retrospective analysis on 120 patients autografted in a single institution. $J$ Clin Oncol $1998 ; 16: 2803-16$. 
39. Williarns CD, Goldstone AH, Pearce RM, et al: Purging of bone marrow in autologous bone marrow transplantation for non-Hodgkin"s lymphoma: A case-matched comparison with unpurged cases by the European Blood and Marrow Transplant Lymphoma Registry. $J$ Clin Oncol 1996;14:2454-64.

40. Schouten $H C$, Kvaloy $S$, Sydes $M_{n}$ et al: The CUP trial: $A$ randomized study analyzing the efficacy of high-dose therapy and purging in low-grade non-Hodgkin's lymphoma (NHL). Ann Oncol 2000;11:91/4.

41. Brunvand $M W_{*}$, Bensinger $W$, Soll $E_{;}$et al: High-dose fractionated total-body irradiation, etoposide and cyclophosphamide for treatment of malignant lymphoma: Comparison of autologous bone marrow and peripheral blood stem cells. Bone Marrow Transplant $1996: 18: 131-41$.

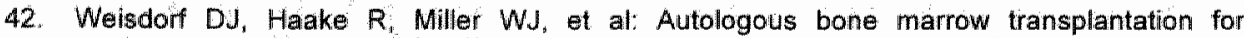
progressive non-Hodgkin's lymphoma: Clinical impact of immunophenotype and in vitro purging: Bone Marrow Transplant 1991;8:135-42.

43. Einsele $H_{\text {, Ehninger }} G$, Schneider $E M$, et al: High frequency of graft-versus-host-like syndromes following syrigeneic bone marrow transplantation. Transplantation 1998:45:579. 85.

44. MeQuaker $1 G$, Haynes AP, Anderson $S$, et al: Engraftment and molecular monitoring of CD34 peripherall-blood stem-cell transplants for follicular lymphoma: A pilot study. J Clin Oncol 1997; 15:2288-95:

45. Flinn IW, O'Donnell PV, Goodrich $A_{i}$ et al: Immunotherapy with rituximab during peripheral blood stem cell transplantation for non-Hodgkin's lymphoma. Biol Blood Marrow Transplant 2000;6:628-32. 


\section{Chapter 10}

\section{General discussion}

Stem cell transplantation in follicular lymphoma: progress at last?

WW Tse, HM Lazarus, K van Besien 


\section{Abstract}

Follicular non-Hodgkin's lymphiomas usually present in advanced stage and although frequently are chemotherapy-sensitive remain incurable using conwentional approaches. Treatment options are evolving rapidly and now include targeted therapies such as monoclonal antibodies. Riecent studies, including the EBMTR-sponsored "CUP Trial' (conventional Chemotherapy. Unpurged autograft Purged autograft), demonstrate that for patients under age 60 years with recurrent chemotherapysensitive disease, autologous stem cell transplantation (ASCT) provides a survival benefit over conventional therapy. Allogen eic stem cell transplantation (alloSCT) has become a more effective option.Al though incorporation of $\mathrm{TBI}$ into the preparative regimen may increase treatiment-related mortality (TRM) n relapses appear to be reduced compared to a chemotherapyalone regimen, Reduced-intensify alloSCT procedures are now being performed at an increasing rate, in part due to a lower risk for TRM. Until more data are available, however, reduced-intensity alloSCT should be considered anly in cases where myeloablative conditioning is contra-indicated. The re are no clear means for choosing ASCT vs alloSCT, a decision influenced by the amount of resiclual tumor, disease-responsiveness, degree of marrow involvement and extent of prior chemotherapy. ASC T or alloSCT in first remission remains an investigational procedure. Future considerations include incorporation of novel preparative regimens, in vitro purging techniques, antifymphoma vaccines, post transplant immunotherapy and ex vivo-manipulated donor lymphocyte infusions. 


\section{Introduction}

Follicular non-Hodgkin's Iymphoma (NHL) comprises approximately one-third of all lymphomas with about $80 \%$ of patients having advanced-stage disease at diagnosis. 'Paradoxically, this chemotherapy-sensitive disorder is generally incurable using conventional means. Median survivals are 8-10 years even in advanced-stage disease, but the annual mortality rate is approximately $6 \%$ per year. Prognosis of individual patients is difficult to predict, and use of prognostic scoring systems such as the Age-Adjusted International Prognostic Index (IPI) is of limited value although more recent data indicate that the Follicular Lymphoma International Prognostic Index (FLIPI) may be helpful. ${ }^{2.3}$ After initial treatment and first recurrence, the natural history of follicular NHL is a continuum of successive relapses of progressively shorter duration and ultimately death from the underlying disease. ${ }^{4.5}$ Conventional chemotherapy has limited or no impact on survival; immunotherapy with agents such as interferon likely has modest impact but often is poorly tolerated and therefore not widely used. ${ }^{6-9}$ Newer treatments such as the monoclonal antibodies rituximab, tositumomab (Bexxars) and ibritumomab tiuxetan (Zevalin®) have excellent activity and a favorable side-effect profile. It will be years, however, before any impact on survival will become apparent. Highdose chemotherapy with autologous stem cell transplantation (ASCT) or allogeneic stem cell transplantation (alloSCT) represents an alternative treatment approach. Advantages of stem cell transplantation include the potential favorable impact upon survival, while disadvantages are toxicity and an adverse side-effect profile. ${ }^{10}$ In this article, we will review the current status of ASCT and alloSCT for follicular NHL.

\section{Autologous stem cell transplantation: indications and results}

\section{ASCT for recurrent disease}

Conventional dose chemotherapy for the treatment of patients with recurrent follicular NHL is likely to produce remissions but of shorter duration each time. Several phase II studies suggest, however, that salvage treatment followed by consolidation with ASCT can prolong disease-free survival (DFS) in relapsed disease patients. Freedman et al. ${ }^{11}$ reported the largest single institution experience. A total of 153 patients were treated using autologous bone marrow purged in vitro with anti-B-cell monoclonal antibody. At a median follow-up of 5 (range 2-13) years, the 8-year DFS and overall survival (OS) were estimated as 42 and $66 \%$, respectively. Table 10.1 lists the major phase II trials that 
showed similar results using different hematopoietic stem cell sources, ex vivo purging methods, highdose conditioning regimens and follow-up periods. ${ }^{11-27}$ All trials suggested an improved median duration of PFS compared to historic controls treated with conventional chemotherapy, a fraction of patients attained prolonged PFS, On the other hand, with langer follow-up, recurrence rates of over $50 \%$ were generally observed and questions remain as to whether the durable responses were due to a treatment effect vs patient selection. Comparisons with historic controls suggesting that transplant results in improved survival were not entirely convincing. 19.28

The EBMTR-sponsored CUP trial (conventional Chemotherapy, Unpurged autograft, Purged autograft) conducted between 1993 and 1997 is the only prospective, randomized trial to address the role of ASCT in prolonging PFS and OS in patients with follicular $\mathrm{NHL}^{24}$ Due to slow accrual, the trial was closed after enrollment of 140 of a planned 250 patients. In all, $65 \%$ of patients were in first relapse, the remainder in subsequent relapses. Patients were given three initial cycles of chemotherapy (usually a CHOP-like regimen) and 89 patients who attained at least a partial response were randomized to one of three treatment arms: further conventional chemotherapy, ASCT using purged and ASCT using unpurged autografts. Too few patients were entered to assess the effect of ex vivo purging. PFS and OS at 2 years after transplant for both patient groups randomized to ASCT were 55 and $71 \%$ compared to 26 and $46 \%$, respectively, for those receiving conventional chemotherapy. ${ }^{24}$ Hazard ratios for survival and PFS were 0.3 and 0.4 , respectivelly, when comparing conventional chemotherapy with ASCT. These data are highly statistically significant and demonstrate that ASCT provides an important survival benefit in patients with chemosensitive recurrences of follicular $\mathrm{NHL}$ and currently should be considered a treatment of choice in this situation.

\section{ASCT as consolidation of first remission}

ASCT also has been used for low-grade NHL patients in first complete or partial remission in order to prolong or render such remissions permanent. Several phase 11 trials are summarized in Table $10.2 .^{15,26,28-36}$ The trial reported by Freedman et al. ${ }^{29}$ "enrolled advanced disease stage patients who had responded to $\mathrm{CHOP}$ chemotherapy and underwent consolidation with $\mathrm{Cy} / \mathrm{TB}$ and ASCT. Although durable responses were observed, the investigators reported a continuous risk of disease recurrence. Horning et al. ${ }^{30}$ used a similar strategy, but described improved disease recurrence risk and survival after ASCT compared to a historic control group ( 30 vs $70 \%$ estimated 10 -year risk of disease recurrence and 84 vs $62 \%$ estimated 10-year survival). Additionally, the results recently reported by Corradini et al. ${ }^{31}$ were similar. 


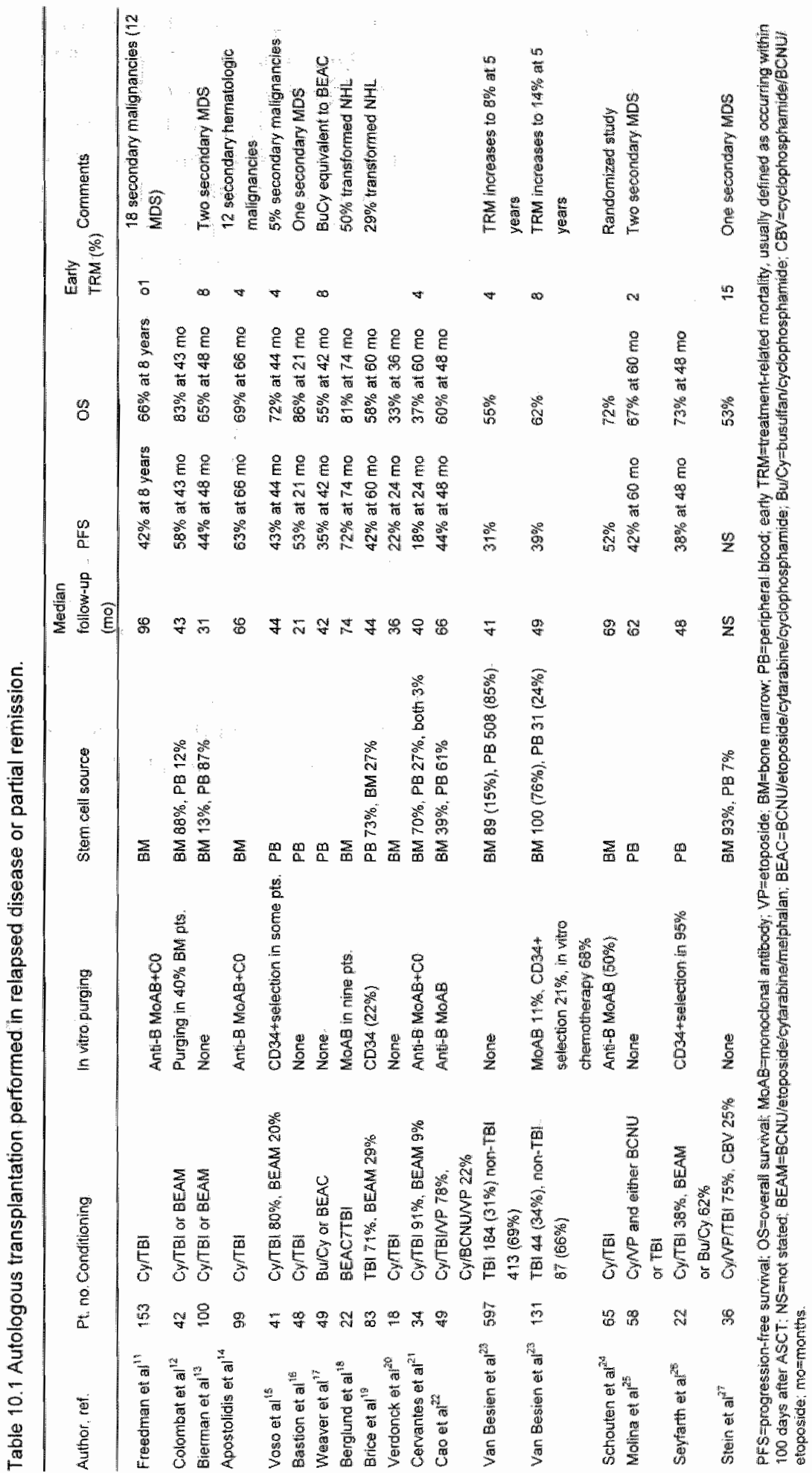


The encouraging phase 11 data summarized in Table 10.2 led several groups to develop multi-center, randomized studies comparing ASCT consolidation vs interferon maintenance or observation. The German Low Grade Lymphoma Study Group randomized chemosensitive indolent (mostly follicular) NHL patients younger than 60 years in first partial or complete remission to ASCT vs maintenance interferon therapy. ${ }^{32}$ A total of 240 follicular NHL patients were evaluable for the comparison of ASCT vs interferon maintenance. At a median follow-up period of 4.2 years, 31 relapses $(27.2 \%)$ were observed in the ASCT study arm and $76(60.3 \%)$ in patients receiving IFN maintenance. In addition, five deaths occurred in remission (four patients in the ASCT study arm and one in the IFN group). Accordingly, the PFS was significantly different in the two study arms. In patients receiving ASCT, the PFS was $79.1 \%$ after 2 years ( $95 \%$ confidence interval $71.4-86.9 \%)$ and $64.7 \%$ after 5 years $(95 \%$ confidence interval $54.6-74.8 \%$ ) in comparison to only $52.7 \%$ (95\% confidence interval $43.8-61.7 \%)$ after 2 years and $33.3 \%$ (95\% confidence interval $24.3-42.3 \%$ ) after 5 years in the IFNa study arm $(P<0.0001)$. This trial, however, does not have sufficient follow-up to assess the impact of ASCT on (OS). The French GOELAM group also reported, in preliminary fashion, that ASCT decreased recurrence rates but did not have any effect on long-term survival. ${ }^{33}$ This finding may be due to the fact that patients undergoing ASCT appeared at increased risk for the development of myelodysplastic syndrome (MDS) ${ }^{37}$ In the absence of a demonstrated survival benefit, the data do not support ASCT in first remission for follicular NHL patients outside of a clinical trial.

\section{Transformed follicular NHL}

Over time a considerable percentage of follicular NHL patients develop disease transformation. Such patients are often treated in a manner similar to large cell NHL patients, but tend to have a poor prognosis and are considered incurable. Early reports indicated ASCT to be ineffective in this patient group.38 Subsequently, improved patient selection resulted in better overall outcome and has led to ASCT as consolidation treatment after reinduction therapy. Table 10.3 illustrates several small studies indicating that consolidation with ASCT can induce durable remissions in some patients. ${ }^{18,22.31,39-42}$ In fact, some larger retrospective analyses suggest a survival benefit of ASCT in the setting of transformation that might be comparable to results in nontransformed follicular NHL or diffuse large cell NHL. ${ }^{41-43}$ For example, in the case-matched report from the EBMTR, a subgroup of patients with chemosensitive minimall residual disease prior to an ASCT had an overall 5-year survival of $69 \%{ }^{41}$ 

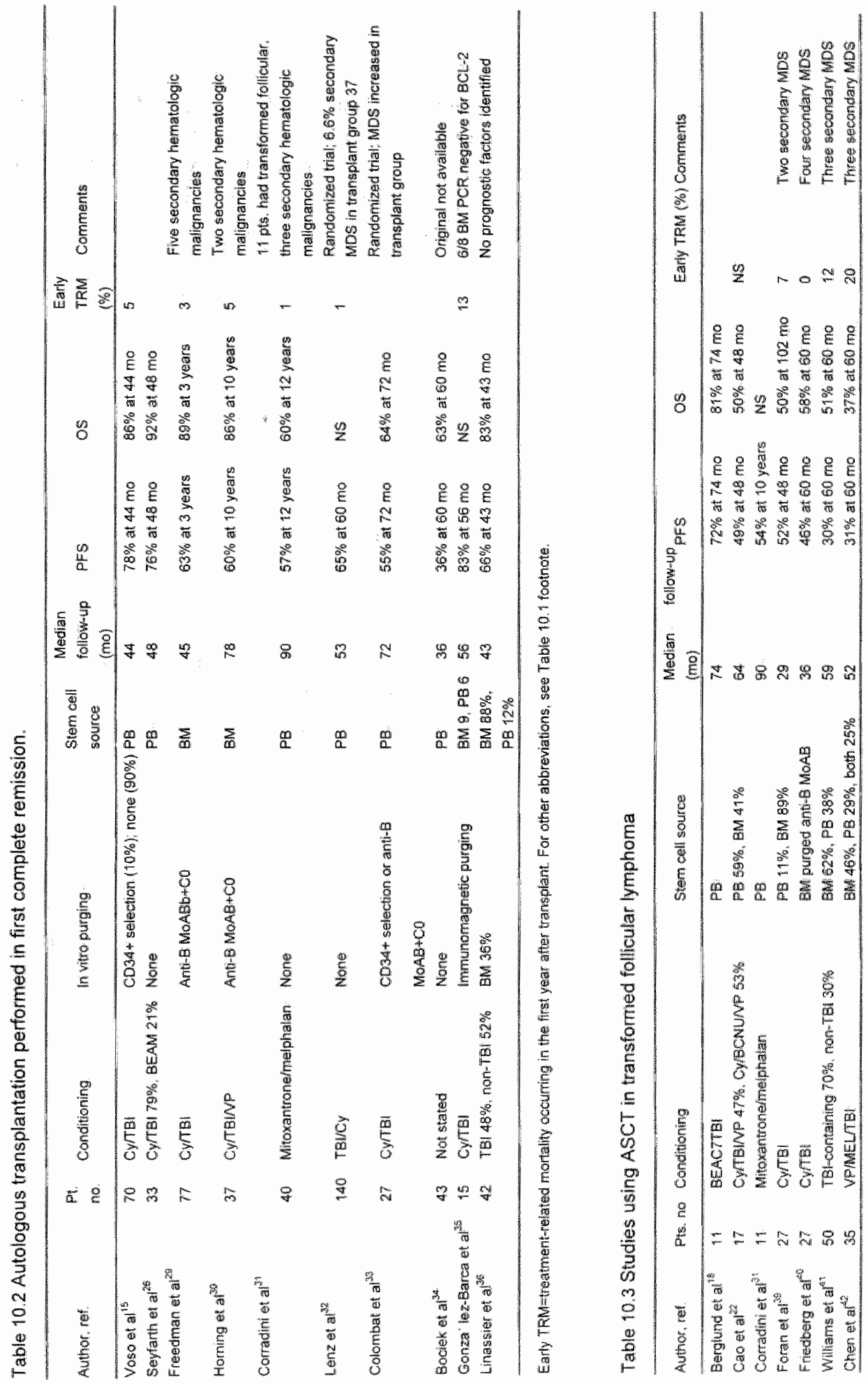


\section{Technical considerations}

Several technical aspects of ASCT such as choice of hematopoietic stem cell source, ex vivo purging, conditioning regimen and aspects of supportive care may have a considerable influence on the outcome of transplant and ideally should be investigated in prospective, randomized studies. For a variety of reasons, including the large number of patients required, considerable expense of such an undertaking and requirement for prolonged follow-up, these aspects of care generally have not been addressed in this fashion. Definitive answers to questions of the optimal preparative regimen or optimal stem cell source therefore are not possible. Some recommendations can be provided by comparison of individual study results, case-control studies and best perhaps from multivariable analysis of large observational data sets.

\section{Conditioning}

Transplant conditioning regimens for ASCT in follicular NHL can be classified into three variants: TBI-containing, high-dose BCNU-based (BEAC, BEAM, CBV) and busulfan-based (Bu/Cy, Bu/NP16). Largely for historic reasons, TBIcontaining or BCNU-based regimens most commonly are used in follicular NHL. Both an EBMTR study and IBMTR analysis indicated that use of TBI might be associated with an increased treatment-related mortality (TRM). Williams et al. ${ }^{41}$ in the EBMTR noted an $18 \%$ TRM (nine of 50 ) in transformed follicular NHL patients undergoing ASCT; all nine patients received TBI. van Besien et al. ${ }^{23}$ in the IBMTR noted nearly a two-fold lower TRM in the 553 patients who received a non-TB| preparative regimen compared to the 348 subjects given TBI $(P=0.008)$. On the other hand, TBI in the preparative regimen was associated with a statistically significant decrease in the rates of disease recurrence $(P=0.02)$.

These observations, while far from definitive, suggest that TBI is a particularly effective, but a rather toxic treatment for follicular lymphoma and provide a rationale for the further development of radio-labeled monoclonal antibodies as part of conditioning regimens for transplant. ${ }^{44}$ In a single-center, phase II study reported by Gopal et al., ${ }^{45} 98$ individuals with follicular lymphoma transplanted using conventional-dose ASCT (70\% received a TBI-containing regimen) were compared to 27 patients transplanted using high-dose chemotherapy and radioimmunotherapy $\left({ }^{131}\right.$ I-anti-CD20 monoclonal antibody, tositumomab). The estimated 5-year OS and PFS were 67 and $48 \%$, respectively, for those subjects given radioimmunotherapy conditioning compared to 53 and $29 \%$, respectively, for conventional ASCT. Further, 100-day TRM was only $3.7 \%$ in the radioimmunotherapy group vs $11 \%$ in the conventional group both groups had similar probabilities of secondary MDS/AML. Interesting preliminary data 
regarding the use of ${ }^{166}$ henium-labeled anti-CD20 followed by autogous stem cell rescue recently were reported by a Geman Group. ${ }^{40}$

\section{In vitro purging}

Most patients with follicular NHL present in advanced disease stage and often with morphologic evidence of marrow involvement. ${ }^{47}$ Even in patients with histologically normal marrow, occult marrow involvement can usually be demonstrated by PCR technique. ${ }^{48}$ It is likely that these lymphoma cells contaminating the stem cell infusate contribute to relapse after ASCT. Whille direct evidence for this hypothesis is lacking, several lines of indirect evidence support this concept. First, several groups have demonstrated that presence of occult stem cells in the graft correlates with risk of disease recurrence. ${ }^{49-5 \%}$ Further, Gribben et al. ${ }^{53}$ used PCR technique to detect Iymphoma celis in the circulation within hours after infusion of stem cells containing occult lymphoma cells. Third, in other hematologic malignancies such as AML, ALL and CML, a direct contribution of the graft to disease recurrence has been demonstrated by gene-marking experiments. ${ }^{54.55}$

Ex vivo technologies to decrease tumor contamination include 'positive' selection, ${ }^{56}$ that is, the in vitro enrichment of the graft for CD34 cells, a marker presumably lacking on עymphoma cells, as well as 'negative' selection, that is, the removal of tumor cells by exposure to lymphoma-specific antibodies. These methods have been extensively investigated and several phase II studies suggest that effective purging is of clinical benefit. For example, the group from the Dana Farber Cancer Institute found that successful in vitro purging was associated with dramatically improved freedom from relapse in follicular $\mathrm{NHL}$ patients undergoing ASCT. ${ }^{11.29}$ Furthermore, Ladetto et al. ${ }^{52}$ showed that successful in vivo purging (i.e., the generation of PCR-negative harvests after intensive induction chemotherapy) was associated with improved PFS. Fouillard et al., ${ }^{50}$ using various purging methods, also found a correlation between ex vivo graft treatment and outcome. Only one group failed to find a correlation between PCR status of the infusate and recurrence. ${ }^{14}$ The obvious corollary of these findings is that occult lymphoma cells contribute to recurrence in tumor-contaminated grafts. The absence of a satisfactory control group in these studies, however, makes it impossible to rule out the alternative explanation, namely that the ability to achieve a tumor-free graft is a surrogate for chemotherapy sensitivity. The CUP trial attempted to address this issue in a prospective fashion, but low patient numbers limited the study's power. ${ }^{24}$ The best, albeit indirect, evidence concerning the role of a tumor-free graft comes from several registry analyses. A case-control study from EBMTR demonstrated an improved PFS in patients given purged rather than unpurged autografts for follicular NHL. ${ }^{58}$ A group of 270 patients given purged (marrow) 
ASCT were compared to 224 casematched unpurged (marrow) ASCT patients. Patients with low-grade NHL did not have a significantly improved PFS if the bone marrow was purged $(P=0.1757)$; however, they did have a significantly improved OS $(P=0.00184)$. This increased OS was found to be associated with non-TBl conditioning and also with the purged patients undergoing transplantation at large transplant centers $(P=0.0016)$. More recently, a retrospective IBMTR study identified stem cell purging as an independent predictor for relapse. PFS and OS $(P=0.03)$ in multivariate analysis. ${ }^{23}$ The hazard ratio for disease recurrence after purged transplant was $75 \%$ of that after unpurged transplantation. Third, a case-control study by Bierman et al. ${ }^{59}$ comparing syngeneic transplants, purged ASCT and unpurged ASCT showed that syngeneic transplants had a very low recurrence rate. When compared with syngeneic transplants, unpurged ASCT had a significantly higher (nearly five-fold) risk of relapse $(P=0.008)$; recipients of purged ASCT had a threefold higher relapse risk than syngeneic transplant recipients, but this difference was not statistically significant $(P=0.10) .{ }^{59}$ We interpret these data as indicative of the importance of providing a tumor-free graft. Current technology limits the efficiency of graft purging. For example, in the Dana-Farber series, persistent marrow involvement could be detected in almost half the patients after negative selection with a panel of monoclonal antibodies. ${ }^{11,29} \| \mathrm{n}$ addition to positive and negative in vitro selection, in vitro chemotherapy exposure has been used for purging of stem cells. ${ }^{50}$ This technique, while of historic and perhaps clinical interest, has fallen out of favor because of its complexity, the associated nonselective damage to normal progenitors and the subsequent delay in hematopoietic recovery after graft re-infusion. More recently, rituximab has also been used as an 'in vivo purging' agent. Pilot studies indicate that rituximab administration may eliminate PCR-detectable cells in a significant proportion of hematopoietic cell harvests but may be associated with late neutropenia and serious infection. ${ }^{60-62}$ Whether transplant outcome will be improved by collecting PBSC after exposure to rituximab remains to be demonstrated. Several novel purging technologies are currently undergoing early evaluation. For example, the anti-CD133 monoclonal antibody targets a primitive stem cell population and is being evaluated for positive stem cell selection. ${ }^{63}$ Others are using pulsed electric fields to deplete tumor cells from a graft selectively. ${ }^{64}$

\section{Late toxicites of ASCT: MDS and treatment-related leukemia}

Although early morbidity is considerable, advances in supportive care significantly reduced the immediate treatment-related mortality associated with ASCT, even in elderly patients. On the other hand, late treatment-related side effects, such as MDS or secondary acute myeloid leukemia (SAML), occur at a 5 to 15 -fold increased incidence. ${ }^{65,66}$ The etiology of post transplant MDS is 
complex and is related to a combination of host-related factors, prior freatment and conditioning. Micallef et al. ${ }^{57}$ reported upon 230 follicular NHL patients given cyclophosphamide and TB followed by ASCT. At a median follow-up of 6 years, $27(12 \%)$ developed therapy-related MDS or AML 4.4-8.8 years after transplant; prior fludarabine therapy $(P=0.009)$ and older age $(\rho=0.02)$ were associated with the development of the secondary malignant processes. Others have related the risk of secondary MDS to pretransplant treatment with etoposide or radiation ${ }^{68}$ or to pretransplant exposure to mechlorethamine or chorambucil. ${ }^{69}$ Excessive doses of radiation in the conditioning regimen may also be associated with increased risk for secondary MDS. ${ }^{69}$ Interestingly, some studies have shown that clonal chromosomall abnormalities can often be detected in the graft of patients who have developed MDS after transplant ${ }^{70,74}$ The outcome for patients who develop treatment-related MDS/AML is Usually is quite poor. $^{72 ; 73}$

\section{Allogeneic stem cell transplantation}

\section{Myeloablative transplantation}

The exact role of alloSCT in follicular NHL remains somewhat difficult to define. AlloSCT was initially used in patients thought not candidates for ASCT due to the extent of disease or marrow involvement; investigators believed that the allogeneic or graft-versus-tumor effect would eradicate disease via adoptive immunotherapy. ${ }^{74-82}$ Several retrospective studies suggest that alloSCT is associated with a very low relapse rate and might be a curative treatment for

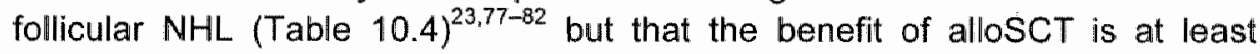
partially offset by high TRM. The IBMTR reported data on 904 follicular NHL patients who during the period 1990 and 1999 underwent either ASCT or alloSCT.23 A total of $176(19 \%)$ patients underwent alloSCT, 131 (14\%) were given purged ASCT and $597(67 \%)$ received unpurged ASCT. The 5-year TRM rates were 30,14 , and $8 \%$ and recurrence rates were 21,43 , and $58 \%$ after alloSCT purged ASCT, and unpurged ASCT, respectively. Furthermore, the 5year probabilities of survival were 51,62 , and $55 \%$ after alloSCT, purged ASCT and unpurged $\mathrm{ASCT}^{23}$ This communication confirms the high TRM yet low recurrence rate associated with the use of alloSCT and overall similar long term patient survivals compared to ASCT. These data do not allow practitioners to make decisions for individual patients regarding the use of alloSCT vs ASCT; such treatment recommendations continue to be guided by physician judgment. Over the past decade, advances in supportive care and better patient selection have resulted in improved outcomes for alloSCT (Figure 10.1). ${ }^{23}$ Also, the risk of secondary MDS after alloSCT is negligible. 

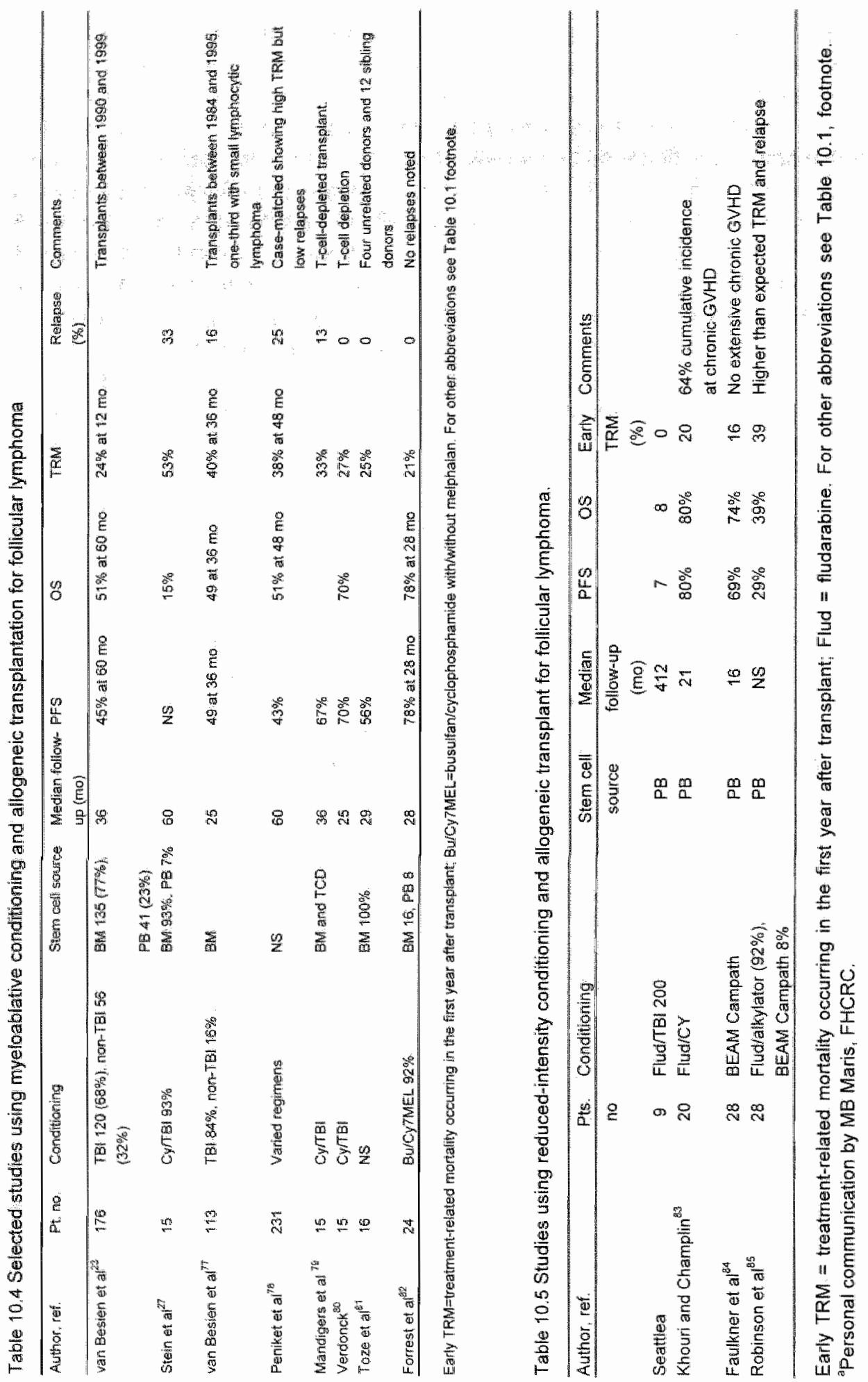
We currently recommend alloSCT as the preferred therapy for recurrent $\mathrm{NHL}$ patients who are aged 50 years or less and who have an HLA-identical sibling donor. Use of a TBI-based conditioning regimen may be preferred due to the decreased recurrence rate associated with that modality.

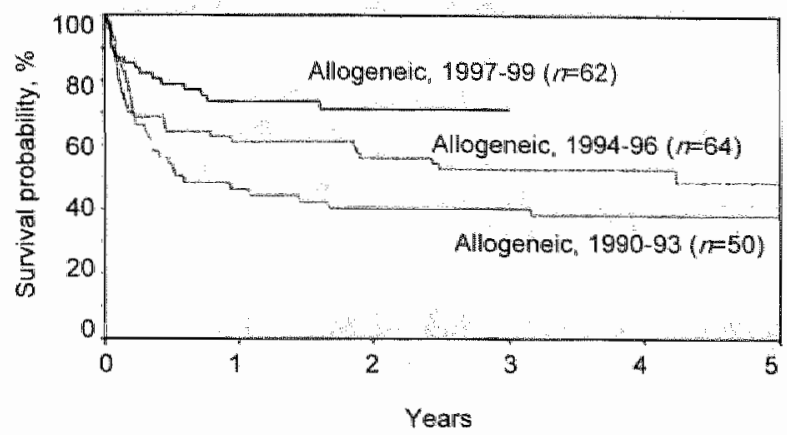

Figure 10.1 Probabilities of survival after HLA-identical sibling transplantation by year of transplantation (reproduced with permission, American Society of Hematology, Bload 2003; 102: 3521-3529).

\section{Reduced-intensity Iransplantation}

Reduced-intensity conditioning regimens, considered less toxic, are being used at increased frequency. The underlying hypothesis of such a strategy is that fewer patients will develop TRM and graft-versus-lymphoma effects will result in curing a greater percentage of patients. Interesting preliminary results indicate that this premise may be the case (Table 10.5). ${ }^{83-85}$ Khouri and Champlin ${ }^{83}$ reported their experience in $49 \mathrm{NHL}$ patients of median age 55 (range 21-68) years, including 20 follicular and 15 transformed NHL. Eight patients had disease relapse after a prior ASCT. At a median follow-up of 19 (range 5-52) months, actuarial survival is $79 \%$. PFS is $85 \%$ for the indolent and $60 \%$ for the transformed NHL patients. The potency of graft-versuslymphoma effects is underscored by the sometimes spectacular responses to donor lymphocyte infusion (DLI). For example, Mandigers et al ${ }^{86}$ reported that two poor-risk, relapsed low-grade NHL patients failing T-cell-depleted siblingmatched allografts re-entered durable complete remission after DLI from the original donors. Still, the considerable risks and toxicity associated with chronic GVHD cannot be underestimated and long-term follow-up on such studies is lacking. Robinson et al. ${ }^{85}$ reported preliminary results of an EBMTR analysis of nonmyeloablative transplantation in lymphoma. The low-grade NHL patients had a disappointing $39 \%$ TRM and $29 \%$ PFS at 1 year after transplant, to a large extent due to GVHD and opportunistic infections. Paradoxically, some of 
the best reported results involve in vivo or in vitro T-cell-depleted transplants such as the recent experience of using BEAM-alemtuzumab reduced-intensity alloSCT in which $70 \%$ of low-grade $\mathrm{NHL}$ patients are alive at 4 years. ${ }^{84}$ The role of reduced-intensity alloSCT hopefully will be established by a recently activated trial conducted by the Blood and Marrow Transplant Clinical Trials Network comparing ASCT vs alloSCT in follicular NHL patients.

\section{Future directions}

The limitations of ASCT transplantation include disease recurrence and risk of secondary MDS. Future improvements are likely to focus on incorporation of targeted monoclonal antibodies into the preparative regimen and post transplant period, novel stem cell purging strategies and use of anti lymphoma vaccines or other forms of therapy in the post transplant period. These studies will be carried out in patients with recurrent disease and, if successful, could be extrapolated for use earlier in the course of the disease. Studies in alloSCT will focus on minimizing treatment-related complications that likely will include newer GVHD prevention approaches, use of new graft-versus-lymphoma maneuvers and incorporation of more advanced techniques of donor lymphacyte infusion (Table 10.6).

Table 10.6 Future direations.

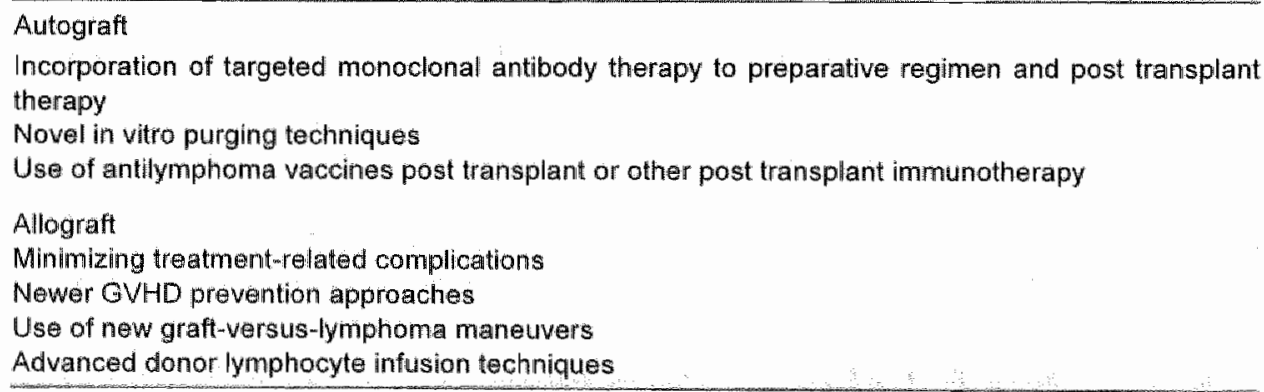




\section{References}

1. A clinical evaluation of the International Lymphama Study Group dassification of nomHodgkin"s lymphoma. The Non-Hodgkin's Lymphoma Classification Project. Blood 1997; 89:3909-18.

2. A predictive model for aggressive non-Hodgkin's lymphoma. The International Non-Hodgkin's Lymphoma Prognostic Factors. Project. N Engl J Med 1993; 329: 987-94.

3. Solal-Celigny $P, R o y, P$, Colombat $P$ et al Follicular lymphoma international prognostic index. Blood 2004; 104:1258-65.

4. Dana BW, Dahlberg S; Nathwani $B N$ et al. Long-term followup of patients with low-grade malignant lymphomas treated with doxorubicin-based chemotherapy or chemoimmunotherapy. J Clin Oncol 1993; 11: 644-51.

5. Johnson PW, Rohatiner $A Z$, Whelan JS et al. Patterns of survival in patients with recurrent follicular lymphoma: a 20-year study from a single center. J Clin Oncol $1995: 13: 140-7$.

6. Bruno SCC $\mathrm{SC}_{i}$ Santarelli MT. Randomized trial of cyclophosphamide (C) versus cyclophosphamide, vincristine, and prednisone(CVP) in low grade lymphoma (LG-NHL). Proc Am Soc Clin Oncol 1988;7:243 (Abstr.).

7. Solal-Celigny $P$, Lepage $E$, Brousse $N$ et al. Recombinant interferon alfa-2b combined with a regimen containing doxorubicin in patients with advanced follicular lymphoma. Groupe d'Etude des Lymphomes de l'Adulte. N Engl J Med 1993;329:1608-14.

8. Fisher RI, Oken MM. Clinical practice guidelines: non-Hodgkin's lymphomas Cleve Clin $J$ Med 1995; 62 (S1): SI6-S42; quiz SI43-5.

9. Fisher $\mathrm{RI}_{\text {, Dana }} \mathrm{BW}$, LeBlanc $\mathrm{M}$ et all. Interferon alpha consolidation after intensive chemotherapy does not prolong the progression-free survival of patients with low-grade nonHodgkin's lymphoma: results of the Southwest Oncology Group randomized phase III study 8809. J Clin Oncol 2000;18:2010-6

10. Freedman $A$, Friedberg $J W_{1}$ Gribben J. High-dose therapy for follicular lymphoma. Oncology (Huntingt) $2000 ; 14: 321-326,9$.

11. Freedman AS, Neuberg D, Mauch $P$ et al. Long-term follow-up of autologous bone marrow transplantation in patients with relapsed follicular lymphoma. Biood 1999:94:3325-33.

12. Colombat $P$, Donadio $D$, Fouillard $L$ et al. Value of autologous bone marrow transplantation in follicular lymphoma: a France Aulogreffe retrospective study of 42 patients. Bone Marrow Transplant 1994;13:157-62.

13. Bierman PJ, Vose JM, Anderson JR et al. High-dose therapy with autologous hematopoietic rescue for follicular llow-grade non-Hodgkin's Iymphoma. I Clin Oncol 1997;15:445-50.

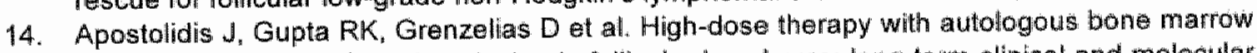
support as consollidation of remission in follicular lymphoma: long-term clinical and molecular follow-up. J Clin Oncol 2000; 18:527-36.

15. Voso MT, Martin $S$, Hohaus S et al. Prognostic factors for the clinical outcome of patients with follicular lymphoma following high-dose therapy and peripheral blood stem cell transplantation (PBSCT). Bone Marrow Transplant 2000;25:957-64.

16. Bastion $Y$, Brice $P$. Haioun $C$ ef al. Intensive therapy with peripheral blood progenitor cell transplantation in 60 patients with poor-prognosis follicullar lymphoma. Blood 1995; $86: 3257-$ 62.

17. Weaver $\mathrm{CH}_{4}$ Schwartzberg $\mathrm{L}_{n}$ Rhinehart $S$ et al. High-dose chemotherapy with BUCY or $B E A C$ and unpurged peripheral blood stem cell infusion in patients with low-grade nonHodgkin's lymphoma. Bone Marrow Transplant 1998;21:383-9.

18. Berglund $A_{*}$ Enblad $G$, Carison $K$ et al. Long-term follow-up of autologous stem-cell transplantation for follicular and transformed follicular lymphoma. Eur J Haematol 2000: 65:17-22.

19. Brice $P$. Simon $D$, Bouabdallah $R$ et al. High-dose therapy with autologous stem-cell transplantation (ASCT) after first progression prolonged survival of follicular lymphoma patients included in the prospective GELF 86 protocoll. Ann Oncol 2000:11:1585-90. 
20. Verdonck LF, Dekker AW, Lokhorst HM et al. Allogeneic versus autologous bone marrow iransplantation for refractory and recurrent low-grade non-Hodgkin's lymphoma. Blood 1997. 90: $4201-5$.

21. Cervantes $F$, Shu $X O$. MoGlave $P B$ et al. Autologous bone marrow transplantation for nontransformed llow-grade non-Hodgkin"s lymphoma. Bone Marrow Transplant 1995;16 387-92.

22. Cao TM, Horning S, Negrin RS et al High-dose therapy and autologous hematopoietic-cell transplantation for follicular lymphoma beyond first remission: the Stanford University experience. Biol Blood Marrow Transplant 2001;7:294-301.

23. van Besien $K$, Loberiza Jr FR, Bajorunaite $R$ et al. Comparison of autologous and allogeneic hematopoietic stem cell transplantation for follicular lymphoma. Blood 2003;102:3521-9.

24. Schouten HC, Qian W, Kvaloy S et al. High-dose therapy improves progression-free survival and survival in relapsed follicular non-Hodgkin's lymphoma: results from the randomized European CUP trial. J Clin Oncol 2003,21:3918-27.

25. Molina $A$ Nademannee $A$, ODonnell MR et al Long-term follow-up and analysis of prognostic factors after high-dose therapy (HDT) and peripheral blood stem cell autografting (ASCT) in 58 patients (pts) with a history of low grade follicular lymphoma (FLGL). Blood 1999;94 (suppl. 1):171a (Abstr).

26. Seyfarth $B_{\text {, Kuse }} R$, Sonnen $R$ et al. Autologous stem cell transplantation for follicular lymphoma: no benefit for early transplant? Ann Hematol 2001;80.398-405.

27. Stein RS, Greer JP. Goodman $S$ et al. High-dose therapy with autologous or allogeneic transplantation as salvage therapy for small cleaved cell lymphoma of follicular center cell origin. Bone Marrow Transplant 1999;23:227-33.

28. Apostolidis J, Foran JM, Johnson PW et al. Patterns of outcome following recurrence after myeloablative therapy with autologous bone marrow transplantation for follicular lymphoma. J Clin Oncol 1999;17:216-21.

29. Freedman AS, Gribben JG, Neuberg D et al. High-dose therapy and autologous bone marrow transplantation in patients with follicular lymphoma during first remission. Blood 1996; 88: $2780-6$.

30. Horning SJ, Negrin RS, Hoppe RT et all. High-dose therapy and autologous bone marrow transplantation for follicular lymphoma in first complete or partial remission: results of a phase II clinical trial. Blood 2001:97:404-9.

31. Corradini $P$, Ladetto $M$, Zallio $F$ et al. Long-term follow-up of indolent lymphoma patients treated with high-dose sequential chemotherapy and autografting: evidence that durable molecular and clinical remission frequently can be attained only in follicular subtypes. $J$ Clin Oncol 2004:22:1460-8.

32. Lenz $G$, Dreyling $M$, Schiegnitz $E$ of al. Myeloablative radiochemotherapy followed by autologous stem cell transplantation in first remission prolongs progression-free survival in follicular lymphoma - results of a prospective randomized trial of the German Low-Grade Lymphoma Study Group (GLSG). Blood 2004;104:2667-74

33. Colombat $P$, Foussard $C$, Bertrand $P$ et al. Value of autologous stem cell transplantation in first line therapy of follicular lymphoma with high tumor burden; first results of the randomized GOELAMS 064 trial. Blood 2001;98:861a (Abstr.).

34. Boclek GR, Bierman PJ, Vose JM et all. High-dose therapy with autologous hematopoletic stem cell transplantation for patients (pts) with low-grade follicular non-Hodgkin's lymphoma in first complete remission (CR) or partial remission (PR). Blood 1999; 94 (Suppl. 1): 171a (Abstr.).

35. Gonza lez-Barca E. Ferna ndez de Sevilla A, Domingo-Claros A et al. Autologous stem cell transplantation (ASCT) with immunologically purged progenitor cells in patients with advanced stage follicular ymphoma after early partial or complete remission; toxicity, followup of minimal residual disease and survival. Bone Marrow Transplant 2000; 26:1051-6.

36. Linassier C. Fouillard L, Milpied $N$ et al. Value of autologous bone marrow transplantation (ABMT) in 42 patients with follicular lymphomas responsive to conventional chemotherapy: a 'France Autogreffe" study. Cancer Detect Prev 1996; 20:11-9.

37. Lenz $G$, Unterhalt $M$, Haferlach $T$ et al. Significant increase of secondary myelodysplasia and acute myeloid leukemia after myeloablative radiochemotherapy followed by autologous stem 
cell transplantation in indolent lymphoma patients -results of a prospective randomized study for the GLSG. Blood 2003; 102 (Suppl 1): 986a-7a (Abstr: 36\%1).

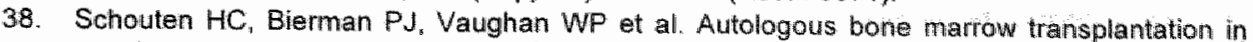
follicular non-Hodgkin's lymphoma before and after histologic transformation. Blood 1989; 74 : 2579-84.

39. Foran JM, Apostolidis J, Papamichael D et al. High-dose therapy with autologous haematopoietic support in patients with transformed follicular lymphoma: a study of 27 patients from a single center. Ann Oncol 1998:9:865-9.

40. Friedberg JW, Neuberg D, Gribben JG et al: Autologous bone marrow transplantation after histologic transformation of indolent B cell malignancies. Biol Blood Marrow Transplant 1999; $5: 262-8$.

41. Williams $\mathrm{CD}$, Harrison $\mathrm{CN}$, Lister TA et al. High-dose therapy and autologous stem-cell support for chemosensitive transformed low-grade follicular non-Hodgkin's iymphoma: a case-matched study from the European Bone Mlarrow Transplant Registry. J Clin Oncol 2001; 19:727-35.

42. Chen $\mathrm{Cl}$, Crump $\mathrm{M}$, Tsang $\mathrm{R}$ et al. Autotransplants for histologically tramsformed follicular non-Hodgkin's lymphoma. Br J Haemtaol 2001;113:202-8.

43. Bolwell $B$, Kallaycio $M$, Andresen $S$ et al. Autologous peripheral blood progenitor cell transplantation for transformed diffuse large-cell lymphoma. Clin Lymphoma 2000; 1:226-31.

44. Pagel $\mathrm{JM}_{2}$ Matthews $\mathrm{DC}$, Appelbaum FR et al. The use of radioimmunoconjugates in stem cell transplantation. Bone Marrow Transplant 2002;29:807-16.

45. Gopal AK, Gooley TA, Maloney DG at al. High-dose radioimmunotherapy versus conventional high-dose therapy and autologous hematopoietic stem cell transplantation for relapsed follicular non-Hodgkin lymphoma: a multivariable cohort analysis. Blood 2003; 102: $2351-7$.

46. Knop $S$, Jakob A, Kanz $L$ et al. 186Rhenium-labeled anti-CD20 antibody radioimmunotherapy followed by autologous peripheral blood stem cell transplantation in patients with relapsed or refractory non-Hodgkin lymphoma. Blood 2004;103:1175.

47. Hunault-Berger $M$, Ifrah $N$, Solal-Celigny $P$. Intensive therapies in follicular non-Hodgkin lymphomas. Blood 2002;100: 1141-52.

48. Finke J. The role of stem cell transplantation in the treatment of follicular lymphoma. Semin Cancer Biol 2003; 13:233-9.

49. Gribben $J G$, Freedman $A S$, Neuberg $D$ et al. Immunologic purging of marrow assessed by PCR before autologous bone marrow transplantation for B-cell lymphoma. $N$ Engl J Med 1991; 325: 1525-33.

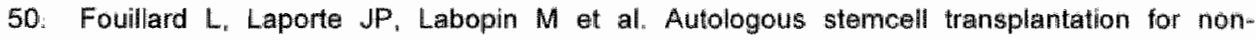
Hodgkin"s lymphomas: the role of graft purging and radiotherapy posttransplantation - results of a retrospective analysis on 120 patients autografted in a single institution. $J$ Clin Oncol 1998; 16: 2803-16.

51. Martin-Henao GA, Picon $M_{i}$ Limon $A$ el al. Immunomagnetic bone marrow (BM) and peripheral blood progenitor cell (PBPC) purging in follicular lymphoma (FL). Bone Marrow Transplant 1999; 23: 579-87.

52. Ladetto $M$, Corradini $P$, Vallet $S$ et al. High rate of clinical and molecular remissions in follicular lymphoma patients receiving high-dose sequential chemotherapy and autografting at diagnosis: a multicenter, prospective study by the Gruppo Italiano Trapianto Midollo Osseo (GITMO). Blood 2002; 100:1559-65.

53. Gribben JG, Neuberg D, Barber M et al. Detection of residual lymphoma cells by polymerase chain reaction in peripheral blood is significantly less predictive for relapse than detection in bone marrow. Blood 1994; 83: 3800-7.

54. Brenner MK, Rill DR, Moen RC et al. Gene-marking to trace origin of relapse after autologous bone-marrow transplantation. Lancet 1993;341;85-6.

55. Deisseroth $A B, Z u Z$, Claxton $D$ et al. Genetic marking shows that $\mathrm{Ph}+$ cells present in autologous transplants of chronic myelogenous leukemia (CML) contribute to relapse after autologous bone marrow in CML. Blood 1994; $83: 3068-76$. 
56. McQuaker 1G, Haynes AP, Anderson S et al. Engraftment and molecular monitoring of CD34- peripheral-blood stem-cell transplants for follicular lymphoma: a pilot study. $\mathrm{J}$ Clin Oncol 1997; 15:2288-95.

57. Yerly-Motta V, Racadot E, Fest T et all. Comparative preclinical study of three bone marrow purging methods using PCR evaluation of residual $1(14 ; 18)$ lymphoma cells. Leuk Lymphoma $1996 ; 23: 313-21$

58. Williams $\mathrm{CD}$, Goldstone $\mathrm{AH}$, Pearce $\mathrm{RM}$ et al. Purging of bone marrow in autologous bone marrow transplantation for non-Hodgkin's lymphoma: a case-matched comparison with unpurged cases by the European Blood and Marrow Transplant Lymphoma Registry. J Clin Oncol 1996:14:2454-64.

59. Bierman PJ, Sweetenham JW. Loberiza Jir FR ef al. Syngeneic hematopoietic stem-cell transplantation for non-Hodgkin's lymphoma: a comparison with allogeneic and autologous transplantation-The Lymphoma Working Committee of the International Bone Marrowt Transplant Registry and the European Group for Blood and Marrow Transplantation. $J$ Clin Oncol 2003:21:3744-53.

60. Flinn IW, O'Donnell PW, Goodrich A et al. Immunotherapy with rituximab during peripheral blood stem cell transplantation for non-Hodgkin's lymphoma. Biol Blood Marrow Transplant $2000 ; 6: 628-32$.

61. Magni $M$, Di Nicola $M$, Devizzi $L$ et al. Successful in vivo purging of CD34-containing peripheral blood harvests in mantle cell and indolent lymphoma: evidence for a role of both chemotherapy and rituximab infusion. Blood 2000;96:864-9:

62. Lemieux $B_{i}$ Tartas $S$, Traulle $\mathbb{C}$ et al. Rituximab-related late onset neutropenia after autologous stem cell transplantation for aggressive non-Hodgkin's lymphoma. Bone Marrow Transplant 2004:33:92:1-3.

63. Gordon PR, Leimig T, Babarin-Dorner A et al. Large-scale isolation of CD133+ progenitor cells from G-CSF mobilized peripheral blood stem cells. Bone Marrow Transplant 2003; $31: 17-22$.

64. Craiu $A_{*}$ Saito $Y$, Eppich $H M$ et al. Flowing cells through pulsed electric fields efficiently purges stem cell preparations of contaminating myeloma cells while preserving stem cell function. Blood 2005; 105:2235-8

65. Armitage JO. Myelodysplasia and acute leukemia after autologous bone marrow transplantation. J Clin Oncol 2000;18:945-6.

66. Armitage $\mathrm{JO}$, Carbone PP, Connors $\mathrm{JM}$ et al. Treatmentrelated myelodysplasia and acute leukemia in non-Hodgkin's lymphoma patients. J Clin Oncol 2003:21:897 -906.

67. Micallef IN, Lillington DM, Apostolidis $\mathrm{J}$ et all. Therapyrelated myeladysplasia and secondary acute myelogenous leukemia after high-dose therapy with autologous hematopoietic progenitor-cell support for lymphoid malignancies. J Clin Oncol 2000;18:947-55.

68. Krishnam AS, Bhatia SML. Slovak ML et al. Predictors of therapy-related leukemia and myelodysplasia following autologous transplantation for lymphoma: an assessment of risk factors. Blood 2000;95:1588-93:

69. Meteyer $\mathrm{C}_{\mathrm{i}}$ Curtis $\mathrm{RE}_{\mathrm{i}}$ Vose J et al. Myelodysplastic syndrome and acute myeloid leukemia after autotransplantation for lymphoma: a multicenter case-control study. Blood 2003: 101:2015-23.

70. Abruzzese $E$, Radford JE, Miller JS et al. Detection of abnormal pretransplant clones in progenitor cells of patients who developed myelodysplasia after autologous transplantation. Blood 1999:94:1814-9.

71. Lillington DM, Micallef $\mathbb{N}$, Carpenter $E$ ell al. Detection of chromosome abnormalities prehigh-dose treatment in patients developing therapy-related myelodysplasia and secondary acute myelogenous leukemia after treatment for non-Hodgkin"s lymphoma. J Clin Oncol 2001;19:2472-81.

72. Baker KS, DeFor TE, Burns LJ et al. New malignancies after blood or marrow stem-cell transplantation in children and adults: incidence and risik factors. J Clin Oncol 2003;21:1352-8. 
73. Friedberg JW, Neuberg D, Stone RM et al. Outcome in patients with myelodysplastic syndrome after autologous bone marrow transplantation for non-Hodgkin's lymphoma. $J$ Clin Oncol 1999; $17: 3128-35$.

74. Weiden PL, Floumoy $N_{4}$ Thomas $E D$ et al. Antileukemic effect of graft-versus-host disease in human recipients of allogeneic-marrow grafts. N Engl I Med 1979:300:1068-73.

75. Weiden $\mathrm{PL}$, Sullivan $\mathrm{KM}$, Flournoy $\mathbb{N}$ et al. Antileukemic effect of chronic graft-versus-host disease: contribution to improved survival after allogeneic marrow transplantation. $N$ Engl $J$ Med 1981;304:1529-33.

76. Sullivan $\mathrm{KM}$, Storb $R$, Buckner $C D$ et al, Graft-versus-host disease as adoptive immunotherapy in patients with advanced hematologic neoplasms. N Engl J Med 1989; 320 : $828-34$

77. van Besien $K$, Sabocinski KA, Rowlings. $P A$ et al. Allogeneic bone marrow transplantation for low-grade lymphoma. Blood 1998;92:1832-6.

78. Peniket AJ, Ruiz de Elvira MC, Taghipour $G$ et al. An EBMT registry matched study of allogeneic stem cell transplants for lymphoma: allogeneic transplantation is associated with a lower relapse rate but a higher procedure-related mortality rate than autologous transplantation. Bone Marrow Transplant 2003;31:667-78.

79. Mandigers $\mathrm{CM}$, Raemaekers JM, Schattenberg AV et al. Allogeneic bone marrow transplantation with T-cell-depleted marrow grafts for patients with poor-risk relapsed lowgrade non-Hodgkin's lymphoma. Br J Haematol 1998;100:198-206.

80. Verdonck LF. Allogeneic versus autologous bone marrow transplantation for refractory and recurrent low-grade non-Hodgkin's lymphoma: updated results of the Utrecht experience. Leuk Lymphoma 1999;34:129-36.

81. Toze CL, Shepherd JD, Connors JM et al. Allogeneic bone marrow transplantation for lowgrade lymphoma and chronic lymphocytic leukemia. Bone Marrow Transplant 2000; 25 :60512.

82. Forrest DL, Thompson $\mathrm{K}_{n}$ Nevill TJ et al. Allogeneic hematopoietic stem cell transplantation for progressive follicular lymphoma. Bone Marrow Transplant 2002; 29:973-8.

83. Khouri IF, Champlin RE. Nonmyeloablative stem cell transplantation for lymphoma. Semin Oncal 2004;31:22-6.

84. Faulkner RD, Craddlock $C$, Byrne JL et al. BEAM-alemtuzumab reduced-intensity allogene ic stem cell transplantation for lymphoproliferative diseases: GVHD, toxicity, and survival in 65 patients. Blood 2004;103:428-34.

85. Robinson SP, Mackinnon S, Goldstone A et al. Higher than expected transplant-related mortality and relapse following non-myeloablative stem cell transplantation for lymphoma adversely affects progression-free survival. Blood 2000; 96 (Suppl. 1): 554a (Abstr.).

86. Mandigers CMPW, Verdonck LF, Meijerink JPP et al Graft-versus-lymphoma effect of donor lymphocyte infusion in indolent lymphomas relapsed after allogeneic stem celf transplantation. Borie Marrow Transplant 2003:32:1159-63. 


\section{Chapter 11}

\section{Conclusion}

"There are known knowns. These are things we know that we know. There are known unknowns. That is to say, there are things that we know we don't know. But there are also unknown unknowns. There are things we don't know we don't know."

Donald Rumsfeld 
164 Chapter 1

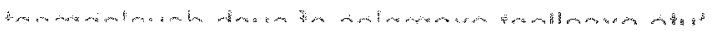




\section{Conclusion}

Episodes of stagnation in medicine alternate with moments of rapid progression. Much of this has to do with the convergence and maturation of new technologies into new so called "medical platforms", that allow new areas of discovery and investigation. Examples of such platforms include the development of cellular pathology in the mid nineteenth century, the development of combination chemotherapy in the sixties and seventies, monoclonal antibody technology in the seventies, molecular biology, stem cell support for autologous transplants and so forth. More subtle, but equally important advances include those in radiology or the development of sophisticated statistical techniques for clinical trial design and interpretation.

This is a heady time for those interested in lymphoma. Our understanding of its biology has dramatically improved in the past decades and new technologies, in particular gene arrays, promise exponentially increase knowledge. The immediate payoff for the clinician may be an improved ability to accurately predict prognosis (l.e. better prognostic scores) and to more accurately predict who might benefit from treatment. Over time, it is hoped that basic knowledge will translate into further rational drug development. Monoclonal antibody therapies constitute excellent examples of such development.

Numerous new drugs are now available that promise to improve the outcome of patients with follicular lymphoma and that provide new opportunities for clinical research. But opportunity also creates new problems and questions. Specifically questions abound on how to test individual drugs, how to accommodate testing of all of them and how to integrate the old treatments with the new.

The experience with interferon serves as a reminder of the complexities of drug development in follicular lymphoma. Unexplained discrepancies in results between randomized studies led to major delays in development of the drug and, for all practical purposes, its abandonment in the US, despite convincing data for its effect on survival. A recent meta-analysis of randomized studies suggests that dosing and potential interactions with various conventional chemotherapies are important determinants of the effects of interferon. The type of chemotherapy it is combined with affects its relative benefit.

Because of such complexities, prospective studies should be carefully designed, conducted and interpreted in a dispassionate manner, with minimal interference by either commercial or career mediated bias. While the randomized study remains the gold standard for drug development, it is not always possible, and much might be gained from incorporating novel designs in clinical studies as well as by incorporation of correlative studies. Ongoing study of the clinical relevance of surrogate markers remains of value because it 
continues to have the potential for shortening the required length of follow-up for future studies.

The role of complicated treatments such as autologous or allogeneic transplantation in follicular lymphoma also requires rethinking. ${ }^{1}$ In our opinion, these treatments continue to be of interest, because more than any other treatment, they hold the potential for cure in follicular lymphoma. For patients under the age of 60 , the German Lymphoma Study Group continues to study the role of autologous transplantation after initial conditioning with $\mathrm{CHOP}$ Rituximab chemotherapy. ${ }^{2}$ Further follow-up of this trial will demonstrate whether there is an additive or synergistic effect between rituximab and autologous transplant on outcome of follicular lymphoma; or possibly whether the benefit of autotransplant is neutralized by that of rituximab. Stem cell purging as a method of reducing the risk of disease recurrence, after autologous transplantation also deserves further study. Allogeneic transplantation still has too much toxicity and is not widely applicable because of issues of donor availability. Until these issues are solved to a significant degree, allogeneic transplantation should be offered only in the absence of alternative treatment options. Whether complex treatments such as transplant will still be used twenty years from now is impossible to predict. Even if they are no longer considered practical treatments, the study of these technologies will have contributed considerably to stem cell and lymphoma biology. 


\section{Reference}

1. Lenz G, Dreyling M, Unterhalt M, Hiddemann W. In Reply Should we Transplant patients with indolent lymphoma. J.Clin. Oncol, 2005;23:6264-6.

2. Hiddemann $W$, Kneba $M$, Dreyling $M$ et al. Front-line therapy with rituximab added to the combination of cyclophosphamide, doxorubicin, vincristine and prednisone (CHOP) significantly improves the autcome of patients with advanced stage follicular lymphomas as compared to CHOP alone - results of a prospective randomized study of the german low grade lymphoma study group (GLSG), 2005:106:3725-32. 
Samenvatting 


\section{Samenvatting}

De eerste beschrijving van folliculair lymfoom dateert van 1925. Het klinisch beeld was nagenoeg compleet tegen het begin der jaren veertig. De aandoening wordt gekenmerkt door wijdverbreide lymfknoopaantasting en een uiterst variabel verloop. De gemiddelde overlevingsduur bedraagt ongeveer tien jaar na het tijdstip van diagnose, maar de overleving kan enorm variëren van patiënt tot patiënt. Ongeveer $20 \%$ van de patiënten sterven in de eerste vier jaar.

Hoofdstuk 1 is een korte geschiedenis van folliculair lymfoom. De diagnose berustte gedurende lange tijd uitsluitend op de typische morfologie, maar er was weinig gekend over de natuur van deze aandoening. In de jaren 70 werd de B-cel origine van folliculair lymfoom herkend, en kort daarna de essentiële rol van de bcl-2 gen mutatie in de pathogenese. Dit heeft dan over de voorbije jaren geleid tot de ontwikkeling van uiterst specifieke therapien, die hier kort worden samengevat. In de rest van het proefschrift bespreek ik de rol van allogene transplantatie als één van een aantal mogelijke behandelingsmethodes. Maar veel vragen over biologie blijven onbeantwoord. Men weet nog maar weinig over de rol van eventuele bijkomende mutaties in de pathogenese en in de modificatie van het ziektebeeld. Er is ook weinig bekend over de etiologie van deze aandoening die nochtans lijkt toe te nemen in frequentie.

De volgende hoofdstukken zijn retrospectieve studies over de rol van allogene transplantatie in folliculair lymfoom. Hoofdstuk 2 was een analyse van allogene transplantaties voor lymfoom in MD Anderson tussen 1981 en 1994. Patiënten met agressief en hooggradig lymfoom hadden een hoog risico zowel voor recidief als voor complicaties. Patiënten met laaggradig lymfoom daarentegen hadden een veel betere prognose. Hoofdstuk 3 is een meer gedetailleerd analyse van tien patiënten die allogene transplantatie ondergingen in MD Anderson Cancer Center in Houston, Texas. Deze studie en een latere followup van dezelfde patiënten (hoofdstuk 3) werd gepubliceerd in het Journal of Clinical Oncology.

Allogene transplantatie voor folliculair lymfoom blijt gewoonlijk beperkt tot jongere patiënten met HLA-identieke familiale donoren. Als een gevolg hiervan is het aantal patiënten zeer beperkt en zijn prospectieve studies bijna onmogelijk. De analyse van databestanden was daarom de meest realistische methode ter confirmatie van mijn originele data. De volgende drie hoofdstukken zijn studies die uitgevoerd werden in samenwerking met het International Bone Marrow Transplant Registry (IBMTR), in Milwaukee, Wisconsin. Zij slagen 
hebben data van ongeveer $75 \%$ van alle beenmerg of stam cel transplantaties in de wereld. In de IBMTR studies bevestigden we dat de kans op recidief na allogene transplantatie uiterst beperkt is. Onze eerste studie, (hoofdstuk 5) gepubliceerd in 1998, besloeg vooral patiënten behandeld in de jaren tachtig. In deze groep vonden we een onaanvaardbaar hoog risico voor fatale complicaties (Treatment-related mortality -TRM). In een latere studie (hoofdstuk 6) van patiënten die in de jaren ' 90 getransplanteerd werden, was de frequentie van complicaties duidelijk veel lager. We vonden ook dat het risico voor complicaties afhankelijk was van de gezondheidstoestand van de patiënt, zijn of haar leeftijd, en de chemotherapie sensitiviteit van het lymfoom. Allogene transplantatie wordt dikwijls gebruikt voor patiënten die een recidief hebben na een vroegere autologe transplantatie. We hebben ook dit scenario bestudeerd in de IBMTR (hoofdstuk 7) en vonden dat ook in deze situatie de chemotherapie sensitiviteit van het lymfoom van groot belang was.

Door deze studies en een aantal studies van andere groepen werd het duidelijk dat allogene transplantatie veruit de meest efficiënte methode is ter genezing van folliculair lymfoom. Maar het risico voor ernstige en vaak fatale complicaties is een grote beperking van deze behandelingsmethode. Complicaties tengevolge van acute of chronische afstotingsverschijnselen (graft vs host disease) zowel als de conditioneringtherapie zijn hiervoor verantwoordelijk. Om vooruitgang te boeken moet de transplantatietechnologie verbeteren. Dit kan in zekere mate gebeuren door een beter begrip van hoe allogene transplantatie werkt. Is het de intensieve radiochemotherapie van de conditionering die nodig is voor genezing, of zijn de immunologische graftversus-lymphoma effects het belangrijkst? Hoofdstukken 8 en 9 bestaat uit twee artikelen die deze vraag op een klinische manier proberen te beantwoorden. In een eerste studie, een analyse van patienten met recidief na allogene transplantatie, tonen we duidelijk het bestaan aan van GVL-effecten. Maar in een belangrijke IBMTR studie van syngene transplantatie, toonde Dr. Bierman aan dat GVL effecten niet essentieel zijn voor permanente genezing na allogene transplantatie.

Hoofdstuk 10 is een overzichtsartikel van studies in allogene en autologe transplantaties voor folliculair lymfoom. In hoofdstuk 11 speculeer ik tenslotte over de huidige en toekomstige rol van transplantatie in de behandeling van folliculair lymfoom. 
Dankwoord 


\section{Dankwoord}

Dit proefschrift is een samenvatting van meer dan tien jaar werk in klinisch onderzoek en klinische zorg. Het is onmogelijk allen te vermelden. Klinische hematologie en stamceltransplantatie is een complexe onderneming en velen behoeven dank om mijn werk mogelijk te maken. Ik vernoem hier vooral de mensen die mij meest geholpen hebben in mijn loopbaan.

Mijn interesse voor de hematologie begon in mijn eerste jaar assistent op de isolatie afdeling in Leuven, met Marc Boogaerts en Guido Tricot. Ik had toen weinig academische ambities, maar wel wat zin voor avontuur. Mijn leven ging een heel onverwachte weg op dank zij een uitnodiging van Guido Tricot, om hem te volgen naar Indiana voor een fellowship in de hematologie en oncologie. In Indianapolis kon ik voor het eerst intensief meewerken aan klinisch onderzoek en kwam ook terecht in het lab van Ron Hoffman waar ik in de beginselen van experimentele hematologie werd ingewijd. De Amerikaanse openheid en ongedwongenheid, gepaard met een rigoureuze intellectuele traditie was voor mij een revelatie. Tot op vandaag ben ik dankbaar voor het privilege om te hebben mogen werken met mensen als Ron Hoffman, Steve Williams, Guido Tricot en Jan Jansen. Maar veel belangrijker, Indiana is waar ik Ok-kyong heb ontmoet en waar onze Herman is geboren. Al denk ik niet dat je ooit al die complicaties had voorzien, mijn welgemeende dank voor de invitatie Guido!

In Brugge heb ik mijn opleiding beëindigd. Het was een tijd om bij te leren in klinische hematologie en hematopathologie van collega's met een enorme ervaring. Mijn dank aan Achiel Van Hoof, Arnold Criel, Melanie Hidajat en Dries Louwagie.

Toen ik naar Texas kwam beloofde het diensthoofd. Al Deisseroth me dat ik miljonair zou worden in Houston. lk ben dat nog steeds niet. MD Anderson was toen (en is nog steeds) de tempel van empirische klinische research in hematologie. Hun aanpak en onderliggende filosofie, hebben een grote invloed gehad op mijn carrière. Teveel vrienden om allemaal te noemen, maar mijn dlank gaat voorall uit naar Dick Champlin, toen mijn baas en nog altijd raadgever, en mijn collegla's en goeie vrienden Sergio Giralt en Rakesh Mehra.

Voor de laatste negen jaar heb ik in Chicago gewerkt eerst aan de UIC en meer recent aan de Universiteit van Chicago. Mentors heb ik niet meer, maar nog altijd buitengewone collega's. Jeff Sossman, Ron Hoffman, David Peace aan UIC. Wendy Stock, Dick Larson, Toyosi Odenike, Mike Thirman en vele anderen maken mijn dagelijkse werk in Chicago aangenaam en zijn een bron 
van informatie en advies. Hopelijk kunnen we nog een hele tijd zo verder werken.

De collega's van CIBMTR, vooral Mary Horowitz die de organisatie op een buitengewone manier leidt. Maar ook de analisten en statistici, in het bijzonder Kathy Sobocinski en Fausto Loberiza:

Mijn dank ook aan Harry Schouten, mijn promotor voor de steun en het geduld gedurende mijn soms trage aanpak. Dank aan Tiny Wouters voor hulp bij het samenstellen van het boekje.

Mijn dank aan de leden van de beoordelingscommissie Prof. dr. Ph. Lambin, Prof. dr. M. Boogaerts, Dr. G.M.J. Bos, Dr. F.J. Bot en Prof. dr. A. Hagenbeek.

Mijn ouders hebben door hun voorbeeld, mij het belang ingeprent van hard werken, nieuwsgierigheid en ruimdenkendheid. Aan hen draag ik dit werk op. Mijn broers en zussen, waren mijn tweede lijn van opvoeders en voorbeelden. Ik ben opgegroeid met jullie als "rolmodel". Altijd was er iets nieuws, te zien of te horen of was er lemand in een ander ver land of in een andere taal. Dat maakte de stap naar de USA relatief gemakkelijk.

Ok-kyong, Herman, Sam en Leen. Teveel te danken, om hier in een paar regels te vertellen. It's great to have you.... 
Curriculum vitae 
$17 d$ 


\section{Curriculum vitae}

Koen van Besien werd geboren op 1 mei 1959 te Tiegem in West-Vlaanderen. $\mathrm{Na}$ de kandidaturen geneeskunde in Namen vervolgde hij zijn studies in Leuven waar hij ook de eerste jaren assistentschap inwendige geneeskunde deed. In 1987 vertrok hij op uitnodiging van Guido Tricot en Ron Hoffman naar Indianapolis voor verdere opleiding in hematologie en oncologie. Van 1990 tot 1992 werkte hij in Brugge met Dries Louwagie en Achiel Van Hoof. Daarna vertrok hij met zijn gezin naar Houston, Texas. In het MD Anderson Cancer Center van 92 tot 97 begon hij zich, op vraag van Richard Champlin specifiek te interesseren in de behandeling van lymfomen. Hij woont sinds 97 in Chicago waar hij de transplantatie afdeling leidt, eerst aan de University of Illinois en sinds 2001 aan de University of Chicago.

Hij is gehuwd met Ok-kyong Chaekal, ook oncologe. Ze hebben drie kinderen: Herman, Sam en Leen. 